(Aus dem k. k. serotherapeutischen Institut [Vorstand: Hofrat Professor Dr. R. Paltauf] und der Kinderabteilung des k. k. Kaiser-Franz-Josef-Spitales

[Vorstand: Primarius Privatdozent Dr. P. Moser] in Wien.)

\title{
Die Bedeutung des Wassers für Konstitution und Ernährung.
}

\author{
Eine klinisch-experimentelle Studie ${ }^{1}$ ) \\ von \\ Dr. Richard Lederer, \\ Assistent der Kinderabteilung. \\ Mit 15 Textfiguren. \\ (Eingegangen am 16. Januar 1914.)
}

I. Einleitung. (S. 366.)

Inhaltsverzeichnis.

II. Fragestellung. (S. 369.)

III. Untersuchungen an Tieren. (S. 369.)

IV. Untersuehungen an Säuglingen.

A) Methodisches. (S. 409.)

B) Die Bedeutung des Wassers für die Physiologie des Neugeborenen und Säuglings. (S. 415.)

1. Die physiologische Gewichtsabnahme des Neugeborenen. (S.425.)

2. Der Wassergehalt des Blutes beim gesunden Brustkind und seine Beziehungen zur Nahrung. (S. 428.)

C) Die Bedeutung des Wassers für die Pathologie chronischer Ernährungsstörungen. (S. 435.)

1. Umstände, welche die Untersuchung stören:

a) Akute Ernährungsstörung. (S. 436.)

b) Reparation. (S. 437.)

c) Fieber. (S. 440.)

2. Die Überernährung oder einseitige Ernährung mit Milch. (S. 443.)

3. Die Anämie der Säuglinge. (S. 451.)

4. Der Mehlnährschaden. (S. 463.)

D.) Die Bedeutung des Wassers für die Pathogenese der exsudativen Diathese. (S. 472.)

V. Anhang. (S. 496.)

A. Die Beziehungen der exsudativen Diathese zur Anämie der Säuglinge.

B. Der Status lymphaticus. (S. 497.)

1) Die Anschaffungskosten der zu den vorliegenden Untersuchungen notwendigen Apparatur, die Beschaffung und Exhaltung des Tiermaterials wurden zum größten Teil aus den Mitteln der Pollack von Parnauschen Studienstiftung bestritten. 


\section{Einleitung.}

Man kann sich wohl kaum einen größeren Gegensatz denken als den zum Umfang und der Bedeutung der Frage nach der Rolle des Wassers im menschlichen Organismus und der Zahl der sicheren Antworten auf diese Frage. Schier unübersehbar weit ist, wie aus den folgenden Darlegungen, die doch nur die unmittelbar in Betracht kommenden Arbeiten anführen werden, der Weg von der Unzahl der Fragestellungen zu einem festen Resultat. Wenn irgendwo auf dem Gebiet des intermediären Stoffwechsels, so gilt hier der vielzitierte Vergleich Hofmeisters des menschlichen Organismus und seines Stoffwechsels mit einem komplizierten Fabriksbetriebe. Wir kennen das eingeführte Material und die nach der Verarbeitung übrig gebliebenen Schlacken und Abfallsprodukte, und mit Hilfe unserer Methoden gelingt es uns nur hie und da, einen Blick in das Innere dieses komplizierten Räderwerkes zu tun und die Arbeit dieses sinnreichsten aller Mechanismen direkt zu beobachten. Und was vom Gesamtstoffwechsel im allgemeinen gesagt werden kann, gilt vom Wasserhaushalt im besonderen, nur unter noch erschwerenderen Bedingungen, da das Wasser im Gegensatz zu anderen Körpern, die wir im Stoffwechselversuch bestimmen können, nicht einmal in allen - um bei dem obigen Vergleiche zu bleiben Einfuhrprodukten und Abfallstoffen (Schweiß usw.) genau gemessen werden kann, da vollends das intermediär im Körper durch Verbrennung von Kohlehydraten und Fetten entstehende Wasser (Oxydationswasser) immer nur Gegenstand einer Schätzung, nie einer direkten Berechnung sein kann.

Es hieße Eulen nach Athen tragen, wollte man die Bedeutung des Wassers für alle Fragen der Physiologie und Pathologie im Detail schildern. Seine Rolle als Lösungs- und Suspensionsmittel, als Transportorgan und Reservestoff ist zur Genüge gekennzeichnet. Diese seine Rolle, die es während des ganzen Lebens zu spielen hat, wird im Säuglings- und Kindesalter noch bedeutend erweitert dadurch, daß die für den jugendlichen Organismus charakteristischeste Erscheinung, das Wachstum, auf das innigste mit Vorgängen im Wasserhaushalt verknüpft ist, da ferner, wie später an Beispielen der Literatur und an eigenen Untersuchungen gezeigt werden soll, der kindliche Organismus nicht nur an sich wasserreicher ist als der des Erwachsenen, sondern auch in der Zeiteinheit relativ ungleich größere Mengen Wasser umzusetzen hat, wie der des zur Reife gelangten Körpers, - was daraus hervorgehen mag, daß ja schon die Nahrung des Säuglings lediglich 
aus im Wasser gelösten oder in lösungsähnlichem Zustande befindlichen Stoffen gebildet werden kann.

Es ist von vornherein klar, daß bei dem oben erwähnten Gegensatz zwischen der Reichhaltigkeit der Fragestellung und der geringen Zahl der wirklich sicheren Resultate, über die wir bisher verfügen, es wenig Aussicht hat, das Thema in seiner Gänze wieder aufzunehmen und ihm mit verschiedenartigster und womöglich komplizierter Methodik zu Leibe zu rücken. Es ergibt sich daher von selbst die Notwendigkeit, die Fragestellung möglichst einzuschränken, und die Methodik so zu wählen, daß dieselbe nicht nur die Untersuchung eines einzelnen Falles, sondern - mit entsprechender Auswahl - ein möglichst großes Material durchzuarbeiten gestattet. Wie sich aus dem späteren ergeben wird, stellt sich dabei aber die Notwendigkeit heraus, eine Reihe von Vorfragen zu beantworten, die am Krankenbett nicht gelöst werden können und zu deren Erledigung es des Tierexperimentes bedarf. Um Wiederholungen zu vermeiden, sei in diesen einleitenden Worten nur kurz auf diejenigen Methoden hingewiesen, welche in dieser Fragestellung: überhaupt ans Ziel führen, beziehungsweise bis jetzt angewendet wurden.

Wie so oft bildeten auch in dieser Frage klinische Beobachtungen den Ausgangspunkt, die zu bekannt und alltäglich sind, als daß sie hier namentlich angeführt werden müßten. Ich werde im Verlaufe der weiteren Ausführungen wiederholt auf diese Tatsachen zurückzukommen haben. Diese klinischen Beobachtungen und Vermutungen nun durch exakte Untersuchungen zu stützen, gibt es zahlreiche Wege. Die Untersuchung von Kindesleichen respektive derjenigen Organe nach dem Tode, die meist als Depots des Wassers in Betracht kommen, unternahmen Steinitz, Weigert, Fehling, Sommerfeld, Ohlmüller, Camerer jun., Tobler. Der Untersuchung am lebenden menschlichen Organismus stand natürlich nur das Blut zur Verfügung, und an diesem wurden alle möglichen Methoden versucht, um direkt oder auf einem Umweg zu Schlüssen auf den Wassergehalt des Blutes zu kommen. Das spezifische Gewicht des Blutes wurde von Hammerschlag, Monti, Schmaltz und anderen bestimmt. Den N-Gehalt ermittelten auf refraktometrischem Wege Schiff, Reiss, Rusz u. a. Die Viscosität des Blutes besonders bei Ernährungsstörungen benützten Berend und Tezner, Rusz, Weill et Gardère u. a., um auf diese Weise etwas über den Wassergehalt des Blutes zu erfahren. Die Gefrierpunktserniedrigung und Leitfähigkeitsmessung wandten Salge und 
seine Mitarbeiter an, um aus der Bestimmung dieser Faktoren Schlüsse auf den Wassergehalt des Blutes ziehen zu können. Auch die histologische Blutuntersuchung (Hock und Schlesinger, Monti u.a.) wurde zur Entscheidung dieser Frage herangezogen. Schließlich machten Dennstedt und Rumpf, Jaksch und seine Mitarbeiter, Schiff, Lust u. a. direkte Bestimmungen des Wassergehaltes im Blut. Erwähnt zu werden verdient noch, daß man auch auf dem Umwege über die Bestimmung der Blutmenge sowohl beim Tier als beim lebenden Menschen Aufschluß über den Wasserhaushalt zu erhalten suchte. Die alte Welckersche Methode, mittels welcher schon Ranke und Darenberger im Jahre 1862 nachweisen konnten, daß die Blutmenge bei jungen Tieren relativ größer sei als bei erwachsenen, mußte den Untersuchungsmethoden weichen, welche die Blutmenge am lebenden Menschen zu messen gestatten. (Plethysmographische Methode von Morawitz, chromophotometrische Methode, neuestens von Plesch in großer Vervollkommnung ausgearbeitet.) Einer in jüngster Zeit von $O p$ penheimer und Kastner unabhängig von einander eingeführten Methode der Bestimmung des Körpervolumens und spezifischen Gewichtes bei lebenden Säuglingen scheinen, wie Pfaundler hervorhebt, noch zu viel Fehler anzuhaften. Aber auch auf dem langwierigen und mühevollen Wege der Untersuchung des Salzstoffwechsels suchte man sich über den Wasserhaushalt des kindlichen Organismus ins Klare zu kommen. Die Arbeiten von Blauberg, Steinitz, Weigert, Bruck, Finkelstein, Meyer, Freund, Grosz, Menschikoff, Schloss, Stolte u.v. a. kennzeichnen diese Etappe der Forschung, die noch durch die bisher spärlichen Untersuchungen des Gesamtstoffwechsels von Rubner und Heubner, Birk, Schlossmann, Niemann vervollständigt wird. Das Tierexperiment verwenden sowohl zur Lösung physiologischer als pathologiseher Fragen der Ernährung Hösslin, Czerny, Weiske und Wildt, Soxhlet, Weigert, Tobler, Eckert. Und schließlich seien an dieser Stelle abgesehen von den Bearbeitungen alter Grundfragen der Physiologie, noch auszugsweise diejenigen Arbeiten hauptsächlich kolloidchemischen Charakters erwähnt (Hofmeister, Pauli, Durig, H. J. Ha mburger, Overton, Höber, Přibram, Traube, Fischer, Marchand, Pinkussohn u. a.), die an toten Substanzen (Fibrin, Gelatine) oder an überlebenden Geweben und ganzen Organen oder Organverbindungen die kolloidchemischen Gesetze der physiologischen und pathologischen Wasserbindung behandeln. 


\section{Fragestellung.}

Aus den folgenden Ausführungen wird hervorgehen, daß von klinischen Beobachtungen, die vorwiegend chronische Ernährungsstörungen und Konstitutionsanomalien im Auge hatten, ausgegangen wurde, die sich im Laufe der Untersuchungen nach Erledigung gewisser Vorfragen zu folgenden konkreten Fragestellungen verdichteten:

1. Welche physiologischen Erscheinungen im Leben des Säuglings stehen in direktem Zusammenhang mit der Wasserzufuhr in der Nahrung und mit dem Wasserhaushalt des Organismus?

2. Welche chronischen Ernährungsstörungen zeigen eine Erhöhung des Wassergehaltes im Blute?

3. Wenn diese Frage zu bejahen ist: Ist diese Erhöhung des Blutwassers pathogenetisch für die betreffende chronische Ernährungsstörung?

4. Welche Schlüsse erlaubt die Erhöhung des Blutwassers bei diesen Ernährungsstörungen a uf den Wassergehalt des Gesamtorganismus?

5. Welche Konstitutionsanomalien zeigen einen direkten Zusammenhang mit dem Wasserstoffwechsel?

Um den Umfang des Themas nicht allzusehr anschwellen zu lassen, mußte eine Beschränkung auf diese fünf Punkte angestrebt werden, und es wird in den folgenden Ausführungen nur auf diese fünf Fragen Rücksicht genommen werden.

Bevqr jedoch an die Beantwortung dieser Fragen am Krankenbette herangegangen werden konnte, mußten gewisse Vorfragen im Tierexperiment studiert werden. Es mußte versucht werden, ob durch entsprechende fehlerhafte Ernährung am Tier Abweichungen in der Zusammensetzung des Körpers und des Blutes zu erzielen wären, ob diese Abweichungen im Sinne einer Wasseranreicherung ausfallen würden, und auf welche Art bejahendenfalls die Wasserbindung zustande käme, und es mußte schließlich die später am kranken Säugling einzuschlagende Methodik am Tier auf ihre Stichhaltigkeit und Möglichkeit der Handhabung geprüft werden. In den einzelnen Abschnitten wird darüber ausführlich berichtet werden.

\section{Untersuchungen an Tieren.}

Zunächst also galt es festzustellen, wie sich der normale Tierkörper bei natürlicher Ernährung verhält, und ob der tierische Organismus

Zeitschrift für Kinderheilkunde. 0 . X. 
unter dem Einfluß einer bestimmten Ernährung Veränderungen im Sinne einer Erhöhung oder einer Erniedrigung seines Wassergehaltes erfährt. Die erste Frage ist wohl eindeutig seit altersher entschieden, und ich führe als Belege darüber die lapidaren Sätze Bezolds aus dem Jahre 1857 an:

„1. Jedes Tierindividuum besitzt einen für seine Art und für sein Alter typischen normalen Gehalt von Wasser, organischer Materie und anorganischen Salzen, der entweder nahezu konstant ist (die höheren Wirbeltiere) oder zwischen engeren oder weiteren Grenzen schwankt

3. Die Entwicklung und das Wachstum eines jeden Tieres ist durch gewisse für die Art oder Gattung desselben typische Veränderungen in dieser Zusammensetzung charakterisiert.

4. Der Typus dieser Veränderungen ist für die drei ersten großen Gruppen des Wirbeltierreiches, für die Säugetiere, Vögel und Amphibien, im wesentlichen ein und derselbe. Die Hauptmomente dieser Veränderungen sind:

a) Abnahme im Gehalt des Organismus an Wasser und flüchtigen Bestandteilen von der Entwicklung des Keimes bis zur Höhe des freien Wachstums;

b) Zunahme im Gehalt an anorganischem festem Material, welche in der ersten Periode nach der Geburt die größte Schnelligkeit besitzt;

c) stetiges und gerade in den ersten Zeiträumen des freien Lebens mit der größten Langsamkeit vor sich gehendes Wachstum des Aschegehaltes bis zur Vollendung der progressiven Entwicklungsperiode."

Diese fundamentalen Sätze, die vor mehr als einem halben Jahrhundert geschrieben wurden, umfassen wohl alles, was wir auch heute über diesen Gegenstand wissen, und es ist zu ihnen, die Forschungen über das Wachstum des menschlichen Säuglings inbegriffen, auch bis heute nichts mehr Wesentliches hinzugekommen.

Ich übergehe hier die neneren Arbeiten über die chemische $\mathrm{Zu}$ sammensetzung des normalen Organismus (ausführliche Literatur darüber bei Eckert, Ursachen und Wesen angeborener Diathesen) ebenso die Arbeiten von Lawes und Gilbert, Hoffmann, Forster, Henneberg, Kern und Wattenberg, Chaniewski. Die letzteren betreffen Gesamtanalysen verschieden ernährter Tiere, sind aber an ausgewachsenen Organismen angestellt und gehören daher nicht hierher.

Weiske und Wildt untersuchten gemästete und nicht gemästete Ferkel. Es handelte sich aber um Tiere verschiedenen Alters, so daß ich die Zahlen als nicht gut verwertbar hier nicht anführe. Soxhlet 
mästete drei annähernd gleichaltrige Schweine mit Gerstenschrot. Es ergab sich die merkwürdige Tatsache, daß das nichtgemästete Kontrolltier fetter war als die beiden gemästeten Tiere, von denen eines eine beträchtliche Erhöhung seines Wassergehaltes zeigte. Weigert untersuchte in verschiedenen Serien junge Hunde desselben Wurfes bei verschiedener Emährung und kommt zu folgenden Resultaten: ,1. Der Wassergehalt der Tiere ist abhängig von ihrem Alter und der Ernährungsweise. 2. Die Schwankungen des Wassergehaltes sind nicht allein bedingt durch die Zunahme oder Abnahme des Fettgehaltes des Tierkörpers, sie sind auch begründet in einem verschieden großen Gehalt an fettfreier Trockensubstanz." Bischoff und Voit schreiben in einer älteren Arbeit aus dem Jahre 1860, „daß die Ernährung von großem Einfluß auf den Wassergehalt des Organismus ist, und daß speziell Tiere, die vorwiegend oder ausschließlich mit Kohlehydraten aufgezogen werden, einen höheren Wassergehalt ihrer Organe aufweisen als kohlehydratarm ernährte Tiere". In Hermanns Handbuch der Physiologie führt dann Voit des näheren noch aus, ,daß ein Hund, der während einer 41 tägigen Fütterung mit Brot eine 3717 Gramm Fleisch entsprechende Stickstoffmenge abgegeben, jedoch nur 351 Gramm an Gewicht verloren hatte, Wasser im Körper zurückbehielt, wodurch eine starke Tränkung desselben mit Wasser stattfand". In neuester Zeit hat Schulz durch Bestimmung der Gefrierpunktserniedrigung und der Leitfähigkeit im Serum an nach der Säugungszeit verschieden genährten wachsenden Hunden. (Kontrolle gemischt ernährt, einer mit Milch, einer mit $1 / 3$ Milch und $2 / 3$ Mehl, einer nur mit Mehl und Wasser) festgestellt, daß die drei Versuchshunde gegenüber dem Normalhund im Wachstum zurückbleiben und eine deutliche Verminderung der Salze in ihrem Serum zeigten. Die tierexperimentellen Untersuchungen Toblers beziehen sich auf das Verhalten von Wasser und Salzen bei akuten Gewichtsstürzen und sollen im Rahmen dieser Arbeit noch später besprochen werden. SchlieBlich hat Eckert in einer experimentellen Studie sechs Hunde desselben Wurfes verschieden ernährt und zu verschiedenen Zeitabschnitten getötet, dann in toto analysiert. Auch er konnte den Satz der physiologischen Austrocknung bestätigen, und aus seinen weiteren Untersuchungen, die noch Gegenstand der Besprechung sein werden, sei jetzt schon hervorgehoben, daß der Hund $V$, der nach der Säugungsperiode ausschließlich mit Kuhmilch ernährt wurde, gegenüber einem gleichalterigen gemischt ernährten Hund eine deutliche Vermehrung seines Wassergehaltes zeigte. 
Im großen und ganzen gehen also die Resultate der bisher ausgeführten Untersuchungen dahin, daß es gelingt, durch länger dauernde einseitige Fütterung mit Kohlehydraten bei Tieren eine Wasseranreicherung ihres Körpers zu erzielen, ein Faktum, das in die Ernährungspathologie des Säuglings übertragen ein Analogon in der hydropischen und hypertonischen Form des Mehlnährschadens findet. Doch davon später! Der Mehlnährschaden in seinen extremen Formen ist in den letzten Jahren unter dem Einfluß von Fürsorge- und Beratungsstellen erfreulicherweise so viel seltener als früher geworden, daß er an Bedeutung hinter den übrigen chronischen Ernährungsstörungen weit, zurückgetreten ist. Es lag daher für mich auch kein Bedürfnis vor, dieser Frage, die ja in der Literatur ziemlich eindeutig beantwortet ist, noch eine Nachprüfung am Tierexperiment zu widmen. Vielmehr war es von Interesse nachzusehen, ob die einseitige Fütterung mit Milch Änderungen im Wassergehalt des Organismus hervorruft, ferner ob selbst bei gemischter Ernährung das Volumen der Nahrung, also die Menge des zugeführten Wassers in irgendwelchen Beziehungen zum Wasserhaushalt im Sinne einer Vermehrung des Blut- oder Körperwassers stehe - eine Voraussetzung, der man ja von Anfang an ziemlich skeptisch gegenüberstehen mußte, da allgemein angenommen wird, daß das überschüssig in den Körper eingeführte Wasser eben wieder ausgeschieden wird, und allenfalls schädigende Wirkungen nur im Sinne einer "Auslaugung" oder „Durchspülung" des Organismus mit einem über das notwendige Maß hinausgehenden Zellverschleiß entfalten könne. - Die Versuchsanordnung und die technische Ausführung einzelner Bestimmungen wird bei den einzelnen Versuchen näher beschrieben werden.

Erster Versuch vom 23. IX. 1911-6. I. 1912.

$\mathrm{Zu}$ dem Versuch wurden vier Tiere desselben Wurfes verwendet, da von vornherein nicht zu entscheiden war, ob die übermäßige Flüssigkeitszufuhr oder die starke Flüssigkeitseinschränkung größere Wirkungen im Tierkörper hervorrufen würde. Die Hunde „Schwarz" und „Grau", beide männlich, dienten als Versuchshunde, die beiden anderen als Kontrolltiere. Da sich jedoch schon nach den ersten Bestimmungen herausstellte, daß die Kontrolltiere in ihren Werten vollkommen mit demjenigen Hunde ubbereinstimmten, der wenig Flüssigkeit bei gemischter Kost erhielt, so wurde letzterer als Kontrolle, die beiden anderen Tiere aber zu anderen Zwecken verwendet. Die Tiere, deren 
Geburtsdatum nicht auf den Tag genau zu ermitteln war, wurden ungefähr vier Wochen bei der Alten belassen, dann erhielten die Kontrolltiere allmählich Zufütterung und später ausschließliche Fütterung mit gemischter Kost (Fleisch, Semmel, Milch) und Wasser in geringen Mengen. Das Tier "Schwarz" bekam vom Tage des Versuches (23. IX.) an ebenfalls allmählich Semmel und Kuhmilch zugefüttert. Am 11. Tage nach Beginn des Versuches (3. X.) wurde er abgesetzt, die Milchmengen wurden sukzessive reduziert, Semmel und Wurst zugefüttert. Eine Zeitlang (ca. 14 Tage) lebte er nur von Semmel und Wurst, ohne Wasser, erhielt nur hie und da durch wenige Tage minimale Wassermengen, um ihn bei Appetit zu erhalten. Da er aber, wie schon erwähnt, trotz dieser scheinbar eingreifenden Maßnahme sich in nichts von den Kontrolltieren unterschied, bekam er dann wieder Wasser in größeren, aber nicht überflüssig großen Mengen (ungefähr $300 \mathrm{ccm}$ ) zu trinken und änderte auch da sein Verhalten nicht. Zu Beginn des Versuches wogen die beiden Tiere nahezu gleich viel, ,Schwarz" 1200, „Grau“ 1220 Gramm im Alter von vier Wochen. Das allmähliche Absetzen auf Kuhmilch, beziehungsweise den Übergang über Kuhmilch zur gemischten Kost, vertrugen beide Tiere ausgezeichnet, ohne Gewichtsverlust. Die Tiere wurden täglich gewogen, Trink- und Futtermengen wurden täglich von einem verläßlichen Diener gemessen, respektive gewogen, und in häufigen Stichproben von mir kontrolliert. Die Tiere befanden sjch in je einem Käfig mit doppeltem Boden. Die obere Schicht des letzteren bestand aus einem Drahtgitter, die untere aus einem nach der Mitte zu gehöhlten Blech mit Ablauf. Der Harn wurde in einem darunter gestellten Gefä $B$ aufgefangen und täglich gemessen. Die Käfige standen in einem lichten Raum, der, besonders solange die Tiere noch jung waren, von einem Gasofen unabhängig von der Hausheizung erwärmt werden konnte und auch bei Nacht geheizt wurde.

In ihrem Aussehen machten diese sowie alle folgenden zu ähnlichen Versuchen dienenden Tiere eine charakteristische Veränderung durch. Während die mit gemischter Kost ernährten Hunde ein weiches Fell und normale Körperproportionen zeigten, war das Fell der ausschließlich mit Kuhmilch ernährten Tiere struppig und die Hunde bekamen deutlich einen großen Bauch. Irgendwelche Veränderungen, die bei äußerer Betrachtung auf Rachitis hingedeutet hätten, konnten während der Versuchsdauer nicht wahrgenommen werden. Ich lasse es dahingestellt, ob die beobachteten Veränderungen (struppiges Fell und Meteorismus) als Zeichen eines „Milchnährschadens" gedeutet werden sollen. Der 
Stuhl zeigte bei den Kontrolltieren die für Hunde charakteristische harte Konsistenz und dunkle Farbe, während der ,Milchhund" während des ganzen Versuches mehr breiige oder salbige Stühle von etwas lichterer Farbe entleerte. Von einem Durehfall konnte während des ganzen Versuches nicht gesprochen werden.

Um ein ungefähres Bild von der Entwicklung der beiden Hunde zu geben, sind in Tabelle 1 bei beiden Tieren in Abständen von je einem Monat - dies der Raumersparnis halber, um nicht die gesamten Gewichtstabellen reproduzieren zu müssen - Körpergewicht, Futter-, Trink- und Harnmenge verzeichnet.

Tabelle I.

\begin{tabular}{|c|c|c|c|c|c|c|c|c|}
\hline \multirow[b]{2}{*}{ Datum } & \multicolumn{4}{|c|}{ Schwarz } & \multicolumn{4}{|c|}{ Grau } \\
\hline & $\begin{array}{c}\text { Körper- } \\
\text { gewicht } \\
\mathrm{g}\end{array}$ & Nahrung & $\begin{array}{c}\text { Harn. } \\
\text { menge } \\
\text { ecm }\end{array}$ & Bemerkung & \begin{tabular}{|c|} 
Körouer- \\
gewicht \\
$\mathrm{g}$
\end{tabular} & Nahrung & $\begin{array}{c}\text { Harn- } \\
\text { menge } \\
\text { ccm }\end{array}$ & Bemerkung \\
\hline $\begin{array}{c}23 . \mathrm{IX} \\
1911\end{array}$ & 1200 & $\begin{array}{c}\text { Brust } \\
+100 \mathrm{~g} \\
\text { Kuhmilch }\end{array}$ & 150 & $\begin{array}{c}\text { Beginn } \\
\text { des } \\
\text { Versuches }\end{array}$ & 1220 & $\begin{array}{c}\text { Brust } \\
+100 \mathrm{~g} \\
\text { Kuhmilch }\end{array}$ & 160 & $\begin{array}{c}\text { Beginn } \\
\text { des } \\
\text { Versuches }\end{array}$ \\
\hline $\begin{array}{c}\text { 23. X. } \\
1911\end{array}$ & 2000 & $\mid \begin{array}{cc}1 & \text { Semmel } \\
2 & \text { Würste } \\
150 \mathrm{~g} \\
\text { Wasser }\end{array}$ & 150 & $\begin{array}{c}\text { Flüssig- } \\
\text { keitsbe- } \\
\text { schrän- } \\
\text { kung }\end{array}$ & 1800 & $\begin{array}{c}600 \mathrm{~g} \\
\text { Kuhmilch }\end{array}$ & 250 & $\begin{array}{l}\text { Aus- } \\
\text { schließlich } \\
\text { bei Kuh- } \\
\text { milch }\end{array}$ \\
\hline $\begin{array}{c}23 . \mathrm{XI} . \\
1911\end{array}$ & 2200 & idem & 150 & - & 2800 & $\begin{array}{c}850 \mathrm{~g} \\
\text { Kuhmilch }\end{array}$ & 500 & idem \\
\hline $\begin{array}{c}23 . \text { XIL. } \\
1911\end{array}$ & 3100 & $\begin{array}{c}\text { idein }+ \\
200-300 \\
g \text { Wasser }\end{array}$ & 400 & $\begin{array}{l}\text { Seit } 4 \text { Ta- } \\
\text { gen Was- } \\
\text { serzufuhr }\end{array}$ & 3500 & $\begin{array}{c}\text { Semmel, } \\
\text { Wurst und } \\
\text { Wasser } \\
\text { wie } \\
\text { Schwarz }\end{array}$ & 350 & $\begin{array}{l}\text { Seit } 4 \mathrm{Ta}- \\
\text { gen ge- } \\
\text { mischte } \\
\text { Kost mit } \\
\text { wenig } \\
\text { Wasser }\end{array}$ \\
\hline $\begin{array}{l}\text { 6. I. } \\
1911\end{array}$ & 3750 & idem & 400 & $\mid \begin{array}{r}\text { Ende des } \\
\text { rsuches }\end{array}$ & 4200 & idem & 350 & $\begin{array}{l}\text { Ende des } \\
\text { Versuches }\end{array}$ \\
\hline
\end{tabular}

Die Tabelle ergänzend ist zu bemerken, daß bei den Tieren am 23. IX. mit der Ablactation durch Beigabe von Kuhmilch begonnen wurde. Dieselbe war bei beiden Tieren am 30. IX. vollendet. Während nun "Grau" weiterhin ausschließlich Kuhmilch in beliebigen Mengen trinken durfte, wurde von diesem Tage angefangen bei "Schwarz" mit der Zulage von Semmel und Wurst begonnen und gleichzeitig die Milchmenge reduziert. Am 13. X. wurde die Milch gänzlich aus der Ernährung 
gestrichen und das Tier ausschließlich bei gemischter Kost und, wie oben beschrieben, unter anfangs nur zeitweiser, später beständiger Zulage von Wasser gehalten. Die Gewichtszunahmen zeigen bei den Tieren einen abweichenden Verlauf. Bei ,Schwarz" waren sie im ersten Monat sehr erheblich, 800 Gramm, im zweiten Monat, offenbar wegen der geringen Flüssigkeitszufuhr sehr klein, sie betrug nur $200 \mathrm{Gramm}$, von da ab unter Zulage von Wasser wieder sehr flott. "Grau" nahm von Anfang bis zum Ende des Versuches sehr regelmäßig zu. Doch scheinen diese Verschiedenheiten im Gewichtsverlaufe nur temporärer Natur gewesen zu sein; denn „Grau", der schon zu Beginn des Versuches um ein Geringes schwerer war als „Schwarz", blieb nur im ersten Monat, wo „Schwarz" sehr rasch zunahm, hinter ihm etwas zurück, holte ihn aber im zweiten Monat wieder ein und war auch am Schluß des Versuches wieder um etwas schwerer als "Schwarz“. Die Nahrung wurde den Tieren dreimal täglich, früh, mittags und abends in den Käfig gestellt und wurde, auch von "Grau" trotz der Eintönigkeit, sehr gern genommen.

Am 19. XII., also nahezu drei Monate, nachdem die Ernährung in dieser Weise durchgeführt worden war, wurde der Versuch abgebrochen, bzw. umgekehrt. „Schwarz“, der bis dahin nur wenig Wasser außer seiner gemischten Nahrung bekommen hatte, erhielt jetzt etwas mehr. "Grau" dagegen wurde an diesem Tage von seiner ausschließlichen Kuhmilchernährung brüsk abgesetzt und erhielt dieselbe Nahrung wie ,Schwarz", Wurst, Semmel und 300 Gramm Wasser. Von diesem Tage an bis zum Ende des Versuches am 6. I. 1912 blieb diese Ernährung konstant.

Wie weiterhin aus der Tabelle hervorgeht, war die Harnmenge entsprechend der verschiedenen Flüssigkeitszufuhr bei beiden Tieren verschieden groß. Bei ,Schwarz" betrug sie während des ersten Teiles des Versuches durchschnittlich $150 \mathrm{ccm}$ pro Tag, manchmal auch darunter, nach Umkehrung des Versuches bis zu $400 \mathrm{ccm}$. Bei "Grau" stieg sie von $160 \mathrm{cem}$ zu Beginn des Versuches kontinuierlich an, erreichte im dritten Monat des Versuches einen Durchschnittswert von $500 \mathrm{ccm}$, betrug aber an manchen Tagen auch $700 \mathrm{ccm}$. Nach Umkehrung des Versuches sank sie dann sofort auf $350 \mathrm{ccm}$ im Durchschnitt und darunter.

Um nun einen Anhaltspunkt dafür zu gewinnen, inwieweit durch diesen Versuch Veränderungen des Wassergehaltes im Organismus dieser Tiere hervorgerufen worden waren, um weiterhin zu sehen, ob 
diese Veränderungen nicht nur in den Geweben des Körpers, welche vorwiegend als Depots des Körperwassers und Regulationsorgane seines Wassergehaltes zu dienen haben, sondern auch im Blut nachweisbar wären, wurden Wasser- bzw. Trockenrückstandsbestimmungen im Blut, in der Muskulatur und im Unterhautzellgewebe, ferner Bestimmungen des $\mathrm{Hb}$-Gehaltes und Zählungen der roten Blutkörperchen vorgenommen.

Man könnte der Methode der direkten Wasserbestimmung durch Wägung des Trockenrückstandes vielleicht vorwerfen, daß sie gegenüber den neneren Methoden der refraktometrischen und Viscositätsbestimmung, der Verwendung der Gefrierpunktserniedrigung und der Messung der elektrisehen Leitfähigkeit etwas veraltet sei. Wenn ich mich trotzdem dieser Methode bediente, so geschah dies aus folgenden Gründen. Die Ermittelung des $\mathrm{N}$-Gehaltes auf refraktometrischem. Wege und die Bestimmung der Viscosität ist nur im Blute, nicht in den Organen anwendbar. Außerdem gibt, in Sonderheit die Bestimmung des NGehaltes mittels des Refraktometers, kein direktes Maß für den Wassergehalt des Blutes. Aus demselben Grunde glaubte ich auch auf die Bestimmung der Gefrierpunktserniedrigung und die Messung der Leitfähigkeit verzichten zu müssen, da dieselben uns wohl den Gehalt an Salzmolekülen, resp. an dissoziierten Salzen anzeigen und auf diese Weise indirekte Schlüsse auf den Wassergehalt erlauben, über diejenigen Mengen Wassers aber, die nicht an Salze, sondern an Kolloide gebunden sind, uns keinen Aufschluß geben.

Die oben erwähnten Untersuchungsmethoden wurden also bei den Versuchstieren in gewissen Abständen, und zwar bei beiden Tieren immer an demselben Tage vorgenommen. Die Wasserbestimmung im Blut geschah auf folgende Weise: Es wurde, nachdem ein Ohr rasiert und mit Äther gewaschen worden war, mit einem kurzen Scherenschlag ein Einschnitt in den Rand des Ohres gemacht, sodaß das Blut mit ziemlicher Geschwindigkeit in ein daruntergehaltenes vorher gewogenes Wägegläschen abtropfte. Ich erwähne dieses Detail deswegen, weil gewisse Ungenauigkeiten, die man dieser Methode besonders bei ihrer Anwendung am Menschen vorgeworfen hat, sicher darauf zurückzuführen sind, daß das Blut nur langsam, möglicherweise sogar unter Pressen entleert wurde, sodaß bis zur Gewinnung der zur Bestimmung nötigen Blutmenge schon so viel Zeit verrann, daß ein Teil des Wassers aus dem körperwarmen Blute während des Offenhaltens des Wägegläschens verdunstete und so der Bestimmung entging. Nachdem 
$0,3-0,5$ Gramm Blut entleert waren, wurde das Gläschen dicht verschlossen, gewogen und bei 100 bis 110 Grad bis zur Gewichtskonstanz getrocknet. Selbstverständlich wurden von jeder Blutprobe Doppelanalysen gemacht. Auch der Methode des Trocknens im Wärmeschrank wurden Vorwürfe der Ungenauigkeit, besonders von Jaksch, Chiarolanza u. a. gemacht und die Trocknung im Vakuumexsiccator empfohlen. Schließlich wurden aber von Jaksch selbst Trockenrückstandsbestimmungen im Wärmeschrank gemacht und gefunden, daß die Differenzen nur minimale seien. Ich habe die Trocknung im Wärmeschrank aus äußeren Gründen deswegen gewählt, weil bei der sehr großen Zahl von Bestimmungen, die ich zu machen hatte, mir nicht so viel Exsiccatoren zur Verfügung standen. Die Trocknung in letzteren dauert zirka 10 bis 14 Tage, auch darüber für die angegebene Blutmenge, während die. Trocknung im Wärmeschrank in längstens drei Tagen beendet ist. Die gefundenen Resultate der Doppelanalysen zeigten Differenzen von höchstens $0,01 \%$, entsprachen also allen Anforderungen an Genauigkeit. Mit Rücksicht darauf, daß sich bei den Bestimmungen der einzelnen Werte zu verschiedenen Zeiten Differenzen von mehreren Prozenten ergaben, ferner mit Rücksicht darauf, daß es sich ja stets um Vergleichswerte handelte, glaubte ich um so leichter von der umständlichen Trocknung im Vakuum absehen zu können.

Die Bestimmung des Wassergehaltes in der Muskulatur und im Unterhautzellgewebe geschah in der Weise, daß die Tiere mit Äther narkotisiert wurden, und daß nun aus der Rückenhaut ovaläre Stücke der rasierten Haut samt dem zugehörigen Unterhautzellgewebe, ferner Stückchen der darunter liegenden langen Rückenmuskeln exzidiert, zwischen Filtrierpapier oberflächlich getrocknet und von Blut gereinigt und dann in vorher gewogenen, gut schließenden Gläschen zur Bestimmung verwendet wurden. Die Hautwunde wurde durch ein paar Nähte vereinigt, mit Kollodium verbunden und heilte in wenigen Tagen per primam. Die Trockenbestimmung erfolgte ebenfalls im Wärmeschrank durch Wägen bis zur Gewichtskonstanz, doch dauerte sie, besonders wenn die herausgeschnittenen Teile etwas fettreicher waren, erheblich länger; die Differenzen in den Kontrollen waren auch etwas größer, zirka 0,1 bis $0,3 \%$. Doch sind auch diese Werte gut verwendbar, da die absoluten Differenzen der einzelnen Werte bei verschiedenen Tieren und verschiedenen Bestimmungen ebenfalls immer mehrere Prozente betrugen.

Die Bestimmung des $\mathrm{Hb}$-Gehaltes erfolgte mittelst des Sahlischen 
Hämometers; die Ablesung wurde immer von einer zweiten Person kontrolliert. Die Zählung der roten Blutkörperchen wurde mittelst der Türkschen Zählkammer in der Weise vorgenommen, daß der Melangeur nur bis zur Marke 0,5 vollgesogen, und immer acht große Quadrate der inneren Kammer ausgezählt wurden. Manchmal muß man noch größere Verdünnungen wählen, da bisweilen Werte von 8 bis 9 Millionen roter Blutkörperchen gefunden werden, die bei den schwächeren Verdünnungen wegen des dichten Beisammenliegens der einzelnen Erythrozyten nur ungenau bestimmt werden könnten.

Der eben in Besprechung stehende Versuch sollte also zunächst in ganz grober Weise über die Veränderungen des Wassergehaltes durch die fehlerhafte Ernährung Aufschluß geben, und es wurden daher zuvörderst einige orientierende Bestimmungen gemacht, die aber so eindeutige Resultate lieferten, daß in den späteren Versuchen in ganz systematischer Weise an die Bestimmungen herangegangen werden konnte. Tabelle II gibt über die Resultate der angestellten Untersuchungen Auskunft.

Tabelle II.

\begin{tabular}{|c|c|c|c|c|c|c|c|c|c|c|c|c|}
\hline Datum & 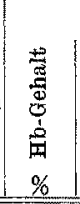 & 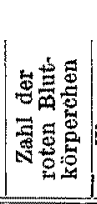 & 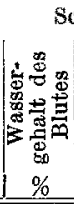 & 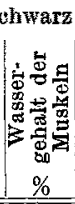 & 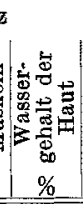 & Bemerkung & 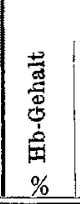 & 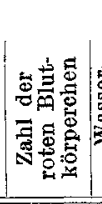 & 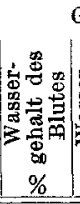 & 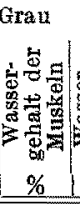 & 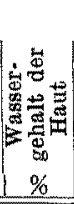 & Bemerkung \\
\hline $\begin{array}{r}\text { 18. X. } \\
1911\end{array}$ & $|49-51|$ & - & - & - & - & $\begin{array}{l}\text { 20Tage bei } \\
\text { gemisch- } \\
\text { ter Kost }\end{array}$ & $36-37$ & - & - & - & - & $\begin{array}{l}20 \text { Tage } \\
\text { bei Kuh- } \\
\text { milch }\end{array}$ \\
\hline 28.X. & 60 & 6,120000 & ) - & - & - & Tage bei & 29 & 8848000 & - & - & - & $30,62 w+39$ \\
\hline $\begin{array}{l}26 . X . \\
1911\end{array}$ & - & - & 82,340 & 74,125 & 41,323 & $\left\{\begin{array}{l}\text { gemiseh- } \\
\text { ter Kost }\end{array}\right.$ & - & - & $|86,68 i|$ & $77,758\}$ & 45,455 & $\left\{\begin{array}{l}\text { Tage bei } \\
\text { Kuhmileh }\end{array}\right.$ \\
\hline 11. XI. & 55 & 7,256000 & - - & - & - & $\mid \begin{array}{c}59, \text { bzw. } 60 \\
\text { Tage bei }\end{array}$ & 35 & 5976000 & - & - & - & \\
\hline $\begin{array}{l}12, \mathrm{XI} \\
1911\end{array}$ & - & - & 82,398 & - & - & $\int \begin{array}{l}\text { gemisch" } \\
\text { ter Kost }\end{array}$ & - & - & $|86,760|$ & - & - & Kuhmilch \\
\hline $\begin{array}{r}30 . \mathrm{XII} \\
1911\end{array}$ & 58 & $?$ & & $\ldots$ & - & 11, bzw. 14 & 47 & 6984000 & - & - & - & $\begin{array}{l}\text { 11, bzw. } 14 \\
\text { Tage nach }\end{array}$ \\
\hline $\begin{array}{l}2.1 . \\
1912\end{array}$ & - & - & 82,670 & - & - & $\begin{array}{l}\text { des Ver- } \\
\text { suches }\end{array}$ & - & - & 83,449 & - & - & $\begin{array}{l}\text { des Ver- } \\
\text { suches }\end{array}$ \\
\hline
\end{tabular}

Ein Vergleich sämtlicher Werte auf der linken und rechten Seite der Tabelle ergibt nun ganz eindeutige Resultate. Eine orientierende Bestimmung des $\mathrm{Hb}$-Gehaltes ergab bereits 20 Tage nach Beginn des Versuches eine Differenz von zirka $14 \%$ zu ungunsten des ausschließlich 
mit Milch ernährten Hundes „Grau“. In den nächsten 10 Tagen vermehrte sich diese Differenz auf 31\%. Eine Zählung der roten Blutkörperchen ergab, daß „Grau“ ungefähr 1,3 Millionen Erythrocyten weniger hatte als ,Schwarz“. Nun wurden drei Tage später, im ganzen 33 Tage nach Beginn des Versuches im Blut, in der Muskulatur und im Unterhautzellgewebe Wasserbestimmungen gemacht, die in allen drei Relationen ein übereinstimmendes Ergebnis zutage förderten. Der Wassergehalt im Blute war bei dem ausschließlich mit Kuhmilch gefütterten Tier um 4,3\%, der Wassergehalt der Muskulatur um 3,6\%, der der Haut samt Unterhautzellgewebe um 4,1\% größer als bei "Schwarz“. Nach ca. 2 Wochen wurden neuerliche Bestimmungen gemacht. Die Differenz im $\mathrm{Hb}$-Gehalte betrug 20\%. Die Zahl der roten Blutkörperehen war auch diesmal bei "Grau" um 1,2 Millionen geringer als bei "Schwarz". Die am nächsten Tage vorgenommene Bestimmung des Wassergehaltes im Blute ergab, daß die Differenz gegenüber der ersten Bestimmung nahezu gleich geblieben war; sie betrug wieder ungefähr $4,3 \%$.

Am 19. XII. wurde der Versuch in der oben beschriebenen Weise umgekehrt and nun 11 Tage später eine Blutuntersuchung aufgestellt. Während der Hb-Gehalt bei "Schwarz" ungefähr gleich geblieben war $(+3 \%)$ war er bei "Grau", der jetzt ebenfalls gemischte Kost mit geringen Flüssigkeitsmengen bekam, um $12 \%$ in die Höhe gegangen. Ebenso war bei diesem Tier die Zahl der roten Blutkörperehen um mehr als eine Million gestiegen. Drei Tage später wurde nochmals eine Bestimmung des Wassergehaltes im Blut angeschlossen, die nun zeigte, daß tatsächlich der ausschließlich mit Milch gefütterte $\mathrm{H} u n d$ das pathologische Verhalten gezeigt hatte, während die Bestimmung bei dem Hund mit anfänglicher Flüssigkeitseinsehränkung keine Veränderung seines Wassergehaltes nach Umkehr des Versuches nachweisen konnte. Während der Wassergehalt im Blute bei "Schwarz" nahezu konstant geblieben war $(+0,2 \%)$ sank er bei "Grau" um 3,3\% gegenüber der letzten Bestimmung bei Kuhmilchernährung und war dabei immer noch um $0,8 \%$ größer als beim Kontrolltier.

Aus diesem Versuch geht also eindeutig hervor, daß bei einem wachsenden Hund, bei dem noch vor Ablauf der Säugungsperiode eine ausschließliche Ernährang mit Kuhmilch eingeleitet und durch ungefähr drei Monate beibehalten wird, diese Art der Ernährung schon nach wenigen Wochen bemerkbare, später um so deutlicher in die Erscheinung tretende Veränderungen seiner chemischen Körperzu- 
sammensetzung im Sinne einer Wasservermehrung bewirkt. Diese Wasseranreicherung äußert sich nicht nur in einer Vermehrung des Wassergehaltes derjenigen Organe, welche die nächsten Beziehungen zum Wasserstoffwechsel haben, nämlich Muskulatur und Bindegewebe, sondern auch im Blutwasser, sodaß bei Ausschluß anderex Faktoren, welche den Gehalt des Blutes an Wasser beeinflussen, von einer Erhöhung desselben auch auf eine Erhöhung des Wassergehaltes in Muskulatur und Bindegewebe geschlossen werden kann. Diese "Hydrämie" äußert sich ferner in einer Verminderung des $\mathrm{Hb}$-Gehaltes und der Zahl der roten Blutkörperchen. Dooh soll dieser Umstand nur als unterstützendes, nicht als ausschließliches methodologisches Moment, ferner wegen gewisser später zu besprechender Beziehungen dieser Zustände zur Anämie der Säuglinge hervorgehoben werden. Rekurriere ich ferner auf die oben zitierten Worte Bezolds, so ist durch diesen Versuch der Beweis erbracht, daß durch die einseitige Ernährung mit Kuhmilch die ,physiologisehe Austrocknung des Organismus" a ufgehalten wird, daß im Gegenteil die physiologische Abnahme des Wassergehaltes in ein Stationärbleiben, ja sogar in eine leichte Zunahme verwandelt wird.

\section{Zweiter Versuch vom 4. I. bis 19. III. 1912.}

Der erste Versuch hatte sehr sinnfällige Unterschiede im Verhalten der beiden Versuchstiere aufgedeckt. Da aber zu Beginn des Versuches der eigentliche Versuchsplan doch noch nicht in allen Details so ausgearbeitet war, war eine Bestimmung des Wassergehaltes vor Beginn des Versuches unterlassen worden. Diese Lücke sollte in dem nun folgenden Versuch ausgefüllt, im übrigen aber nachgesehen werden, ob sich die Ergebnisse des ersten Versuches bestätigen ließen. Auch sollte durch Einführung einiger Details die Versuchsanordnung etwas modifizirt werden.

Vor allem wurden diesmal drei Hunde zum Versuch verwendet, von denen einer ausschließlich mit Kuhmilch (I), einer mit Semmeln, Fleisch und beliebigen Mengen Milch als Kontrolle (II) und der dritte ausschließlich mit Semmeln und Fleisch (III) ernährt werden sollte. Die Tiere, sämtlich Weibchen, waren am 1. XII. 1911 geworfen und wurden bis 8. I. 1912 bei der Alten gelassen. Am 4. I. 1912 wurde zunächst bei sämtlichen Tieren eine Wasserbestimmung im Blut gemacht. Wie aus Tabelle IV ersichtlich, differieren diese Werte nicht sehr, sie Jiegen zwischen 86 und $87 \%$. Um nun einen Versuchsfehler auszuschalten, 
den man allenfalls darin hätte begehen können, daß der Hund mit dem ohnehin höchsten Wassergehalt auf Milch gesetzt worden wäre, wurde das Tier mit dem niedrigsten Wassergehalt im Blute als dasjenige gewählt, das ausschließlich mit Kuhmilch gefüttert wurde. Am 8. I. begann die Ablactation. Es ist zu bemerken, daß diesmal sämtliche Tiere die Ablactation nicht so gut vertrugen wie die der ersten Serie, sie tranken schlecht, nahmen etwas an Gewicht ab, und brauchten ziemlich lange, ehe sie den Statusquo erreicht hatten. Dann aber kamen alle gut fort und nahmen gleichmäBig zu. Ein ungefähres Bild von dem Verhalten der drei Tiere gibt Tabelle III.

Tabelle III.

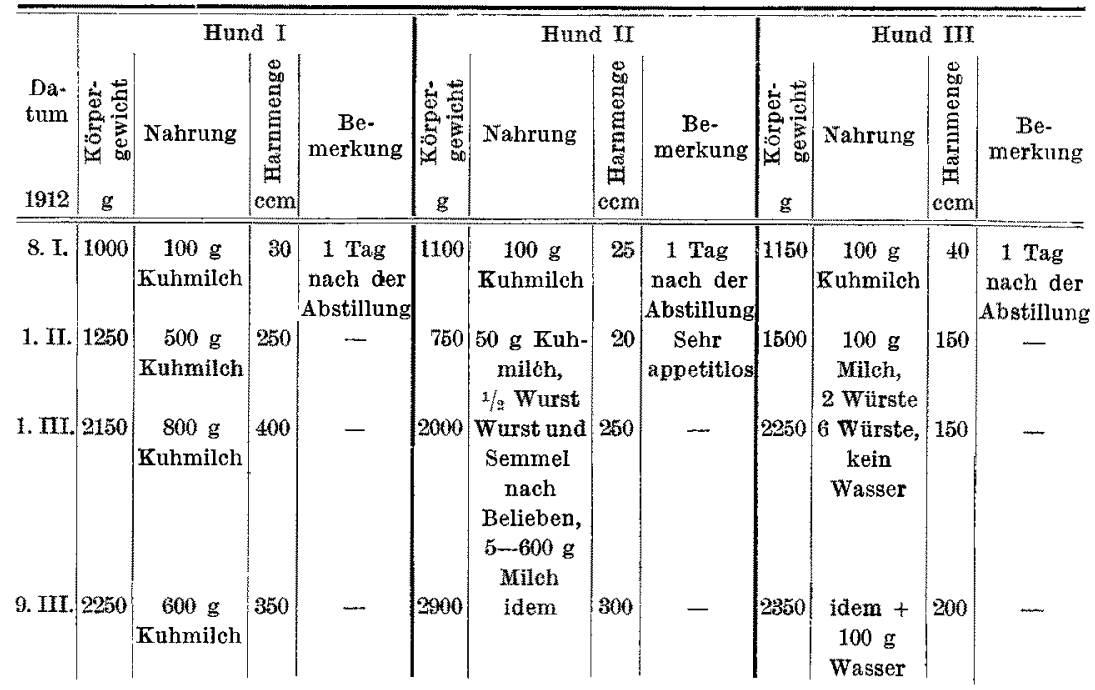

Wie aus der Tabelle hervorgeht, verhalten sich die Tiere der Nahrung gegenüber sehr verschieden. Besonders Hund II konnte sich lange nicht an die neue Nahrung gewöhnen und hat drei Wochen nach der Abstillung sein Gewicht zur Zeit der Ablactation noch nicht erreicht. Erst im zweiten Monat holt er mächtig nach, ebenso im dritten, so da $B$ er am Ende der Versuchszeit das schwerste der drei Tiere ist. Was seine Nahrung anlangt, ist hervorzuheben, daß dem Tier die Bestimmung seiner Nahrung vollkommen freigestellt wurde, sowohl was Menge der festen Nahrung, als was die Trinkmenge anbetrifft. Es sollte damit von vornherein gezeigt werden, daß sich das Tier, trotzdem es ziemlich erhebliche Mengen trank und rapid zunahm, doch anders 
verhält als das ausschließlich mit Milch gefütterte Tier. Die Wasserbestimmungen werden dies näher erläutern. Hund I nahm nach anfänglicher leichter Abnahme bald gut zu, so daß er drei Wochen nach der Abstillung sein damaliges Gewicht schon um $250 \mathrm{~g}$ überschritten hatte. Die gute Zunahme hielt auch während des zweiten Versuchsmonates an, erst in den letzten zwei bis drei Wochen nahm er weniger $\mathrm{zu}$, trank auch weniger als früher. Auch III büßte anfänglich etwas an Gewicht ein, holte aber bald nach und nahm die ersten beiden Monate gut zu. Auch er zeigte dann im dritten Versuchsmonat schlechtere Zunahme. Wegen der anfänglichen Abnahme verzögerten sich auch die ersten Analysen. Dieselben konnten erst dann angestellt werden, als alle Hunde in guter Zunahme waren und man annehmen mußte, daß ihr Verhalten sonst ein völlig normales und demjenigen der Tiere im ersten Versuch gleich war. Der Stuhl verhielt sich bei den Tieren so wie im ersten Versuch. Durchfall wurde niemals beobachtet. In seinem Äußeren zeigte Hund I Unterschiede gegenüber II und III, er bekam struppiges Fell, großen Bauch und auch etwas unsicheren Gang. III dagegen war immer sehr aufgeregt, sprang unermüdlich in seinem Käfig umher, bellte fortwährend usw. - Die Wartung der Hunde und die Zuwägung der Nahrung, ebenso die chemischen Bestimmungen geschahen in derselben Weise wie im ersten Versuch. Über die gefundenen Resultate berichtet Tabelle IV.

Tabelle IV.

\begin{tabular}{|c|c|c|c|c|c|c|c|c|c|c|c|c|}
\hline \multirow{3}{*}{$\begin{array}{r}\text { Datum } \\
1912 \\
\end{array}$} & \multicolumn{4}{|c|}{ Hund 1} & \multicolumn{4}{|c|}{ Fund II } & \multicolumn{4}{|c|}{ Hund III } \\
\hline & \multicolumn{3}{|c|}{ Wassergehalt in $\%$} & \multirow{2}{*}{$\begin{array}{c}\mathrm{Be} \\
\text { merkung }\end{array}$} & \multicolumn{3}{|c|}{ Wassergehalt in \% } & \multirow{2}{*}{$\begin{array}{c}\text { Be- } \\
\text { merkung }\end{array}$} & \multicolumn{3}{|c|}{ Wassergehalt in $\%$} & \multirow{2}{*}{$\begin{array}{c}\text { Be- } \\
\text { merhung }\end{array}$} \\
\hline & Blut & $\begin{array}{c}\text { Mas- } \\
\text { kel }\end{array}$ & Faut & & Blut & $\begin{array}{c}\text { Mus" } \\
\text { kel }\end{array}$ & Haut & & Blut & $\begin{array}{c}\text { Mus- } \\
\text { kel }\end{array}$ & Hant & \\
\hline 4. I. & 86,008 & - & - & $\begin{array}{l}\text { Vor Be* } \\
\text { ginn des } \\
\text { Versuches } \\
\text { bei Brust }\end{array}$ & 86,784 & - & - & wie I & 87,021 & - & - & wie I \\
\hline 2. III. & $87.5 \% 1$ & $\dot{-}$ & - & $\begin{array}{l}\text { Aus- } \\
\text { sehlieblich } \\
\text { bet Kuh- } \\
\text { mileh }\end{array}$ & 83,782 & - & - & $\begin{array}{c}\text { Bellebige } \\
\text { Nahrungs } \\
\text { und Trink- } \\
\text { mengen }\end{array}$ & 82,692 & - & - & $\begin{array}{c}\text { Nur bei } \\
\text { Tleiseh } \\
\text { und Sem- } \\
\text { mel }\end{array}$ \\
\hline 19. III & - & 76,373 & 36,692 & jdem & - & 3,594 & 36,294 & & - & 74,186 & 36,436 & idem \\
\hline
\end{tabular}

Bei Diskussion der in der Tabelle vereinigten Resultate ergibt sich folgendes: 'Die drei Hunde haben im Alter von ungefähr viereinhalb Wochen bei ausschließlicher Brusternährung in ihrem Blut ungefähr gleiche Wasserwerte. Dieselben liegen je ungefähr $0,5 \%$ auseinander. Zwei Monate nach Beginn des Versuches ergeben sich folgende Diffe- 
renzen. Der Hund mit dem niedrigsten Wasserwert (I), der ausschließlich mit Kuhmilch ernährt wurde, zeigt nun einen um 1,5\% höheren Wasserwert im. Blut gegenüber der ersten Bestimmung. Sein Blut ist also sicher keiner physiologischen Austrocknung unterlegen, sondern wasserreicher geworden. Es ist um 3,8\% wasserreicher als das des Kontrollhundes, der neben gemischter Kost beliebige Mengen Mileh getrunken hat, also sicher nicht wasserarm war. Es ist um $4,9 \%$ wasserreicher als das des Hundes III, der unter Aussehluß von Wasser- und Milchzugabe zu seiner Nahrung gehalten wurde.

Zwei Wochen später wurden auch Haut- und Muskulatur der Tiere untersucht, um zu sehen, ob auch hier Veränderungen im Wassergehalt nachweisbar wären. Nur wurde diesmal kein Unterhautzellgewebe mit zur Trocknung verwendet, sondern lediglich das Epithel und das Corium. Da zeigte sich nun, daß diese letzteren Organe Schwankungen im Wasserhaushalt kaum mitmachen, da sie nur als Schutz- und Stützorgane dienen. Die Werte sind bei allen drei Tieren nahezu identisch, immerhin aber bei dem mit Milch ernährten Tier höher als bei den beiden anderen. Dagegen zeigen die Werte, die bei Bestimmung des Muskelwassers gefunden wurden, wieder große Unterschiede. Der Wassergehalt des Muskels bei I ist um 2,8\% höher als bei II und um 2,2\% höher als bei III.

Aus dem Versuch ergibt sich also eine vollständige Bestätigung des ersten Versuches. Ausschließliche Fütterung mit Kuhmilch über die Säugungsperiode hinaus bedingt beim wachsenden Tier ein Aufhalten des physiologischen Austrocknungsprozesses. Sein Körperwasser nimmt nicht nur nicht ab, sondern sogar zu. Es zeigt sich ferner, daß sich das Tier II, das beliebige Nahrungs- und Trinkmengen zu sich nehmen darf, ganz ähnlich verbält wie Tier III, das unter Flüssigkeiteinschränkung gehalten wird, daß also der anscheinend viel schwerere Eingriff des Flüssigkeitsentzuges sich im chemischen Verhalten des Organismus viel weniger geltend macht als die erzwungene abundante Zufuhr von ausschlieBlich flüssiger Nahrung. Es zeigt sich ferner, ebenso wie im ersten Versuch, daß an dieser Wasseranreicherung durch ausschließliche Fütterung mit Kuhmilch Muskel und Blut gleichmäßig teilnehmen.

In dieser letzteren Ansicht, daß nämlich an der Wasseranreicherung der Gesamtorganismus beteiligt ist, werde ich noch durch Untersuchungsresultate Eckerts bestätigt, der - allerdings zu anderen 
Zwecken - eine ähnliche Versuchsanordnung aufstellte und dann Gesamtanalysen der getöteten Tiere machte. Eckert verwendete sechs Hunde desselben Wurfes zur Untersuchung. Der Verfasser nimmt als Säugungsperiode für seine Tiere etwa 4 Wochen an und versucht nun, durch verschiedene Ernährung Änderungen in der chemischen Zusammensetzung des Organismus der Tiere resp. Zusammenhänge zwischen dieser und eventuellem Entstehen von Diathesen nachzuweisen. Inwieweit ihm dies gelungen ist, soll an anderer Stelle erörtert werden. Hier soll nur eine kurze Besprechung der Untersuchungsergebnisse gegeben werden, da sie auch für unsere Frage wichtig sind. Hund I wurde also sofort nach der Geburt getötet und als Kontrolle der Gesamtanalyse unterworfen. Hund II wurde nach 13 Tagen, also etwa in der Mitte der angenommenen Säugungsperiode, Hund III am Ende derselben getötet. IV wurde über die normale Zeit hinaus bis zum 45 . Tage an der Brust gelassen und dann getötet, Hund $V$ wurde nach der Stillzeit vom 31. bis 62 . Tage ausschließlich mit Kuhmilch ernährt, dann getötet und analysiert. Hund VI wurde am 31. Tage von der Brust abgesetzt und nun mit Hundekuchen, Fleisch, Knochen, Milch möglichst gut und rationell ernährt, am 67. Lebenstage getötet und zur Analyse benützt. - Auf unsere Versuchsanordnung übertragen entspricht also Hund VI meinem Kontrolltier, Hund 5 meinem mit Kuhmilch ernährten Tier, nur wurde in diesem Versuch Eckerts die Zeit des Experimentes nicht sehr lange ausgedehnt. Da beide Tiere zu ungefähr derselben Zeit getötet wurden ( $V$ am 62., VI am 67. Lebenstage), können sie sehr gut zum Vergleich herangezogen werden. - Die Hunde wurden sofort nach der Tötung zerkleinert und in der üblichen Weise zur Gesamtanalyse vorbereitet. Ich habe, um eine bessere Übersicht zu ermöglichen, aus verschiedenen Berechnungen und Tabellen Eckerts folgende Tabelle $\mathrm{V}$ zusammengestellt.

Tabelle V.

\begin{tabular}{r|c|c}
\hline $\begin{array}{c}\text { Hund } \\
\text { Nr. }\end{array}$ & $\begin{array}{c}\text { Wassergehalt } \\
\text { des Gesamttieres } \\
\text { in \% }\end{array}$ & $\begin{array}{c}\text { Wassergehalt des } \\
\text { fett- und asche- } \\
\text { frei gedachten } \\
\text { Tierkörpers in \% }\end{array}$ \\
\hline I & 80,7 & 84,3 \\
II & 70,9 & 84,7 \\
III & 67,1 & 84,2 \\
IV & 62,6 & 80,8 \\
V & $\mathbf{6 8 , 6}$ & $\mathbf{8 2 , 7}$ \\
VI & $\mathbf{6 1 , 5}$ & $\mathbf{8 0 , 5}$
\end{tabular}


Betrachtet man zunächst die erste Kolonne der Tabelle, so findet man auch hier die Bestätigung des Gesetzes von der physiologischen Austrocknung. Der nach der Geburt getötete Hund ist der wasserreichste, der Hund VI, der am längsten gelebt hat, der wasserärmste. Es ergibt sich aber mit Deutlichkeit, daß der nach der Säugungsperiode ausschließlich mit Kuhmilch genährte und ungefähr zu derselben Zeit getötete Hund $V$ um $7,1 \%$ wasserreicher ist als die Kontrolle VI. Der zweite Stab der Tabelle $V$ wurde von Eckert berechnet und von mir wiedergegeben, um einem Einwand Rubners zu begegnen. Rubner schreibt: ,Zahlen über den Wassergehalt des Menschen hängen ganz von dem Umstand ab, ob der Betreffende viel oder wenig Fett abgelagert hat. Bei Tieren sieht man mit der Zeit der Mast den prozentigen Wassergehalt sinken und mit der Magerkeit steigen. Am häufigsten begegnet man großer Magerkeit, also wasserreichen Organen bei der Tuberkulose. - Wenn in ein normales, fettarmes Gewebe Fett eingelagert wird, so muß, weil letztere Substanz wasserfrei ist, der prozentige Wassergehalt sinken, ohne daß der Organismus selbst auch nur die geringste Wassermenge verloren zu haben braucht." F. Steinitz glaubte sich auf Grund von Analysen von vier an Ernährungsstörungen gestorbenen Kindern dieser Ansicht anschließen zu sollen. Die entsprechenden Zahlen für den Wassergehalt auf den Gesamtorganismus berechnet, lauten: $71,0,79,9,82,3,79,9 \%$. Auf fettfreien Körper berechnet lauten die Zahlen: $81,0,81,1,83,8,81,5 \%$. Daraus zieht Steinitz den Schluß, daß mit Ausnahme des Fettgehaltes das Verhältnis zwischen Körperfixa und Wassergehalt durch die Ernährungstörung nicht geändert worden ist, und daß es durch alimentäre Änderungen nicht gelingt, wieder mit Ausnahme des Fettes, Veränderungen in der chemischen $\mathrm{Zu}$ sammensetzung des Körpers zu erzielen. - Wie Eckert sehr mit Recht betont, und wie aus dem zweiten Stab der Tabelle $V$ hervorgeht, lassen sich diese Ansichten nicht vollständig aufrechterhalten. Auch aus den auf fett- und aschefrei gedachten Tierkörper berechneten Zahlen erhellt sowohl die physiologische Austrocknung als die Wasseranreicherung durch ausschlieBliche Milchfütterung. Übrigens wurde die Ansicht Rubners schon durch die oben zitierten Versuche Weigerts widerlegt. Auch Thomas (zitiert nach Eckert) gibt in einer Tabelle die betreffenden Untersuchungsresultate eigener Versuche und der anderen bekannten Gesamtanalysen, aus denen eine Bestätigung der Weigertschen Anschauungen erhellt.

Übrigens hat auch Orgler Unterschiede im Wassergehalt bei natür- 
lich und künstlich genährten Hunden gefunden, die vier, bzw. sechs Wochen am Leben gelassen wurden. Nur sind die Unterschiede im Wassergehalt nicht so sinnfällig, da ja beide Gruppen von Tieren mit Milch genährt wurden, aber immerhin besonders bei den sechs Wochen alten Tieren, die also offenbar über die Säugungsperiode hinaus mit Kuhmilch ernährt wurden, sehr deutlich. Die entsprechenden Werte gebe ich in den folgenden kurzen, aus Orglers Tabellen zusammengestellten Zahlen wieder.

4 Wochen alte Tiere.

6 Wochen alte Tiere.

\begin{tabular}{|c|c|c|c|c|c|c|c|}
\hline & \multicolumn{2}{|c|}{$1000 \mathrm{~g}$ Tier enthalten } & $\begin{array}{c}1000 \mathrm{~g} \text { fett- } \\
\text { freies Tier } \\
\text { enthalten } \\
\text { Wasser }\end{array}$ & & \multicolumn{2}{|c|}{$1000 \mathrm{~g}$ Tier enthalten } & $\begin{array}{l}1000 \mathrm{~g} \text { fett- } \\
\text { freies Tier } \\
\text { enthalten } \\
\text { Wasser }\end{array}$ \\
\hline $\begin{array}{l}\text { natürlich } \\
\text { ernährt }\end{array}$ & $\begin{array}{l}653,6 \\
623,4\end{array}$ & $\begin{array}{l}201,2 \\
232,3\end{array}$ & $\begin{array}{l}818,3 \\
812,0\end{array}$ & natürlich & 625,6 & 222,5 & 804,6 \\
\hline $\begin{array}{l}\text { künstlich } \\
\text { ernährt }\end{array}$ & $\begin{array}{l}723,9 \\
747,4\end{array}$ & $\begin{array}{l}125,1 \\
105,4\end{array}$ & $\begin{array}{l}827,4 \\
835,5\end{array}$ & künstlich & 705,2 & 140,4 & 835,5 \\
\hline
\end{tabular}

Aus den Zahlen geht also hervor, daß die künstlich genährten Tiere wasserreicher sind als die natürlich genährten. Auch aus den zweiten Berechnungen auf fettfreies Tier, die ebenfalls mit Rücksicht auf Rubners Einwand angestellt wurden, erhellt, daß die natürlich ernährten Tiere wasserärmer sind als die künstlich ernährten. Aus der zweiten kleinen Tafel sieht man ferner die physiologische Austrocknung (gegenüber den Werten der ersten Tafel), und im letzten Stab der zweiten Tafel fällt auf, daß die beiden Wasserwerte schon viel größere Differenzen haben als bei den vier Wochen alten Tieren.

Dritter (Doppel-)Versuch vom 1. V. bis 14. VIII. 1912.

Dieser Versuch sollte zunächst eine Wiederholung der beiden ersten Versuche bringen und ihre Ergebnisse kontrollieren. Er sollte aber weiterhin eine neue Frage anschneiden. Hat überschüssig in den Organismus eingeführtes Wasser einen Einfluß auf die chemische Zusammensetzung des Körpers? - Es soliten ferner einige weitere Fragen über die Art der Bindung des Wassers im Körper zu lösen versucht werden.

Diesmal werden vier Hunde (sämtlich Männchen) in Versuch genommen. Je zwei derselben stammen von demselben Wurf. Das erste 
Paar ( $I$ und II) ist bei Beginn des Versuches fünf Wochen alt und hat bis dahin nur bei der Alten getrunken. Bei diesem Paar wird der Versuch in der alten Weise wiederholt. I erhält nach der Abstillung Kuhmilch in beliebiger Menge, II wird langsam von Milch entwöhnt, behält aber eine geringe Menge derselben und bekommt außerdem Wurst und Semmeln. Das zweite Paar (III und IV) ist bei Beginn des Versuches vier Wochen alt und ist bis dahin ebenfalls nur bei Brust gewesen. Nach der Abstillung über Kuhmilch erhält III etwas Milch, Wurst und Semmeln, IV bekommt nach kurzer Milchperiode ebenfalls Wurst und Semmeln, aber keine Milch, sondern reichlich Wasser. Das Durstgefühl des Tieres kann man leicht dadurch steigern, daß man etwas Paprika auf die Semmeln streut, so daß das Tier bis zu $1400 \mathrm{ccm}$ täglich trinkt. Um an diesem durch längere Zeit durchgeführten Versuch den Modus procedendi im Detail vorzuführen, habe ich in Tabelle VI und VII für beide Paare den Gewichtszuwachs, die Futter-, Trink- und Harnmengen zusammengestellt.

Bei Beginn des Versuches waren I und II ungleich schwer, I wog 3400 , II $2800 \mathrm{~g}$. Die brüske Ablactation auf Kuhmilch wurde von beiden Tieren gut vertragen, sie nahmen gleich von Anfang an gut zu. Schon ungefähr nach eineinhalb Monaten jedoch zeigte sich, daß I langsamer wuchs als II, die Differenz wurde im Laufe der Versuchszeit immer kleiner. Am 24. VII., also nach zweidreiviertelmonatiger Versuchszeit, war I nur mehr um $500 \mathrm{~g}$ schwerer als II. Von diesem Tage an begann er appetitlos zu werden, nahm sehr viel ab, und erst als der Versuch nach dieser langen Zeit abgebrochen und er auf gemischte Kost gesetzt wurde, begann er wieder zuzunehmen. Da diese Appetitlosigkeit erst in der allerletzten Zeitauftrat, waren dadurch der Versuch und die Bestimmungen in keiner Weise gestört. - III und IV waren zu Beginn des Versuches ungefähr gleichschwer. Die Absetzung mußte, da das Muttertier nicht im Hause bleiben konnte, auch bei ihnen brüsk erfolgen. Die Tiere zeigten keinerlei Störung, blieben aber im Gewicht eine Zeitlang stehen, nahmen sogar unerheblich ab, aber nach einigen Tagen wieder gut zu. Die Gewichtskurve verlief, wie die Tabelle VII zeigt, in den ersten Wochen ganz gleich. Erst im zweiten Monat begann IV etwas zurückzubleiben und wog am Ende des Versuches um $670 \mathrm{~g}$ weniger als III. Der Stuhl war bei den Tieren immer geformt, nur bei I war er immer breiig und weich. - Alles Nähere über die Dauer der Einführung der neuen Nahrung, die Art des sukzessiven Vorgehens bei derselben, über die Nahrungs- und Trinkmengen erhellt aus den Tabellen. 
Tabelle VI.

\begin{tabular}{|c|c|c|c|c|c|c|c|c|c|c|}
\hline \multirow{3}{*}{ Datum } & \multicolumn{5}{|c|}{ Hund I } & \multicolumn{5}{|c|}{ Hund II } \\
\hline & \multirow{2}{*}{$\begin{array}{l}\text { Körper- } \\
\text { gewicht }\end{array}$} & \multicolumn{3}{|c|}{ Nahrung } & \multirow{2}{*}{$\begin{array}{l}\text { Harn- } \\
\text { menge }\end{array}$} & \multirow{2}{*}{$\begin{array}{l}\text { Körper- } \\
\text { gewicht }\end{array}$} & \multicolumn{2}{|c|}{ Nahrung } & \multirow[b]{2}{*}{ Wurst } & \multirow{2}{*}{$\begin{array}{l}\text { Harn- } \\
\text { menge }\end{array}$} \\
\hline & & Milch & Semmel & Wurst & & & Milch & Semmel & & \\
\hline 1. V. & 3400 & 300 & & & 100 & 2800 & 300 & & & 120 \\
\hline 2. & 3450 & 400 & & & 150 & 2950 & 300 & & & 250 \\
\hline 3. & 3550 & 500 & & & 200 & 2950 & 400 & & & 300 \\
\hline 4. & 3600 & 600 & & & 500 & 2900 & 400 & & & 400 \\
\hline 5. & 3600 & 600 & & & 400 & 2850 & 500 & & & 200 \\
\hline 6. & 3800 & 700 & & & 600 & 2950 & 500 & & & 300 \\
\hline 7. & 3900 & 600 & & & 500 & 3000 & 400 & & & 300 \\
\hline 8. & 3950 & 600 & & & 500 & 3000 & 400 & & & 400 \\
\hline 9. & 3900 & 800 & & & 250 & 3100 & 300 & 1 & & 300 \\
\hline 10. & 4000 & 900 & & & 650 & 3100 & 200 & 1 & & 300 \\
\hline 11. & 4050 & 900 & & & 650 & 3150 & 100 & 1 & & 350 \\
\hline 12. & 3800 & 1000 & & & 500 & 3100 & 100 & 1 & & 400 \\
\hline 13. & 4150 & 1100 & & & 700 & 3200 & 100 & 3 & $1 / 2$ & 150 \\
\hline 14. & 4250 & 1200 & & & 750 & 3250 & 100 & 3 & $1 / 8$ & 75 \\
\hline 15. & 4300 & 1200 & & & 750 & 3200 & 100 & 3 & $1 / 2$ & 50 \\
\hline 16. & 4300 & 1200 & & & 750 & 3250 & 100 & 3 & $1 / 2$ & 25 \\
\hline 17. & 4350 & 1200 & & & 450 & 3300 & 100 & 3 & 1 & 60 \\
\hline 18. & 4500 & 1200 & & & 650 & 3350 & 100 & 3 & 1 & 10 \\
\hline 19. & 4500 & 1100 & & & 550 & 3350 & 100 & 3 & 1 & 50 \\
\hline 20. & 4400 & 1200 & & & 500 & 3400 & 100 & 4 & 1 & 100 \\
\hline 21. & 4600 & 1200 & & & 700 & 3500 & 100 & 4 & 1 & 70 \\
\hline 22. & 4600 & 1200 & & & 600 & 3500 & 100 & 4 & 1 & 70 \\
\hline 23. & 4700 & 1200 & & & 600 & 3500 & 100 & 4 & 1 & 50 \\
\hline 24. & 4750 & 1200 & & & 600 & 3600 & 100 & 4 & 1 & 60 \\
\hline 25. & 4800 & 1200 & & & 700 & 3600 & 100 & 4 & 1 & 40 \\
\hline 26. & 4900 & 1200 & & & 650 & 3650 & 100 & 4 & 1 & 40 \\
\hline 27. & 4750 & 1200 & & & 600 & 3650 & 100 & 4 & 1 & 50 \\
\hline 28. & 4800 & 1200 & & & 650 & 3700 & 100 & 4 & 1 & 25 \\
\hline 29 . & 4900 & 1200 & & & 650 & 3800 & 100 & 4 & $\vec{I}$ & 40 \\
\hline 30. & 5000 & 1200 & & & 400 & 3900 & 100 & 4 & 1 & 60 \\
\hline 31. & 5000 & 1200 & & & 500 & 4000 & 100 & 4 & 1 & 90 \\
\hline I. VI. & 5150 & 1200 & & & 650 & 4000 & 100 & 4 & 1 & 90 \\
\hline & 5150 & 1100 & & & 450 & 4150 & 100 & 4 & 1 & 75 \\
\hline 3. & 5100 & 1200 & & & 600 & 4100 & 100 & 4 & 1 & 60 \\
\hline 4. & 5250 & 1200 & & & 650 & 4200 & 100 & 4 & 1 & 50 \\
\hline 5. & 5300 & 1200 & & & 640 & 4200 & 100 & 4 & 1 & 50 \\
\hline 6. & 5000 & 1200 & & & 600 & 4200 & 100 & 4 & 1 & 50 \\
\hline 7. & 5350 & 1200 & & & 700 & 4300 & 100 & 4 & 1 & 50 \\
\hline 8. & 5400 & 1200 & & & 600 & 4400 & 100 & 4 & 1 & 40 \\
\hline 9. & 5420 & 1200 & & & 600 & 4500 & 100 & 4 & 1 & 50 \\
\hline 10. & 5500 & 1200 & & & 650 & 4500 & 100 & 4 & 1 & 10 \\
\hline 11. & 5500 & 1200 & & & 600 & 4550 & 100 & 4 & 1 & 50 \\
\hline 12. & 5600 & 1200 & & & 600 & 4600 & 100 & 4 & 1. & 70 \\
\hline 13. & 5400 & 1200 & & & 600 & 4650 & 100 & 4 & 1 & 50 \\
\hline 14. & 5600 & 1200 & & & 650 & 4700 & 100 & 4 & 1 & 60 \\
\hline 15. & 5650 & 1200 & & & 600 & 4750 & 100 & 4 & 1 & 60 \\
\hline 16. & 5700 & 1200 & & & 650 & 4750 & 100 & 4 & 1 & 80 \\
\hline 17. & 5800 & 1200 & & & 600 & 4750 & 100 & 4 & 1 & 70 \\
\hline 18. & 5600 & 1200 & & & 600 & 4850 & 100 & 4 & 1 & 100 \\
\hline 19. & 5850 & 1200 & & & 650 & 4900 & 100 & 4 & $\overrightarrow{1}$ & 120 \\
\hline 20. & 5800 & 1200 & & & 600 & 4950 & 100 & 4 & 1 & 100 \\
\hline 21. & 5900 & 1200 & & & 700 & 4850 & 100 & 4 & 1 & 50 \\
\hline 22. & 5950 & 1200 & & & 600 & 4900 & 100 & 4 & 1 & 40 \\
\hline
\end{tabular}


Tabelle VI (Fortsetzung).

\begin{tabular}{|c|c|c|c|c|c|c|c|c|c|c|}
\hline \multirow[b]{2}{*}{ Datum } & \multicolumn{5}{|c|}{ Hand I } & \multicolumn{5}{|c|}{ Hund II } \\
\hline & $\begin{array}{l}\text { Körper- } \\
\text { gewicht }\end{array}$ & Mileh & $\begin{array}{l}\text { Nahrung } \\
\mid \text { Semmel } \\
\end{array}$ & Wurst & $\begin{array}{l}\text { Harn- } \\
\text { menge }\end{array}$ & $\begin{array}{l}\text { Körper- } \\
\text { gewicht }\end{array}$ & Milch & $\begin{array}{l}\text { Nahrung } \\
\mid \text { Semmel }\end{array}$ & Wurst & $\begin{array}{l}\text { Harn- } \\
\text { menge }\end{array}$ \\
\hline 23. & 5910 & 1100 & & & 600 & 5000 & 100 & 4 & 1 & 50 \\
\hline 24. & 5950 & 1100 & & & 650 & 5000 & 100 & 4 & 1 & 60 \\
\hline 25. & 5900 & 1200 & & & 600 & 5100 & 100 & 4 & 1 & 65 \\
\hline 26. & 5810 & 1200 & & & 570 & 5100 & 100 & 4 & 1 & 50 \\
\hline 27. & 5750 & 1200 & & & 500 & 5200 & 100 & 4 & 1 & 60 \\
\hline 28. & 5700 & 1000 & & & 500 & 5250 & 100 & 4 & 1 & 50 \\
\hline 29. & 5950 & 1100 & & & 550 & 5300 & 100 & 4 & 1 & 50 \\
\hline 30. & 5700 & 1100 & & & 750 & 5350 & 100 & 4 & 1 & 30 \\
\hline 1. VII. & 5700 & 1200 & & & 600 & 5400 & 100 & 4 & 1 & 40 \\
\hline & 5850 & 1200 & & & 600 & 5450 & 100 & 4 & 1 & 40 \\
\hline 3. & 5950 & 1200 & & & 650 & 5500 & 100 & 4 & 1 & 30 \\
\hline 4. & 6000 & 1200 & & & 600 & 5500 & 100 & 4 & 1 & 40 \\
\hline 5. & 5900 & 1200 & & & 600 & 5550 & 100 & 4 & 1 & 40 \\
\hline 6. & 5850 & 1000 & & & 650 & 5600 & 100 & 4 & 1 & 30 \\
\hline 7. & 5800 & 1000 & & & 600 & 5600 & 100 & 4 & 1 & 50 \\
\hline 8. & 5800 & 900 & & & 620 & 5700 & 100 & 4 & 1 & 40 \\
\hline 9. & 5750 & 1100 & 1 & & 650 & 5750 & 100 & 4 & 1 & 50 \\
\hline 10. & 6000 & 1300 & 1 & & 600 & 5800 & 100 & 4 & 1 & 40 \\
\hline 11. & 6350 & 1300 & 1 & & 650 & 5850 & 100 & 4 & 1 & 70 \\
\hline 12. & 6350 & 1300 & 1 & & 650 & 5750 & 100 & 4 & 1 & 60 \\
\hline 13. & 6450 & 1400 & 1 & & 650 & 5750 & 100 & 4 & 1 & 50 \\
\hline 14. & 6450 & 1400 & 1 & & 600 & 5800 & 100 & 4 & 1 & 70 \\
\hline 15. & 6500 & 1400 & 1 & & 610 & 5800 & 100 & 4 & 1 & 50 \\
\hline 16. & 6550 & 1500 & 1 & & 650 & 5800 & 100 & 4 & 1 & 60 \\
\hline 17. & 6550 & 1500 & 1 & & 650 & 5800 & 100 & 4 & 1 & 70 \\
\hline 18. & 6550 & 1500 & 1 & & 700 & 5850 & 100 & 5 & 1 & 40 \\
\hline 19. & 6700 & 1500 & 1 & & 700 & 6000 & 100 & 5 & 1 & 50 \\
\hline 20. & 6750 & 1500 & 1 & & 650 & 6100 & 100 & 5 & 1 & 40 \\
\hline 21. & 6900 & 1500 & 1 & & 700 & 6150 & 100 & 5 & I & 20 \\
\hline 22. & 6850 & 1500 & 1 & & 600 & 6200 & 100 & 5 & 1 & 25 \\
\hline 23. & 6800 & 1500 & 1 & & 700 & 6250 & 100 & 5 & 1 & 40 \\
\hline 24. & 6800 & 1500 & 1 & & 750 & 6300 & 100 & 5 & 1 & 50 \\
\hline 25. & 6750 & 1500 & 1 & & 700 & 6350 & 100 & 5 & 1 & 60 \\
\hline 26. & 6500 & 1000 & 1 & & 500 & 6350 & 100 & 5 & 1 & 70 \\
\hline 27. & 6200 & 1000 & 1 & & 100 & 6400 & 100 & 5 & 1 & 75 \\
\hline 28. & 6000 & 900 & 1 & & 300 & 6400 & 100 & 5 & 1 & 50 \\
\hline 29. & 6000 & 900 & 1 & & 400 & 6600 & 100 & 5 & 1 & 50 \\
\hline 30. & 6150 & 1000 & 1 & & 600 & 6600 & 100 & 5 & 1 & 70 \\
\hline 31. & 6150 & 100 & 5 & 1 & 100 & 6650 & 100 & 5 & 1 & 50 \\
\hline 1. VIII. & 6000 & 100 & 3 & 1 & 60 & 6650 & 100 & 5 & 1 & 50 \\
\hline 2. & 5850 & 100 & 4 & 1 & 25 & 6650 & 100 & 5 & 1 & 40 \\
\hline 3. & 5800 & 100 & 4 & 1 & 20 & 6750 & 100 & 5 & 1 & 25 \\
\hline 4. & 5810 & 100 & 4 & 1 & 10 & 6850 & 100 & 5 & 1 & 20 \\
\hline 5. & 5950 & 100 & 4 & 1 & 5 & 6850 & 100 & 5 & 1 & 50 \\
\hline 6. & 6050 & 100 & 4 & 1 & 10 & 6900 & 100 & 5 & I & 20 \\
\hline 7. & 6000 & 100 & 4 & 1 & 15 & 6950 & 100 & 5 & 1 & 30 \\
\hline 8. & 6100 & 100 & 4 & 1 & 20 & 7000 & 100 & 5 & I & 30 \\
\hline 9. & 6200 & 100 & 4 & 1 & 10 & 7100 & 100 & 5 & 1. & 20 \\
\hline 10. & 6250 & 100 & 4 & 1 & 10 & 7100 & 100 & 5 & 1 & 5 \\
\hline 11. & 6200 & 100 & 4 & 1 & 20 & 7100 & 100 & 5 & 1 & 10 \\
\hline 12. & 6250 & 100 & 5 & 1 & 25 & 7050 & 100 & 5 & 1. & 15 \\
\hline 13. & 6250 & 100 & 5 & 1 & 20 & 7150 & 100 & 5 & 1 & 10 \\
\hline 14. & 6250 & 100 & 5 & 1 & 10 & 7200 & 100 & 5 & 1 & 15 \\
\hline
\end{tabular}


Tabelle VII.

\begin{tabular}{|c|c|c|c|c|c|c|c|c|c|c|c|}
\hline \multirow{3}{*}{ Datum } & \multicolumn{5}{|c|}{ Hund III } & \multicolumn{6}{|c|}{ Hund IV } \\
\hline & \multirow{2}{*}{$\begin{array}{l}\text { Körper- } \\
\text { gowicht }\end{array}$} & \multicolumn{3}{|c|}{ Nahrung } & \multirow{2}{*}{$\begin{array}{l}\text { Harn- } \\
\text { menge }\end{array}$} & \multirow{2}{*}{$\begin{array}{l}\text { Körper- } \\
\text { gewicht }\end{array}$} & \multicolumn{4}{|c|}{ Nahrung } & \multirow{2}{*}{$\begin{array}{l}\text { Harn- } \\
\text { menge }\end{array}$} \\
\hline & & Milch & & Wurst & & & Milch & Semmel & Wurst & Wasser & \\
\hline 1. V. & 2100 & 300 & & & 90 & 2200 & 200 & & & & 90 \\
\hline & 2050 & 300 & & & 120 & 2100 & 200 & & & & 90 \\
\hline 3. & 2050 & 300 & & & 50 & 2100 & 300 & & & & 50 \\
\hline 4. & 2000 & 300 & & & 40 & 2100 & 300 & & & & 40 \\
\hline 5. & 2050 & 300 & & & 40 & 2100 & 300 & & & & 40 \\
\hline 6. & 2050 & 300 & & & 50 & 2050 & 300 & & & & 50 \\
\hline 7. & 2000 & 300 & & & 40 & 2050 & 300 & & & & 40 \\
\hline 8. & 2050 & 300 & & & 50 & 2100 & 300 & & & & 50 \\
\hline 9. & 2100 & 200 & 1 & & 40 & 2050 & 200 & 1 & & 200 & 60 \\
\hline 10. & 2050 & 200 & 1 & & 30 & 2050 & 100 & 1 & & 150 & 170 \\
\hline 11. & 2100 & 200 & 1 & & 20 & 2200 & 100 & 1 & & 250 & 250 \\
\hline 12. & 2000 & 300 & 1 & & 100 & 2000 & 100 & 1 & & 250 & 300 \\
\hline 13. & 2100 & 150 & 2 & & 40 & 2250 & 100 & 2 & & 300 & 100 \\
\hline 14. & 2050 & 150 & 2 & & 30 & 2250 & 100 & 3 & & 300 & 250 \\
\hline 15. & 2000 & 100 & 2 & $1 / 2$ & 30 & 2200 & 100 & 4 & & 400 & 250 \\
\hline 16. & 2150 & 100 & 3 & 1 & 10 & 2300 & 100 & 4 & & 400 & 250 \\
\hline 17. & 2200 & 100 & 3 & 1 & 40 & 2300 & 100 & 4 & & 500 & 300 \\
\hline 18. & 2200 & 100 & 3 & 1 & 20 & 2250 & & 4 & $1 / 2$ & 600 & 280 \\
\hline 19. & 2300 & 100 & 3 & $\mathrm{l}$ & 15 & 2500 & & 4 & 1 & 600 & 300 \\
\hline 20. & 2250 & 100 & 4 & 1 & 75 & 2350 & & 4 & 1 & 700 & 400 \\
\hline 21. & 2300 & 100 & 4 & 1 & 70 & 2500 & & 4 & 1 & 700 & 500 \\
\hline 22. & 2300 & 100 & 4 & 1 & 50 & 2500 & & 4 & 1 & 700 & 500 \\
\hline 23. & 2400 & 100 & 4 & 1 & 30 & 2700 & & 4 & 1 & 700 & 400 \\
\hline 24. & 2450 & 100 & 4 & 1 & 50 & 2650 & & 4 & 1 & 700 & 400 \\
\hline 25. & 2500 & 100 & 4 & 1 & 25 & 2650 & & 4 & 1 & 750 & 750 \\
\hline 26. & 2750 & 100 & 4 & 1 & 25 & 2950 & & 4 & 1 & 800 & 600 \\
\hline 27. & 2750 & 100 & 4 & 1 & 25 & 2800 & & 4 & 1 & 900 & 450 \\
\hline 28. & 2650 & 100 & 4 & 1 & 50 & 2750 & & 4 & 1 & 900 & 360 \\
\hline 29. & 2700 & 100 & 4 & 1 & 90 & 2800 & & 4 & 1 & 900 & 350 \\
\hline 30. & 2750 & 100 & 4 & 1 & 75 & 2850 & & 4 & 1 & 850 & 600 \\
\hline 31. & 2900 & 100 & 4 & 1 & 150 & 2900 & & 4 & 1 & 900 & 620 \\
\hline 1. VI. & 2950 & 100 & 4 & 1 & 100 & 2950 & & 4 & 1 & 900 & 550 \\
\hline 2. & 3000 & 100 & 4 & 1 & 100 & 3250 & & 4 & 1 & 900 & 610 \\
\hline 3. & 3000 & 100 & 4 & 1 & 90 & 3150 & & 4 & 1 & 900 & 650 \\
\hline 4. & 3050 & 100 & 4 & 1 & 60 & 3200 & & 4 & 1 & 1000 & 650 \\
\hline 5. & 3100 & 100 & 4 & I & 75 & 3200 & & 4 & 1 & 1000 & 700 \\
\hline 6. & 3050 & 100 & 4 & 1 & 70 & 3000 & & 4 & 1 & 1000 & 600 \\
\hline 7. & 3250 & 100 & 4 & 1 & 50 & 3200 & & 4 & 1 & 1000 & 700 \\
\hline 8. & $\mathbf{3 3 5 0}$ & 100 & 4 & 1 & 70 & 3350 & & 4 & 1 & 1000 & 700 \\
\hline 9. & 3400 & 100 & 4 & 1 & 100 & 3400 & & 4 & 1 & 1000 & 650 \\
\hline 10. & 3400 & 100 & 4 & 1 & 60 & 3450 & & 4 & 1 & 1000 & 700 \\
\hline 11. & 3450 & 100 & 4 & 1 & 100 & 3450 & & 4 & 1 & 1000 & 700 \\
\hline 12. & 3500 & 100 & 4 & 1 & 110 & 3500 & & 4 & 1 & 1100 & 700 \\
\hline 13. & 3550 & 100 & 4 & 1 & 100 & 3550 & & 4 & 1 & 1100 & 700 \\
\hline 14. & 3550 & 100 & 4 & 1 & 105 & 3550 & & 4 & 1 & 1000 & 700 \\
\hline 15. & 3550 & 100 & 4 & 1 & 70 & 3550 & & 4 & 1 & 1100 & 600 \\
\hline 16. & 3700 & 100 & 4 & 1 & 100 & 3700 & & 4 & 1 & 1100 & 600 \\
\hline 17. & 3750 & 100 & 4 & 1 & 100 & 3600 & & 4 & 1 & 1200 & 750 \\
\hline 18. & 3800 & 100 & 4 & 1 & 90 & 3700 & & 4 & 1 & 1200 & 750 \\
\hline 19. & 3900 & 100 & 4 & 1 & 130 & 3700 & & 4 & 1 & 1200 & 760 \\
\hline 20. & 3850 & 100 & 4 & 1 & 120 & 3750 & & 4 & 1 & 1200 & 750 \\
\hline 21. & 3800 & 100 & 4 & 1 & 75 & 3700 & & 4 & 1 & 1200 & 700 \\
\hline 22. & 3800 & 100 & 4 & 1 & 70 & 3750 & & 4 & 1 & 1200 & 760 \\
\hline
\end{tabular}


Die Bedeutung des Wassers für Konstitution und Ernährung.

Tabelle VII (Fortsetzung).

\begin{tabular}{|c|c|c|c|c|c|c|c|c|c|c|c|}
\hline \multirow{3}{*}{ Datum } & \multicolumn{5}{|c|}{ Hund III } & \multicolumn{6}{|c|}{ Hund IV } \\
\hline & \multirow{2}{*}{$\begin{array}{l}\text { Körper- } \\
\text { gewieht }\end{array}$} & \multicolumn{3}{|c|}{ Nahrung } & \multirow{2}{*}{$\begin{array}{l}\text { Harn- } \\
\text { menge }\end{array}$} & \multirow{2}{*}{$\begin{array}{l}\text { Körper- } \\
\text { gewicht }\end{array}$} & \multicolumn{4}{|c|}{ Nahrung } & \multirow{2}{*}{$\begin{array}{l}\text { Harn- } \\
\text { menge }\end{array}$} \\
\hline & & Milch & Semmel & Wurst & & & Mileh & |Semmel| & Wurst & |Wasser| & \\
\hline 23. & 3900 & 100 & 4 & 1. & 70 & 3750 & & 4 & 1 & 1300 & 700 \\
\hline 24. & 3950 & 100 & 4 & 1 & 75 & 3750 & & 4 & 1 & 1200 & 700 \\
\hline 25. & 3950 & 100 & 4 & 1 & 70 & 3800 & & 4 & 1 & 1200 & 750 \\
\hline 26. & 4000 & 100 & 4 & 1 & 70 & 3850 & & 4 & 1 & 1200 & 650 \\
\hline 27. & 4000 & 100 & 4 & 1 & 75 & 3800 & & 4 & 1 & 1300 & 700 \\
\hline 28. & 4050 & 100 & 4 & 1 & 80 & 3950 & & 4 & 1 & 1200 & 650 \\
\hline 29. & 4150 & 100 & 4 & 1 & 60 & 3750 & & 4 & 1 & 1300 & 550 \\
\hline 30. & 4150 & 100 & 4 & 1 & 40 & 3950 & & 4 & 1 & 1200 & 400 \\
\hline 1. VII. & 4250 & 100 & 4 & 1 & 70 & 3950 & & 4 & 1 & 1200 & 550 \\
\hline 2. & 4300 & 100 & 4 & 1 & 90 & 4050 & & 4 & 1 & 1200 & 650 \\
\hline 3. & 4250 & 100 & 4 & 1 & 30 & 4050 & & 4 & 1 & 1200 & 700 \\
\hline 4. & 4250 & 100 & 4 & 1 & 20 & 3850 & & 4 & $l$ & 1100 & 600 \\
\hline 5. & 4300 & 100 & 4 & 1 & 70 & 3950 & & 4 & 1 & 1100 & 700 \\
\hline 6. & 4350 & 100 & 4 & 1 & 60 & 4050 & & 4 & 1 & 1200 & 600 \\
\hline 7. & 4400 & 100 & 4 & 1. & 50 & 4000 & & 4 & 1 & 1200 & 500 \\
\hline 8. & 4450 & 100 & 4 & 1 & 40 & 4200 & & 4 & 1 & 1200 & 300 \\
\hline 9. & 4450 & 100 & 4 & 1 & 100 & 4100 & & 4 & 1 & 1200 & 750 \\
\hline 10. & 4500 & 100 & 4 & 1 & 120 & 4000 & & 4 & 1 & 1200 & 700 \\
\hline 11. & 4500 & 100 & 4 & 1 & 100 & 4200 & & 4 & 1 & 1300 & 750 \\
\hline 12. & 4450 & 100 & 4 & I & 90 & 4200 & & 4 & I & 1300 & 750 \\
\hline 13. & 4450 & 100 & 4 & 1 & 70 & 4200 & & 4 & I & 1300 & 700 \\
\hline 14. & 4500 & 100 & 4 & I & 90 & 4250 & & 4 & 1 & 1300 & 750 \\
\hline 15. & 4600 & 100 & 4 & 1 & 100 & 4300 & & 4 & 1 & 1300 & 700 \\
\hline 16. & 4620 & 100 & 4 & 1 & 90 & 4100 & & 4 & 1 & 1300 & 700 \\
\hline 17. & 4620 & 100 & 4 & 1 & 70 & 4100 & & 4 & 1 & 1400 & 800 \\
\hline 18. & 4700 & 100 & 4 & 1 & 75 & 4200 & & 5 & 1 & 1400 & 750 \\
\hline 19. & 4750 & 100 & 4 & 1 & 70 & 4300 & & 5 & I & 1400 & 700 \\
\hline 20. & 4800 & 100 & 4 & 1 & 70 & 4200 & & 5 & I & 1400 & 700 \\
\hline 21. & 4850 & 100 & 4 & 1 & 75 & 4400 & & 5 & I & 1400 & 750 \\
\hline 22. & 4850 & 100 & 4 & 1 & 75 & 4350 & & 5 & 1 & 1300 & 700 \\
\hline 23. & 4900 & 100 & 4 & 1 & 70 & 4350 & & 5 & I & 1300 & 700 \\
\hline 24. & 4950 & 100 & 4 & 1 & 70 & 4500 & & 5 & 1 & 1400 & 750 \\
\hline 25. & 5000 & 100 & 4 & 1 & 90 & 4550 & & 5 & 1 & 1300 & 700 \\
\hline 26. & 5050 & 100 & 4 & 1 & 80 & 4600 & & 5 & 1 & 1300 & 650 \\
\hline 27. & 5050 & 100 & 4 & 1 & 75 & 4600 & & 5 & 1 & 1300 & 600 \\
\hline 28. & 5200 & 100 & 4 & 1 & 50 & 4650 & & 5 & 1 & 1300 & 470 \\
\hline 29. & 5200 & 100 & 5 & 1 & 70 & 4750 & & 5 & I & 1400 & 780 \\
\hline 30. & 5300 & 100 & 5 & 1 & 20 & 4800 & & 5 & 1 & 1400 & 800 \\
\hline 31. & 5350 & 100 & 5 & 1 & 50 & 4650 & & 5 & 1 & 100 & $?$ \\
\hline 1. VIII. & 5350 & 100 & 5 & 1 & 50 & 4500 & & 5 & 1 & 100 & 100 \\
\hline 2. & 5350 & 100 & 5 & 1 & 50 & 4400 & & 5 & 1 & 100 & 75 \\
\hline 3. & 5350 & 100 & 5 & 1 & 20 & 4500 & & 5 & 1 & 100 & 50 \\
\hline 4. & 5400 & 100 & 5 & 1 & 10 & 4500 & & 5 & 1 & 100 & 60 \\
\hline 5. & 5400 & 100 & 5 & 1 & ? & 4550 & & 5 & 1 & 100 & 40 \\
\hline 6. & 5500 & 100 & 5 & I & $?$ & 4600 & & 5 & 1 & 100 & 10 \\
\hline 7. & 5500 & 100 & 5 & 1 & 25 & 4650 & & 5 & 1 & 100 & 20 \\
\hline 8. & 5550 & 100 & 5 & 1 & 25 & 4700 & & 5 & 1 & 100 & 30 \\
\hline 9. & 5550 & 100 & 5 & 1 & 25 & 4750 & & 5 & 1 & 100 & 20 \\
\hline 10. & 5550 & 100 & 5 & 1 & 20 & 4900 & & 5 & 1 & 100 & 10 \\
\hline il. & 5550 & 100 & 5 & 1 & 15 & 4900 & & 5 & 1 & 100 & 15 \\
\hline 12. & 5550 & 100 & 5 & 1 & 20 & 4900 & & 5 & 1 & 100 & 10 \\
\hline 13. & 5600 & 100 & 5 & 1 & 25 & 4920 & & 5 & $\mathbf{I}$ & 100 & 15 \\
\hline 14. & 5600 & 100 & 5 & 1 & 15 & 4930 & & 5 & 1 & 100 & 10 \\
\hline
\end{tabular}


In diesem Versuch wurden Bestimmungen des Wassergehaltes im Blute, ferner hie und da Bestimmungen des Hb-Gehaltes und der roten Blutkörperchen und in späteren Stadien des Versuches auch Bestimmungen der Gesamtasche im Blute vorgenommen. Die erste Bestimmung des Wassergehaltes im Blute erfolgte am Tage, wo die Tiere noch bei Brust waren, und wurde das Tier (I, IV) mit dem niedrigeren Wassergehalt als dasjenige ausgewählt, welches ausschließlich mit Milch, resp. mit großen Mengen Wassers neben gemischter Kost gefüttert werden sollte. Die nächsten Bestimmungen wurden erst dann gemacht, bis die Ablactation vollendet war und die Tiere bei ihrer Nahrung gute Gewichtszunahme zeigten; das war fünf Wochen nach der Abstillung. Die Resultate der nun in verschiedenen Intervallen wiederholten Bestimmungen sind in den beiden folgenden Tabellen VIII und IX vereinigt.

$\mathrm{Zu}$ Tabelle VIII ist zunächst folgendes zu bemerken: Am 1. V., als die Hunde im Alter von fünf Wochen noch bei Brustnahrung in Versuch genommen und der Wassergehalt ihres Blutes untersucht wurde, betrug derselbe bei I um 2,2\% weniger als bei II. Normalerweise hätten nun beide Hunde im Wassergehalt ihres Blutes konstante Abnahme zeigen sollen. Um daher die Versuchsbedingungen gleichsam noch zu erschweren, setzte ich I auf reine Kuhmilch ab, während II Fleisch, Semmel und etwas Milch erhielt. Trafen die in den ersten Versuchen gemachten Erfahrungen auch diesmal wieder zu, so mußte bei II die normale physiologische Austrocknung bereits im Gange sein, d. h. die Werte für den Wassergehalt immer kleiner werden, bei I durften sie sich nicht vermindern, sondern mußten sich in gleicher Höhe halten, oder eventuell noch ansteigen. In letzterem Falle also mußten, wenn man die entsprechenden Werte in ein Koordinatensystem eintrug, die beiden Kurven sich überkreuzen. Daß letztere Tatsache zutrifft, zeigt Fig. 1, auf der ich für beide Versuchspaare die gefundenen Werte graphisch dargestellt habe. (Die gestrichelte Linie verbindet die Werte, welche bei den Kontrolltieren gefunden wurden, während die ausgezogene Linie die bei den fehlerhaft ernährten Versuchstieren gefundenen Resultate darstellt.)

Doch zunächst noch Einiges zur Diskussion der Tabelle VIII. 5 Wochen nach Beginn des Versuches, 3 Wochen, nachdem die endgültigen Nahrungsmengen erreicht sind, wird eine Wasserbestimmung im Blut von I und II gemacht. Während bei II die physiologische Austrocknung sich bereits bemerkbar zu machen beginnt $(-0,05 \%)$, 
ist der Wassergehalt im Blut bei I um ungefähr 1,5\% gestiegen. Am 30. VI, also 25 Tage nach der letzten Bestimmung, wird eine neuerliche Untersuchung gemacht. Die Nahrung war bei allen Tieren dieselbe geblieben und wurde auch gern genommen. Bei I ergab sich eine Zunahme von ungefähr $1 \%$, bei II eine Abnahme von $1,46 \%$ im Wassergehalt des Blutes gegenüber der letzten Bestimmung. In den nächsten Tagen wurde nebenbei eine histologische Blutuntersuchung vorgenommen, um die im ersten Versuch gewonnenen Resultate einer Revision zu unterziehen. Auch hier zeigte sich vollkommene Utbereinstimmung: $42 \%$ Hb-Gehalt gegenüber $63 \%, 6,7$ Millionen Frythrocyten gegenüber 6,9 Millionen bei I und II. Die Hydrämie drückt sich also auch hier, wenn auch nicht in so sinnfälliger Weise wie bei der

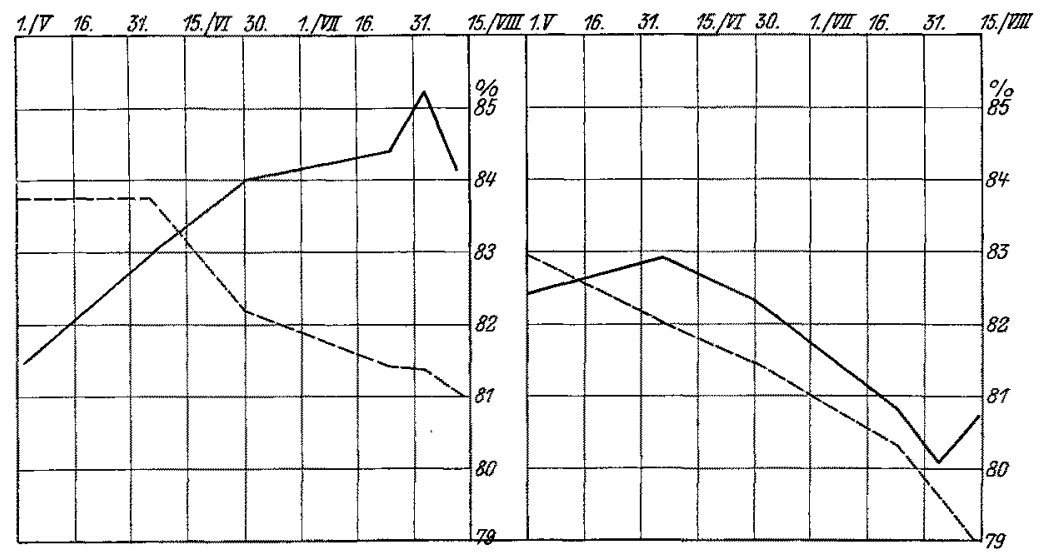

Fig. 1.

chemischen Untersuchung aus. Am 25. VII, ergab eine neuerliche Untersuchung bei I eine weitere Zunahme von $0,4 \%$, bei II eine Abnahme um $0,8 \%$. Von diesem Tage an begann I die ausschließliche Milchernährung zu verweigern, trank sehr wenig und nahm auch entsprechend ab. Am 31. VII. wurde er definitiv auf gemischte Kost gesetzt und 3 Tage später wieder eine Blutuntersuchung gemacht. Diese ergab keine wesentlichen Veränderungen gegenüber früher. I hat sogar gegenüber dem 25. VII. um 1,1\%, gegenüber dem 23. VII., an dem der Höhepunkt seines Gewichtes war und an dem zufällig eine Wasserbestimmung gleichzeitig mit der später zu besprechenden Aschenbestimmung gemacht worden war, um $0,25 \%$ in seinem Blutwasser zugenommen. II hat wieder um ein Weniges abgenommen. Wie also ersichtlich, wird 
R. Lederer:

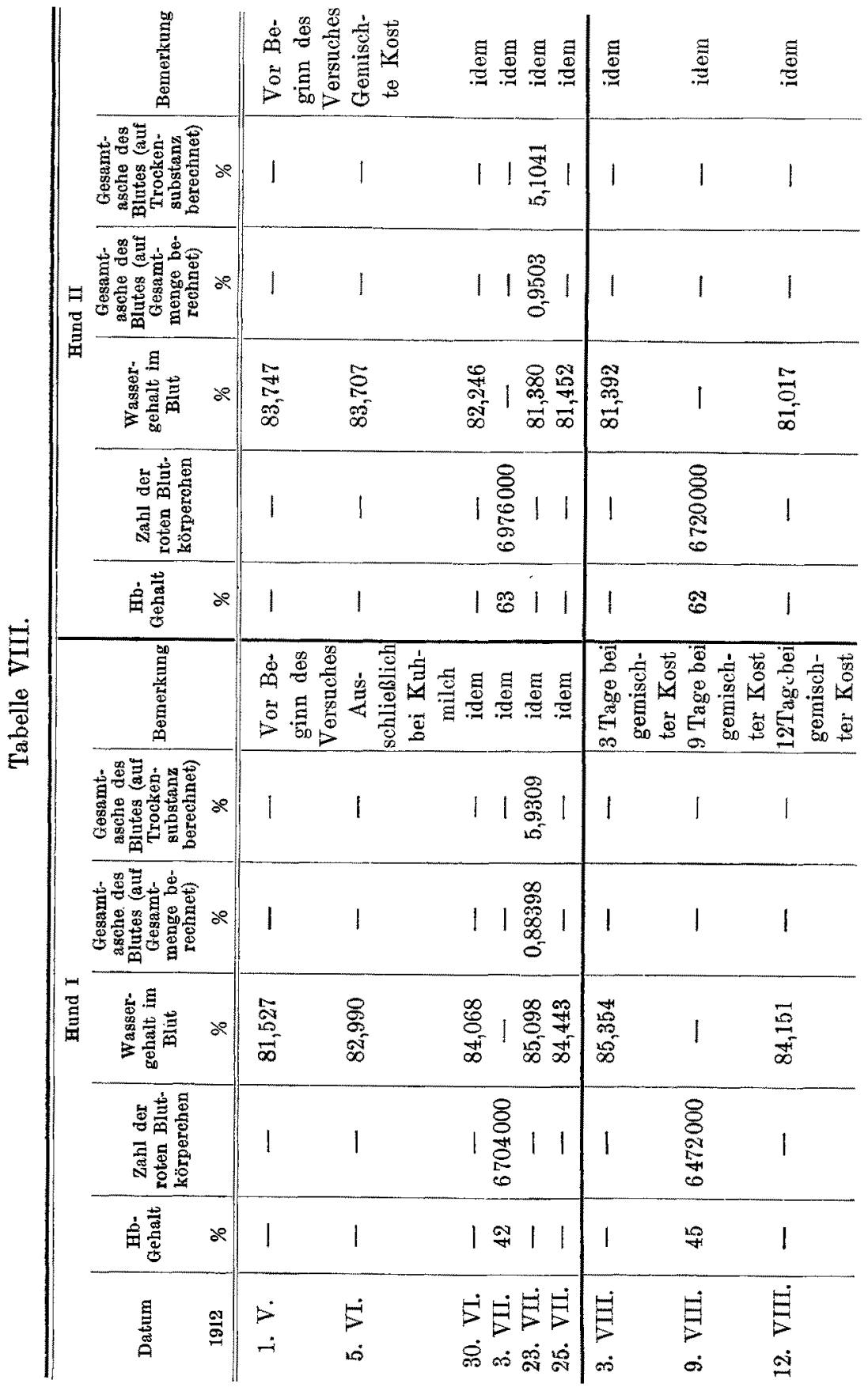


Die Bedeutung des Wassers für Konstitution und Ernährung.

\begin{tabular}{|c|c|c|c|c|c|c|}
\hline & \multicolumn{2}{|l|}{ 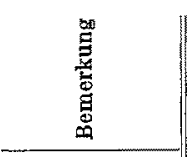 } & \multicolumn{2}{|c|}{ 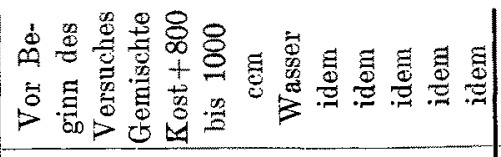 } & \multicolumn{2}{|c|}{ 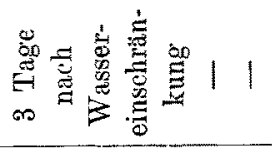 } \\
\hline & 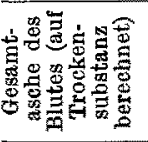 & 8 & 1 & 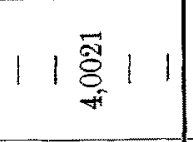 & 1 & 11 \\
\hline & 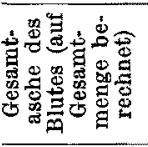 & 8 & 1 & ||$\frac{\vec{m}}{\sqrt[m]{5}}|1|$ & 1 & 11 \\
\hline & 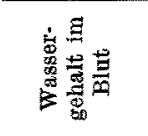 & 2 & $\begin{array}{l}\mathscr{D} \\
\stackrel{2}{\mathscr{2}} \\
\stackrel{\infty}{\infty}\end{array}$ & 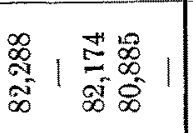 & $\frac{\infty}{\infty}$ & $1 \underset{\infty}{\stackrel{\infty}{\infty}}$ \\
\hline & 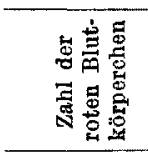 & & 1 & 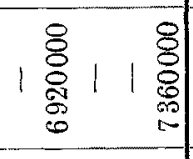 & 1 & 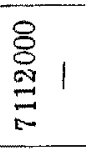 \\
\hline & 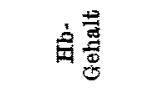 & 2 & 1 & $|:| \begin{array}{lll}1 & 1 & 1\end{array}$ & 1 & $尺 1$ \\
\hline & 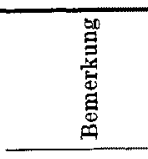 & & 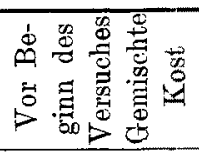 & 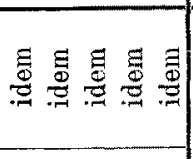 & $\stackrel{\Xi}{ \pm}$ & 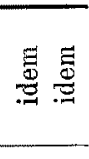 \\
\hline & 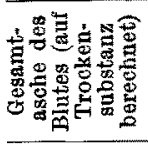 & 2 & 1 & ||$\frac{\infty}{\infty}||$ & 1 & 11 \\
\hline & 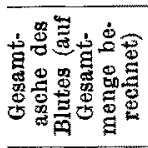 & 2 & 1 & ||$\frac{18}{5}||$ & 1 & 11 \\
\hline $\begin{array}{l}0 \\
\vdots \\
\Xi \\
9\end{array}$ & 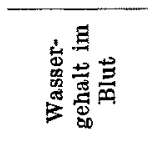 & $\approx$ & 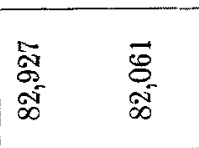 & 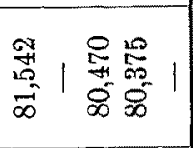 & $\begin{array}{l}2 \\
\stackrel{2}{5} \\
\stackrel{5}{2}\end{array}$ & $1 \stackrel{0}{8}$ \\
\hline & 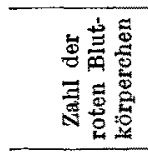 & & 1 & 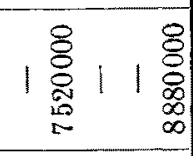 & 1 & 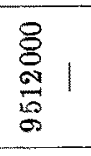 \\
\hline & 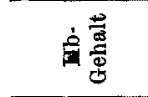 & $3 e$ & 1 & 18118 & 1 & $\rightarrow \infty$ \\
\hline & 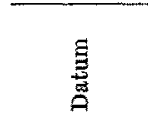 & $\frac{9}{9}$ & $\dot{r}$ & 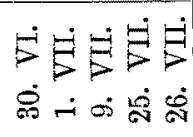 & $\dot{B}$ & 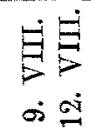 \\
\hline
\end{tabular}


das im Laufe der monatelangen fehlerhaften Ernährung aufgestapelte Wasser nicht sehr rasch abgegeben. Erst 12 Tage nach der Absetzung zeigt sich bei flott ansteigendem Körpergewicht unter dem Einfluß der gemischten Ernährung bei I eine Abnahme um 1,2\% gegenüber der letzten Bestimmung, während die Kontrolle ihre langsame Abnahme des Blutwassers in einem geringen Wert von $0,3 \%$ autsdrückt.

Auch dieser Versuch ergibt also eine vollständige Bestätigung der früher gefundenen Tatsachen. Durch dreimonatige Versuchsdauer wird in wiederholten Bestimmungen nachgewiesen, daß die ausschließliche Fütterung mit Kuhmilch beim wachsenden Tier die physiologische Austrocknung in den umgekehrten Prozeß der Wasseranreicherung zu verwandeln vermag. Das aufgestapelte Wasser wird nach Absetzen a uf gemischte Kost nur langsam abgegeben.

Ergänzend zu Tabelle IX ist zu bemerken, daß die Hunde III und IV am 1. V. vier Wochen alt und bei Brust waren und Blutwasserwerte von 82,9 , resp. 82,4 aufwiesen, also eine Differenz von $0,5 \%$ zuungunsten von IV. Dieser letztere Hund mit dem niedrigeren Wasserwert wurde nun als derjenige gewählt, der nach Zufütterung von gemischter Kost reichlich Wasser zu trinken bekam. Das Tier gewöhnte sich sehr bald an die großen Wassermengen und trank schon nach wenigen Wochen $3 / 4$ bis 11 Wasser täglich. 5 Wochen nach der Ablactation, 3 Wochen nach Einführung dieser Diät wurde die erste Bestimmung gemacht, und auch hier zeigte sich, daß sich die Kurven zunächst überkreuzen (vgl. Fig. 1, rechte Hälfte). Während beim Kontrolltier eine physiologische Abnahme von ungefähr $0,4 \%$ eingetreten ist, hat der Wassergehalt des Blutes bei IV um mehr als $0,5 \%$ zugenommen. Am 30. VI., also weitere 25 Tage später, ist der Blutwassergehalt bei beiden Tieren um $0,5 \%$ gesunken. Weitere 25 Tage später ist der Wert bei III um ein Weniges $(0,1 \%)$ bei IV stark $(1,3 \%)$ zurückgegangen, immerhin aber für IV noch um $0,5 \%$ höher als für III. Auch diese Tiere wurden am 31. VII. auf gleiche Kost gesetzt, d. h. also, es wurden bei IV die großen Wassermengen weggelassen. Bei einer 3 Tage später vorgenommenen Untersuchung zeigen beidể Tiere fast gleichmäßige Abnahme ihres Blutwassergehaltes, III um $0,6 \%$, IV um $0,7 \%$. 12 Tage später hat III neuerdings um ein Weniges abgenommen, IV sogar an Blutwassergehalt zugenommen. Einige histologische Blutuntersuchungen, welche bei beiden Tieren gemacht wurden, ergaben in sämtlichen Stadien des Versuches eindeutig das Bestehen einer Hydrämie bei 1V. Die an den- 
selben Tagen vorgenommenen Bestimmungen des $\mathrm{Hb}$-Gehaltes bei III und IV betrugen 65 gegenüber $55 \%, 80$ gegenüber $66 \%$ und 81 gegenüber $70 \%$. Die entsprechenden Zahlen für die roten Blutkörperchen lauten: 7,5 Millionen gegenüber 6,9 Millionen, 8,8 Millionen gegenüber 7,3 Millionen und 9,5 Millionen gegenüber 7,1 Millionen.

Aus diesen letzteren Zahlen sowohl wie aus den Ergebnissen der chemischen Blutwasserbestimmung erhellt also, daß III eine regelmäßige physiologische Austrocknung mitgemacht hat, während bei IV anfänglich eine Wasseranreicherung stattfand, die schon in den ersten Wochen nach Beginn des Versuches ihr Maximum erreichte, daB also die überschüssige Zufuhr von Wasser imstande ist, die physiologische Austrocknung für einige Zeit hinauszuschieben. Dieselbe beginnt erst später, gleichsam von einem höheren Niveau aus, die Differenz im Blutwassergehalte mit einem Plus für den mit Wasser reichlich getränkten Hund bleibt während des ganzen Versuches erhalten. Die rechte Hälfte der Figur 1 zeigt dies in anschaulicher Weise.

Kehren wir zu dem ersten Typus der Versuche mit ausschließlicher Kuhmilchernährung zuräck, so konnte gezeigt werden, daß unter dem Einfluß ausschließlicher Kuhmilchernährung über die normale Säugungsperiode hinaus eine Wasseranreicherung derjenigen Gewebe, welche den Wasserstoffwechsel regulieren, der Muskulatur and des Bindegewebes, und auch des Blutes erzielt werden konnte. Nun erhebt sich eine weitere Frage: In welcher Weise kommt dieses Wasser zur Bindung? Wir stehen heute noch so unter dem Einfluß der Lehre vom osmotischen Druck, daß reflektorisch jeder Gedanke an Wasserbindung auch den Salzstoffwechsel assoziiert. Bevor ich meine diesbezüglichen Untersuchungsresultate diskutiere, soll in groben Umrissen angeführt werden, was in der Literatur über den Gegenstand, natürlich nur soweit er unsere Frage berührt, vorliegt. Seit den grundlegenden Untersuchungen Pfeffers war man gewohnt, den osmotischen Druck als einzige Triebkraft für den Wassergehalt der Zellen anzusehen. Doch haben die Arbeiten Hof meisters und seiner Mitarbeiter, ferner die Untersuchungen von Hoeber, Overton, H. J. Hamburger, Durig, Pauli u.a., welche ebenfalls dieses Thema behandeln, im wesentlichen einen ablehnenden Standpunkt eingenommen. Es ist hier nicht der Ort, Einzelheiten dieser Arbeiten zu bringen und die verschiedene Art, wieso nach Ansicht der betreffenden Autoren die Wasserbindung im Organismus zu erklären wäre, im Detail anzuführen. Wie sehr aber diese Frage noch im Dunkeln liegt, mag daraus hervorgehen, daß in neuerer und 
neuester Zeit noch eine ganze Reihe von Arbeiten erschienen sind und noch täglich bekannt werden, welche sich mit diesem komplizierten Thema beschäftigen. Zum Teil grenzen ja diese Fragen an wichtige Kapitel der Pathologie, und ein Teil dieser Autoren ist auch bemüht, vom extremsten Ausdruck der Wasserbindung, vom Ödem aus, der Frage an den Leib zu rücken. So hat vor allem M. H. Fischer das Ödem nur als Endpunkt, gleichsam als Extrem dessen, was im Organismus überhaupt etwas mit Wasserbindung zu tun hat, betrachtet. Die Ursache des Ödems liegt nach seiner Ansicht in den Geweben. Die alte „Drucktheorie" sowohl wie die osmotische Theorie, ob mit oder ohne permeable oder semipermeable Membran, kommen nicht oder nur in beschränktem Maße dafür in Betracht. In seinen Untersuchungen an Fibrin und an Gelatine, ebenso an ganzen Geweben und Organen, ja an ganzen Extremitäten (vom Frosch) weist er nach, daß sie in Wasser quellen, und daß diese Quellung durch geringe Säuremengen, weniger durch Laugen enorm gesteigert, durch Salze aufgehalten wird. An den verschiedensten physiologischen und pathologischen Zuständen von Wasserbindung und Ödem weist er das Vorhandensein von geringen quellungsbefördernden Säuremengen nach. Diese „Säurekolloidtheorie" Fischers wurde in der verschiedensten Weise aufgenommen. Während z. B. die Versuche Borowikows, der an Pflanzenkeimlingen nachweisen konnte, daß geringe Mengen von Säure die Wachstumsgeschwindigkeit beschleunigen, und daß diese Beschleunigung sich in der Reihenfolge der Anionen abstuft, wie sie für die Quellung der Kolloide bekannt ist, sehr für Fischers Anschauungen sprachen, kommt, um nur einen von vielen herauszuheben, A. R. Moore auf Grund seiner am gleichen Objekte wie Fischer angestellten Untersuchungen zu einer vollständigen Ablehnung der Säurekolloidtheorie. Nach Untersuchungen sowohl von theoretischer wie von klinischer Seite scheint aber das Problem der Wasserbindung sich nach osmotischen Gesetzen nicht erschöpfen zu lassen. Traube stellt den osmotischen Druck nur als eine Teilerscheinung des Haftdruckes hin. Hoeber wendet zwar die Lehre vom osmotischen Druck sowohl auf die Zellen wie auf ganze Gewebe an, kommt aber schließlich doch zu dem Schluß, daß ein Teil des Wassers nicht osmotisch gebunden sein kann, sondern als Quellungswasser in den Zellen disponibel sein muß. Durigs ausgedehnte Versuche sind zwar alle am Kaltblüter angestellt und betreffen hauptsächlich Fragen der Resorption, sind also auf unsere Frage nicht direkt übertragbar. So viel aber geht 
aus ihnen hervor, daß selbst für diese scheinbar einfachsten Probleme eine Erklärung nach osmotischen Gesetzen nicht ausreichend ist, daß vielmehr die Kräfte der Quellung und Entquellung wirksam sein müssen. Přibram ist der Frage näher getreten und weist bei den verschiedensten Zuständen Quellung und Entquellung nach; er hat auch für die verschiedenen Formen der Wasserbindung sich ein Schema zurechtgelegt, das, wenn auch mit unseren Methoden derzeit noch nicht direkt meB- und nachweisbar, doch wegen seiner leichten Anwendbarkeit auch auf Momente, die für unsere Frage in Betracht kommen, anspricht und deshalb hier in Kürze wiedergegeben sein mag: ,Die Wasserverteilung im kolloiden System der Zelle ist die Folge der gegenseitigen Löslichkeit von Wasser und kolloiden Bestandteilen des Zellinhalts. Wie wir später ausführen wollen, müssen wir im Zellinhalt. unterscheiden zwischen assimilierten (artspezifischen) Kolloiden (,Protoplasma" im engeren Sinn) und den nichtassimilierten ,Reservestoffen" und ,Stoffwechselprodukten“. Die Wasserbindung ist in beiden insofern verschieden, als nur der Quellungszustand der Reservestoffe veränderlich ist und auf diese Weise für die Zellfunktion in Betracht kommt. Eine bestimmte für alle Zellen eines Organismus wahrscheinlich gleiche Wassermenge ist innig an das Vorhandensein des Protoplasmas geknüpft und an dieses in fester Form gebunden. ....., d. h., der Quellungszustand dieses Zellbestandteiles ist ein konstanter, unabhängig von allen in der Zelle vor sich gehenden Zustandsänderungen... Für Änderungen der Wasserverteilung im Zellinhalt kommen also die übrigen Zellbestandteile, die wir unter dem Titel ,Reservestoffe" und ,Stoffwechselprodukte" zusammenfassen wollen, in Betracht." - Diese Ausführungen geben ein anschauliches Vorstellungsvermögen der Wasserbindung in der Zelle, sie sagen aber noch nichts aus über die Art der Wasserbindung. Daß das Problem nicht einfach liegt, beweisen eine Reihe neuerer Arbeiten, die meist von klinischen Fragestellungen ihren Ausgang nahmen. Marchand verlegt die primäre Flüssigkeitsansammlung beim Ödem nicht in die Gewebe selbst, sondern in die Gewebsspalten, von denen aus dann sekundär möglicherweise eine Quellung der Gewebe eintreten kann. Ziegler will das Ödem nicht als kolloidchemisches Problem allein auffassen, sondern will auch Osmose, Diffusion und hydrostatischen Druckwirkungen eine maßgebende Rolle zuschreiben. Strauß, der für das Kochsalz die Ausdrücke der ,,Seroretention" und ,Historetention“ geprägt hat, glaubt, daß die Hauptmasse des 
Wassers an die Gewebe gebunden ist, daß die Gewebe zumindest imstande seien, große Schwankungen im Wassergehalt mitzumachen, während das beim Blut weniger der Fall ist. Wir haben gesehen, daß dies wenigstens für den wachsenden Organismus nicht vollständig zutrifft. Pincusşohn, der an Gelatinewürfeln und verschiedenen Geweben arbeitet, hält die Fischersche Anschauung für zu allgemein und weist nach, daß die Säurequellung nicht für alle Gewebe gleichmäßig anwendbar ist. Iscovesco, Schade, Wahlgren, Padtberg weisen ebenfalls auf die Wichtigkeit des Bindegewebes für das Problem der Wasserbindung, Busch in einer neuesten Arbeit auf die regulatorische Tätigkeit des Capillargebietes der Leber für den Eiweiß- und Wassergehalt des Blutes hin, eine Tatsache, auf die vor längerer Zeit schon Dastre und Loye aufmerksam gemacht haben, während Frey der Niere einen maßgebenden Einfluß dahingehend zuschreibt, daß die Niere Wasser ohne feste Bestandteile ausscheiden kann.

Diese wenigen Angaben mögen zur Illustration der Tatsache genügen, wie schwer es ist und auf wie vielfache Art es bereits unternommen wurde, zu sicheren Anschauungen über die Art der Wasserbindung im Organismus zu kommen. Wenn auch diese zahlreichen Untersuchungen bis jetzt zu keinem definitiven Resultat geführt haben, so erhellt doch eines aus ihnen: Allein nach osmotischen Gesetzen kann die Wasserbindung, zumal im pathologischen Fall, nicht verlaufen. Es sind sich alle neueren Autoren darüber klar, daß, abgesehen von hydrostatischen und osmotischen Momenten, auch Quellungskräfte beteiligt sein müssen, wenn Wasser im Körper, besonders über das normale Maß hinaus zurückgehalten werden soll, oder mit anderen Worten, daß Salz- und Wasserstoffwechsel getrennte Wege gehen. Wie weit das für pathologische Zustände des Säuglingsalters bereits nachgewiesen ist, soll im klinischen Teil dieser Arbeit erörtert werden. Jedenfalls war es auch bei unseren in Besprechung stehenden Versuchen lohnend, dieser Frage näherzutreten und neben dem Wassergehalt auch den Aschegehalt im Blute der Versuchstiere zu untersuchen.

Der Einfachheit halber und, da es sich ja um Vergleichswerte handelt, wählte ich die Bestimmung der Gesamtasche. Es wurde so wie bei den Wasserbestimmungen Blut aus dem Ohr entnommen, in einem verschließbaren Platingefä $ß$ aufgefangen, rasch gewogen und zunächst bei $100-110^{\circ}$ bis zur Gewichtskonstanz getrocknet, dann in demselben Gefäß die Gesamtaschenbestimmung nach Stolte vorgenommen. Die 
Werte in der Tabelle sind sowohl auf Gesamtmenge des untersuchten Blutes als auch auf dessen Trockensubstanz berechnet. Aus äuBerèn Gründen konnte ich erst in späteren. Stadien des Versuches diese Untersuchung vornehmen. Ausgangsuntersuchungen sollen in den späteren Versuchen nachgetragen werden.

Osmotischen Gesetzen folgend, sollte nun — so würde man erwarten -- dasjenige Blut, welches reicher an Wasser ist, auch reicher an Salzen sein. Bei Einsichtnahme der entsprechenden Zablen in den beiden Tabellen findet man nun ein überraschendes Resultat. Ausgehend von der Gesamtmenge des Blutes ist das wasserreichere Blut des Tieres I das salzärmere, und umgekehrt, das wasserärmere Blut des Tieres II ist das salzreichere. Einem Wert von $85,098 \%$ Wasser bei I entspricht ein Gesamtaschenwert von $0,88 \%$, während einem prozentualen Wassergehalt von 81,38 bei II ein Gesamtaschengehalt von $0,9503 \%$ entspricht. Erst wenn man die Gesamtaschenwerte auf Trockensubstanz berechnet, also gleichsam auf die festen Bestandteile des Blutes, dann kommt auf das wasserreichere Blut auch der größere Aschengehalt. Ein Teil des Wassers ist also gleichsam überschüssig und nicht an Salze gebunden. Wie aus Tabelle IX hervorgeht, haben genau dieselben Verhältnisse bei dem Versuchspaare IIT und IV statt.

Dasselbe Verhalten scheint nun auch für das Gesamttier, nicht nur für das Blut zuzutreffen. In der schon wiederholt zitierten Eckertschen Arbeit finde ich die Berechnung, daß bei dem über die Säugungsperiode hinaus mit Kuhmilch genährten Hund auf $1 \mathrm{~g}$ Asche $27,7 \mathrm{~g}$ Wasser kommen, während bei dem gemischternährten und ungefähr zu derselben Zeit getöteten Tier auf $1 \mathrm{~g}$ Asche nur $24 \mathrm{~g}$ Wasser entfallen. Ich habe dieselbe Berechnung für das Blut der von mir untersuchten Hunde aufgestellt und in Tabelle $X$ vereinigt.

Tabelle X.

\begin{tabular}{c|c|c}
\hline $\begin{array}{c}\text { Hund } \\
\text { Nr. }\end{array}$ & Ernährung & $\begin{array}{c}\text { Auf } 1 \mathrm{~g} \text { Asche } \\
\text { im Blut } \\
\text { kommen Wasser }\end{array}$ \\
\hline I & Ausschließlich Kuhmilch & $94,076 \mathrm{~g}$ \\
II & Kontrolle: gemischte Kost & $85,636 \mathrm{~g}$ \\
\hline IV & Gemischte Kost + viel Wasser & $115,18 \mathrm{~g}$ \\
III & Kontrolle: gemischte Kost & $107,7 \mathrm{~g}$
\end{tabular}

Aus diesen Zusammenstellungen erhellt, daß bei den in Rede stehenden Vorgängen kein Parallelgehen der Salz- und Wasserbindung statt- 
findet, daß vielmehr ein Überschuß an Wasser im Körper verbleibt, der nicht auf osmotische Weise gebunden sein kann. Auf etwaige Einflüsse des verschiedenen Salzgehältes in der Nahrung wird später eingegangen werden.

Vierter Versuch vom 5. II. bis 30. III. 1913.

Dieșer Versuch konnte nur begonnen und wegen Erkrankung des einen Tieres nicht zu Ende geführt werden, sei aber hier angeführt, weil er gegenüber dem vorangegangenen und dem folgenden Versuch einige Vergleichswerte, die von Wichtigkeit sind, ergab. In Versuch wurden drei reinrassige männliche Colliehunde genommen, die am 23. I. 1913 geworfen waren und am 5. II. in meinen Besitz kamen. Die damaligen Gewichte waren: $\mathrm{I}=1000 \mathrm{~g}, \mathrm{II}=850 \mathrm{~g}$, III $=760 \mathrm{~g}$. Die Tiere wurden bei Brust gelassen und zeigten am 22. II., also einen Monat alt, folgende Körpergewichte: $\mathrm{I}=2180 \mathrm{~g}, \mathrm{II}=1800 \mathrm{~g}, \mathrm{III}=$ $1880 \mathrm{~g}$. An diesem Tage wurde bei allen Tieren in der üblichen Weise im Blut Wasser- und Aschengehalt bestimmt, eine histologische Blutuntersuchung gemacht und auch der $\mathrm{N}$-Gehalt (nach Kjeldahl) ermittelt. Diese Werte sollten als Ausgangswerte dienen. Tags darauf wurden die Tiere in der üblichen Weise abgesetzt, I erhielt lediglich Kuhmilch und trank davon bis zu $1300 \mathrm{~g}$, II erhielt gemischte Kost. Die Tiere nahmen anfänglich gut $\mathrm{zu}$, doch stellte sich bei I nach ungefähr dreiwöchentlicher ausschließlicher Ernährung mit Kuhmilch ein Durchfall ein, der zu starkem Gewichtsverlust führte. Da derselbe unbedingt mit Störungen des Wasserhaushaltes einhergehen mußte, brach ich den Versuch ab. - $\mathrm{Zu}$ verwerten sind also nur die Ausgangsuntersuchungen, die angestellt wurden, solange die Tiere nur bei Brust waren. Die Resultate derselben sind in der folgenden Tabelle XI zusammengestellt.

Tabelle XI.

\begin{tabular}{|c|c|c|c|c|c|c|c|c|c|}
\hline \multicolumn{5}{|c|}{ Hund I } & \multicolumn{5}{|c|}{ Hund II } \\
\hline 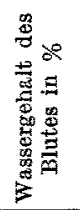 & 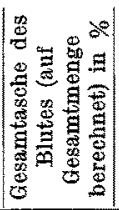 & 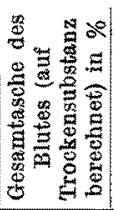 & 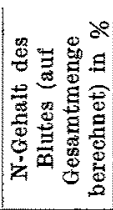 & 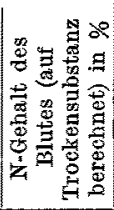 & 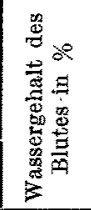 & 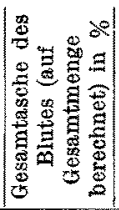 & 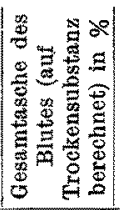 & 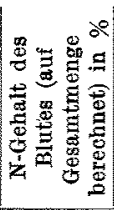 & 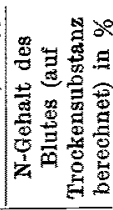 \\
\hline 248 & 0,89474 & 6,0653 & 1,9883 & 13,887 & 86,368 & 0,90487 & 6,6371 & 1,7967 & 13,569 \\
\hline
\end{tabular}

Die Wasserwerte differieren um ungefähr $1 \%$. Interessant ist das Verhalten der Gesamtaschenwerte. Bei dem früheren Versuch ergaben 
sich in dieser Beziehung große Differenzen zwischen dem normal ernährten und dem ausschließlich mit Kuhmilch gefütterten Tier. Hier haben wir zwei Vergleichstiere vor uns; die von demselben Wurf stammend bei Brust ganz gleich genährt sind. Es zeigt sich nun; daß dem Tier mit dem höheren Blutwassergehalt auch der höhere Gesamtaschengehalt entspricht, sowohl auf Gesamtmenge, wie auf Trockensubstanz berechnet. Stellen wir dieselbe Berechnung wie in Tabelle $\mathrm{X}$ an, so kommen auf $1 \mathrm{~g}$ Asche bei I $95,3 \mathrm{~g}$ Wasser

bei II $95,4 \mathrm{~g} \quad$,

also vollständig. gleiches Verhalten. Diese Werte mögen mit aller Deutlichkeit das pathologische Verhalten der im vorigen Versuch verwendeten Tiere zeigen.

Aus den Zahlen über den Stickstoffgehalt ist eine eindeutige Beziehung zum Wassergehalt kaum zu entnehmen. Die histologische Untersuchung ergab folgende Werte $\mathrm{I}: \mathrm{Hb}=51 \%, 4,216000$ Rote; II : $\mathrm{Hb}=50 \%, 3,664000$ Rote.

Fünfter Versuch vom 14. V. bis 5. VIIT. 1913.

Dieser Versuch sollte neuerdings eine Revision der Resultate der vorhergegangenen Versuche und die Anwendung einer weiteren Modifikation in der Versuchsanordnung bringen. Am 14. V. warf eine Hündin, die schon ca. 14 Tage vorher in meinem Besitz gewesen war, vier Junge, von denen eines bald nach der Geburt starb, die anderen drei (sämtlich Weibchen) am Leben blieben. Die Geburtsgewichte der-drei Tiere waren: I $260 \mathrm{~g}$, II $220 \mathrm{~g}$, III $250 \mathrm{~g}$. Am 16. V., nachdem die Tiere sich ein wenig erholt und Gewichte von 340, bzw. 330 und $300 \mathrm{~g}$ hatten, machte ich aus einem später $\mathrm{zu}$ erörternden Grunde die ersten Wasserbestimmungen. Wegen der Kleinheit der Tiere und der geringen erhältlichen Blutmenge mußte ich auf Doppelanalysen verzichten und machte diesmal nur einfache Bestimmungen. Die Werte für dieselben sind weiter unten verzeichnet. Die Tiere blieben nun vorerst bei Brust (ihre physiologische Säugungsperiode wurde von einem exfahrenen Tierarzt auf ungefähr vier Wochen geschätzt) und ich untersuchte nun nach Ablauf dieser Zeit Wasser-, Gesamtascheund $\mathrm{N}$-Gehalt im Blut. Nachher wich ich etwas von der bisher gewählten Versuchsanordnung ab und lieB die Tiere über die physiologische Säugungszeit hinaus weiter bei der Alten, um den Einfluß länger hinausgezogener ausschlieBlicher Ernährung bei der Brust beobachten zu können (12. VI,). Es wurden daher weitere elf Tàge später 
R. Lederer:

\begin{tabular}{|c|c|c|c|c|c|c|}
\hline \multirow{4}{*}{$\begin{array}{l}\text { 日 } \\
\text { 苛 }\end{array}$} & 岕 & 11 & $\overrightarrow{\|}$ & $\breve{H}$ & 1 & $\mid$ \\
\hline & 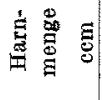 & $\infty$ & $\approx$ & 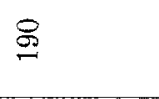 & 怘 & 8 \\
\hline & 害 & 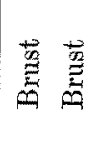 & $\overbrace{\mathscr{n}}$ & 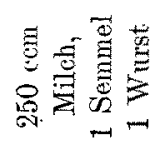 & $\stackrel{\overline{3}}{:}$ & 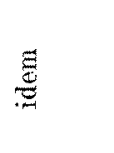 \\
\hline & 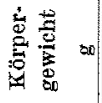 & 满 尽 & 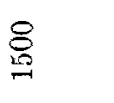 & $\frac{8}{9}$ & $\S_{8}^{8}$ & 胥 \\
\hline \multirow{4}{*}{$\begin{array}{l}\Xi \\
\Xi \\
\Xi\end{array}$} & 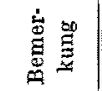 & 11 & $\ddot{11}$ & 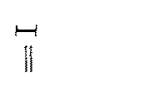 & 1 & 1 \\
\hline & 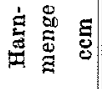 & $\infty \infty$ & $\infty$ & $\stackrel{8}{10}$ & 8 & 8 \\
\hline & 劳 & 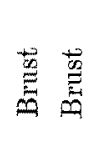 & 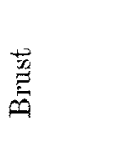 & 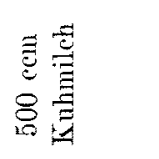 & 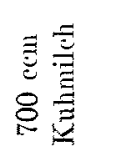 & $\stackrel{\Xi}{\underline{\Xi}}$ \\
\hline & 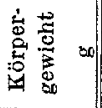 & : & 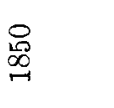 & 8 & $\underset{0}{\stackrel{0}{\circ}}$ & $\sum_{\text {足 }}$ \\
\hline \multirow{4}{*}{ 泀 } & 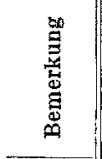 & 11 & 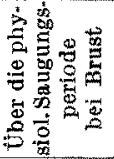 & 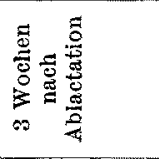 & 1 & 1 \\
\hline & 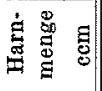 & $\infty$ & $\infty$. & 8 & $\stackrel{8}{E}$ & $\underset{8}{8}$ \\
\hline & $\begin{array}{l}\text { 量 } \\
\text { 营 } \\
\text { 㐬 }\end{array}$ & 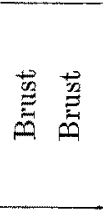 & 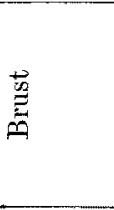 & 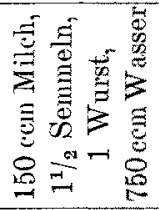 & 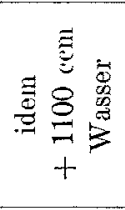 & 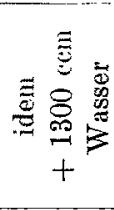 \\
\hline & 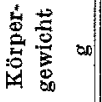 & 兽邑 & $\underset{10}{10}$ & 念 & : & $\stackrel{8}{\circ}$ \\
\hline & 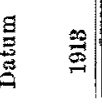 & $\stackrel{\vec{D}}{\dot{8}}$ & $\stackrel{\dot{\Delta}}{\dot{\Delta}}$ & $\begin{array}{l}\exists \\
\oplus\end{array}$ & $\begin{array}{l}\dot{B} \\
\dot{D} \\
\dot{a}\end{array}$ & 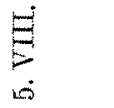 \\
\hline
\end{tabular}


die nächsten Untersuchungen vorgenommen. Nun wurden die Tiere in der üblichen Weise ablactiert, I erhielt gemischte Kost und viel Wasser zu trinken, II bekam ausschließlich Kuhmilch und III diente als Kontrolle bei gemischter Ernährung. Tabelle XII gibt Aufschluß über die Körperentwicklung, Nahrungs- und Trinkmengen der Tiere.

Wie aus der Tabelle ersichtlich, entwickelten sich die Tiere dem Gewicht nach fast gleichmäßig gut, nur zeigte sich, daß II, der ausschließlich mit Kuhmilch ernährt war, ziemlich viel „Schwankungen" in der Gewichtskurve aufwies. Mit der Zeit machte sich aber im Aussehen der Tiere ein großer Unterschied geltend. Während III (Kontrolle) ruhig in seinem Käfig saß, ein weiches wolliges Fell und einen walzenförmigen Rumpf hatte, waren I und II sehr aufgeregt und lebhaft. Beide, besonders aber I, waren ziemlich mager und hatten einen großen Bauch. Irgendwelche äußere Zeichen von Rachitis konnten nicht bemerkt werden. Der Stuhl war bei allen Tieren immer gut, niemals durchfällig.

Wie im klinischen Teil der Arbeit näher ausgeführt werden soll, war es schon vielen Beobachtern aufgefallen,.daß das Blut des Neùgeborenen sehr konzentriert ist. Ich werde dort auch über meine eigenen diesbezüglichen Beobachtungen beriehten. Der Zufall, daß diese Versuchstiere sofort nach der Geburt in meinen Besitz gelangt waren, sollte dazu benützt werden, um das Verhalten der Tiere bezüglich dieses anfänglichen niedrigen Blutwassergehaltes zu prüfen. Die Wasserbestimmungen 48 Stunden nach der Geburt ergaben tatsächlich Werte, die weit unterhalb der in den früheren Versuchen bei älteren Tieren gefundenen lagen, 82,7, 83,4 und 80,4\%. Aus den Angaben der Tabelle XIII, in welcher auch die Ergebnisse aller übrigen an diesen Tieren gemachten Bestimmungen verzeichnet sind, geht hervor, daß diese Werte am Ende der physiologischen Säugungsperiode weit überholt sind; sie betrugen alle rund $86 \%$. (Schon in einer Arbeit aus dem Jahre 1864 hebt Panum hervor, daß das Blut eines neugeborenen Hundes $21,6 \%$ Trockenrückstand, das eines acht Wochen alten Hundes aber nur mehr $13,23 \%$ besitzt).

Bei der Untersuchung nach vierwöchiger Ernährung bei der Brust ergab sich also das gleiche Verhalten wie für die beiden Tiere des vierten Versuches. Der Blutwassergehalt ist bei allen Tieren derselbe, ebenso der Gehalt an Gesamtasche. Die kleinen Differenzen im Blutwassergehalt gehen vollständig parallel den Differenzen im Aschengehalt (siehe unten). Dagegen läßt sich kein direkter Parallelismu 
R. Lederer:

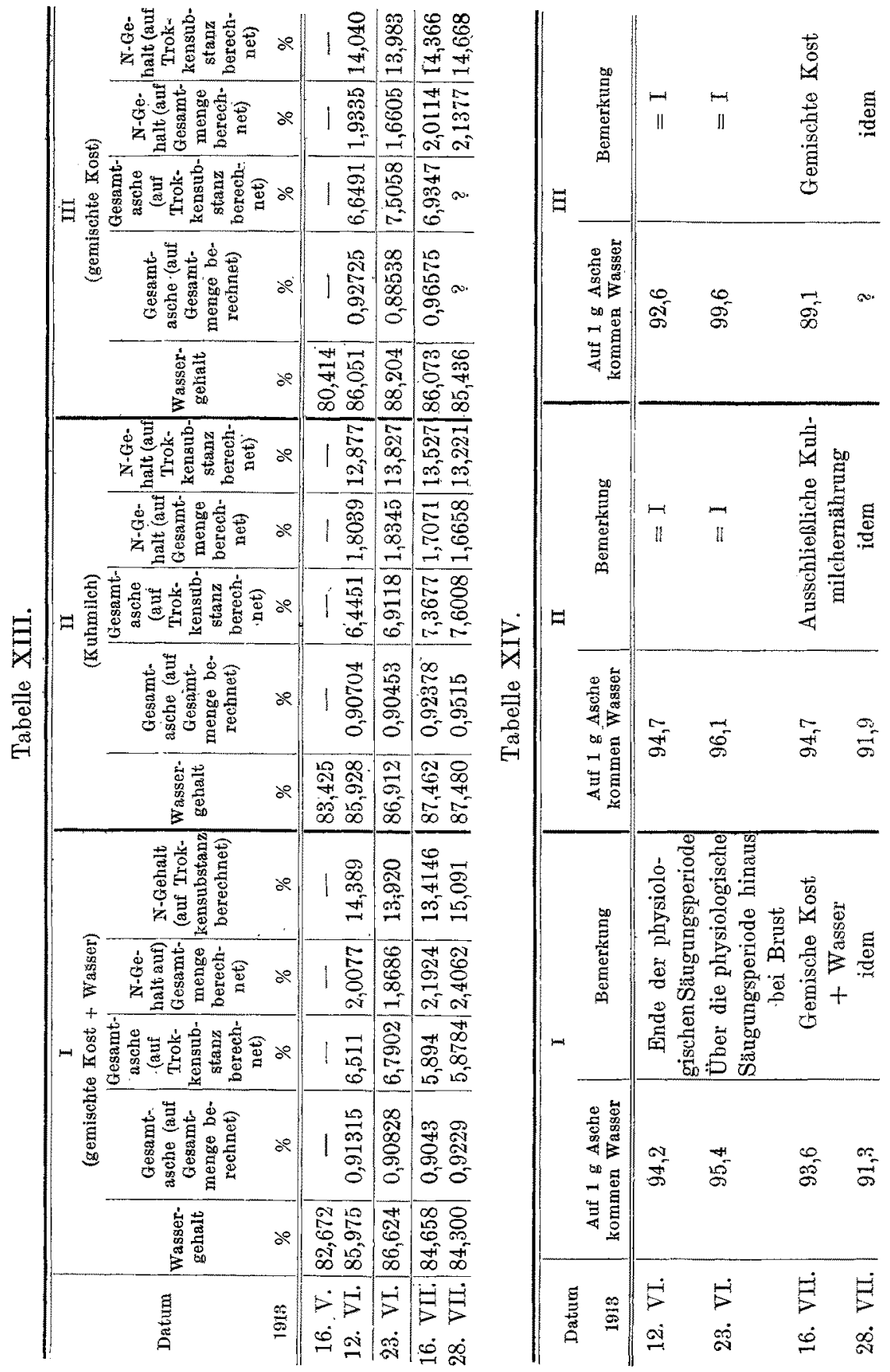


zwischen Wassergehalt und $\mathrm{N}$-Gehalt und zwischen Aschengehalt und $\mathrm{N}$-Gehalt nachweisen. Nun wurden die Tiere über die physiologische Säugungsperiode hinaus weiter bei der Brust gelassen und nach elf Tagen neuerliche Bestimmungen vorgenommen. Dieselben ergaben, daß der Wassergehalt bei allen drei Tieren noch zugenommen hat, bei I um $0,7 \%$, bei II um $1,0 \%$, bei III um $2,2 \%$, also ist von einer physiologischen Austrocknung noch keine Rede. Betrachten wir dagegen den Gesamtaschengehalt bei den drei Tieren. In Stab 2 der Tabellen, wo der Gesamtaschengehalt, auf Gesamtmenge des Blutes in Prozenten berechnet, verzeichnet ist, findet man bei allen Hunden eine Verminderung, in Stab 3, wo der Aschengehalt auf Trockensubstanz umgerechnet ist, eine Vermehrung des prozentualen Aschengehaltes, also das ganz analoge Verhalten wie bei den beiden Versuchshunden des dritten Versuches. Es ist also bei über das Normale hinausgehender ausschließlicher Ernährung an der Brust der Gesamtaschengehalt der fixen Bestandteile des Blutes direkt proportional dem Wassergehalt, wenn man aber die Gesamtmenge des Blutes (inkl. Wasser) in Rechnung zieht, indirekt proportional dem Wassergehalte desselben.

Nun wurden die Tiere in der oben beschriebenen Weise ablactiert und, nachdem durch mehr als drei Wochen I gemischte Kost und reichlich Wasser, II ausschließlich Kuhmilch und III bloß gemischte Kost erhalten hatte, wurden am 16. VII. neuerliche Bestimmungen gemacht. Hier findet sich nun, wenn man den Wassergehalt des Blutes betrachtet, wieder eine vollständige Bestätigung der vorhergehenden Versuche. Die Kontrolle III erleidet die normale physiologische Austrocknung, der Wassergehalt des Blutes nimmt um 2,2\% ab. Der reichlich mit Wasser getränkte Hund, bei dem der Beginn der physiologischen Austrocknung ja durch die übermäßig lange Brusternährung ohnedies schon hinausgeschoben worden war, nimmt jetzt ebenfalls um $2 \%$ ab. Der ausschließlich mit Kuhmilch gefütterte Hund III dagegen nimmt in seinem Blutwassergehalt noch $0,5 \% \mathrm{zu}$. Ebenso ergibt eine 12 Tage später vorgenommene Bestimmung ganz genau dasselbe Resultat. Die Kontrolle III hat einen um $0,6 \%$ niedrigeren Wassergehalt im Blute, der mit Wasser getränkte Hund I hat nur um $0,3 \%$ abgenommen, II (mit Kuhmich gefüttert) hat noch um ein Weniges an Blutwassergehalt zugenommen $(0,02 \%)$.

Um auch in diesem Versuche das Verhältnis zwischen Asche und Wasser deutlicher zu machen, resp. um Schlüsse auf die Wasserbin- 
dung ziehen zu können, habe ich in der folgenden Tabelle XIV in den einzeinen Versuchen ausgerechnet, wieviel Gramm Wasser auf je $1 \mathrm{~g}$ Asche kommen.

In der ersten Reihe stehen die Werte, wie sie nach dieser Art der Berechnung gewonnen wurden, am Ende der physiologischen Säugungsperiode. Sie sind sehr nahe den im vierten Versuch gewonnenen und untereinander wenig verschieden. Bei Brusternährung über die normale Stillperiode hinaus wird der Quotient $\frac{\text { Wasser }}{\text { Asche }}$ bei allen drei Tieren größer. Nun folgt die Ablactation auf die verschiedenen Nahrungsgemische. Die physiologische Austrocknung markiert sich auch hier, der Quotient $\frac{\text { Wasser }}{\text { Asche }}$ wird bei allen Tieren kleiner, aber nur bei der Kontrolle III um ein erhebliches Maß $(10,5)$, bei dem mit Wasser neben gemischter Kost getränkten Hund um 1,8, bei dem ausschließlich mit Milch gefütterten Hund nur um 1,4. Es hat also das Absetzen auf gemischte Kost bei der Kontrolle eine Verminderung des Wassergehaltes oder eine Vermehrung des Salzgehaltes oder beides hervorgerufen, während bei den beiden fehlerhaft ernährten Tieren einer oder beide Prozesse aufgehalten wurden. Die Wiederholung der Bestimmung am 28. VII. erlaubt keinen Vergleich mit der Kontrolle, da die Aschenbestimmungen derselben (sie sind in Tabelle XIII und XIV mit einem Fragezeichen vermerkt) durch ein Versehen bei der Analyse nicht als sicher anzunehmen sind; aber die Betrachtung der Werte für I und II ergibt, daß dieselben auch jetzt noch nur sehr wenig abgenommen haben. - Auf eine detaillierte Diskussion der N-Analysen hier einzugehen, erübrigt sich, da so wie in früheren Versuchen auch diesmal eindeutige Beziehungen des $\mathrm{N}$-Gehaltes zum Aschengehalt im Blut aus den Tabellen nicht ersichtlich sind. Dagegen fällt deutlich auf, daß z. B. in Tabelle XIII beim Kontrolltier III die N-Werte kontinuierlich größer, beim Milchtier II in demselben Maße kleiner werden, woraus ebenfalls auf eine Hydrämie bei II geschlossen werden kann.

Auch dieser letzte Versuch ergibt also sowohl in seinen einzelnen Resultaten als im Zusammenhang mit den früheren Untersuchungen, daß ausschließliche Ernährung mit Kuhmilch jenseits der Säugungsperiode die normale A ustrocknung des Organismus verhindert, vielmehr zu einer Vermehrung des Wassergehaltes im Blute führt: daß übermäßige $Z$ ufuhr von Wasser 
neben gemischter Kost den Beginn der physiologischen Austrocknung hinaususchieben und den Wassergehalt des Blutes dauernd höher als normal zu halten vermag; daß eine auschließliche Ernährung an der Brust über die physiologische Stillzeit hinaus in demselben Sinne wirkt, und daB schließlich im wachsenden Körper ein Teil dieses über die Norm vermehrten Wassers durch Quellungsvorgänge zurückgehalten wird.

\section{Untersuchungen an Säuglingen.}

\section{A. Methodisches.}

Durch die im ersten Teile dieser Arbeit gefundenen Resultate war ein Hinweis darauf gegeben: 1. welche physiologischen Zustände des Neugeborenen- und Säuglingsalters Zusammenhänge mit dem Wasserhaushalt zeigen; 2. welche chronischen Ernährungsstörungen außer der schon bekannten durch dauernde Kohlehydratfütterung hervorgerufenen des Mehlnährschadens, Beziehungen zum Wasserstoffwechsel haben und 3. auch welche Methodik, richtig angewendet, bei möglichster Einfachheit die größtmögliche Anzahl von Analysen und damit ein sichereres Urteil als bisher erlauben würden.

Um gleich den letzten Punkt herauszugreifer, mußten systematische Trockenrückstandsbestimmungen im Blut, wenn sie mit Ausschluß gewisser, unten näher zu besprechender Fehlerquellen und bei richtiger Auswahl des Materials ausgeführt wurden, nicht nur Schlüsse auf den Blutwassergehalt als solchen, sondern auch mit klinischen Beobachtungen vereint und unter Berücksichtigung der im ersten Teil der Arbeit gefundenen Resultate auch Schlüsse auf den Wassergehalt des Gesamtorganismus zulassen.

In der Form allerdings, wie die Trockenrückstandsbestimmungen am Versuchstier gemacht wurden, konnten sie mit Erfolg am kranken Säugling kaum angewendet werden. Für eine oder mehrere in größeren Zeitabschnitten getrennt voneinander vorzunehmende Untersuchungen hätte man allerdings auch die gewöhnliche Wasserbestimmung machen können. Doch ist die Blutmenge, die man dafür braucht (Lust z. B. benötigte für seine Bestimmungen immer 0,25-0,5 ccm Blut), insonderheit bei frühgeborenen oder schwerkranken Kindern, die man nötigenfalls täglich zu. untersuchen hat, doch ein zu großer Verlust für das betreffende Kind. Ich mußte mich daher nach einer anderen Methode umsehen, die mit kleineren Mengen bei gleichgroßer Genauig- 
keit zu arbeiten gestattete. Die zu derselben Zeit, als ich diese Untersuchungen aufnahm, von Pregl angegebene "Mikroelementaranalyse" war mir daher zur Ausführung meiner Bestimmungen sehr willkommen. Aus dem Preglschen Inventar, das, soweit die betreffenden Untersuchungsmethoden bis jetzt publiziert sind, vor allem zur Mikroanalyse von $\mathrm{C}, \mathrm{N}$ usw. dient, habe ich nur die Analysenwage von Wilh. $\mathrm{H}$. F. Kuhlmann in Hamburg benutzt. Da sowohl in der Preglschen Publikation im „Handbuch der biochemischen Arbeitsmethoden" als in einer neuen Arbeit von Dona u über "Arbeitsmethoden der Mikrochemie" keine detaillierten Vorschriften für eine mikrochemische Trockenrückstandsbestimmung enthalten sind, so mußte ich mir das notwendige Instrumentarium selbst konstruieren. Da die mikrochemische Methode in diesem Fall ja einfach eine Verklẹinerung (nicht wie bei den anderen Methoden auch eine zeitliche Verkürzung und daher teilweise qualitative Änderung) der gewöhnlichen Methoden bedeutet, so kam es nur. darauf an, die auch der gewöhnlichen Methode noch anhaftenden Fehlerquellen durch geeignete Modifikationen tunlichst zu verkleinern, womöglich ganz auszuschließen.

Die Analysenwage von $\mathrm{Kuhlmann}$ ist ein außerordentlich handliches Instrument; es verträgt bei gleichbleibender Empfindlichkeit eine Maximalbelastung von $20 \mathrm{~g}$. Der Balken hat eine Länge von nur $70 \mathrm{~mm}$, erlaubt daher ziemlich rasche Schwingungen und ist maschinell gekerbt, so daß der Reiter an jeder Stelle des Balkens stets den gleichen Sitz einnehmen muß. Da die Kerbungen sehr nahe beieinander liegen und mit freiem Auge kaum abgelesen werden können, ist an der Reiterversohiebung eine vergrößernde Lupe angebracht, die mit ersterer läuft, so daß die Ablesung des Reiterstandes jedesmal bequem durch die Lupe erfolgen kann. Die Schwingungen der Zunge werden ebenfalls wegen der Kleinheit der Skala nicht direkt abgelesen. Dieselbe ist an der dem Untersucher abgekehrten Seite einer kleinen Elfenbeinplatte angebracht und wird durch einen gegenüberstehenden Hohlspiegel ebenfalls vergrößert. Immerhin aber bedeutet das Ablesen von Reiterstand und Zungenausschlag, besonders bei länger dauerndem Arbeiten, eine ziemliche Inanspruchnahme der Augen. Die Empfindlichkeit dieser Wage ist nun so eingestellt, da $ß 1 / 10 \mathrm{mg}$ eine Ausschlagsvergrößerung von 10 Teilstrichen nach der entgegengesetzten Seite bedingt, und daß demnach ein Ausschlagsunterschied von 1 Teilstrich $1 / 100$ mg gleichkommt. Es können daher an der Wage mit absoluter Genauigkeit 4 Dezimalen abgelesen, die fünfte nach der Ausschlagsdifferenz zwischen rechts und 
links bestimmt und ev. sogar die sechste geschätzt werden. Ioh habe, um die größtmöglichste Genauigkeit zu erzielen, wenn einmal das Gewicht in der vierten Dezimale bestimmt war und daher nur noch unter 10 Teilstriche liegende Ausschläge nach rechts und links möglich waren, immer drei Ablesungen gemacht und bei vorkommenden Differenzen das arithmetische Mittel gewählt. Ich fand es zweckmäßig, sich daran zu gewöhnen, erst dann abzulesen, wenn die Zunge immer gleichmäßig nach einer Seite $z$ uerst ausschlägt, da ich wiederholt gefunden habe, daß sich kleine Differenzen ergaben, je nachdem ob die Zunge beim ersten Abheben der Arretierung den Ausschlag nach rechts oder nach links gab.

Um sicher arbeiten zu können, muß die Wage auf einer genau horizontal liegenden Marmorplatte angebracht sein, die auf in die Mauer eingelassenen Eisenträgern fest aufliegt. Auch soll die Wage, besonders bei sehr hochgelegenen und dem Wind frei exponierten Gebäuden, in einem nicht zu hohen Stockwerk und in einem möglichst vor Wind geschützten (nicht Eck-)Zimmer stehen. Die Platingewichte sowie die Elfenbeinpinzette, die zum Herausheben. derselben gehört, werden nicht im Zimmer-selbst, sondern im Wagengehäuse in der Nähe der rechten Wagschale offen aufbewahrt, um Temperaturdifferenzen zwischen den Gewichten und den Bestandteilen der Wage zu vermeiden. Selbstverständlich darf kein Bestandteil der Wage, der Gewichte und der zur Wägung kommenden Gegenstände mit der Hand angetastet werden. Ich habe dazu eine Pinzette mit langen Branchen und Platinspitzen und außerdem immer beim Arbeiten Zwirnhandschuhe verwendet, um jede nur mögliche Befenchtung der Wage und der Gläser auszuschließen. „Absolute Reinlichkeit des Wagetisches, insbesondere der Wage selbst, ist die erste Voraussetzung erfolgreicher Analysen", schreibt Pregl, dessen Arbeit ich die meisten der hier wiedergegebenen Bemerkungen entnehme. Die Wage muB jeden Monat einmal gereinigt werden. Mit Recht hebt Pregl hervor, daß die Wage dann durch einige Stunden bis einen Tag , krank" ist. Es ist ganz merkwürdig, daß unmittelbar nach der Reinigung eine Wägung nahezu ausgeschlossen ist, daß es kaum gelingt, die Wage mehreremal hintereinander zum gleichmäßigen Einspielen zu bringen, während 24 Stunden später, ohne daß etwas an der Wage berührt worden wäre, das Instrument tadellos funktioniert. Offenbar spielen Temperaturschwankungen während des Offenstehens des Wagenkastens und minimale Staubpartikelchen, die vielleicht auf einzelne Teile herunterfallen, eine Rolle. - Vor jeder Serie von Wägungen 
muß der Nullpunkt der Wage geprüft und, wenn nötig, neu eingestellt werden.

Die Wägegläschen müssen folgenden Bedingungen entsprechen: 1. sie dürfen nur ungefähr $2 \mathrm{~g}$ schwer sein und müssen 2 . absolut dicht schließen. Die erste Bedingung wird dadurch erfüllt, daß der untere Teil des Wägegläschens aus möglichst dünnem Glasrohr verfertigt, und daß der Deckel hohl gemacht wird; dem zweiten Punkt ist dann Genüge geleistet, wenn der Schliff zumindest so hoch ist, wie bei einem gewöhnlichen ,großen" Wägeglas, d. h. $1 / 2-3 / 4 \mathrm{~cm}$, und daß die Schliffe von Glas und Deckel absolut genau aufeinander passen. An die Seitenwände des Gläschens ist eine kleine Glasperle angeschmolzen, die bequem von den Platinspitzen der Pinzette gefaßt wird, so daß jede Berührung mit der Hand entfällt.

Auch die Exsiccatoren selbst mußten etwas modifiziert werden. $\mathrm{Da}$ es sich meist um mehrere gleichzeitige Bestimmungen handelt, also viele Gläschen in einem Exsiccator stehen müssen, andererseits die Gläschen so klein sind, daß sie leicht umfallen, ließ ich über dem unteren Teil des Exsiccators zwei Glasplatten anbringen. Die untere vermittelt den Durchzug der Luft zwischen dem unteren mit Schwefelsäure gefüllten Teil des Exsiccators und dem oberen Luftraum, ist daher in der Mitte durchlöchert, und am Rande dient sie als Boden für die Wägegläschen. Die obere Glasplatte, die von der unteren durch ein aufgelegtes Glastriangel ungefähr $1 / 2 \mathrm{~cm}$ getrennt ist, trägt am Rande eine Reihe von kreisrunden Öffnungen, in welche die Gläschen hineinpassen $\left.^{1}\right)$.

Da es Zweck der hier angewandten Methodik war, möglichst wenig Blut zu verbrauchen, so konnte auch nicht auf ein freies Abtropfen desselben gerechnet werden. Ich legte daher vor der Leerwägung des Gläschens eine oder zwei mit diesem gleichzeitig getrocknete Glascapillaren bei, die dann leer mitgewogen wurden. Die Blutentnahme geschah wie bei einer histologischen Blutuntersuchung. Der frei (ohne Pressen) heraustretende Blutstropfen wurde von einer Capillare, die natürlich ebenfalls nur mit der Pinzette angefaßt wurde, nach Art der alten Fleischlschen Hämometereapillaren aufgesaugt und nun samt der Capillare in das Wägegläschen gebracht und gewogen. Trocknen bis zur Gewichtskonstanz bei $100^{\circ}$ wie gewöhnlich.

Es wurden von jeder Bestimmung Doppelanalysen gemacht. $\mathrm{Zu}$

1) Wägegläschen und Exsiccatoren wurden nach meinen Angaben vom Glasbläser Ewald, Wien IX, van Swieten-Gasse 6, angefertigt. 
jeder solchen Doppelbestimmung braucht man $0,02-0,03 \mathrm{ccm}$ Blut, das ist ungefähr soviel wie zu einer Hb-Bestimmung - eine Blutmenge, deren Verlust auch debilen Kindern sehr oft zugemutet werden kann. Die Resultate zeigten dieselbe U̇bereinstimmung wie die mit gewöhnlicher Methodik vorgenommenen. Die Zahl der Untersuchungen, die ieh in den letzten zwei Jahren im Rahmen dieser Arbeit vornahm, betrug ungefähr 800 mit ca. 3000 Wägungen.

Die Blutentnahme geschah meist zu derselben Tageszeit. Da die Aufnahme der flüssigen Nahrung einen Einfluß auf den Wassergehalt des Blutes hat, so mußte auch eine gewisse Zeit nach der Mahlzeit verstreichen, ehe man zur Blutentnahme schreiten konnte. Sehmaltz konnte mittels des Capillarpyknometers nachweisen, daß bei Aufnahme größerer Mahlzeiten das spezifische Gewicht des Blutes sofort sinkt, um nach einer halben Stunde wieder zur Norm zurückzukehren. Hammerschlag, der sich der von ihm angegebenen Methode der spezifischen Gewichtsbestimmung bedient, gibt an, daß die Erniedrigung des spezifischen Gewichts des Blutes sich 15-35 Minuten nach der Mahlzeit bemerkbar macht, nach 45 Minuten bis 1 Stunde aber wieder verschwunden ist. Lust, der Wasserbestimmungen im Blute vor und nach dem Trinken macht, bemerkt, daß die Aufnahme der llüssigen Nahrung den Wassergehalt des Blutes um $0,2-0,4 \%$ erhöht, und wartet 3 Stunden, ehe er Blut zur Bestimmung entnimmt. Auch ReiB, der mit der refraktometrischen Methode arbeitet, wartet 3 Stunden. Sämtliche von mir vorgenommenen Untersuchungen wurden ebenfalls mindestens 2-3 Stunden, nachdem das betreffende Kind Nahrung genommen hatte, ausgeführt.

Im übrigen aber wurde getrachtet, nicht nur möglichst viele Kinder zu untersuchen, sondern auch jedes einzelne Kind wiederholt auf den Wassergehalt seines Blutes zu prüfen, da, wie Berend und Tezner ganz richtig hervorheben, die einmalige Untersuchung eines Individuums und die Berechnung von Mittelwerten, die aus'solchen Einzeluntersuchungen gewonmen werden, ungenaue Resultate ergibt, da die Unterschiede zwischen den einzelnen Kindern durch die verschiedensten Faktoren, wie unten ausgeführt werden soll, bedingt und sehr groß sind. Tch habe daher auch bei den vorliegenden Untersuchungen vón der Berechnung von Mittelwerten im allgemeinen abgesehen.

An dieser Stelle sei auch noch eines Einwandes gedacht, der vor Jahren ähnlichen Untersuchungen gemacht wurde, heute aber wohl endgültig widerlegt ist, nämlich der Behauptung, daß das Blut über- 
haupt seine Konzentration nicht ändere und dieselbe mit eiserner Zähigkeit festhalte. So meinte seinerzeit R. Magnus, ,daß das Blut mit großer Energie seine Zusammensetzung konstant zu erhalten' bestrebt ist, während in den Geweben ein Depot zur Verfügung steht, in welchem Überschüsse abgelagert und aus welchem Fehlbeträge gedeckt werden können". Bekanntlich war auch Plehn ein eifriger Verfechter dieser Anschauung und meinte, , daß ein direkter Einfluß von Wasseraufnahme und Wasserabgabe, wie er als ,Verwässerung" oder ,Eindickung6 des Blutes, speziell des Blutserums sich bekunden soll, beim Gesunden tatsächlich nicht existiert... Das Rlut besitzt in außerordentlichem Grade die Fähigkeit, seinen Wassergehalt bei demselben Individuum konstant zu erhalten". (Im Original gesperrt.) Schon Panum war über diese Frage der entgegengesetzten Ansicht, und durch Grawitz wurde, zum Teil in einer Polemik gegen Plehn, der wohl heute allgemein angenommene Standpunkt in seiner ,klinischen Pathologie des Blutes" festgelegt. „Das Gesamtblut ist nicht als ein abgeschlossenes Organ von invariablem Volumen anzusehen, sondern steht durch das die Capillaren umgebende System von Lymphräumen in ununterbrochenem Austausch von Stoffen mit den Flüssigkeiten der Gewebe.

Die Blutmischung kann durch chemische, physikalische und nervöse Einflüsse vorübergehend geändert werden, und zwar können diese Änderungen sehr schnell eintreten dadurch, daß Flüssigkeiten oder fremde Stoffe durch die Capillarwände in die umgebenden Lymphspalten treten, und umgekehrt Lymphe in das Blut eindringt.

Das Blut hat die Eigenschaft, alle diese Änderungen in kurzer Frist auszugleichen, die fremden, resp. überschüssigen Stoffe auszuscheiden und wieder in sein mittleres Volumen und Konzentrationsverhältnis zurüekzukehren.

Dieser Ausgleich tritt, soweit es sich um Flüssigkeitszu- oder -abnahme handelt, einerseits im Capillargebiete selbst, andererseits im Lungengewebe ein; in letzterem scheint besonders für länger dauernde Blutdruckänderungen eine wichtige Stätte der Regulation des Flüssigkeitsgehaltes im Blute vorhanden zu sein."

In den vorliegenden Untersuchungen soll es sich also nicht darum handeln, kurz dauernde und vorübergehende Änderungen der Blutzusammensetzung im Sinne einer Verwässerung oder Eindickung zu studieren, wie sie eben unter vorübergehenden Einflüssen zustande kommen, sondern sỉ sollen denjenigen Veränderungen des Blutes gewidmet sein, die unter dem Einfluß dauernder Einwirkungen stehen, sollen 
also dasjenige Blut betreffen, das, in ununterbrochenem Austausch von Stoffen mit den Flüssigkeiten der Gewebe" steht.

\section{B. Die Bedentung des Wassers für die Physiologie des Neugeborenen und Säuglings.}

Es ist ja von vornherein klar, daß wir bei dem Organismus des Neugeborenen und jungen Säuglings, der ja viel wasserreicher ist, als der des Erwachsenen, der in der ersten Zeit seines Wachstums dasselbe zum größten Teil auf Kosten von Wasseransatz bestreitet, und der ja ausschließlich von in Wasser gelöster Nahrung lebt, wichtige Aufschlüsse in dieser Beziehung undZusammenhänge zwischen diesen einzelnen Faktoren werden erwarten können. Sehen wir uns daher zunächst in der Literatur um, was uns über die chemische Zusammensetzung des Neugeborenen und Säuglings puncto Wassergehalt bekannt ist, und schließen wir gleich daran, welche Meinungen von den verschiedenen Autoren über die Beziehungen des Salzstoffwechsels zum Wasserhaushalt vertreten werden. Dabei wird auch gleich die Frage zu berücksichtigen sein, was mit einer im Úberschuß zugeführten Menge von Wasser im Körper geschieht, was andererseits ein zuwenig an Wasser zu bedeuten hat.

Wir müssen auch hier wieder von dem schon wiederholt zitierten Gesetz der physiologischen Austrocknung ausgehen. Dieses ist der rote Faden, der sich durch die ganze Lehre von der Physiologie des Wasserhaushalts im wachsenden Organismus zieht. Die progrediente Abnahme an Wasser wurde von Fehling schon an Föten nachgewiesen. Der kleinste untersuchte Foetus war $2,5 \mathrm{~cm}$ lang, stammte aus der sechsten Schwangerschaftswoche und hatte einen Wassergehalt von $97,54 \%$. Föten aus dem neunten Monat hatten einen Wassergehalt von $73,9-74,7 \%$. Zu ähnlichen Zahlen kommt Michel. Er findet $94 \%$ gegen die Mitte des dritten Monates der Gravidität und $69 \%$ beim Neugeborenen. Jakubowitsch untersuchte die chemische Zusammensetzung der Muskeln von Embryonen, die ja gewiß auch, besonders was den Wassergehalt betrifft, wichtig für den Wassergehalt des gesamten Foetus sind. Er findet 99,4\% Wasser im frühesten Stadium der Gravidität. Dieser Wassergehalt sinkt allmählich bis auf $81,2 \%$ unmittelbar vor der Geburt.

Neugeborene wurden untersucht von Bisch off und von Camerer jun. Ersterer fand bei einem neugeborenen Mädchen von $2969 \mathrm{~g}$ Gewicht 66,4\%. Wasser, letzterer hat in verschiedenen Publikationen 
eine Reihe von Analysen beim Neugeborenen veröffentlicht, die ich nachstehend zusammenfasse:

$\begin{array}{rrc}\text { I. } & 71,64 \% & \text { Wasser } \\ \text { II. } & 69,15 \% & , \\ \text { III. } & 72,88 \% & , \\ \text { IV. } & 71,73 \% & , \\ \text { V. } & 72,2 \% & \% \\ \text { VI. } & 71,98 \% & ,\end{array}$

Damit sind aber unsere Kenntnisse über den Wassergehalt des Neugeborenen erschöpft. Die Gesamtanalysen, die an älteren Kindesleichen gewonnen wurden, haben vor allem die unangenehme Beigabe, daß die betreffenden Kinder meist an kürzer oder länger dauernden Ernährungsstörungen gelitten hatten, die natürlich mit Veränderungen im Wassergehalt einhergegangen waren. Meist waren die Kinder einer akuten Ernährungsstörung erlegen und hatten große Einbußen an organischer und anorganischer Substanz und vor allem an Wasser erlitten. Die meisten Untersuchungen betreffen ,atrophische" Kinder. So vergleicht Ohlmüller drei an Atrophie gestorbene Kinder mit einem ,,normalen", an einer Capillärbronchitis zugrunde gegangenen Kinde. Der Wassergehalt der drei Atrophiker zeigte gegenüber dem Vergleichskinde in den einzelnen Organen eine Zunahme, die besonders in der Haut sehr bedeatend ist. Auch auf fettfreie Substanz gerechnet sind diese Differenzen, wenn auch nicht mehr so groß, aber immerhin deutlich. Sommerfelds Untersuchungen erstrecken sich auf die Muskulatur von zehn Kindern im Alter von 19 Tagen bis 12 Monaten, von denen die meisten an Ernährungsstörungen zugrunde gegangen waren, und auf zwei Gesamtanalysen, bei einem atrophischen und bei einem ,ziemlich gut genährten“: Kinde. Die ersten Untersuchungen ergaben Wasserwerte in der Muskulatur von 73,06 bis $81,53 \%$, also große Differenzen, und gerade diese beiden Extreme betreffen zwei Atrophiker ungefähr gleichen Alters. Die Gesamtanalysen ergaben Wasserwerte von 75,61 bis $70,15 \%$. Die erstere Zahl gilt für das atrophische Kind. Steinitz und Weigert analysierten ein ein Jahr altes atrophisches und rachitisches Kind und fanden einen Wasserwert von $83,26 \%$, bei einem früher untersuchten tuberkulösen Kind einen Wert von $83,06 \%$. Der hohe Wert (z. B. gegenüber den Camererschen Zahlen) ist auffallend, und es sei gleich erwähnt, daß bei beiden Kindern auch eine Vermehrung von $K$, $\mathrm{Na}$ und $\mathrm{Cl}$ gefunden wurde. Schließlich seien noch die früher schon 
zitierten Analysen von Steinitz erwähnt, der Werte von 71,0, 79,9, $82,3,79,9 \%$ für den Wassergehalt des Gesamtorganismus fand.

Bei einem ganz groben Ubberblick über alle hier angeführten Zahlen ergibt sich nun sofort, daß fast sämtliche Wasserwerte, die durch Gesamtanalysen oder durch Analysen von Muskeln gefunden wurden, bei älteren Kindern höher sind als bei den von Camerer und Bischoff untersuchten Neugeborenen, bzw, bei den entsprechenden Zahlen für die Muskeln Neugeborener. Insonderheit bei den vier letztgenannten Zahlen Steinitz' fällt der bei einem ganz jungen Kinde gefundene erste Wert von $71,0 \%$ einerseits ziemlich genau mit den von Camerer gefundenen Zahlen zusammen und andererseits ganz ans der Reihe der übrigen, bei älteren Kindern gefundenen Zahlen. Diese Tatsachen scheinen also dem Gesetz von der kontinuierlichen physiologischen Austrocknung des Organismus von der Zeit der Befruchtung bis zur Vollendung des Wachstums zu widersprechen.

Vierordt, der sich im wesentlichen auf die Angaben von Bischoff, Voit und Bezold beruft, nimmt die physiologische Austrocknung als kontinuierlich an, und Niemann, der neuerdings durch sehr genaue Untersuchungen des Gesamtstoffwechsels im Respirationsapparat die Frage exakt zu lösen versuchte, erzielte bei wiederholten Versuchen an einem normalen künstlich genährten Säugling, der zu verschiedenen Zeiten, einmal im Alter von dreieinhalb Monaten bei Buttermilch, das zweite Mal im Alter von fünf Monaten bei Magermilch mit Kohlehydratzusatz, das dritte Mal in der 36. Woche bei reiner Mehldiat und das vierte Mal im Alter von neun Monaten bei Vollmilchernährung von 1 Liter täglich, immer — auch bei Einrechnung sämtlicher Fehlerquellen negative Wasserbilanzen, manchmal enormen Grades und kommt daher zu dem Schluß, ,daß ein leidlich normaler Säugling, wie es unser Versuchskind war, mit der Zunahme an Körpersubstanz Wasser verliert, daß er, auch unter ungünstige Ernährungsbedingungen gebracht, und gezwungen, Körpersubstanz zu verbrennen, dieses sein Verhalten dem Wasser gegenüber nicht ändert und jedenfalls kein Wasser ansetzt." Diese negative Wasserbilanz konnten mit derselben Methodik Frank und Wolff auch an einem atrophischen Säugling nachweisen.

Fassen wir daher das bisher Gesagte zusammen, so ergibt sich für den menschlichen Organismus, daß das Gesetz der physiologischen Austrocknung für ihn offenbar erst von einem gewissen Alter an in uneinge- schränktem Maße gilt, daß dagegen die Analysen von Föten und Neugeborenen auffallend niedrige Wasserwerte ergeben. Es muß also zwischen 
diesen beiden Zeitpunkten ein Stadium liegen, wo der menschliche Organismus wasserreicher wird, also von dem Gesetz der kontinuierlichen Austrocknung abweicht.

Nicht am Gesamtorganismus, sondern am Blut geprüft, verfügen wir bezüglich des Verhaltens von Neugeborenen und älteren Kindern schon über weit mehr Angaben. Vor allem sind alle Autoren, gleichgültig welcher Methode sie sich bedienen, darin einig, daß das Blut des Neugeborenen eine größere Konzentration aufweist, als das des älteren Kindes. Monti wies dies mittelst der Hammerschlagschen Methode der Bestimmung des spezifischen Gewichtes nach. Z Zu gleichem Resultat kam mit derselben Methode Karnitzki. Schiff untersuchte 36 Neugeborene bis zum 10. Lebenstage, und zwar bestimmte ex in täglichen Messungen Trockenrückstand-, Asche- und EiweiBgehalt. Er weist auf die großen individuellen Schwankungen in allen drei Bestandteilen bei einzelnen Kindern hin und findet, daß sowohl der Trockenrückstand- als auch der Asche- und Eiweißgehalt des Blutes am ersten Tage die höchsten Werte zeigen. Die größte Abnahme erfährt in der Folge der Trockenrückstandsgehalt des Blutes, und zwar in den ersten Tagen sehr rasch, später etwas weniger. Der Aschegehalt dagegen nimmt bis zum dritten Tage ab, steigt dann aber wieder zu derselben (prozentualen) Höhe an. Daraus erhellt, daß nach der anfänglichen Eindickung des Blutes zunächst Wasser in größeren Mengen aufgenommen wird, dem die Salzaufnahme langsamer nachfolgt. Auch Reiß findet mit der refraktometrischen Methode eine Eindickung des Blutes beim Neugeborenen gegenüber dem älteren Säugling. Gundobin, der sich im wesentlichen auf Untersuchungen von Jones Loyd, Hock und Schlesinger, Moeli, Monti usw. beruft, erklärt ebenfalls, daß die Dichtigkeit des Blutes beim Kind geringer ist als beim Erwachsenen, daß aber Neugeborene die größte Dichtigkeit des Blutes besitzen. Bu usz hat bei seinen viscosimetrischen und refraktometrischen Untersuchungen weniger Reihenbestimmungen gemacht, als vielmehr die statistische Methode bevorzugt. Nach seinen Angaben steigt die Viscosität in den ersten Tagen des Lebens und sinkt dann stark. Diese Abnahme setzt sich in geringerem Maße durch das ganze erste Lebensjahr fort. Die Refraktion steigt in den ersten Lebenstagen auch an, daran schließt sich eine bis zum vierten bis achten Lebenstage dauernde Abnahme, dann beginnt die Refraktion neuerlich zu steigen. Diese Zunahme dauert in immer geringerem Maße durch das ganze erste Lebensjahr an. Inwieweit bei diesen Untersuchungen Einflüsse der „,physiologischen“" Gewichtsabnahme 
in Betracht kommen, soll später erörtert werden. Salge fand durch Bestimmung des osmotischen Druckes eine starke Eindickung des Blutes am Neugeborenen. Ferner liegen noch direkte Wasserbestimmungen von Dennstedt und Rumpf und von Lust vor. Letzterer untersuchte Neugeborene im Alter von einer Stunde bis zu 30 Tagen und berechnete einen Mittelwert von 77,7\%. Den niedrigsten Wert zeigt ein 10 Stunden altes Neugeborenes von 71,8\% Wassergehalt im Blut. Tm Laufe der ersten Monate nimmt der Wassergehalt des Blutes zu, er beträgt bei gesunden Brustkindern jenseits des zweiten Monates ( 4 wurden untersucht) im Mittel 81,9 , bei 5 künstlich genährten Kindern 80,6 bis $83,0 \%$, ist also bei letzteren höher als bei ersteren. Allerdings fehlen bei diesen letztgenannten Zahlen Angaben über die Ernährung und allenfalls vorhandene Konstitutionsanomalien. Nach dem Säuglingsalter verliert das Blut seinen Wasserreichtum und stellt sich allmählich auf die Konzentration des Blutes beim Erwachsenen ein. 6 Kinder im Alter von $1 \frac{1}{4}$ bis 11 Jahren zeigen einen Mittelwert von 80,62, Schwankungen von 79,8 bis $83,4 \%$ Wassergehalt im Blut.

Wir sehen also bei den mit den verschiedensten Methoden angestellten Untersuchungen, daß auch das Blut des Nengeborenen konzentrierter ist als das des älteren Säuglings und daß bis zu einem gewissen Zeitpunkte - wann derselbe eintritt, und wovon er abhängt, ist aus den bisherigen Publikationen nicht ersichtlich - eine Zunahme im Wassergehalt des Blutes statthat.

Es muß also in dieser vorläufig noch nicht näher umgrenzten Zeit Wasser in irgendeiner Form im Körper zur Bindung gelangen. Was an Kenntnissen über die Wasserbindung im Tierexperiment und im Laboratoriumsversuch vorliegt, wurde im experimentellen Teil dieser Arbeit erwähnt. Die Meimungen, die man sich über diesen Vorgang am Bette des gesunden und kranken Säuglings gebildet hat, beruhen vorwiegend auf dem Glauben an einen unbedingten Zusammenhang des Salzstoffwechsels mit dem Wasserhaushalt. Dies beweist schon die Methodik, deren man sich bedient hat, um Schlüsse auf den Wasserhaushalt ziehen zu können; es ist entweder die Bestimmung der Mineralstoffbilanz im Stoffwechselversuch oder direkt die Bestimmung von osmotischem Druck und Leitfähigkeit im Blut (Salge, Hagner, Schulz). Es ist selbstverständlich, daß in kurz dauernden Versuchen, wo über das normale Maß hinaus dem Körper Salzmengen einverleibt werden, dieselben einfach auf osmotischem Wege wirksam sind und in dieser Weise den Wasserhaushalt beeinflussen. Wie Schloss mit Recht her- 
vorhebt, ist cs das, ,Sohicksal des superponierten Salzes, welches hauptsächlich die Wirkungen auf den Wasseransatz und also auch die klinischen Wixkungen bedingt." In seinen ausgedehnten Untersuchungen bemerkt aber Schloss weiter ganz richtig: ,Durch diese Feststellungen werden die sonstigen mannigfachen Tatsachen über die Physiologie und Pathologie der Wasserbindung im Organismus nicht berührt. Die hier am Säugling gefundenen Tatsachen stellen nur ein Sonderkapitel dieses ungemein komplizierten Problems dar." Freund suchte den Zusammenhang zwischen Wasser- und Salzstoffwechsel durch Untersuchungen des Cl-Stoffwechsels bei Säuglingen zu lösen, welche große Gewichtsschwankungen, sowohl im Sinne rapider Abnahme als großer Zunahme mitmachten. Er kommt zu dem Schluß, daß der Wasseransatz das Primäre, die Cl-Retention das Sekundäre sei. L. F. Meyer, der wiederholt bei den verschiedensten Ernährungsstörungen Mineralstoffwechselbilanzen aufgestellt hat, läßt hingegen ,die Frage offen, ob der Organismus nicht auch ohne entsprechende Veränderungen im Salzbestande wasserärmer und -reicher werden kann," da z. B. bei kohlehydratreicher, kochsalzarmer Nahrung der Wasserretention keine ClRetention parallel geht. Czerny-Keller äußern sich nicht direkt über diese Frage, heben aber den besonderen Wasserreichtum der Frauenmilch hervor. „Gehen wir von der Frauenmilch aus, so erscheint uns zunächst bemerkenswert, daß sie eine außerordentlich wasserreiche Nahrung ist. Der große Wasserreichtum dés kindlichen Organismus weist uns darauf hin, daß diese Eigentümlichkeit der Nahrung eine notwendige ist." Diese Tatsache ist insofern wichtig, als wir wissen, daß die Frauenmilch gleichzeitig eine sehr salzarme Nahrung ist. Während uns nach den Feststellungen Rubners und Heubners bekannt ist, daß der künstlich genährte Säugling eine größere Wasserbilanz hat als der natürlich ernährte (nach ihnen scheidet der künstlich genährte Säugling pro $\mathrm{kg}$ in 24 Stunden $44,39 \mathrm{~g}$ Wasserdampf aus, während die entsprechende Zahl für das natürlich genährte Kind 38,2 beträgt), während wir andererseits nach den Feststellungen von Blauberg wissen, daß wir es bei künstlich mit Kuhmilch genährtem Säugling ,,mit einer Überernährung bezüglich gewisser Mineralstoffe zu tun haben", daß wir also hier ein gewisses Parallelgehen von Wasser- und Salzbilanz bemerken können, sehen wir beim natürlich genährten Kind eine gewisse Diskrepanz zwischen den in der Frauenmilch zugeführten großen Wasser- und kleinen Salzmengen.

Wir rollen damit gleichzeitig die Frage auf, wieviel Wasser ein Säug- 
ling überhaupt braucht, oder mit anderen Worten, was geschieht, wenn ein Säugling zu wenig oder zu viel Wasser erhält. Daß in den ersten Tagen nach der Geburt genügende Wasserzufuhr eine der ersten Forderungen ist, ist zu bekannt, um eigens hervorgehoben werden zu müssen. Tch erwähne diesen Umstand aber hier deshalb, weil uns gewisse Erfahrungen in dieser Beziehung sagen, daß das Neugeborene, das mit großen Reserven an fast sämtlichen Konstituenten des Organismus zur Welt kommt, gerade dieses wichtigsten Bestandteiles entbehrt und uns schon darin einen Hinweis auf seine relative Wasserarmut gibt. Ich verweise besonders auf eine Beobachtung von Camerer jun.: „Verfasser hat jedoch einen Fall beobachtet, in welchem einem kräftigen Kinde (dem erstgeborenen) trotz durchaus ungenügender Milchsekretion außer etwas Wasser keine Beinahrung gegeben wurde, und das, abgesehen von einem mäßigen Gewichtsverlust ohne jede Schädigung des Kindes, bis endlich am 14. Tage (!) das Stillgeschäft in Gang kam ...... Mit Recht weisen daher auch Langstein, Rott und Edelstein neuestens darauf hin, daß das Colostrum eine zu trockene Nahrung darstellt und daß die empirisch gefundene Regel, in den ersten Tagen für genügende Flüssigkeitszufuhr zu sorgen, durch ihre Untersuchungen des Nährwertes des Colostrums eine Bestätigung erhalten.

Wohin ungenügende Zufuhr von Wasser führt, haben $O$. und $W$. Heubner und L. F. Meyer gezeigt. Erstere konnten beobachten, daß ein gesundes Brustkind, das kalorisch vollkommen ausreichend ernährt wurde (Energiequotient von 100 und darüber), in den ersten 30 Tagen nicht zunahm, und machten das zu geringe Wasserangebot für diesen Gewichtsstillstand verantwortlich. L. F. Me yer rechnete diesen Versuch nach und konnte tatsächlich finden, daB dieses Brustkind nur $126 \mathrm{~g}$ Wasser pro Tag und Kilo trank, während das normale Kind $142 \mathrm{~g}$ Wasser trinkt. In einer späteren Versuchsreihe an künstlich genährten Kindern stellte nun Meyer drei Typen von Kindern auf, je nachdem sie auf Einschränkung von Flüssigkeitszufuhr reagieren: 1. solche, die bei Ernährung mit konzentrierter (kalorisch ausreichender), aber flüssigkeitsarmer Nahrung Gewichtsabfall und Temperatursteigerung zeigen, 2. in solche, die erst Gewichtsstillstand aufweisen, auf Wasserzulage dann zunehmen, und 3. solche, die schon bei konzentrierter Nahrung zunehmen, bei Wasserzulage dann aber besser gedeihen. Er berechnet für das künstlich genährte Kind des ersten Lebensquartales pro Tag und $\mathrm{kg} 150 \mathrm{~g}$ Wasserbedarf. In einer anderen Arbeit berechnet 
Meyer aus Camerers Zahlen, daß ein 10 Wochen alter Säugling pro Kilo und Tag $140 \mathrm{~g}$ Wasser aufnimmt und $148 \mathrm{~g}$ abgibt. Diese Unterschiede im Verhalten der Wassereinschränkung gegenüber haben wohl ihre Ursache in einer großen individuellen Verschiedenheit. Es ist ein großes Verdienst Meyers, auf diese Unterschiede schon im frühesten Säuglingsalter aufmerksam gemacht zu haben. Denn bei älteren Kindern sieht man in dieser Beziehung ja die größten Schwankungsbreiten, manchmal am besten bei Geschwistern. Während das eine Kind zu jeder Mahlzeit mehrere Glas Wasser trinkt und auch in den Zwischenzeiten wiederholt das Bedürfnis zu trinken hat, nippt das Geschwister, das ja unter denselben Ernährungs- und Pflegebedingungen aufwächst, kaum am Glas und äußert kaum Durstgefühl. Auch bei Erwachsenen sind diese Verschiedenheiten bemerkt worden und das geringe, manchmal geradezu überhaupt fehlende Durstgefühl wurde von internistischer Seite direkt als Neurose aufgefaßt (Sch midt, Jungklaus). Auf diesen Verschiedenheiten beruht es wohl zum Teil, daß nicht bei allen Kindern, die unter entsprechende Eirnährungsbedingungen gesetzt wurden, das Durstfieber (Müller, Crandell) gefunden wird. Eine Bestätigung der Ansichten Meyers ist auch in einer der neueren Beobachtungen Niemanns gegeben. Wie schon oben erwähnt, fand Niemann bei allen seinen Versuchen am Respirationsapparat negative Wasserbilanzen. Nur einmal konnte Niemann eine positive Bilanz bei einem atrophischen Säugling beobachten. Daß dieser Befund aber mit der Atrophie als solcher nichts zu tun hat, erhellt aus folgendem: Das Versuchskind hatte bei $700 \mathrm{~g}$ Halbmilch Gewichtsstillstand geboten. Trotz eines Energiequotienten von 120 wurde es auf $900 \mathrm{~g}$ Halbmilch gesteigert und da setzte eine rapide Gewichtszunahme ein. In diesem Moment begann der Versuch, der eine positive Wasserbilanz ergab. Zweifellos befand sich das Versuchskind Niemanns in demselben Stadium, wie das Kind von $O$. und W. He ubner und wie die Versuchskinder Meyers der zweiten Gruppe. Es bot Gewichtsstillstand trotz kalorisch ausreichender Ernährung, aber bei zu geringem Wasserangebot. Wir können aus diesem exakten Versuch sehen, wie wichtig genügende Wasserzufuhr ist, respektive wie große Mengen der betreffende Säugling entbehrt haben mußte und jetzt resorbierte, daß die Wasserbilanz nach Abzug von Oxydationswasser usw. positiv wurde.

Daß andererseits bei wasserreichen Individuen teilweiser oder zeitweiser Wasserentzug therapeutisch wirksam sein kann, beweisen die Resultate Singers am Erwachsenen und Vogts bei chronisch lungen- 
kranken Kindern. Daß aber Wasserentziehungen von längerer Dauer Schädigungen im Stoffwechsel, besonders im N-Stoffwechsel hervorrufen können, zeigen die Untersuchungen Spieglers, der gesteigerten N-Zerfall nach Wasserentziehung beweisen konnte, und Czernys, der am Tierexperiment zeigte, daß extreme Eindickung zum Tode führt, je nach der Geschwindigkeit, mit welcher dieselbe erfolgt.

Die Anschauungen, die man sich bisher über den Einfluß vermehrter Wasserzufuhr für den Organismus gebildet hat, fußen vorwiegend auf den Ergebnissen kurz dauernder Experimente an Tieren und Menschen. Oppenheim findet nach vermehrter Aufnahme von Wasser vermehrte Harnstoffausscheidung und erklärt dies als „Auswaschung des Organismus". R. O. Ne u ma n n nennt die durch plötzliche Wassersteigerung hervorgerufene Vermehrung der Stickstoffausfuhr eine „Auslaugung der Gewebe". Margolis, der dieselbe Frage im Stoffwechselversuch an Süuglingen prüfte, hält ebenso die vermehrte $\mathrm{N}$-Ausfuhr nicht für Gewebszerfall, sondern nur für eine ,Ausspülung N-haltiger Produkte". Sehon aus diesen Versuchen mußte also gefolgert werden, daß eine dauernde Mehrzufuhr von Wasser gewisse Gefahren in sich birgt. So schreiben auch Schloss mann und Som merfeld: „Während, die Lehre von den Gefahren der Überernährung in ihrer Bedeutung heute allgemein erfaßt ist, steht man der Ưberwässerung vielfach gleichgültig gegenüber. Fest steht aber, daß jeder Tropfen Wasser, der über das Bedürfnis hinaus aufgenommen worden ist, ausgeschieden werden muß, und zwar unter einer entsprechenden Mehrbelastung des Organismus an Arbeit und unter erhöhter Inanspruchnahme von Zelltätigkeit." Czerny-Keller halten die Gefahr dauernder Mehrzufuhr von Wasser für nicht sehr groß, da sie niemals ,,durch kritische Beobachtungen sichergestellt" sei. „Úberschüssiges Wasser, welches in den Organismus eingeführt wird, wird wieder ausgeschieden." Dagegen anerkennen sie die Gefahren des überflüssigen Zellverschleißes. Über die Wirkung lange fortgesetzter starker Wasserdurchspülung auf den Wärmeumsatz wissen wir nichts Bestimmtes. (Magnus - Levy.) Nun liegt aber tatsächlich die Frage nicht so einfach, da es in praxi nicht angeht, das Wasser für sich, getrennt von den übrigen Bestandteilen der Nahrung zu betrachten. Mit der Nahrung werden ja immer Substanzen eingeführt, welche imstande sind, Wasser zu binden, seien es Salze oder Kolloide. Und da ist es nun nicht gleichgültig, welche Mengen Wassers diesen Substanzen zur Bindung zur Ver- 
fügung stehen. Das geht schon aus den alten Anschauungen von Cohnheim und Lichtheim, ferner aus Versuchen von Magnus und Ponfick hervor, welch letzterer zeigen konnte, daß bei Einbringung von großen Mengen Wassers natürlich eine Vermehrung der Harnmenge, eine Diurese, auftritt, daß dagegen bei Einbringung großer Mengen „künstlichen Serums", bestehend aus 1 proz. Kochsalzwasser und. Hühnereiweiß keine Vermehrung der 24stündigen Harnmenge in Erscheinung tritt, welcher Umstand also darauf hinweist, daß das eingebrachte. Wasser im Körper zurückgehalten worden sein muß. Auch Bittorf weist in seinen umfassenden Zusammenstellungen über den Wasser- und Salzstoffwechsel auf ähnliche Tatsachen hin. Wenn wir uns aber mit dem Gedanken einmal vertraut gemacht haben, daß es nicht gleichgültig ist, wieviel Wasser gleichzeitig mit anderen Nahrungsbestandteilen in den Organismus eingeführt wird, und daß der Überschuß im Körper ganz oder teilweise zurückgehalten werden kann, drängt sich uns unwillkürlich ein Begriff auf, der für den wichtigsten Bestandteil der Nahrung, den Stickstoff, aufgestellt wurde, ich meine den Begriff der Luxuskonsumption. „Wenn die gesamte Zufuhr größer ist als der Bedarf, wird der Nahrungsäberschuß nach Abzug kleinerer, für die Deckung der vermehrten Darmarbeit nötiger Nahrungsausgaben im Körper aufgestapelt" ( $\mathrm{Krug}$ ). Wenn es mir auch vollständig ferne liegt, den Begriff in diesem oder etwa im Biedertschen Sinn für das Wasser einführen zu wollen, da er tatsächlich, auf das Wasser angewendet, nur Ähnliches, nicht Gleiches, sagen könnte - ist doch das Wasser immer nur Ersatzstoff und Lösungs- und Transportmittel, kein Energiespender -, so muß nach den eben entwickelten Anschauungen doch mit der Ansicht gebrochen werden, daB die Menge des eingeführten Wassers, das mit den übrigen Nahrungsbestandteilen einverleibt wird, für den Organismus gleichgültig ist und restlos wieder ausgeschieden wird. Daß sich auch hier, ebenso wie bei der zu geringen Wasserzufuhr, große individuelle Verschiedenheiten bemerkbar machen können, liegt auf der Hand, und wird dadurch bewiesen, daß man neuerdings sogar für Kinder, welche leicht Wasser aufnehmen und festhalten, eine eigene Konstitution oder Diathese aufstellt. Czerny nennt sie „hydropische Konstitution", Lesage "Dysosmotische oder Salzdiathese". Dabei ist natürlich von schwer pathologischen angeborenen Zuständen, wie sie Edgeworth und Schridde beschrieben haben, nicht die Rede. 
1. Die physiologische Gewichtsabnahme des Neugeborenen.

Während man früher die Ursache für die „physiologische" Gewichtsabnahme mehr in allgemeinen Schädigungen, denen der Organismus des Neugeborenen ausgesetzt ist, suchte - z. B. charakterisiert Camerer sen. die physiologische Abnahme als einen Hungerzustand, hervorgerufen dadurch, daß sich das Neugeborene ,zum Saugen an der Mutterbrust, seiner ersten verhältnismäßig bedeutenden Arbeit, erst dann bequemt, wenn es stark hungert" - wurden in neuerer Zeit tiefere Beziehungen zum Stoffwechsel gefunden. Gundobin schuldigt eine Abweichung des N-Stoffwechsels von der Norm für das Verhalten der Neugeborenen an. Langstein und Niemann konstatierten im Stoffwechselversuch an drei normalen und einem frühgeborenen Kinde vom 3. bis 5. Tag vermehrten N-Zerfall. Ebenso erreichte die Harnsäureund P-Ausscheidung um diese Zeit die höchsten Grade. Beziehungen zum Wasserstoffwechsel wurden von den verschiedensten Seiten gefunden. Lust fand bei einem Fall während der physiologischen Gewichtsabnahme eine Eindickung des Blutes, bei einem anderen, der schon gleich bei der Geburt einen sehr niedrigen Blutwassergehalt hatte, fehlte während dor Abnahme eine weitere Eindickung des Blutes. Lust glaubt, daß ,an der physiologischen Gewichtsabnahme des Neugeborenen Schwankungen des Wassergehaltes des Körpers zweifellos mitbeteiligt sind." Daß auch die viscosimetrischen und refraktometrischen Untersuchungen von $R u s z$ darauf hinwiesen, daß während der physiologischen Abnahme eine starke Konzentration des Blutes eintritt, wurde schon oben erwähnt. Rott glaubt nach Refraktometerbestimmungen, daß die Abnahme ausschließlich durch Wasserverlust zu erklären sei. Pies spricht sich nicht näher über einen Erklärungsversuch aus, während Birk und Edelstein durch einen exakt angestellten Respirationsstoffwechselversuch am Neugeborenen zu folgendem Resultat kommen: „Es geht aus dieser Zusammenstellung hervor, daß der Gewichtsverlust bei weitem nicht durch Meconium und Urin (und Nabelschnurrest) allein bedingt wird. Dahingegen ist die Annahme, daß der Hauptanteil der physiologischen Abnahme durch das von der.Haut und den Lungen abgegebene Wasser sowie auch bis zu einem gewissen geringen Grade durch eingeschmolzenes Gewebe gebildet wird, in jeder Weise gerechtfertigt."

Da es die Art des Krankenhausbetriebes mit sich bringt, daB gesunde Neugeborene nur selten unmittelbar nach der Geburt zur klinischen Beobachtung kommen, so konnte ich die vorliegende Frage nur 
streifen, und bringe unter anderem zwei Fälle, die mit der oben beschriebenen Methodik untersucht wurden.

Das Kind R. S. wurde 18 Stunden vor der Einlieferung in einem Alter von $6^{1 / 2}$ bis 7 Schwangerschaftsmonaten geboren. Die Frühgeburt war künstlich wegen Eklampsie der Mutter eingeleitet worden, die trotzdem einen Tag nach dem Partus starb. Das Kind war bei der Aufnahme $1500 \mathrm{~g}$ schwer und $43 \mathrm{~cm}$ lang. Es zeigte alle Zeichen der Frühgeburt, war aber sonst körperlich normal gebildet. Es bekam am 1. Tag nur Tee, am 2. Tag außerdem dreimal abgespritzte Frauenmilch. Mit der

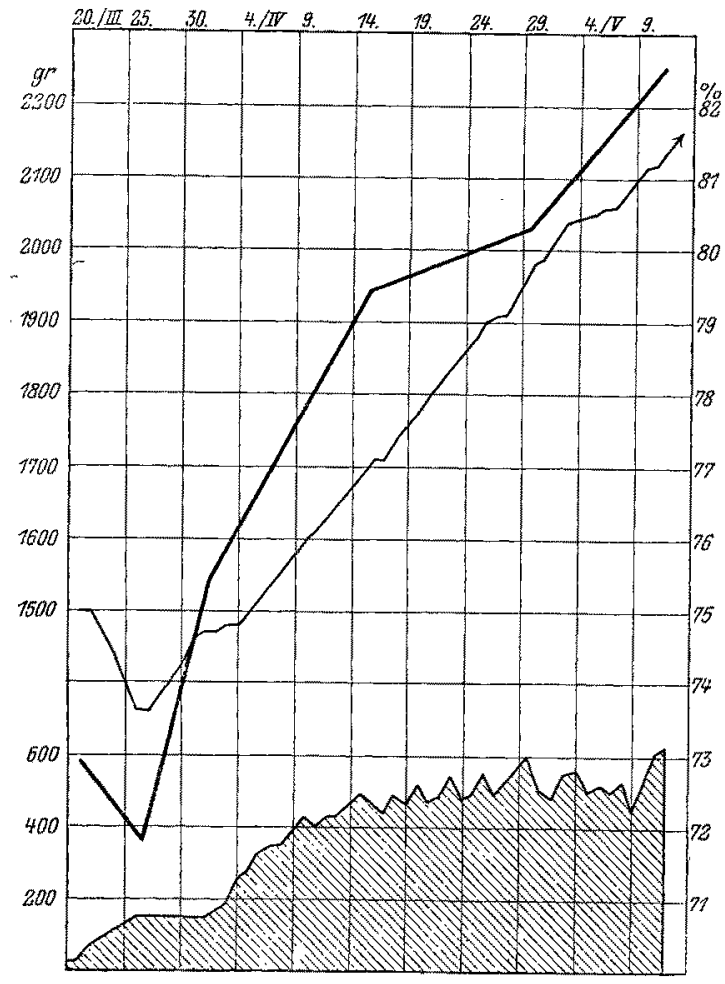

Fig. 2.

Zahl der Mahlzeiten wurde sehr rasch gestiegen, da das Kind nicht recht trinken wollte und bei den einzelnen Mahlzeiten immer nur sehr geringe Mengen zu sich nahm: Erst am 6. Tage erreichte die Trinkmenge $150 \mathrm{~g}$ und hielt sich in dieserHöhe weiter durch 5 Tage; von da an trat eine rasche Steigerung der Trinkmengen bei täglich 8 Mahlzeiten ein. Vom 3. bis 10. Tage fieberte das Kind täglich um $38^{\circ}$, ohne daß eine organische Ursache für dieses Fieber hätte gefunden werden können. (Transitorisches Fieber der Neugeborenen, v. ReuB.)

Betrachten wir nun den ersten Teil der Fig. 2 näher, so sehen wir, daß das Kind von seinem Anfangsgewicht im Laufe von 5 Tagen $200 \mathrm{~g}$ verlor und sein Eintrittsgewicht am 15. Tage wieder erreichte. (In dieser sowie in den folgenden Figuren bezeichnet die dünn ausgezogene Linie das Körpergewicht, der dick gezeichnete Strich den prozentualen Wassergehalt des Blutes. Und zwar ist die Einteilung so gewählt, daß für die erstere Kurve der, Abstand zweier Linien des Koordinatensystems $100 \mathrm{~g}$, für letztere $1 \%$ beträgt.) Der Wassergehalt im Blute 
dieses Kindes wurde sofort bei der Aufnahme untersucht und betrug $72,9 \%$. Am tiefsten Punkt der Gewichtskurve betrug er $71,8 \%$, also $1,1 \%$ weniger. Dann nahm der Wassergehalt im Blut rapid zu. Ich will besonders hervorheben, daß infolge der Lebensschwäche des Kindes die Trinkmengen anfänglich sehr klein waren und bis zum 6. Tage, also bis zum Tiefpunkt der Gewichtskurve 1/10 des Körpergewichtes nicht erreichten, und daß der Ausfall der Blutuntersuchung es erlaubt, die mehrtägige Fiebersteigerung als Durstfieber anzusehen.

Diesem Kind soll ein zweites gegenübergestellt werden, das ebenfalls von der Geburt an in meiner Beobachtung stand.

A. K. wurde auf einer der Abteilungen unseres Krankenhauses am normalen Schwangerschaftsende geboren und sofort unserer Säuglingsabteilung überstellt. Anfangsgewieht 3340 g, $52,5 \mathrm{~cm}$ Körperlänge. Erstes Kind der Frau, somatischer Befund vollständig normal. Das Kind erhielt am ersten Tag nur Tee, am 2. Tage dreimal Brust, am 3. Tage fünfmal Brust und vom 5. Tage sechsmal Brust täglich. Niemals Temperatursteigerungen.

Das Kind nahm im Laufe von 3 Tagen $180 \mathrm{~g} \mathrm{ab}$, hielt sich dann längere Zeit auf diesem Gewicht und erreichte sein Geburtsgewicht erst am 16. Lebenstage, also auch hier fast ebenso spät wie im ersten Falle. Die Trinkmenge stieg gleich von Anfang, wie aus Fig. 3 ersichtlich ist, stark an. $O b$ ein ziemlich heftiger Ikterus, der durch zirka eine Woche anhielt, für das späte Erreichen des Anfangsgewichtes verantwortlich gemacht werden kann, bleibe dahingestellt. Der Stuhl

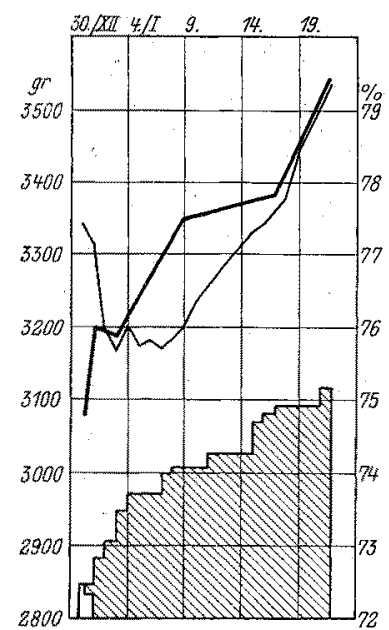

Fig. 3. war immer in Ordnung. Vergleicht man aber in diesem Falle die beiden Linien, so findet man, daß die Gewichtskurve und die Kurve des Wassergehaltes im Blute keineswegs so parallel verlaufen wie im erstbeschriebenen Fall. Wir finden auch hier einen sehr niedrigen Anfangswert von $74,7 \%$; derselbe ist aber genau 24 Stunden später, nachdem das Kind nichts anderes getrunken hatte als Tee und $30 \mathrm{~g}$ Brustmilch, um 1,3\% gestiegen. Trotz weiterer Gewichtsabnahme hielt sich der prozentuale Wassergehalt des Blutes 2 Tage später auf derselben Höhe und stieg dann mit zunehmendem Gewicht und wachsenden Trinkmengen rapid an.

Aus diesen beiden Beispielen ergibt sich also keineswegs ein auschließlicher Zusammenhang von Wassergehalt des 
Blutes mit der physiologischen Gewichtsabnahme. Vielmehr werden die Ursachen für letztere eben noch in anderen Momenten (Gewebszerfall, Abkühlung, Abgang von Meconium, Nabelschnurrest usw.) zu suchen sein. Die Veränderungen im Wassergehalt des Blutes während der physiologischen Abnahme sind auch verschwindend klein gegenüber der kolossalen Wasseraufnahme nach der Geburt, wie sie im nächsten Abschnitt besprochen werden soll. Wohl aber ergibt sich ein Zusammenhang zwischen dem Wassergehalt des Blutes und der Trinkmenge der Kinder. Beide Kinder erleiden eine "physiologische" Abnahme, sind also gute Vergleichsobjekte. Aber das erste Kind nimmt wegen Debilitas und Appetitlosigkeit nur sehr wenig Nahrung zu sich, das zweite, ein kräftiges Kind, nimmt gleich von Anfang an genügend Flüssigkeit auf, was die Beobachtung um so eindeutiger macht: Der Wassergehalt seines Blutes nimmt in den ersten 24 Stunden, in denen das Kind nur Tee trinkt, und sein Körpergewicht um $140 \mathrm{~g}$ abnimmt, um 1,3\% zu.

2. Der Wassergehalt des Blutes beim gesunden Brustkind und seine Beziehungen zur Nahrung.

Schon bei diesen beiden eben beschriebenen Kindern, deren Blutwassergehalt unmittelbar nach der Geburt untersucht werden konnte, wird der niedrige Wert des letzteren aufgefallen sein, im Gegensatz z. B. zu dem Durchschnittswert von 81,9 , den Lust für Brustkinder jenseits des zweiten Lebensmonates aufgestellt hat. Es wird nun Aufgabe dieses Kapitels sein, diese Beobachtung weiter zu prüfen, gleichzeitig aber die Ursache dieses niedrigen Wertes zu erforschen.

J. F., wurde am 16. VII. 1912 mit einem Gewicht von $3300 \mathrm{~g}$ and $51 \mathrm{~cm}$ Länge geboren. 11 Tage später wurde das Kind mit seiner Mutter auf unsere Abteilung aufgenommen und wog $3400 \mathrm{~g}$. Prozentualer Wassergehalt des Blutes 76,7. Am 13. VIII. konnte ich das Kind noch einmal untersuchen, es wog inzwischen $3850 \mathrm{~g}$, der prozentuale Wassergehalt des Blutes betrug 79,2. Aus äußeren Gründen konnte ich den Fall nicht weiter verfolgen.

Das Kind zeigte also 11 Tage nach der Geburt einen Wassergehalt seines Blutes, der weit unter dem Durchsehnitt der für ältere Kinder angegebenen Zahlen liegt und im Laufe von 17 Tagen um 2,5\% stieg.

Schon diese wenigen Zahlen im Verein mit den im vorigen Kapitel mitgeteilten erlauben den Schluß, daß die von anderen Autoren mittels anderer Methoden und die von Lust ebènfalls mittels direkter Wasserbestimmung gefundene erhöhte Konzentration des Blutes beim Neugeborenen zweifellos zu Recht besteht und daß die 
Konzentration des Blutes im Laufe der ersten Säuglingszeit abnimmt. Man kann sich nun schwer vorstellen, daß das Blut allein eine solche Konzentrationserhöhung zeigt, während die übrigen Gewebe normalen oder, wie nach dem Gesetz der physiologischen Austrocknung zu schlieBen wäre, sogar erhöhten Wassergehalt bieten sollten. Man kann sich kaum denken, daß die Gewebe, sagen wir nur denselben Wassergehalt hätten wie 2 Monate später, daß aber das Blut, das in ununterbrochenem Austausch mit ihnen steht, einen Wassergehalt besäße, der manchmal bis $\mathrm{zu} 10 \%$ niedriger wäre als zu dieser Zeit. Ganz abgesehen aber von der Schwierigkeit dieser Erklärung sprechen die wenigen vorliegenden Gesamtanalysen des Neugeborenenkörpers von Camerer jun. und Steinitz, die oben zitiert wurden, mit aller Deutlichkeit dafür, daß auch an den Geweben eine solche Wasserarmut sich geltend macht. Schon aus diesen Ausführungen erhellt, daß das Gesetz der physiologischen Austrocknung nicht kontinuierliche Geltung hat. Der Organismus trocknet von der Zeit der Befruchtung an bis zur Geburt aus. Dann muB er eine Wasseranreicherung erfahren und erst später beginnt neuerlich die ,physiologische" Austrocknung. Es gilt nun zu entscheiden, 1. wie lange dauert die Zeit dieser Wasseranreicherung, 2. wovon ist sie abhängig, 3. was hat sie für Bedeutung?

Um nicht durch äberflüssiges Material zu ermüden, gebe ich immer nur Typen von Krankengeschichten und Kurven wieder, die sich bei allen untersuchten Fällen ausnahmslos decken.

M. M. wurde am 18. VII. 1912 am normalen Schwangerschaftsende mit $3000 \mathrm{~g}$ Gewicht geboren. Am 18. VIII, also genau einen Monat alt, wurde sie mit einem Gewicht von $3580 \mathrm{~g}$ samt ihrer Mutter im Spital aufgenommen. Blutwassergehalt $80,8 \%$. Bei relativ geringen Trinkmengen fast sohwankungslose Zunahme. Am 28. IX, $4600 \mathrm{~g}$ Gewicht, Blutwassergehalt 82,9\%. Bald darauf Beifütterung von Halbmilch, dabei weiter ungestörte Zunahme. Am 6. XI., noch bei Allaitement mixte, $5300 \mathrm{~g}$ schwer. Blutwassergehalt $82,6 \%$.

Wir sehen also, daß in diesem Falle, der im Alter von einem Monat zum ersten Male untersucht wurde, der prozentuale Wassergehalt des Blutes schon bedeutend höher ist und sich der von Lust angegebenen Zahl nähert. Doch steigt er im Laufe des nächsten Monates noch weiter, so daß er 6 Wochen später noch um 2,1\% höher liegt. Erst weitere 2 Monate später macht sich eine leichte Abnahme geltend. Die $\mathrm{Zu}$ nahme im Wassergehalt bei diesem Fall dauert also wenigstens bis in den 2. bis 3. Monat hinein. Ich erwähnte nun in der Krankengeschichte, daß die Zunahme bei dem Kinde sehr gleich- 
mäßig bei anfangs relativ kleinen Trinkmengen erfolgte. Nach der Aufnahme trank das Kind durchschnittlich $600 \mathrm{~g}$ Brustmilch täglich. Diese Mengen steigerten sich in der Folge, erreichten am 20. IX. zum ersten Male 700 und hielten sich nun in der ganzen folgenden Zeit zwischen 700 und $800 \mathrm{~g}$. Diese Mengen sind nun nicht sehr groß (gegenüber rund $900 \mathrm{~g}$ Tagesmenge der Norm). Auch der höchste Blutwassergehalt, der bei diesem Kinde gefunden wurde, steht um etwas gegenüber der von Lust aufgestellten Durehschnittszahl und den von mir bei anderen Kindern gefundenen Werten zurück. Es scheint also bei diesem Fall ein ungezwngener, direkter Zusammenhang zwischen dieser Zunahme des Blutwassergehaltes beim Neugeborenen mit der Trinkmenge, sowohl was seine Quantität als was seine Dauer betrifft, zu bestehen.

P. G. wurde am 8. XI. 1912 mit einem Gewicht von $3000 \mathrm{~g}$ und $51 \mathrm{om}$ Körperlänge geboren. 11 Tage später Aufnahme im Spital als Ammenkind. Somatisch vollkommen normaler Befund. Wird 4stündlich angelegt. Glänzendes Gedeihen bei relativ kleinen Trinkmengen. Erste Untersuchung am Tage der Aufnahme. Blutwassergehalt von $74,9 \%$. Eine Woche später neuerliche Untersuchung. Durchschnittliche Zunahme von $30 \mathrm{~g}$ täglich, bei Trinkmengen von 500 bis $590 \mathrm{~g}$. Blutwassergehalt $76,8 \%$. Eine Woche später Trinkmenge durchschnittlich $580 \mathrm{~g}$, tägliche Zunahme durchsehnittlich $30 \mathrm{~g}$. Blutwassergehalt 77,7\%. Am 11. XII., ungefähr 5 Wochen nach der Geburt, sind die Trinkmengen auf 660 bis $680 \mathrm{~g}$ täglich gestiegen, Gewicht $3820 \mathrm{~g}$. Blutwassergehalt $80,0 \%$. Am 31. XII., 8 Wochen nach der Geburt, beträgt das Gewicht $4450 \mathrm{~g}$. Die Trinkmenge erreicht zum erstenmal $800 \mathrm{~g}$ und bleibt von da ab konstant um diese Zahl. Blutwassergehalt $81,4 \%$. Am 16. I. $4800 \mathrm{~g}$ sehwer. Trinkmenge $800 \mathrm{~g}$, Blutwassergehalt $81,3 \%$. Am 2. III. (Nachuntersuchung) $5800 \mathrm{~g}$ Gewicht bei Allaitement mixte, $830 \mathrm{~g}$ Trinkmenge, Blutwassergehalt $80,6 \%$.

Wir finden also bei einem normalen, gut gedeihenden Brustkind niedrige Anfangswerte im Blutwassergehalte entsprechend den bei anderen Kindern gefundenen Zahlen. Dieselben steigen bis zum Alter von 8 Wochen kontinuierlich an, von 74,9 bis 81,4 , also um $6,5 \%$. Von da ab bleibt der Blutwassergehalt leicht abfallend. Die Trinkmengen steigen genau bis zu demselben Termin an und bleiben von da konstant. Wir finden weiters, daß auch in diesem Falle die Trinkmengen nicht sonderlich groß sind und im ersten Quartal durehschnittlich 1/s des Körpergewichtes (gegenüber $1 / 5$ der Norm) betragen, und daß auch die Zahlen für den prozentualen Wassergehalt des Blutes hinter den Durchschnittszahlen von Lust und den anderen von mir gefundenen Werten etwas zurückbleiben. Es ergibt sich also auch in diesem Falle ein direkter Zusammenhang zwischen der Zunahme des 
Wassergehaltes im Blut unmittelbar nach der Geburt und der Trinkmenge.

J. St. wurde am 25. II. 1913 geboren und am 10. III. mit einem Gewicht von $2770 \mathrm{~g}$ als Ammenkind aufgenommen. Es wurde täglich sechsmal an die Brust gelegt und gedieh ausgezeichnet. Körperlich vollkommen normaler Befund. Stuhl immer in Ordnung. Prozentualer Blutwassergehalt am 1. Tage nach der Aufnahme $76,6 \%$, Trinkmenge $460 \mathrm{~g}$. 8 Tage später Gewicht $3100 \mathrm{~g}$, Trinkmenge $500 \mathrm{~g}$,

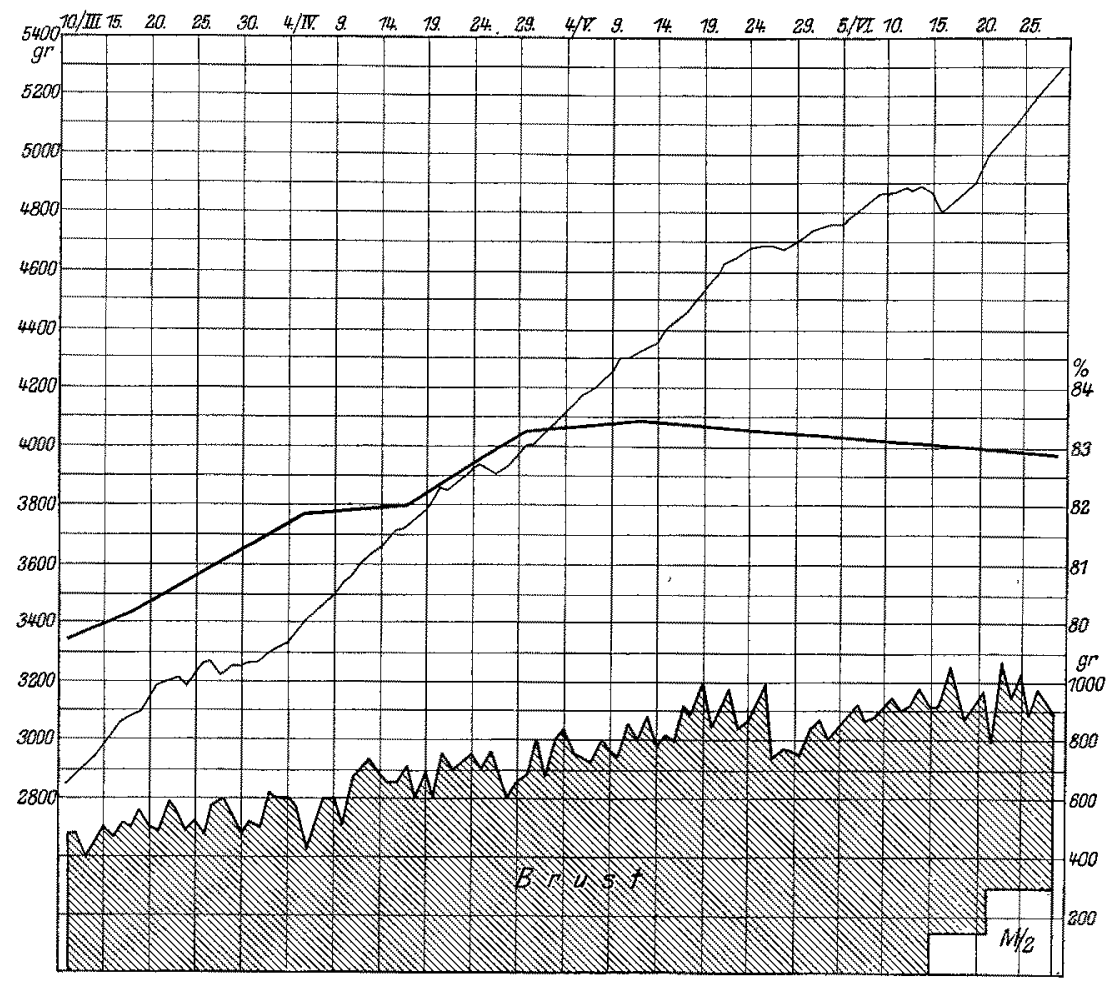

Fig. 4.1)

Wassergehalt des Blutes 77,6\%. Am 6. IV. $3340 \mathrm{~g}$ schwer, Trinkmenge $600 \mathrm{~g}$, Wassergehalt des Blutes 80,7\%. Am 15. IV. $3610 \mathrm{~g}$, Trinkmenge $610 \mathrm{~g}$, Blutwassergehalt $80,9 \%$. Am 29. IV. $3900 \mathrm{~g}$ Gewicht, Trinkmenge $780 \mathrm{~g}$, Blutwassergehalt 83,5\%. Am 11. V. $4200 \mathrm{~g}$ schwer, Trinkmenge 800 bis $900 \mathrm{~g}$, Blutwassergehalt $83,9 \%$. Am 5. VI. $4760 \mathrm{~g}$ sohwer, Trinkmenge 800 bis $900 \mathrm{~g}$, Blutwassergehalt 83,2\%. Am 25. VI. (Tag der Entlassung) $5170 \mathrm{~g}$ Gewicht, Trinkmenge 800 bis $900 \mathrm{~g}$, Blutwassergehalt $82,9 \%$ \%

1) In dieser Figur sind, um die Zeichnung nicht zu hoch erscheinen $\mathrm{zu}$ lassen, die Ordinatenabstände für das Körpergewieht um die Hälfte verkürzt. 
Wir sehen also auch béi diesem vollkommen normal gedeihenden Brustkind (Fig. 4) im Alter von 11 Tagen einen niedrigen Blutwassergehalt, der vollkommen den bei den anderen Kindern gefundenen Werten entspricht. Das Kind entwickelt sich bei Brust vollständig normal, zeigt die charakteristische steile, nur von wenigen Schwankungen unterbrochene Gewichtszunahme und auch das normale Verhaiten der Trinkmenge, nämlich rasehes Ansteigen bis ungefähr zur Mitte des 3. Monates. Von da ab bleiben die Trinkmengen mit geringen Schwankungen gleich groß. Der Blutwassergehalt steigt genau bis zu diesem Termin rapid an, im ganzen um 6,3\% vom 11. Tage an. (Dazu muß natürlich noch die gewiß sehr beträchtliche Zunahme in den ersten 11 Lebenstagen gerechnet werden, die aber, da das Kind erst am 11. Tage aufgenommen wurde, nicht berechenbar ist.) Von diesem Tage $a b$ zeigt die Kurve des prozentualen Wassergehaltes einen ganz flachen Abfall - die physiologische Austrocknung hat begonnen. Ich möchte diesen Fall, sowohl was die Trinkmenge als was den höchsten Wert des erreichten Blutwassergehaltes betrifft, da derselbe genau mit den Durchschnittszahlen übereinstimmt, als den Normalfall hinstellen.

Ich muß in diesem Zusammenhang noch einmal auf den im vorigen Kapitel zitierten, unter Fig. 2 dargestellten Fall R. St. zurückkommen, der ein frühgeborenes Kind von $1500 \mathrm{~g}$ Anfangsgewicht betraf, das nach physiologischer Abnahme bei Brust gut gedieh und dann durch ungefähr $2 \frac{1}{2}$ Monate in Beobachtung stand. Wie aus der Figur erhellt, zeigte die Gewichtszunahme einen fast geradlinigen Verlauf mit einer durchschnittlichen täglichen Zunahme von $20 \mathrm{~g}$, also weniger als normal. Die Trinkmengen dagegen zeigten, nachdem sie anfangs wegen großer Schwäche und Appetitlosigkeit des Kindes unter der Norm geblieben waren, dann eine rapide Zunahme und erreichten noch vor Vollendung des ersten Lebensmonates ungefähr $500 \mathrm{~g}$, so daß das Kind z. B. am 19. III. bei einem Körpergewicht von $1770 \mathrm{~g} 520 \mathrm{~g}$ Brustmilch, also nahezu 1/3 seines Körpergewichtes trank, was einem Energiequotienten von ungefähr 200 entspricht (dabei nur tägliche Zunahme von $20 \mathrm{~g}$ !). Betrachten wir nun in diesem Falle die Zunahme des prozentualen Wassergehaltes, so sehen wir, daß er in der Zeit der Beobachtung von 71,8 auf $82,5 \%$, das ist also um $10,7 \%$ (!) zugenommen hat. Dieses Verhalten drückt sich auch in der Figur sehr deutlich aus, in der Weíse, daß die Kurve der Trinkmengen gleichzeitig mit der Wassergehaltskurve sehr stark ansteigt und daß letztere die Gewichtskurve überkreuzt. Es ergibt sich also auch in diesem Falle ein direkter und quanti 
tativer Zusammenhang zwischen der Trinkmenge und der Zunahme im Blutwassergehalt unabhängig von der Körpergewichtszunahme.

Dieses Gesetz finden wir in anderer Form bei Ca merer sen. bestätigt. Camerer konnte nämlich einen direkten Zusammenhang zwischen der Trinkmenge und der Perspiratio insensibilis entdecken, indem bei einem normalen Brustkind auffallend große Trinkmengen, auffallend große Schwankungen in denselben und gleichzeitig auch ganz entsprechende Schwankungen in der Perspiratio insensibilis gefunden wurden. Um nicht viel Worte zu verlieren, gebe ich die Ca mererschen Zahlen wieder.

$\begin{array}{cccccc}\text { Lebenstage } & \text { Milchmenge } & \text { Perspir. insens. } & \text { Lebenstage } & \text { Milchmenge } & \text { Perspir. insens. } \\ 1 & - & - & 15 & 460 & 105 \\ 2 & 160 & 82 & 16 & 470 & 114 \\ 3 & 310 & 114 & 17 & 505 & 108 \\ 4 & 345 & 114 & 18 & 540 & 111 \\ 5 & 425 & 103 & 19 & 500 & 120 \\ 6 & 450 & 176 & 20 & 565 & 153 \\ 7 & 560 & 126 & 21 & 545 & 162 \\ 8 & 610 & 147 & 22 & 620 & 149 \\ 9 & 475 & 110 & 23 & 585 & 142 \\ 10 & 580 & 130 & 24 & 465 & 144 \\ 11 & 565 & 155 & 25 & 545 & 123 \\ 12 & 525 & 133 & 26 & 475 & 127 \\ 13 & 500 & 133 & 27 & 645 & 122 \\ 14 & 505 & 127 & 28 & 595 & 104\end{array}$

Naoh den im Vorstehenden geschilderten Untersuchungen lassen sich also die beiden ersten der drei oben aufgeworfenen Fragen leicht beantworten. Die Kurve der physiologischen Austrocknung erleidet nach der Geburt eine jähe Unterbrechung. Der Blutwassergehalt des neugeborenen Kindes nimmt von der Geburt bis ungefähr zur Mitte des 3 . Monates um 6 bis $10 \%$ zu. Diese Zunahme steht in unmittelbarem und direktem $\mathrm{Zu}$ sammenhang mit der Menge der aufgenommenen Brustmilch. Von der Mitte des 3. Monates an beginnt die langsame physiologische A us trocknung, während die Trinkmengen bekanntlich von diesem Zeitpunkt ungefähr gleich bleiben.- Es erübrigt also noch, die dritte Frage, welche Bedeutung dieses Verhalten hat, zu entscheiden.

Wir wissen, daß das Neugeborene mit einer Reihe von kongenitalen Depots (z. B. N, Fe) auf die Welt kommt, die es in den Stand setzen, während der ersten Zeit der Säuglingsperiode mit einer Nahrung, die 
im wesentlichen wasser- und fetthaltig ist, nicht nur sein Auslangen zu finden, sondern auch Substanz anzusetzen und zu wachsen. Da das Fett vorwiegend zur Bestreitung der Wärmeökonomie dient, so müssen wir in diesem Falle dem in der Frauenmilch vorhandenen reichlichen Wassergehalt (bei relativer Salzarmut) eine wesentliche Bedeutung zuschreiben. Erinnern wir uns z. B., welche Rolle der Turgor beim Säugling spielt, erinnern wir uns daran, daß die Haut und das Unterhautbindegewebe des Neugeborenen sich nicht so derb und prall anfühlen wie beim ungefähr 2 Monate alten, gesunden Brustkind, wie von Reuss neuerdings betont hat, und daß dieser Turgor im wesentlichen eine Funktion des Wassergehaltes der betreffenden, vor allem zum Wasserstoffwechsel in Beziehung stehenden Organe ist, so werden wir unschwer die Bedeutung dieser starken Wasseranreicherung unmittelbar nach der Geburt erkennen. Wir werden ferner eine Zweckmäßigkeitserscheinung darin erblicken können, wenn intrauterin, wo so viele Depots für das spätere extrauterine Leben angelegt werden, gerade an. Wasser kein Vorrat aufgestapelt wird, da ja die Zusammensetzung der normalen Brustnahrung es dem Kinde leicht ermöglicht, diesen wichtigen Bestandteil des Organismus unmittelbar nach der Geburt zu ergänzen. In diesem Zusammenhang sei nun noch einmal darauf hingewiesen, daß diese Wasseraufnahme aus einer salzarmen Nahrung, ja wie wir oben gesehen haben, aus vollständig salz- und zuckerfreiem Wasser (Saccharintee) erfolgt, also nicht auf osmotischem Wege vor sich gehen kann, sondern augenseheinlich durch eine Quellung der in Betracht kommenden Gewebe (Bindegewebe und Muskulatur) zustandekommt, daß somit diese physiologische Wasseranreicherung beim gesunden Brustkind unmittelbar nach der Geburt auf dieselbe Weise erfolgt, wie wir sie im experimentellen Teil dieser Arbeit bei der pathologischen Wasseranreicherung der Versuchstiere gesehen haben. Im Verfolge dieses Gedankens aber sehen wir in dieser Wasseraufnahme nach der Geburt einen weiteren ZweckmäBigkeitsvorgang für das Wachstum des Kindes. Friedenthal schreibt: „Die Zuwachskurve des Menschen gleicht, wenn man die allerersten Stadien des Lebens unberücksichtigt läßt, einer Parabel. Dabei nimmt das spezifische Gewicht wachsender Teile im Laufe des Wachstums und der Entwicklung in nicht geringem Grade zu, während in den allerersten Entwicklungsstadien durch reichliche Wasseraufnahme ein sehr schnelles Sinken des spezifischen Gewichtes bei denjenigen Lebewesen zu konstatieren ist, die durch Anhäufung von Reservestoffen für ein beschleunigtes Wachstum am Lebensbeginn Sorge ge- 
tragen haben." Am Menschen haben wir nun ein solches Lebewesen vor uns, das zu Beginn seines Lebens ein sehr schnelles Wachstum zeigt (wächst doch der Säugling am raschesten im ersten Lebensquartal), und dessen spezifisches Gewicht durch reichliche Wasseraufnahme gerade zu dieser Periode stark erniedrigt wird. Rosenstern bemerkt ganz richtig, ,daß nach Erfahrungen der Tier- und besonders der Pflanzenphysiologie überall da, wo Wachstum stattfindet, ein hoher Wassergehalt anzutreffen ist, daß ein gewisser Grad von Quellung. Voraussetzung für normales Wachstum darstellt." Wie nahe die Beziehungen von Wachstum und Quellung sind, zeigen besonders schön die schon oben zitierten Versuche ron Boxowikow an Pflanzenkeimlingen, der bewiesen hat, daß die Wachstumsgeschwindigkeit durch Säuren beeinflußt wird, und zwar in genau derselben Reihenfolge der Anionen angeordnet, wie sie bei der Quellung der Kolloide bekannt ist.

Die dritte Frage wäre daher etwa folgendermaßen zu beantworten. Der niedrige Wassergehalt des Neugeborenen ist teleologisch zweckmäßig, weil dadurch die Anlage eines kongenitalen Depots für Wasser, das extrauterin leicht beschafft werden kann, erspart wird. Die Aufnahme des Wassers in den ersten zwei bis drei Monaten nach der Geburt geschieht nicht allein auf osmotischem Wege, sondern vorwiegend durch Quellung. Dies ermöglicht eine Erhöhung des Wassergehaltes des Bindegewebes und der Muskeln, somit die Herstellung des für das normale Brustkind charakteristischen guten Turgors (und vielleicht auch des Tonus der Muskulatur). Diese Quellung ist ferner unumgänglich notwendig fur das besonders rasche Wachstum im ersten Lebensquartal.

\section{Die Bedeutung des Wassers für die Pathologie chronischer Ernährungsstörungen.}

Den eingangs aufgestellten Fragen folgend, soll nun untersucht werden, welche chronischen Ernährungsstörungen Beziehungen zum Wasserstoffwechsel haben, und zwar soll nur eine etwaige Anreicherung an Wasser dem Rahmen der vorliegenden Arbeit eingefügt werden. Es ergibt sich nun eine große methodische Schwierigkeit in der Auswahl des zur Untersuchung verwendeten Materials. Wie leicht verständlich, sind in einem Krankenhaus, auch wenn es über reichliches Material verfügt, nicht immer Kinder ausfindig zu machen, 
die an chronischen Ernährungsstörungen leiden, deren Krankheit aber durch keinen anderen Faktor, der imstande ist, den Wassergehalt des Körpers resp. des Blutes zu beeinflussen, kompliziert ist. Da aber Wert darauf gelegt wurde, die betreffenden Untersuchungen nicht nur an einem Kind allein, sondern an vielen Kindern und dies in wiederholten Bestimmungen an demselben Individuum vorzunehmen, so bedurfte es mehr als zweijähriger Arbeit, bevor das entsprechende Material gesammelt war.

Bevor ich also daran gehe, die Untersuchungsresultate bei chronisch ernährungsgestörten Kindern zu besprechen, müssen erst jene Umstände erwähnt werden, welche imstande sind, den Wassergehalt des Blutes vorübergehend oder dauernd zu erhöhen oder zu erniedrigen oder - mit anderen Worten - welche Kinder, wenn anders man gültige Schlüsse auf den Zusammenhang zwischen Wassergehalt des Blutes und chronischer Ernährungsstörung ziehen will, von diesbezüglichen Untersuchungen ausgeschlossen werden müssen. $\mathrm{Zu}$ diesen ich möchte beinahe sagen - Versuchsfehlern gehören 1. die akute Ernährungsstörung, 2. die Reparation nach solcher, und 3. das Fieber.

1. Umstände, welche die Untersuchung stören.

a) Akute Ernährungsstörung.

Der Wasserverlust bei akuter Ernährungsstörung wurde von allen Autoren, gleichgültig, mit welcher Methode sie arbeiteten, gefunden. Reiss fand ihn bei seinen refraktometrischen Versuchen, Berend und Tezner durch Bestimmung der Viscosität des Blutes, Salge konnte ihn durch Bestimmung des osmotischen Druckes und der Leitfähigkeit nachweisen. Neuestens haben Weill und Gardère durch viscosimetrische Bestimmungen die Befunde bestätigt. Tobler hat den Versuch gemacht, das Wesen der akuten Ernährungsstörungen im Tierexperiment nachzuahmen und hat vor allem dabei den Mineralstoffwechsel studiert. Schon der leichteste Grad des Gewichtssturzes, der "Konzentrationsverlust", um bei Toblers Nomenklatur zu bleiben, ist durch Wasserverlust gekennzeichnet. Um so mehr die nächsten Stadien des ,Reduktionsverlustes" mit gleichzeitig erfolgender Ausschwemmung von Salzen, und des, „Destruktionsverlustes“ mit weitgehender Gewebszerstörung. Im Stoffwechselversuch wurde der Wasserund Salzverlust von Meyer festgestellt. Auch Lust konnte durch direkte Wasserbestimmung im Blut bei akuten Ernährungsstörungen leichtere und schwerere Grade des Wasserverlustes nachweisen. 
L. E., 21/2 Monate alt (Fig. 5), ist schon seit einiger Zeit auf der Abteilung und gedeiht leidlich bei Drittelmilch und Schleim. Am 25. XI. 1912 erkrankten gleichzeitig (offenbar infolge von Milchverderbnis) mehrere Kinder der Station an leichter Emährungsstörung. Auch dieses Kind bekam vermehrte schleimige Stühle und erlitt, da der Sache anfänglich keine Bedeutung beigemessen und die Nahrung nicht restringiert wurde, einen allmählichen Gewichtsverlust von ungefähr $300 \mathrm{~g}$. Nach kurzem Hungern und Umsetzen auf Eiweißmilch wurde die Störung sofort behoben und das Kind erholte sich sehr gut. Der Wassergehalt nahm im Verlaufe des absteigenden Teiles der Gewichtskurve um beinahe $2 \%$ ab und dann in der Reparation um ebensoviel zu.

Bei leichter Ernährungsstörung schon findet also eine deutliche Eindickung des Blutes statt und es wäre fehlerhaft, wollte man eine allenfalls bestehende chronische Ernährungsstörung an diesem Kinde studieren, den Wassergehalt seines Blutes in der

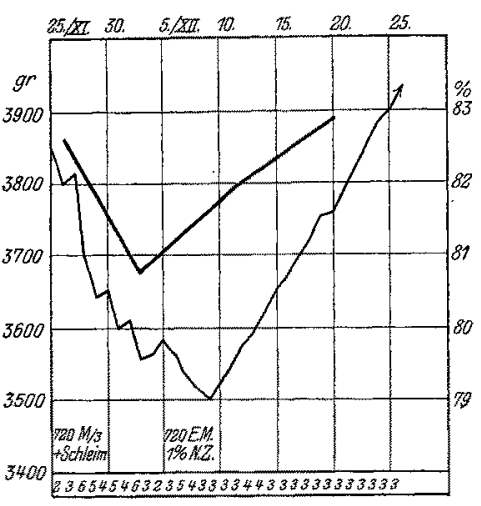

Fig. 5. Zeit der akuten Emährungsstörung za untersuchen. Da dieser Wasserverlust während akuter Ernährungsstörung bei zahlreichen Fällen von mir festgestellt wurde und mit den von anderen Autoren gefundenen Resultaten übereinstimmt, unterlasse ich die Beschreibung weiterer Fälle.

\section{b) Reparation.}

Nahezu von allen Autoren, welche das Verhalten des Blutwassers bei akuten Ernährungsstörungen studierten, wurden natürlich auch die entsprechenden Vorgänge bei der Reparation berücksichtigt, und im allgemeinen herrscht die Ansicht vor, daß während der Reparation zunächst ein Teil des verloren gegangenen Wassers ersetzt wird, während der Ersatz der anderen in Verlust geratenen Körperstoffe erst später erfolgt. Wieso diese rasche Aufnahme von Wasser zustande kommt, darin allerdings ist man sich nicht einig. Schon von Keller wurde auf die verschiedene Art der Reparation bei Brust und bei künstlichen Nährgemischen hingewiesen. Während sich bei Frauenmilch die Reparation langsam vollzieht, und die Kinder mitunter wochenlang im Gewichte stillstehen, setzt bei kohlehydratreichen Gemischen der Gewichtsanstieg sofort ein. Zu denselben Resultaten kommt Freund auf Grund von Stoffwechselversuchen. Um diesen Widerspruch auf- 
zuklären, greift Freund zu der Hypothese, daß bei den an der Brust sich erholenden Kindern Körperfett abgegeben wird, für das Wasser nur in geringem Maße eintritt, während bei den Kindern, die sich rasch erholen, mit dem Wasseransatz gleichzeitig ein Ansatz anderer Körpersubstanzen stattfindet. Anschließend an diese Untersuchungen Freunds konstatiert Meyer, daß die Größe der Zunahme bei den in Reparation sich befindenden Kindern in umgekehrtem Verhältnisse zur Menge des Harnwassers steht, daß dagegen die Cl-Bilanzen dem nicht immer parallel gehen, und kommt daher auf Grund dieser Untersuchungen zu der schon einmal zitierten Anschauung, daß möglicherweise der Organismus ,aưch ohne entsprechende Veränderung im Salz-

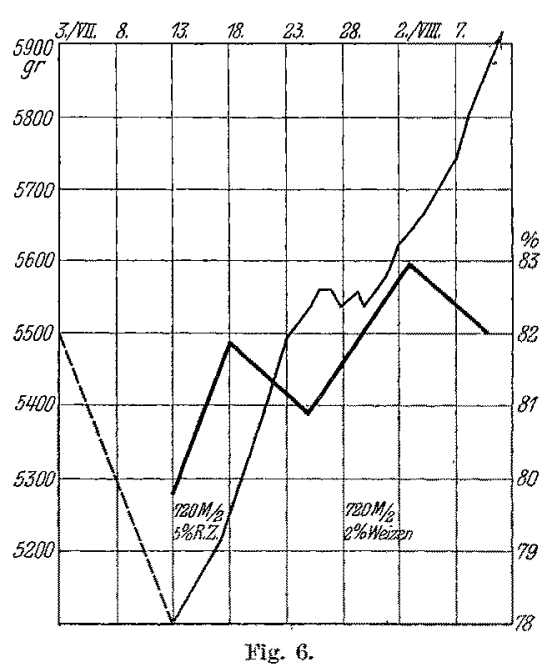

Hig. 6. bestande wasserärmer und -reicher werden kann". Koeppe glaubt, daß es sich bei dieser Wasseraufnahme nicht um eine Wasserretention sensu strictiori handelt, sondern spricht von einer Restitution des verloren gegangenen Wassers, mit dem gleichzeitig auch Salze retiniert werden. Doch ist auch er der Ansicht, daß Salz- und Wasserstoffwechsel im Organismus getrennte Wege gehen.

Mit der von mir angewendeten Methodik untersucht, stellt Fig. 5 einen typischen Fall dar. Der Abnahme des Blutwassergehaltes während des absteigenden Teiles der Gewichtskurve folgt die Zunahme während des aufsteigenden Kurvenschenkels. Und zwar ist die Zunahme um ein geringes größer als die Abnahme, so daß die Vermutung naheliegt, daß diese Wasserretention bei Reparation gleichsam etwas über das Ziel hinausschießt. Fig. 6 stellt einen zweiten Fall von Reparation dar.

Th. P., 14 Wochen alt, war bis vor 4 Wochen an der Brust, wurde dann auf Halbmilch und Grießbrei ablactiert und ist seit 8 Tagen krank. Wieçerholtes Erbrechen, täglich 5 bis 6 grünliche übelriechende Stühle. Einige Tage vor der Aufnahme wurde das Kind in der Ambulanz gewogen und zeigte ein Gewicht von $5500 \mathrm{~g}$. Da sich bei ambulatorischer Behandlung der Zustand nicht besserte, wurde es am 13. VII. 1912 mit einem Cewicht von $5100 \mathrm{~g}$ und einer Körperlänge von $63 \mathrm{~cm}$ aufgenommen. Die Bauchdeckenspannung war mäßig, Herzaktion etwas 
beschleunigt, Turgor leioht herabgesetzt. Temperatur 38,2. Sonst normaler Befund. Nach 12stündiger Teediat wurde es auf Halbmilch mit $5 \%$ Rohrzucker gesetzt, dabei gute Zunahme um mehr als $400 \mathrm{~g}$ in 15 Tagen, dann Gewichtsstillstand. Daranf wird der Nahrung $2 \%$ Weizenmehl zugegeben, dabei weiter tadellose Zunahme um $350 \mathrm{~g}$ in 2 Wochen.

Wir haben also eine akute Dyspepsie vor uns, die vom Tage der Aufnahme an bei einer keineswegs sehr kohlehydratreichen Milchmischung in gute Reparation übergeht. Der Blutwassergehalt, der am Tage der Aufnahme 79,8\% betragen hatte, schnellt im Laufe der ersten 5 Tage auf 81,9 , also um mehr als $2 \%$ hinauf.

Nun zeigt diese Kurve eine Eigentümlichkeit, die bei vielen anderen ähnlichen Beispielen gefunden wurde und die eine Besprechung verdient. Schon Lust hat darauf aufmerksam gemacht, daß bei der Reparation der Organismus zunächst seinen Wassergehalt zu regenerieren sucht. Nun notiert dieser Autor das merkwürdige Vorkommnis, daß dann trotz gleichbleibendem Anstieg der Gewichtskurve die Wasserkurve noch einmal sinkt, um dann später wieder anzusteigen, und erklärt das damit, daß das aufgenommene Retentionswasser zunächst an die Gewebe abgegeben wird und erst dann, wenn sich diese mit Wasser gesättigt haben, das Blut seinerseits Wasser zurückbehält, bis es seine Konzentration erreicht hat. Ein äbnliches, wenn auch nicht dasselbe Verhalten, zeigt Fig. 6. Nach dem ersten steilen Anstieg der Gewichtskurve und rascher Regeneration des Blutwassers sinkt der Wassergehalt des Blutes wieder ab und steigt erst dann, nachdem nach vorübergehendem Gewichtsstillstand (1) der Nahrung Mehl zugefügt wurde. Dann aber sinkt der Blutwassergehalt neuerdings auch bei weiter flott ansteigendem Körpergewicht. Doch möchte ich diesem Verhalten eine etwas andere Deutung geben als Lust. Nach dieser relativ leichten Dyspepsie stellt sich bei einer Nahrung, die unter dem Erhaltungsbedaxf liegt (Energiequotient ungefähr 70) zunächst der Wassergehalt zur Norm ein. Nachdem dies erreicht ist, tritt Gewichtsstillstand ein, während sich im Wassergehalt eine Senkung (physiologische Austrocknung + Inanition) bemerkbar macht. Auf Zulage von Kohlehydrat, die immer zu einer Hydrämie führt, tritt neuerlich eine Steigerung des Gewichts und des Blutwassergehaltes ein. Während aber das Gewicht bei einem Energiequotienten von jetzt mehr als 80 weitersteigt, tritt neuerdings als Ausdruck der physiologischen Austrocknung eine Senkung im Blutwassergehalt auf. Derartige Kurven konnte ich wiederholt beobàchten. 
Auf ein weiteres merkwürdiges Verhalten des Blutwassers während der Reparation wurde seinerzeit schon von Reiss hingewiesen. Reiss konnte zeigen, daß während der Reparation, wenn die Wasserverluste aufhören, auch wenn die Stühle noch schlecht sind, wieder eine Blutverdünnung eintritt. Ich kann diese Ansicht bestätigen und in folgender Weise ergänzen. Diese Regeneration des Blutwassers

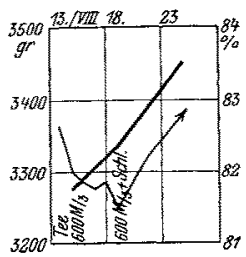

Fig. 7. tritt nicht nur ein, wenn die Stühle noch schlecht sind, sondern sogar noch während des abfallenden Teiles der Gewichtskurve, so dab man aus der Zunahme des Wassergehaltes im Blut trotz noch vorhandener Gewichtsabnahme die Prognose auf baldige Reparation stellen kann. Ein Beispiel dieses Verhaltens gibt Fig. 7.

F. A., 2 Monate alt, wird wegen akuter Dyspepsie aufgenommen. Wegen stark saurer Stühle 12 Stunden Tee und dann $600 \mathrm{~g}$ Drittelmilch ohne Kohlehydratzusatz. Dabei noch 5 Tage Gewichtsabnahme, hierauf Besserung der Stühle und nach Zusatz von Schleim gute Zunahme.

Der Wassergehalt beträgt am Tage nach der Aufnabme 81,7\%. 4 Tage später, auf dem Tiefpunkt der Gewichtskurve, ist er um $0,6 \%$ höher. Auf Zulage von Schleim steigt er bei gutem Gewichtsansatz um weitere 1,2\%. Die Reparation hat sich also in diesem Falle noch während des Gewichtsabfalles in einer Erhöhung des Blutwassergehaltes angekündigt.

Diese Fälle sollen uns also zeigen, welchen Schwankungen der Blutwassergehalt während der Zeit der Reparation nach akuter Ernährungsstörung unterworfen ist.

c) Fieber.

Wie leicht aber der Wassergehalt des Blutes beeinfluBbar ist, und wie vorsichtig man daher mit der Auswahl des Materials sein muB, wenn man Schlüsse auf den sonstigen Wassergehalt des Blutes und des Körpers ziehen will, zeigt am besten das Verhalten im Fieber. Koeppe findet, „, bei ernährungsgesunden Säuglingen mit 1 bis 10 tägigem Fieber bis $40^{\circ}$ eine Gewichtszunahme, wenn während des Fiebers keine Durchfälle auftreten, und die Nahrungs- und Flüssigkeitsaufnahme nicht gegen früher vermindert war." (Im Original gesperrt.) Dagegen glaubt Monti, der mit der spezifischen Gewichtsbestimmung nach Hammerschlag arbeitet, bei Pneumonie, Typhus, Pleuritis, Meningitis, wenn sie mit Fieber verlaufen, eine Erhöhung der Blutdichte für gesetzmäßig halten zu sollen. Schwenkenbecher und 
Inagaki finden im Verlaufe zahlreicher Fieberkrankheiten (Sepsis, Typhus, akute Tuberkulose) immer eine Wasseranreicherung der Gewebe, deren Ursache sie in erster Linie der Kachexie zuschreiben. Sandelowsky, der bei Pneumonie immer eine Wasser- und Kochsalzretention findet, schreibt dieser reichlichen Wasseraufnahme während des fieberhaften Prozesses eine wärmeregulatorische Bedeutung zu, welche, nach Tierversuchen zu schließen, eine gesteigerte Wärmeabgabe durch SchweiBbildung und Wasserverdunstung ermöglicht. Grawitz hält ebenfalls eine Wasseranreicherung des Blutes beim Fieber für erwiesen und erklärt sie in geistvoller Weise dahin, daß während des Fiebers eine Blutdrucksenkung eintritt, welche eine Aspiration von Wasser aus den Geweben in die Blutbahn bewirkt. Wie hochgradig diese ,Hydrämie“ sein kann, beziehungsweise zu welchen Fehlschlüssen sie bei Beurteilung des sonstigen Wassergehaltes des Blutes führen kann, beweist am besten der Umstand, daß selbst die hochgradigen Wasserverluste, wie sie bei schweren akuten Dyspepsien, selbst bei alimentären Intoxikationen zustande kommen, durch diese Wasseranreicherung im Verlauf von fieberhaften Prozessen kaschiert werden können. Lust z. B. beschreibt ein Kind, das während einer schweren akuten Dyspepsie nahezu $700 \mathrm{~g}$ abnahm und dabei eher zu-

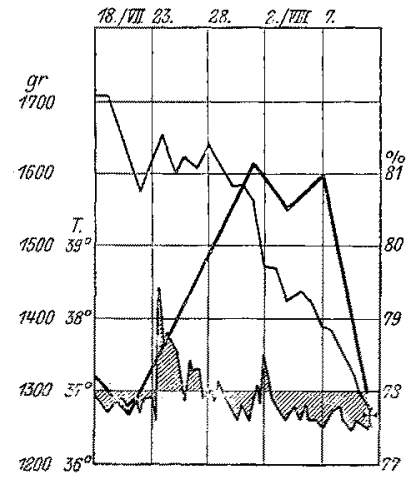

Fig. 8. nehmenden Wassergehalt seines Blutes zeigte. Das Kind litt aber gleichzeitig an Furunculose. In einem zweiten Fall aus der eben genannten Publikation hat der Wassergehalt des Blutes trotz rapider Gewichtsabnahme sogar bedeutend zugenommen; das Kind starb und die Obduktion ergab eine diffuse Pneumonie.

Ich hatte wiederholt Gelegenheit, bei fiebernden Kindern Blutwasserbestimmungen $\mathrm{zu}$ machen und gebe zur Illustration dieses Verhaltens aus der großen Reihe der Untersuchungen nur zwei wieder, ein Kind mit Pneumonie und ein zweites mit einer Phlegmone.

B. St. (Fig. 8), 5 Wochen alt, ist eine Frühgeburt, die "seit Geburt" abnehmen, wiederholt des Tages erbrechen und sehr häufige und schlechte Stühle haben soll. Das Kind wird mit einem Gewicht von $1700 \mathrm{~g}$ im Zustande schwerer Atrophie aufgenommen. Miserabler Turgor, schlaffe Muskulatur, sehr schlecht entwickeltes Fettpolster. Blaßgraues Hautkolorit, blasse Schleimhäute. Innerer Befund normal, Temperatur unter $37^{\circ}$. Im Laufe der Beobachtung bei Eiweil- 
milch kontinuierlich absinkendes Gewicht, unaufhörliches Erbrechen, zahlreiche schlechte, durch keine Medikation zu bessernde Stüble. Im Laufe von 24 Tagen progrediente Gewichtsabnahme um mehr als $400 \mathrm{~g}$, so daß das Kind vor dem Exitus das Bild zußerster Macies bietet.

Am Tage der Aufnahme wurde eine Blutwasserbestimmung gemacht und ergab einen sehr niedrigen Wert von 78,3\%. 3 Tage später (das Gewicht hatte inzwischen um $140 \mathrm{~g}$ abgenommen) war auch der Blutwassergehalt um $0,6 \%$ gesunken. Wenige Tage später begann das Kind bis über $38^{\circ}$ zu fiebern; als Ursache der Temperaturerhöhung wurde eine Pneumonie der Lingula und des linken Unterlappens konstatiert, die sich im Laufe der nächsten Tage auch auf den rechten Unterlappen erstreckte. Eine jetzt vorgenommene Blutwasseruntersuchung ergab einen Wert von $81,2 \%$, also um $3,5 \%$ (!) höher als bei der letzten Bestimmung noch während der fieberlosen Zeit. Dieser hohe Wassergehalt hielt nach dem Resultat mehrerer Bestimmungen durch einige Tage an und sank erst unmittelbar vor dem Ende wieder ab.

Einen zweiten ähnlichen Fall gebe ich auszugsweise wieder.

M. K., 5 Wochen alt, wegen Atrophie und akuter Dyspepsie mit einem Gewicht von $2570 \mathrm{~g}$ aufgenommen. Das Kind ist stark heruntergekommen, zejgt elenden Turgor, schlaffe Muskulatur, nahezu fehlenden Panniculus adiposus. Die Hautdecken sind livid, die Herzaltion gut, Lungenbefund normal. Temperatur unter $37^{\circ}$.

Das Kind zeigt am Tage der Aufnahme einen Blutwassergehalt von $75,3 \%$. Es nahm im Laufe der nächsten zwei bis drei Wochen kontinuierlich ab, zeigte trotz Brusternährung schlechte Stühle und wiederholtes Erbrechen. Sein Körpergewicht betrug zur Zeit der letzten Untersuchung nur $2300 \mathrm{~g}$, also nahezu $300 \mathrm{~g}$ weniger als zu Beginn, sein Blutwassergehalt jedoch $79,3 \%$, also u $\mathrm{m} 4,0 \%$ (!) mehr als bej der ersten Untersuchung vor wenigen Tagen. Das Kind hatte zwei Tage nach der Aufnahme eine Phlegmone des linken Unterschenkels bekommen, welche durch mehr als zwei Wochen die Temperatur zwischen 38 und $39^{\circ}$ hielt.

Diese beiden Beispiele mögen an Stelle von zahreichen anderen genügen.

Es wird daher, falls man mit der angegebenen Methodik der wiederholten Blutwasseruntersuchung die Beziehungen z/wischen chronischer Ernährungsstörung und Wassergehalt des Blutes, beziehungsweise des Organismus suchen will, geboten sein, Kinder, die eben eine, wenn auch noch so leichte akute Ernährungsstörung durchmachen oder sich 
in Reparation von einer solchen befinden, ebenso Kinder mit Fieber aus irgendwelchen Ursachen, von diesbezüglichen Untersuchungen auszuschlieBen, oder falls aus diesem oder jenem Grunde die Untersuchung notwendig ist, das Resultat derselben in das Kalkül nicht einzubeziehen.

2. Die Úberernährung oder einseitige Ernährung mit Milch.

Ich wähle mit Absicht diese Bezeichnung und nicht den Ausclruck "Milchnährschaden", da ja nicht notwendigerweise aus der fehlerhaften Ernährung auch der Nährschaden folgen muB. Es soll hier derjenigen Säuglinge gedacht werden, die entweder zu lange Zeit ausschließlich mit Milch ernährt werden oder, - bei kürzerer Daner dieser Ernährung - deren tägliches Milchquantum das zulässige Maß überschreitet

Ich muß hier auf den ersten experimentellen Teil dieser Arbeit zurückkommen, in welchem gezeigt wurde, daß es gelingt, bei wachsenden Hunden die nach der Säugungsperiode ausschließlich mit großen Milchmengen eruährt wurden, eine Wasseranreicherung ihres Blutes, beziehungsweise ihres Körpers herbeizuführen oder die physiologische Austrocknung des Organismus aufzuhalten. Es ist nun die Frage: Gibt es solche Zustände auch in der menschlichen Säuglingspathologie?

Wie wir oben gesehen haben, erreicht der Wasssergehalt des Blutes beim normalen Brustkind - und nur dieses können wir als Vergleichsobjekt heranziehen - sein Maximum etwa um die Mitte des dritten Lcbensmonates und sinkt von da an langsam und konstant ab. In den Rahmen dieser Untersuchungen werden daher Sänglinge zu fallen haben, die entweder lange über dieses Alter hinaus ausschlieBlich mit Milch ernährt wurden, oder aber solche, die schon früher übergroße Milchmengen zu trinken bekommen haben. Um nun aber zu entscheiden, wo die Grenze des Pathologischen liegt, müßte eigentlich ein Normalwert aufgestellt werden. Lust, der im übrigen einen wesentlichen Einfluß der. Ernährung auf den Wassergehalt des Blutes nicht konstatieren konnte, glaubt füx natürlich genährte Kinder jenseits des 2. Monates einen Mittelwert von 81,9 , bei künstlich genährten ernährungsgesunden. Kindern Werte von 80,6 bis 83,0 als Normalwerte aufstellen zu sollen. Wie ich aber schon bei der Beschreibung normaler Brustkinder zeigen konnte, ergeben sich nicht unbeträchtliche indivi- 
duelle Verschiedenheiten, die vor allem von der täglichen Trinkmenge, vielleicht aber auch von vorläufig unbekannten konstitutionellen Momenten abhängig sind, individuelle Verschiedenheiten, die so weitreichend sind, daß - wie Salge sehr richtig hervorhebt - dieselbe fehlerhafte Ernährung bei dem einen Individuum zum Nährschaden, beim anderen aber zu keiner Schädigung führt. Man kann sich vorstellen, daß, abgesehen von den eben zitierten Unterschieden, in Konstitution und Ernährungsart, doch vielleicht auch Verschiedenheiten der kongenitalen Depots eine Rolle spielen, welche das eine Kind in den Stand setzen, seine Ernährungsfunktion, seine Wärmeökonomie und sein Wachstum auch mit einer fehlerhaften Nahrung zu bestreiten, während ein anderes Individuum dabei Einbußen erleidet, die eben zum Nährschaden führen.

Es wird also nach dem Gesagten kaum angängig sein, einen Mittelwert aufzustellen, sondern wird sich als notwendig erweisen, jedes Individuum für sich zu betrachten. Da ist es nun wieder eine Forderung, jedes Kind oft zu untersuchen und aus seinem Verhalten wird es, wie wir sehen werden, möglich sein, zu konstatieren, ob es sich der Norm - die wir ja genau kennen - entsprechend verhält, das heißt, ob der Wassergehalt seines Blutes, abgesehen natürlich von den oben zitierten Fehlerquellen, jenseits der Mitte des dritten Lebensmonates langsam und konstant abnimínt, während sein Körpergewicht die normale Zunahme zeigt, oder ob sich Abweichungen von diesem Verhalten, welches uns als normal zu gelten hat, nachweisen lassen.

Nun wäre es natürlich wünschenswert, abgesehen von diesen nur durch wochenlang dauernde Untersuchungen zu erhaltenden Resultaten, einen Anhaltspunkt dafür zu haben, ob ein Säugling, den man mit einer auf Milchüberernährung lautenden Anamnese zur Untersuchung bekommt, tatsächlich ein pathologisches Verhalten seines Blutwassergehaltes zeigt, und wenigstens im groben eine obere Grenze des Normalen aufzustellen. Wir haben gesehen, daß Lust als höchste Zahl bei ernährungsgesunden, künstlich genährten Kindern $83 \%$, bei natürlich genährten etwas darunter gefunden hat. Auch meine Zahlen bei gesunden, normal genährten Kindern, überschreiten selbst zur Zeit des Maximums des Blutwassergehaltes die Zahl 83 nicht oder nur wenig. Ich möchte daher wenigstens für die erste Untersuchung den Wert von $83 \%$ um die Mitte des dritten Lebensmonates als höchsten Wert des Normalen aufstellen. Wir werden sehen, daß die bei Milchüberernährung gefundenen Zahlen sämtlich darüber liegen, daß 
aber bei extremer Kohlehydratfütterung und noch mehr bei der sogenannten Anämie der Säuglinge exzessive Werte gefunden werden, die - auch in viel späteren Lebensepochen - weit über dieser Zahl liegen. Doch soll, wie gesagt, diese Zahl von $83 \%$ nur einen Anhaltspunkt für die erste oberflächliche Beurteilung eines solchen Falles geben; das Wesentliche wird immer sein, wie sich der Blutwassergehalt in Relation zum Körpergewicht und zur Ernährung bei längerer Beobachtung verhält,

Daß zu lange oder einseitige Überernährung mit Milch zu einer Vermehrung des Blut- oder Körperwassers führen kann, ist früher wohl angedeutet worden, in der Literatur aber meines Wissens nirgendwo exakt nachgewiesen worden. Czerny-Keller schreiben: „Würde eine Fettablagerung in den dazu prädestinierten Geweben die einzige Folge einer Überernährung sein, so brauchten wir derselben keine große Beachtung zu schenken. Dies ist aber zumeist nicht der Fall. Parallel mit dem Fettansatz entwickelt sich auch ein starker Wasseransatz im Organismus und überdies hypertrophieren mit dem Fettgewebe gleichzeitig die lymphoiden Organe." Früher schon und besonders in nenerer Zeit hat Czerny wiederholt darauf hingewiesen, welche Gefahren für die natürliche Immunität diese vermutete Wasseranreicherung hat; er stützt sich hierbei im wesentlichen auf die Untersuchungen Weigerts. Speziell für die Ausheilung einer bestehenden Tuberkulose ist jede Ernährung, welche eine Wasseranreicherung des Organismus vermittelt, von Schaden. DaB eine Ernährung, welche starken Wasseransatz vermeidet, tatsächlich günstig für die Abheilung einer Tuberkulose ist, habe ich vor einiger Zeit an 6 Fällen von Lungentuberkulose beim Säugling zeigen können. Lust hat zwar versucht, bei chronisch ernährungsgestörten Kindern Blutwasserbestimmungen zu verwerten. konnte aber keinerlei Einfluß der Ernährung auf den Wassergehalt des Blutes bei solchen Kindern entdecken.

Ich habe nun im experimentellen Teil dieser Arbeit gezeigt, daß sogar schon die einseitige Ernährung an der Brust über die normale Säuglingszeit hinaus die physiologische Austrocknung am Versuchstier aufhalten kann. Dieses Faktum läßt sich nun nicht leicht auf die menschliche Pathologie übertragen, da ja die Zeit der ,physiologischen“" Säugung großen Schwankungen unterworfen ist. Aus den oben genannten Gründen wird ein Kind, das noch mit 10 Monaten ausschließlich an der Brust trinkt, vielleicht noch sein Auslangen finden und dabei wachsen, während ein anderes Kind schon nach fünfmonatiger Brust- 
ernährung seine kongenitalen Depots erschöpft hat und mit der wasserund fettreichen, aber $\mathrm{N}$ - und salzarmen Frauenmilch (Eisenmangel) seinen Bedarf nicht mehr decken kann.

Nach den experimentellen Untersuchungen zu schließen, mußte es also Kinder geben, die, wenn sie zu lange ausschließlich an der Brust trinken, ein pathologisches Verhalten ihres Blutwassergehaltes zeigen. Dasselbe aber mußte bei Kindern in Erscheinung treten, welche entweder mit übergroßen Mengen Kuhmilch oder zu lange ausschließlich mit Kuhmilch ernährt wurden.

F. W., 7 Monate alt, Frühgeburt, wurde von der Geburt bis heute ausschließlich an der Brust genährt und bekam alle 2 bis 3 Stunden zu trinken. Die Amme verließ plötzlich das Haus, und da sich die Eltern keinen Rat wußten, brachten sie das Kind in das Krankenhaus. Hier wurde das Kind mit Rücksicht auf die vorliegenden Untersuchungen aufgenommen. - Es ist $54 \mathrm{~cm}$ lang, $4680 \mathrm{~g}$ schwer, ziemlich muskelkräftig, hat ein dickes Fettpolster, ist aber etwas ",pastös“. Es zeigt Zeichen florider Rachitis: Ausgedehnte Kraniotabes, starke Rosenkranzbildung, Perlschnurfinger. Die Halsdrüsen sind leieht gesehwollen. Die Milz überragt den Rippenbogen um ungefähr 1 Querfinger. Sonst somatisch vollständig normaler Befund. Keine Temperatursteigerung. Da das Kind nach der Aufnahme brüsk ablaktiert werden mußte, wurde es wegen der Rachitis zunächst auf Drittelmilch und Schleim gesetzt; nach wenigen Tagen, als sich zeigte, daß das Kind die Ablaktation gut vertrug, wurde der Schleim durch Weizenmehl ersetzt und außerdem eine Mahlzeit Griessuppe gegeben. Gesamtmenge $720 \mathrm{~g}$. Während der nun folgenden Tage nahm das Kind langsam und kontinuierlich $a b$, dabei bestand aber keinerlei Zeichen einer Ernährungsstörung. Die Stühle waren immer tadellos geformt, die Zahl 2 pro Tag niemals überschreitend. Niemals Erbrechen. Die Abnahme - im ganzen $540 \mathrm{~g}$ - dauerte bis zum 13. Tage und von diesem Tage an begann, ohne daß an der Ernahrung irgend etwas geändert worden wäre oder auch, daß sich eine Änderung im Befinden des Kindes (Appetit usw.) bemerkbar gemacht hätte, eine regelmäßige Zunahme.

Wir haben also ein frühgeborenes Kind vor uns, das 7 Monate ausschließlich bei Brust genährt wurde und eine schwere Rachitis akquirierte. Nach der brüsken Ablaktation und Umsetzen auf kleinere Nahrungsmengen, die seinem Alter entsprachen und vollständig gut vertragen wurden, nahm das Kind durch 13 Tage ab, und dann unvermittelt ohne Nahrungsänderung wieder normal zu. Welches sind nun die Ergebnisse der Wasserbestimmnng im Blut? Am Tag der Aufnahme betrug der Blutwassergehalt $84,2 \%$, überschritt also bei diesem 7 monatlichen Kind die oben für ein Kind von $21 / 2$ Monaten mit $83 \%$ aufgestellte Höchstzahl um ein Beträchtliches. Nach mehreren Tagen war der Blutwassergehalt nur ganz wenig um $0,03 \%$ gesunken. Nach einer Woche betrug er $83,8 \%$, am Tiefpunkt der Kurve $82,0 \%$. Von da ab 
blieb der Blutwassergehalt in dieser Höhe und hatte bei einer Nachuntersuchung nach einem Monat wieder ein wenig abgenommen. Der Fall zeigt also, daß bei einem frühgeborenen, bis zum 7 . Monate a usschließlich mit Brustmilch ernährten, rachitischen Kind der Blutwassergehalt nicht nur keine physiologische Austrocknung zeigt, sondexn sogar erhöht ist. Nach Uberführen auf eine rationelle Diät sinkt der Blutwassergehalt um mehr als $2 \%$ und bleibt dann bei guter körperlicher Entwicklung leicht abfallend. Der

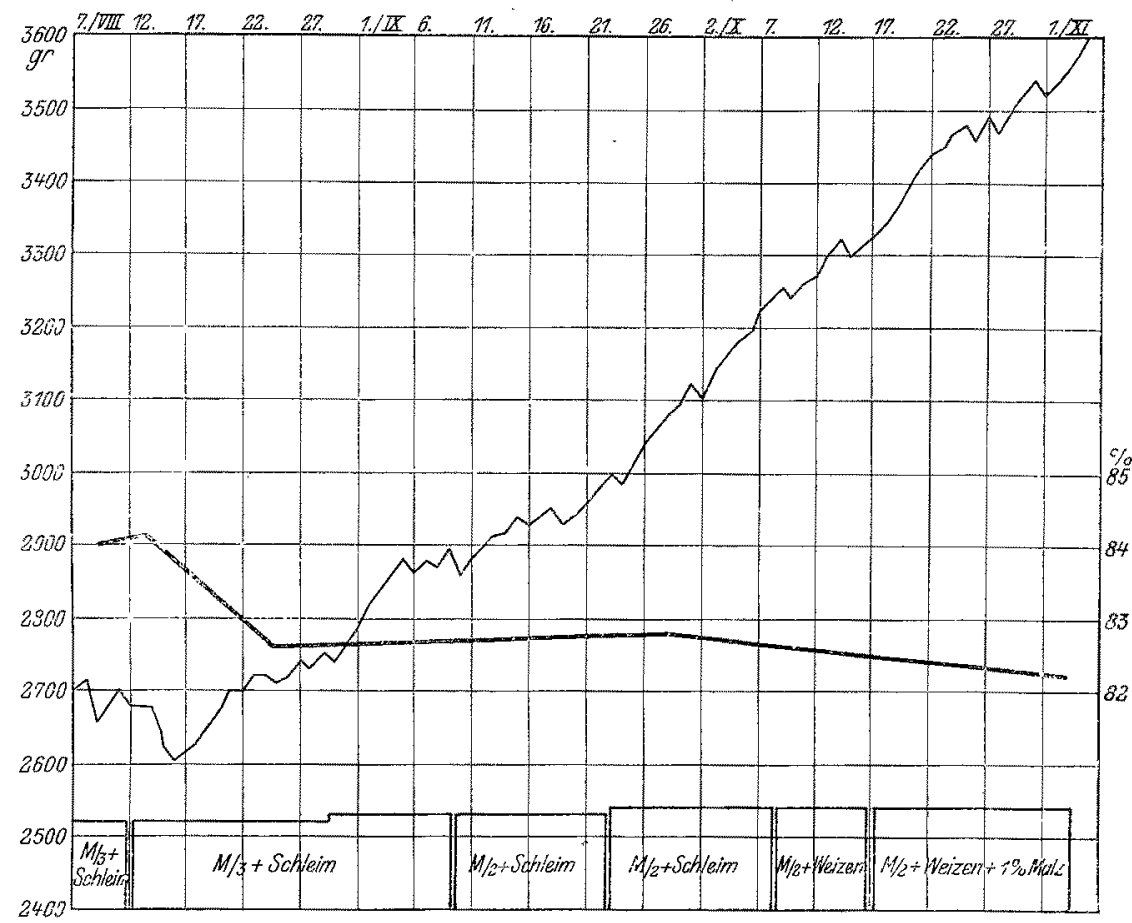

Fig. 9.

Zeitraum vom Eintritt bis zur Erreichung dieses niedrigen Wassergehaltes im Blut - und das ist für das Spätere wesentlich - beträgt 13 Tage.

Diesem lange Zeit ausschließlich mit Brustmilch ernährten Kind soll nun ein zweiter Fall gegenübergestellt werden, der noch in frühestem Alter durch Genuß von exzessiven Mengen verdünnter Kuhmilch dieselben Erscheinungen bot wie das erstgenannte Kind.

F. S., 2 Monate alt (Fig. 9), soll etwas zu früh geboren sein. Enührung bis zum Tage der Aufnahme: täglich $1 \frac{1}{2}$ Liter (!) Drittelmilch mit etwas Zucker. Die 
Mutter bringt das Kind wegen ungenügenden Gedeihens zur Aufnahme. Bei der Aufnahme $54 \mathrm{~cm}$ lang, $2750 \mathrm{~g}$ schwer, mäBig entwickeltes Fettpolster, schlaffe Muskulatur. Keine Zeichen von Rachitis oder exsudativer Diathese, minimale Drüsenschwellungen im Nacken, am Kieferwinkel und in den Achselhöhlen. Herz und Lungen o. B. Temperatur normal. Stuhl in Ordnung. Nach der Aufnabme sofort auf $600 \mathrm{~g}$ Drittelmilch + Schleim gesetzt. Darnach durch volle 14 Tage Gewichtsstillstand, wobei die Stühle immer gut sind, kein Erbrechen eintritt. Nach 14 Tagen setzt eine langsame Gewichtssteigerung ein, ohne daß zunächst an der Nahrung irgend etwas geändert worden wäre. Unter langsam gesteigerten Nahrungsmengen, zunächst auf 660, dann auf $720 \mathrm{~g}$, unter Ersatz zunächst des Schleims durch Weizen, später durch Malzsuppe, tritt eine fortlaufende Steigerung des Gewichtes bei guter körperlicher Entwicklung ein, so daß das Kind im Laufe der nächsten drei Monate ungefähr $1 \mathrm{~kg}$ zunimmt.

Der Fall betrifft also ein 2 monatliches Kind, das mit großen Mengen von Drittelmilch ernährt worden war, aber keinerlei Zeichen einer manifesten Ennährungsstörung bot. Am Tag der Aufnahme betrug der Wassergehalt des Blutes $84,0 \%$, also mehr als normal. Nun folgt ein Zeitraum von 14 Tagen, in welchem das Gewicht mit ganz geringen Schwankungen stillstand. Während dieses Zeitraumes sank der Wassergehalt des Blutes auf $82,6 \%$, also um 1,4\%. Ohne daß an der Ernährung zunächst etwas geändert worden wäre, begann nun der normale Gewichtsanstieg, der sich bei langsam gesteigerten Nahrungsmengen, die aber immer sehr bescheiden blieben, durch 3 Monate kontinuierlich beobachten ließ. Während dieser ganzen Zeit aber hielt sich der Wassergehalt des Blutes im Gleichen und zeigte dann geringe Tendenz zum Fallen. (Fig. 9.)

Der Fall zeigt also, daß bei einem mit übergroßen Mengen vonstark verdünnter Kuhmileh genährten Kind der Wassergehalt des Blutes die Norm überschreitet, lediglich durch Umsetzen auf geringe Nahrungsmengen zur Norm herabgedrückt werden kann und während des nun folgenden Gewichtsanstieges durch 3 Monate normales Verhalten zeigt. Der zum Abfall des Blutwassergehaltes notwendige Zeitraum beträgt 14 Tage.

Der nächste Fall stellt gleichsam eine Kombination der eben beschriebenen vor.

A. L., 8 Monate alt, rechtzeitig geboren, bekam bis vor 2 bis 3 Wochen jede Stunde (!) die Brust. Das Kind wurde damn abgesetzt und bekam täglich 2 mal Grießbrei und 3 Liter Halbmilch (!). Das Kind entwickelte sich immer gut, war aber stets blaß3. Mit 4 Monaten hatte es eine Lungenentzündung, hat sich aber danach gut erholt. Der Stuhl war immer in Ordnung, 1 mal täglich von gelber 
Farbe. Das Kind wurde wegen Unruhe aufgenommen. - Bei der Aufnahme $62 \mathrm{~cm}$ lang, $7080 \mathrm{~g}$ schwer, ist ausgesprochen pastös, schlaff, hat einen leichten Rosenkranz; Perlschnurfinger angedeutet, noch keine Zähne. Dabei Zeichen von Spasmophilie. Chvostek und Trousseau auslösbar. K. S. Z. 2,0, A. S. Z. 0,4, K. Ö. Z. 2,0, A. O. Z. 4,0. Intern vollständig normaler Befund. Niemals Temperatursteigerung. - Das Kind wurde sofort nach der Aufnahme auf 2 mal 140 Halbmilch mit Griesbrei und $4 \mathrm{mal} 140 \mathrm{Halbmilch}$ gesetzt. Bei dieser Ernährung blieb es während der ganzen Zeit der Beobachtung. Auch während des Spitalsaufenthaltes zeigten sich bei dem Kinde keinerlei Zeichen einer Ernährungsstörung, auch von seiten der spasmophilen Diathese wurden keine manifesten Erscheinungen bemerkt. Das Kind nahm nun während des Spitalsaufenthaltes zunächst mit Sehwankungen, aber kontinuierlich ab. Es ist hier mit Rücksicht auf das Spätere wichtig zu betonen, daß das Kind anfänglich die neue Nahrung nicht recht nehmen wollte und erst später, nach ungefähr 7 bis 8 Tagen seine volle Ration erhielt, so daß im Anfang wohl auch Unterernährung im Spiel ist. Der Gewichtsverlust betrug im ganzen 600 g. Diese Abnahme dauerte genau 21. Tage. Von diesem Tage ab setzte, ohne daß an der Nahrung etwas geändert worden wäre, eine schwankungslose Gewichtszunahme ein, welche das Kind die Abnahme in nicht ganz 3 Wochen einholen ließ.

Auch hier haben wir es mit einem Kinde zu tun, das lange Zeit ausschließlich an der Brust war, dann durch 2 bis 3 Wochen mit ganz unglaublich großen Mengen von Halbmilch gefüttert wurde. Der Blutwassergehalt am Tage der Aufnahme betrug $83,2 \%$, also für ein 8 Monate altes Kind mehr als normal. In wiederholten Bestimmungen zeigte sich nun, daß auch hier der Blutwassergehalt in Schwankungen, welche dem Körpergewicht nahezu parallel liefen (linke Hälfte der Fig. 15), abnahm und einen Wert von 81,3 bis 81,7 erreichte. Auch während der rapiden Zunahme überschritt der Blutwassergehalt die letztgenannte Zahl niemals. Das Verhalten des Blutwassergehaltes bei diesem Falle ist also ganz analog wie bei den ersten beiden Fällen.

Die Analogie im Verhalten der hier beschriebenen Fälle mit den am Tierexperiment gefundenen Tatsachen ist auffallend und deckt sich in jeder Hinsicht in den Resultaten. Úberlange a usschlieBliche Ernährung an der Brust, ebenso einseitige oder zu lange Ernährung mit großen Kuhmilchmengen führen zu einer Vermehrung des Wassergehaltes im Blut, bzw. 'zu einer Verhinderung der physiologischen Austrocknung. Setzt man die betreffenden Kinder auf das richtige Nahrungsvolumen mit entsprechender Koständerung, so sinkt dieser Wassergehalt im Blut langsam im Laufe von 2 bis 3 Wochen, um dann das normale Verhalten der kontinuierlichen phy- 
siologischen Austrocknung zu zeigen. Ich will hier noch einmaI erwähnen, daß dieses Verhalten des Blutwassers - und damit. wird gleichzeitig eine der Hauptfragestellungen beantwortet, - offenbar nicht das pathogenetische Moment des Milchnährschadens darstellt. Obwohl alle Fälle das eine oder andere Symptom dieser chronischen Ernährungsstörung zeigten (Blässe, mangelhafte. Gewichtszunahme, Milztumor nsw.), so war doch das Krankheitsbild. nicht zur Gänze entwickelt (vor allem fehlten die Fettseifenstühle) und allen Fällen, die so eindeutige Veränderungen in ihrem Blutwassergehalt zeigten, waren nur die obengenannten durch die Ernährung. bedingten Momente gemeinsam.

Eine weitere Gemeinsamkeit liegt in dem Verhalter nach Absetzen der zur Vermehrung des Blutwassers führenden Nahrung - und damit. ist gleich ein natürlicher Hinweis auf die Therapie gegeben. Alle diese Fälle zeigen nach Absetzen auf kleine Nahrungsvolumina und Einleitung der für das betreffende Alter notwendigen qualitativen Änderung der Nahrung das gleiche Verhalten. Die Kinder nehmen an Gewicht. so lange $a b$ oder bleiben im Gewicht stehen, bis ein entsprechend niedriger Wassergehalt ihres Blutes zustande gekommen ist, und erst dann beginnt unter gleichzeitigem normalen Verhalten des Blutwassergehaltes der Körpergewichtsanstieg. Es liegt daher die Auffassung nahe, daß diese Körpergewichtsabnahme, respektive der Stillstand, welche bei den hier beschriebenen Fällen relativ lange ( 2 bis 3 Wochen) dauern, der Ausdruck der Abgabe des überschüssig angesammelten Wassers sind, und daß das weitere normale Wachstum erst beginnen kann, wenn eine richtige Zusammensetzung des Blutes bzw. des Körpers Platz gegriffen hat. „Umstimmung des Organismus" nennen CzernyKeller diesen Vorgang. Daß eine solche Umstimmung der Körperzusammensetzung alimentär bewirkt werden kann, haben mit Bezug auf andere Zustände schon früher Birk und Langstein vindiziert. Sie fordern eine „Richtigstellung“. der Ernährung oder, wie Finkelstein für die Therapie des Ekzems fordert, eine „,durch die Ernährungsweise zu bewirkende Umwandlung der pathologisehen Zusammensetzung der Körpergewebe und speziell der Haut in die normale": Ob. eine solche fehlerhafte Zusammensetzung des Körpers für das Ekzem tatsächlich zu Recht besteht, soll später erörtert werden. Nun wurde allerdings bis jetzt noch nie gesagt, worin die pathologische Zusammensetzung des Körpers besteht, und womit demgemäß die Richtigstellung. der Ernährung und damit die Umwandlung der pathologischen Zu- 
sammensetzung in die normale zu erfolgen hat. Nach den vorliegenden Untersuchungen ist es wohl zweifellos, daß die fehlerhafte Zusammensetzung des Organismus bei den eben beschriebenen Ernährungsfehlern in einer Wasseranreicherung besteht und daß die Richtigstellung in einer Vermeidung dieser Wasseranreicherung zu erfolgen hat. Es ergibt sich ferner aus diesen Untersuchungen, daß dieser Zweck nicht nur erreicht wird, wenn man salz- und kohlehydratreiche Gemische auf das notwendige Maß beschränkt, sondern daß auch die Menge des gleichzeitig gebotenen Wassers, mit anderen Worten, das Volumen der Nahrung nicht zu groß sein darf.

Nicht um die Zahl der bisher gebrauchten Ausdrücke um einen weiteren zu vermehren, sondern weil nach den beschriebenen Untersuchungen das Wesen der Sache näher getroffen wird, soll hier der Ausdruck, ,innerer Umba u“ eingeführt werden. Die betreffenden Kinder erfahren während der Zeit der Wasserabgabe bis zu dem Punkte, wo der Wassergehalt sein richtiges Maß erreicht hat, eine Veränderung ihrer Zusammensetzung, und erst wenn dieser neue Ausgangspunkt ihrer Entwicklung erreicht ist, setzen Wachstum und Zunahme gleichsam auf der richtigen Grundlage ein. In diesem Sinne angewendet, besteht dann gewiB der von Schloss eingeführte Begriff der "Korrelations-Störung", also in letzter Linie doch als Ernährungs-, nicht als Wachstumsstörung zu Recht.

\section{Die Anämie des Säuglinge.}

Wir haben es bisher mit einer mehr passiven Wirkung der Wasseranreicherung zu tun gehabt; sind doch die bisher im Tierexperiment und am menschlichen Säugling nachgewiesenen Zustände einfach durch eine Verhinderung der physiologischen Austrocknung zustande gekommen. Dieser Abschnitt führt uns einen Schritt weiter. Der Unterschied gegenüber früher drückt sich schon ganz grob in den gefundenen Zahlenwerten aus. In den im vorigen Kapitel beschriebenen Zuständen war der Wassergehalt des Blutes durch die überlange oder überreichliche ausschlieBliche Milchernährung entweder um ein Geringes $(1,0$ bis $1,5 \%)$ erhöht, oder das pathologische Verhalten drückte sich nur darin aus, daß zu einer Zeit, in der das Blutwasser längst abgenommen haben sollte, sein Wert noch immer auf dem überhaupt möglichen Maximum des Normalen stand. Wie ein kurzer Blick auf die weiter unten zu veröffentlichenden Zahlen bei anämischen Kindern lehrt, handelt es sich 
hier um weit höhere Werte, bis zu $88 \%$ und mehr, Zahlen, die den Unterschied gegenüber der Norm um so größer erscheinen lassen, da die von der Anämie betroffenen Säuglinge ja gewöhnlich schon im zweiten oder dritten Lebenshalbjahr stehen, also physiologischerweise schon viel niedrigere Wasserwerte haben sollten.

$\mathrm{Da} B$ bei anämischen Personen eine Verminderung der Blutdichte besteht, wurde wiederholt nachgewiesen. $V$. Jaksch fand bei allen Formen von Leukämie, Chlorose, perniziöser Anämie, sekundärer Anämie nach Blutungen, Tumoren usw. immer eine Steigerung des Wassergehaltes und eine Verminderung der N-Menge im Blut. Monti bestätigt diesen Befund an Anämien und Leukämien des Kindeslaters. E. Schlesinger konnte bei leichten Formen von Atrophie eine Abnahme der Blutdichte konstatieren, während die Zahl der roten Blutkörperchen und der Hb-Gehalt etwas sank, also wirkliche Verdünnung des Blutes stattfand. Hock und Schlesinger fanden, daß bei Rachitis ohne Anämie keine Verminderung der Blutdichte bestand, während Rachitis mit Anämie immer eine Verminderung der Blutdichte zur Folge hatte. Dagegen konnte E. Müller mit moderner Methodik, aber bei größeren ( 6 bis 16jährigen) Kindern keine wesentlichen Unterschiede in der Blut- und Hb-Menge zwischen den blassen und gesund aussehenden Kindern entdecken.

Eine Schwierigkeit in der Bearbeitung dieses Kapitels liegt nun darin, daß wir bis heute über eine einheitliche Einteilung der Anämie im Kindesalter noch nicht verfügen. Ohne auf die spezielle Literatur hier eingehen zu wollen, soll nur mit Berücksichtigung zusammenfassender Publikationen oder von Lehrbuchdarstellungen gezeigt werden, wie weit wir heute noch von einer systematischen Gruppierung der hierher gehörigen Krankheitsbilder entfernt sind. Was hat nur die Frage des Milztumors, um mit Naegeli zu sprechen ,in der pädiatrischen Literatur für eine gewaltige Konfusion hervorgerufen"! Auch heute sind wir über diese Grundfrage noch nicht einig. Czerny erachtet den Milztumor für die Beurteilung eines Falles als Säuglingsanämie gleichgültig. Er entwickelt die alimentäre Anämie zwanglos aus dem Milchnährschaden und mißt nur der Frage der Leukocytenvermehrung eine größere Rolle bei. Wenn letztere gefunden werde, dann sollen sekundäre Prozesse mit im Spiele sein. Diese Ansicht erweitern Czern y-Keller dahin, daß die Pseudoleucaemia Jakschii nicht restlos in der Anämie alimentären Ursprungs aufgehe, sondern daß sie in einem Teil der Fälle infektiösen Ursprungs sei. Der Milztumor 
nicht infektiösen Ursprungs aber sei ein Symptom der exsudativen Diathese, weil er sich durch zweckentsprechende Ernährung zur Rückbildung bringen lassen kann. Finkelstein lehnt ebenfalls eine Einteilung in Anämien mit oder ohne Milztumor, ebenso aber auch die Einteilung von Ehrlich-Lazarus in Anämien mit postembryonalem oder embryonalem Typus der Erythrocytenregeneration ab und reiht seine Fälle in die Anaemia pseudoleucaemica, die er als ,,sekundäre Anämie der mit angeborener Schwäche der blutbereitenden Organe behafteten Säuglinge" auffaßt. Ein Zusammenhang mit Rachitis sei zweifelhaft. Japha sowohl als Flesch handeln eigentlich die alimentäre Anämie der Säuglinge und die Anaemia pseudoleucaemica unter einem Titel ab. Japha schreibt: „Dennoch haben alle diese Krankheitsfälle durch den Zeitpunkt der Entstehung am Ende des Säuglingsalters, durch die Pathogenese, durch ein für das Säuglingsalter charakteristisches Blutbild und nicht zum mindesten durch die Möglichkeit eines günstigen Ausgangs auch bei schweren Blutveränderungen so viele Berührungspunkte, daß ihre Vereinigung zu einer einzigen Gruppe gerechtfertigt erscheint." (Im Original gesperrt.) Gundobin dagegen anerkennt keine Notwendigkeit, die Jakschsche Form der Pseudoleukämie überhaupt aufzustellen, da die Milzvergrößerung bei Anämien verschiedenster Art und auch bei vielen anderen Krankheiten gefunden werde, und da auch mikroskopisch die Jakschsche Pseudoleukämie nichts Charakteristisches darbietet. Die betreffenden Veränderungen fänden sich sowohl bei einfachen Anämien wie bei Leukämien. Auch die Einteilungsversuche von Tixier, der hauptsächlich hämolytische Momente als Ursache der Säuglingsanämien anführt, haben das Bild nicht zu klären verstanden.

Wichtig ist, daß fast sämtliche Autoren, gleichgültig, ob sie die Anämie alimentären Ursprungs für sich oder gemeinsam mit der Jakschschen Anaemia pseudoleucaemica betrachten, die Ứberernährung oder zu lange Ernährung mit Milch als einen der ätiologischen Faktoren anschuldigen, daß aber nur die wenigsten der bisherigen Bearbeiter des Themas daraus die Konsequenz für die Therapie zogen und vor allem eine Einschränkung der Milchzufuhr forderten. Der Hauptsache nach wird doch einer Eisen- oder Lebertrantherapie das Wort geredet.

Im folgenden habe ich mich der Mehrzahl der Autoren, welche alimentäre Anämie und Pseudoleukämie gemeinsam betrachten, angeschlossen, da sämtliche Fälle, die ich beobachten konnte, gemein- 
same Momente beider Erkrankungen aufwiesen und eindeutig weder in das eine noch in das andere Krankheitsbild allein eingereiht werden konnten. Die Fälle zeigen sämtlich die bekannte, von Flesch folgendermaßen in Kürze geschilderte Symptomatologie: Blässe der Haut und Schleimhäute, Milztumor, Verminderung der roten Blutkörperchen und des Hb-Gehaltes, Vermehrung der Leukocyten, Anisocytose und Polychromasie, Auftreten kernhaltiger roter Blutkörperchen und Vorwiegen der Lymphocyten unter den Leukocyten. Alle Fälle zeigen hochgradige Vermehrung des Blutwassergehaltes.

Es wird sich aus der Beschreibung der einzelnen Fälle ergeben, inwieweit dieser letztere Umstand Beziehungen zur Ätiologie, Pathologie und Therapie dieser Krankheitszustände hat.

A. W., 12 $\frac{1}{2}$ Monate alt, Frühgeburt im 8. Monat, bis zu 11 Monaten 2 bis 3 stündliche Brusternährung. Seit dem 6. Monat mit Semmelbrei etwas zugefüttert. Seit der Abstillung in 2stïndlichen Intervallen abwechselnd Milch, Milchbrei und Suppe. Das Kind braucht pro Tag durchschnittlich 1 I Milch, bekommt außerdem noch Wasser und Tee, hat noch niemals regelmäßig feste Nahrung bekommen. Das Kind war von Geburt an schwächlich und wegen Ernäbrungsstörung und Bronchitis einmal in ambulatorischer Behandlung. Im Alter von 7 Monaten hatte es bereits eine im Ambulatorium festgestellte Anämie. Seitdem war die Frau ausgeblieben. Erste Dentition mit 6 Monaten, kann mit Unterstützung gehen. Hat niemals Ausschläge oder Krämpfe gehabt, aber wiederholt Schnupfen und Husten. Seit einem halben Jahre wird das Kind von Tag zu Tag blässer und ist sehr übellaunig, nimmt sehr wenig an Gewicht zu. Es hat immer viel Durst und trinkt besonders bei Nacht viel. Es schwitzt so stark, daß die Kissen immer ganz naß sind. Zweimal täglich sehr harter, lichtgelber Stuhl, der gewöhnlich unter großer Anstrengung entleert wird. - Das Kind ist für sein Alter klein, $70 \mathrm{~cm}$ lang, die Fontanelle steht auf $2 \times 3 \mathrm{~cm}$ offen. Körpergewicht $7000 \mathrm{~g}$. Die Haut des ganzen Körpers von wachsartiger Blässe, stellenweise grünlichgelb, an den dünnen Partien (Ohren, Finger) durchscheinend. Bis auf die offene Fontanelle keine Zeichen von Rachitis. Normal fortgeschrittene Dentition. Lungen o. B. Nor. male Herzgrenzen, an allen Ostien ein leises blasendes systolisches Geräusch, an der Basis lauter als·an der Spitze. Das Abdomen steht im Thoraxniveau, ist mäßig gespannt. Die Leber reicht bis in Nabelhöhe, den Rippenbogen um 3 Querfinger überschreitend und reicht nach links bis nahe an die Milz. Letztere ist als großer harter Tumor deutlich fühlbar. Sie reicht bis 2 Querfinger unterhalb des Nabels und medial bis in die Parasternallinie, so daß sie mit der Leber in der Mitte des linken Rippenbogens zusammentrifft. Blutbefund: $\mathrm{Hb}=26 \%$ (Sahli), 4496000 Rote, Färbeindex $=0,29,16500$ Weiße, davon $75,3 \%$ groß- und kleinkernige Lymphocyten, 20,8\% Polynucleäre, 3,9\% große Mononucleäre. Reichlich Polychromasie und Poikilocytose, kernhaltige Rote in mäßiger Menge. Keine pathologischen Formen der Weißen. Pirquet und Wassermann negativ.

Das Kind wurde des Versuches halber brüsk von seiner bisherigen Nahrung abgesetzt und bekam folgende Diät: Zuim Frühstück $150 \mathrm{ccm}$ Mils $\mathrm{h}$ mit Biskuit, 
Vormittag einen geschabten Apfel, mittags $200 \mathrm{ccm}$ Grießsuppe und 2 EBlöffel passiertes Gemüse, nachmittags $150 \mathrm{ccm}$ Milch mit Biskuit und abends $200 \mathrm{ccm}$ Grießbrei. Das Kind aß alles, was es bekam, schlief gut, nahm aber in den ersten 48 Stunden um $500 \mathrm{~g}$ ab. Die Temperatur stieg bis $37,4^{\circ}$, Zunge und Mundschleimhaut waren sehr trocken. Die Temperatursteigerung hielt durch 5 Tage an. Nach dem ersten Gewichtssturz blieb das Kind zunächst durch einige Tage im Gewicht stehen und nahm dann langsam zu. Nach 7 Tagen war die Milz deutlich kleiner, sie stand gut 2 Querfinger höher als am Tage des Eintrittes und reichte medial nur bis zur Mammillarlinie. 2 Wochen nach der Aufnahme lautete der Blutbefund: $\mathrm{Hb}=38 \%, 4080000$ Rote, $\mathrm{F} . \mathrm{J}_{.}=0,46,11200 \mathrm{WeiBe}$, davon $19,2 \%$ Polynucleäre, $80,0 \%$ Lymphocyten, $0,8 \%$ große Mononucleäre. 4 Wochen nach der Aufnahme war die Milz nur mehr als ungefähr I Querfinger breite Kuppe unterhalb des Rippenbogens tastbar. Die Leber stand in der Höhe desselben. Der Blutbefund lautete: $40 \%$ Hb, 5808000 Rote, F. J. $=0,36,13700$ Weiße. - Das Kind bekam jetzt zu seiner Mahlzeit noch Fleisch und nahm fortlaufend langsam an Gewicht zu, hatte aber zu dieser Zeit sein Eintrittsgewicht noch nicht erreicht. Im folgenden Monat änderte sich im Befinden des Kindes gar nichts. Die Hautfarbe war wohl besser als zu Beginn, aber immer noch war die Anämie deutlich zu erkennen. Der Blutbefund blieb mit einigen Schwankungen im gleichen, die Milz blieb dauernd klein, aber immerhin unter dem Rippenbogen tastbar. Nur das Körpergewicht nahm fortlaufend $\mathrm{zu}$, so daß es $2^{1} / \mathbf{2}$ Monate nach der Aufnahme $250 \mathrm{~g}$ mehr betrug als zur Zeit des Eintrittes. Von nun ab wurde täglich etwas Eisen in Form des Liqu. ferr. mang. sacch. gegeben. In der nächsten Zeit änderte sich aber im Befund gar nichts. Das Kind bekam wohl etwas bessere Farbe, hatte aber sicher noch kein normales Kolorit. Leber und Milz blieben in den früheren Grenzen, das Gewicht nahm kontinuierlich zu. 4 Monate nach der Aufnahme wog das Kind $900 \mathrm{~g}$ mehr als beim Fintritt, $1400 \mathrm{~g}$ mehr als zur Zeit des tiefsten Gewichtsstandes. Ein Bluthefund ergab keine wesentlichen Veränderungen gegenüber früher: 6649000 Rote, $46,0 \% \mathrm{Hb}$, F. J. $=0,34,11100$ Weiße, davon 12,7\% Polynucleäre, 3,5\% große Mononucleäre und 83,0\% Lymphocyten. Es bestanden immer noch' geringe Größen- und Färbeunterschiede der Roten, und ganz vereinzelte Kernhaltige wurden ebenfalls gefunden. Mit einem ganz ähnlichen Befund wurde das Kind nach beinahe 5 monatlicher Beobachtung entlassen. Während derselben war die Diät im großen ganzen dieselbe geblieben.

Das Kind zeigt also in der Anamnese einen deutlichen Hinweis auf eine Milchübererıährung, der somatische Befund aber spricht für das Bestehen einer Anämia pseudoleucaemica. Die Untersuchung des Blutwassergehaltes ergab bei der Aufnahme einen Wert von $88,7 \%$, also einen Wert, der weit über den bisher genannten Zahlen liegt. Die fortlaufenden Untersuchungen ergaben nun eine vollständige Ubbereinstimmung mit den Ergebnissen der hämatologischen Untersuchung. Schon in den ersten 48 Stunden, während das Kind $1 / 2 \mathrm{~kg}$ an Gewicht abnahm, sank der Blutwassergehalt um 0,7\%, nach 11 Tagen war er um weitere $1,3 \%$ gefallen. Nach weiteren 9 Tagen sank er wiederum 
um $0,8 \%$, von da ab aber blieb er auf diesem immerhin noch hohen Wert stehen, ebenso wie der Blutbefund ja gleich am Anfang eine bedeutende Besserung zeigte, aber auf einem immer noch pathologischen Zustand verblieb. Und ganz analog verhielt sich die Milz, welche im Anfang sehr rapide Veränderungen zeigte, von beinahe Kindskopfgröße auf einen kleinapfelgroßen, eben noch unter dem Rippenbogen zu tastenden Körper sich zurückbildete, auf diesem Stand aber während der ganzen Beobachtungszeit durch mehrere Monate stehen blieb. Eine während dieser Zeit eingeleitete Eisentherapie hatte keinerlei Erfolg. Das Gewicht. nahm dabei dauernd und langsam zu. Es macht also ganz den Eindruck, als ob hier zwei Faktoren im Spiele wären, die alimentäre Komponente und eine zweite unbekannte, welche die Erscheinungen der Pseudoleukämie auslöst und ebenfalls in ganz hervorragendem. Maße imstande sein muß, eine Vermehrung des Wassergehaltes im Blut. hervorzurufen. Die erste Komponente läßt sich durch die Therapie beeinflussen: Das Körpergewicht und mit ihm ein Teil des vermehrten Blutwassers und in ganz besonders eklatanter Weise der Milztumor nehmen rasch ab; die übrigen Symptome aber, die blasse Hautfarbe, der pathologische Blutbefund und die Reste des Milztumors bleiben bestehen.

J. S., 9 Monate alt. 2 Monate ausschließlich bei der Brust, dann Zufütterung von Semmelbrei; bekommt jetzt 6 bis 7 mal täglich Brust und 3 mal täglich Semmelbrei, außerdem reichlich Tee und Suppe. Hat erst seit einer Woche 2 Zähne, sitzt noch nicht und hat seit ein paar Wochen Gneis. Das Kind soll immer blaß ausgesehen haben, seit ein paar Wochen ist die Blässe auffallend. Es ist sehr unruhig und nimmt nicht recht an Gewicht zu. Seit 3 Monaten ist der Bauchumfang sehr gewachsen. Stuhl gewöhnlich 2 mal täglich, hellgelb, homogen. Alle (10) Kinder der Frau waren immer blaß, 6 davon sind gestorben. - Pat. ist bei der Aufnahme $6100 \mathrm{~g}$ schwer, $60 \mathrm{~cm}$ lang, die Fontanelle steht weit $(6 \times 6 \mathrm{~cm})$ offen. Hochgradige Rachitis, keine spasmophilen Erscheinungen. Das Abdomen ist mächtig vorgewölbt, die Milz reicht beinahe bis zum Ligam. Pouparti und medial nahezu bis zur Mittellinie. Die Leber steht in normalen Grenzen. Lungen und Herz o. B. Blutbefund: 4336000 Rote, $36 \% \mathrm{Hb}$, F. J. $=0,41,28300$ Weiße, davon $17,6 \%$ Polynucleäre, 80,1\% Lymphocyten, 2,3\% große Mononucleäre. Auffallend viel Eosinophile (im Stuhl keine Parasiteneier!). Sehr starke Poikilocytose und Polychromasie, reichlich kemhaltige Rote. Pirquet und Wassermann negativ.

Das Kind wurde auf dieselbe Kost gesetzt wie das vorige und nahm ebenfalls in den ersten 4 Tagen um $850 \mathrm{~g}$ ab. Die Nahrung wurde anstandslos genommen. Der Stuhl war immer in Ordnung. Vom 5. Tage ab nahm das Körpergewicht langsam zu. Nach 6 Tagen war die Milz, deren Kleinerwerden man beinahe von Tag zu Tag verfolgen konnte, wesentlich geschrumpft, sie reichte noch bis in Nabelhöhe, medial etwas über die Mammilearlinie hinaus. Der Blutbefund lautete: 
2912000 Rote, $\mathrm{Hb}=32 \%$, F. J. $=0,55,52100$ WeiBe. An diesem Tage bekam das Kind eine Pneumonie, der es bald erlag.

Das Kind zeigte fast in allen Punkten, sowohl was die Anamnese (starke Milchüberernährung) als was den somatischen Befund anlangt, weitgehende Ähnlichkeiten mit dem erstbeschriebenen Fall. Der Blutwassergehalt am Tag der Aufnahme betrug 86,2\%, 48 Stunden später $84,1 \%$, also $2,1 \%$ weniger und hielt sich in dieser Höhe. Nach Eintritt der Pneumonie wurde der Blutwassergehalt noch einmal untersucht und ergab einen Wert von $87,3 \%$. Die Wirkung des Fiebers ist also unverkennbar. Deswegen wurde auch die weitere Beobachtung abgebrochen. Wir sehen also auch hier, daß durch das Absetzen von der Milchüberernährung in eklatantester Weise der Blutwassergehalt herabgedrückt und die Milz bis zu einem gewissen Grade rapid zur Verkleinerung gebracht werden konnte; der übrige pathologische Befund aber blieb bestehen.

A. G., I Jahr alt, Frühgeburt, war 4 Wochen bei der Brust, dann durch einen Monat auf unserer Abteilung, von wo das Kind in gutem Ernährungszustande entlassen wurde. Nachher bekam es Zweidrittelmileh, und zwar in der Gesamtmenge von 11 , später von $1 \frac{1}{2} 1$ täglich. Hat noch niemals etwas anderes als Milch bekommen. War immer schwächlich und kam nie recht fort. - Bei der Aufnahme $60 \mathrm{~cm}$ lang, $6300 \mathrm{~g}$ schwer, zeigt floride Rachitis, weit offene Fontanelle, starke Craniotabes, Rosenkranz, Verbiegung des Rippenbogens. Die Hautfarbe war blaßgelblich, durchscheinend. Herz und Langenbefund normal. Die Leber überragt den Rippenbogen um 2 Querfinger, die Milz reicht medial bis in die Mammillarlinie, nach abwärts bis in Nabelhöhe und zieht von da fast horizontal nach rückwärts. Blutbefund: 3520000 Rote, $30 \% \mathrm{Hb}$, F.J. $=0,43,8460$ WeiBe. Im gefärbten Präparate starke Färbe- und Größenunterschiede der Roten, keine Kernhaltigen. Keine pathologisehen Formen der Weißen. Pirquet und Wassermann negativ.

Das Kind wurde auf dieselbe Diät wie die übrigen Kinder gesetzt und nahm sie von Anfang an gut. In den ersten 3 Tagen nahm es um $400 \mathrm{~g} a b$, von da an sehr langsam zu, so daß es sein Eintrittsgewicht exst einen Monat nach der Aufnahme erreichte. 6 Tage nach der Aufnahme war die Milz bedeutend kleiner geworden, erreichte kaum die Mammillarlinie und stand oberhalb des Nabels. Der Blutbefund lautete: 3960000 Rote, $40 \% \mathrm{Hb}$, F. J. $=0,5,9980$ Weiße. Davon $24,3 \%$ Polynucleäre, 3,4\% große Mononucleäre, $72,3 \%$ Lymphocyten, hie und da ein Eosinophiler. Reichliche Anisocytose und Polychromasie, sehr viel Kernhaltige, deren Kerne wie zerfallen aussehen. Die Temperatur war in diesen ersten Tagen subfebril, ohne daß hiefür eine besondere Ursache hätte nachgewiesen werden können. 3 Wochen später war die Milz noch kleiner geworden und eben noch als kleiner, rundlicher, harter Körper unterhalb des Rippenbogens hervorkommend, zu tasten. Das Kind hatte an Gewicht zugenommen, war aber noch immer blaß, der Blutbefund war im wesentlichen identisch mit dem vorhergehenden. Und dasselbe Bild hielt sich noch durch weitere 3 Wochen der Beobachtung. 
Die Milz kaum tastbar, aber immerhin unter dem Rippenbogen fühlbar. Blutbefund: 2980000 Rote, $34 \% \mathrm{Hb}, \mathrm{F}$. J. $=0,58,7500$ Weiße. Die pathologischen Erscheinungen an den Erythrocyten waren ebenso ausgespròchen wie vorher.

Also im wesentlichen wieder dasselbe Bild wie bei den anderen Fällen. Bei einem $1 \mathrm{Jahr}$ alten Kind, das ausschließlich mit übergroßen Kuhmilchmengen ernährt worden war, entstand das Bild der Anaemia pseudoleucaemica mit einem großen Milztumor und starker Rachitis. Der Wassergehalt des Blutes bei der Aufnahme betrug 87,7\%, also wieder weit über der Norm liegend. Nach 48 Stunden beträgt er $87,0 \%$, nach weiteren 3 Tagen $86,5 \%$, nach weiteren 4 Tagen $85,8 \%$, woraus sich eine Abnahme von $1,9 \%$ in 8 Tagen ergibt. Während derselben Zeit hatte auch das Körpergewicht abgenommen und wax die Milz bedeutend kleiner geworden. Von da ab aber blieben die Blutwasserwerte in derselben Höhe, die immer noch weiter über der Norm lagen und die Symptome der Anämie dauerten, wenn auch in vermindertem Grade, weiter an.

Die nächsten beiden Fälle betreffen ambulatorisch beobachtete Kinder, und ich gebe deren Krankengeschichten nur auszugsweise wieder.

A. P. und M. P. (Zwillinge), 15 Monate alt. Die Kinder waren 3 Monate bei der Brust, wurden dann abgesetzt und bekamen zuletzt täglich $1 \frac{1}{4} 1$ Vollmilch, 1 Ei, 1 Teller Suppe und Gemüse. Beide Kinder leiden an deutlichen Manifestationen von exsudativer Diathese, haben wiederholt Ekzeme, sehr oft Schnupfen und Husten gehabt. Die Kinder sind im Wachstum etwas zurückgeblieben, sehr blaß, deutlich rachitisch und haben einen großen Bauch. Bei beiden Kindern reicht die Milz bis in Nabelhöhe. Die Kinder wurden auf eine ähnliche, etwas reichlichere Kost wie die früher beschriebenen, gesetzt, bekamen im ganzen $1 / 3$ I Milch täglich, Suppe, Brei, Gemüse, Fleisch und Obst. Der Wassergehalt des Blutes betrug am 1. Tage der Beobachtung bei A. P. 86,6 , bei M. P. $86,8 \%$. Der Mutter wurde eingeschärft, die vorgeschriebene Diät einzuhalten, auch wenn die Kinder sehr dürsten. Nach 1 Woche wurden die Kinder wieder vorgestellt. Die Mutter gab an, daß sie die neue Nahrung anstandslos gegessen, aber sehr gedürstet hätten. Während der ersten Tage war die Zunge sehr trocken und die Kinder fieberten (1). "Wo sie ein Glas sehen, wollen sie trinken". Die Urinsekretion ist sehr zurückgegangen. Früher konnte die Mutter nicht genug Windeln auftreiben, jetzt kann sie die Kinder, da sie nur wenige Male im Tag urinieren, gut abhalten. Die Milz, die bei beiden Kindern vor 8 Tagen in Nabelhöhe stand, ist stark verkleinert, bei M. P. Kleiner als bei A. P. Die Kinder bekommen jetzt täglich Eisentropfen. Der Wassergehalt des Blutes ist bei A. P. in dieser Woche um $0,7 \%$, bei M. P. um $0,5 \%$ zurückgegangen. Nach 4 Wochen sah ich die Kinder wieder. Die Mutter gibt an, daß sich die Kinder an die kleinen Trinkmengen vollständig gewöhnt haben und nicht mehr dürsten. Die Milz ist bei keinem der Kinder mehr tastbar. Beide haben sichtlich bessere Farbe, sehen aber noch immer blaß aus. Der Wassergehalt des Blutes ist bei beiden Kindern gleichgeblieben. Nach einem weiteren Monat 
hat der Blutwassergehalt wieder etwas abgenommen, die Milz ist absolut nicht zu tasten, beide Kinder sind zwar noch blaB, sehen aber wieder besser aus als das letzte Mal. Später blieb die Frau mit den Kindern aus.

Bei diesen beiden Fällen handelte es sich zweifellos um leichtere Formen der Erkrankung. Sie zeigen vollkommen analoge Erscheinungen wie die übrigen, ein vollkommenes Parallelgehen von Abnahme im Blutwassergehalt bis zu einer gewissen Grenze und rapides Kleinerwerden der Milz durch ein forciertes Absetzen auf flüssigkeitsarme, gemischte Kost mit starker Milcheinschränkung. Die Symptome der Flüssigkeitseinschränkung, großer Durst, Durstfieber, Urinkonzentration, treten so deutlich in Erscheinung, daß es die Mutter spontan anzugeben vermag.

Der letzte Fall dieser Gruppe fällt insofern aus der Reihe, als er ein relativ junges Kind mit sehr schweren Erscheinungen von Anämie betraf, bei dem es wegen des niedrigen Alters im Anfang sehr schwer war, die flüssige Nahrung möglichst auszuschalten, und bei dem dann, als die richtige Diät eingeleitet werden konnte, ohne jede andere Maßnahme eine vollständige Heilung erzielt wurde.

F. P., 7 Monate alt, bis zum Tage der Aufnahme bei Brust, außerdem etwas Tee. Seit 4 Wochen erbricht das Kind sehr häufig und ist unruhig. Es soll angeblich schon bei der Geburt blaß gewesen sein, die Blässe hat aber im Laufe der letzten Wochen stark zugenommen. Stuhl einmal täglich. - Bei dex Aufnahme $61 \mathrm{~cm}$ lang, $41 \mathrm{~cm}$ Kopfumfang, Fontanelle auf $4 \times 4 \mathrm{~cm}$ offen. $5800 \mathrm{~g}$ schwer. Die Haut und die sichtbaren Schleimhäute sind außerordentlich blaß, die Haut sehr dünn und durchscheinend. Das Fettpolster ist sehr mangelhaft entwickelt, der Turgor schlecht. Leichte Zeichen von Rachitis, mäßig vorspringende Tubera frontalia, leichte Rosenkranzbildung, untere Thoraxapertur aufgetrieben. Keine Zeichen von Spasmophilie, dagegen bietet das Kind sehr oft Anfälle von Wegbleiben. Herz und Lungenbefund o. B. Der Bauch ist stark vorgetrieben, mäßig gespannt. Die Leber steht 1 Querfinger unter dem Rippenbogen, die Milz reicht nahe bis an das Ligam. Pouparti, medial bis nahe an die Mittellinie und ist als großer, harter runder Tumor zu tasten. Blutbefund: 2736000 Rote, $26 \% \mathrm{Hb}, \mathrm{F} . \mathrm{J}$. $=0,47,60300$ Weiße (!), davon 95,6\% Lymphocyten (!), 4,0\% Polynucleäre, der Rest große Mononucleäre und ein paar Eosinophile, sonst keine pathologischen Formen der Weißen. Im gefärbten Präparate relativ wenig Größen- und Färbeunterschiede der Roten, dagegen massenhaft kernhaltige Rote. Pirquet und Wassermann negativ.

Zunächst war es nicht möglich, das Kind, das bis dahin noch bei Brust und erst etwas über 7 Monate alt war, auf gemischte Kost zu setzen. Es wurde daher nur die Flüssigkeitsmenge möglichst eingeschränkt, dem Kinde 2 mal dicker Griesbrei und ungefähr $1 / 21$ Halbmileh mit Weizenmehl gegeben. Wie aus der Fig. 10 ersichtlich ist, nahm nun in der nächsten Zeit das Körpergewioht unter Schwankungen langsam zu, um von einem gewissen Punkte ab wieder umzukehren und beinahe das Eintrittsgewicht wieder zu erreichen. Die Symptome der Anämie 
zeigten in den ersten Tagen eher eine Verschlechterung. 2504000 Rote, $24 \% \mathrm{Hb}_{\text {, }}$ F. J. $=0,48,62600$ Weiße (!). Der Milztumor blieb gleich groß. Nach 3 Wochen machte sich jedoch eine deutliche Besserung bemerkbar. Die Zahl der Roten und der $\mathrm{Hb}$-Gehalt stieg an, während die Zahl der Weißen langsan sank. 3780000 Rote, 34\% Hb, F. J. $=0,45,44600$ Weiße, davon $81,6 \%$ Lymphocyten. Der Milztumor reichte bis in Nabelhöhe, medial gleich weit wie früher. Nach weiteren 3 Wochen war das Gewicht wieder abgesunken, der Blutbefund jedoch schon bedeutend besser. 4352000 Rote, $57 \%$ Hb, F. J. $=0,65,23500$ Weiße, davon $72,7 \%$ Lymphocyten, $22,6 \%$ Polynucleäre, der Rest große Mononucleäre und Eosinophile. Noch immer viel kernhaltige Rote. Die Milz war wieder kleiner geworden, reichte zwar noch bis in Nabelhöhe, medial aber nur mehr bis etwa in die Mammillarlinie. Auch das Aussehen des Kindes war sichtich friseher. Die

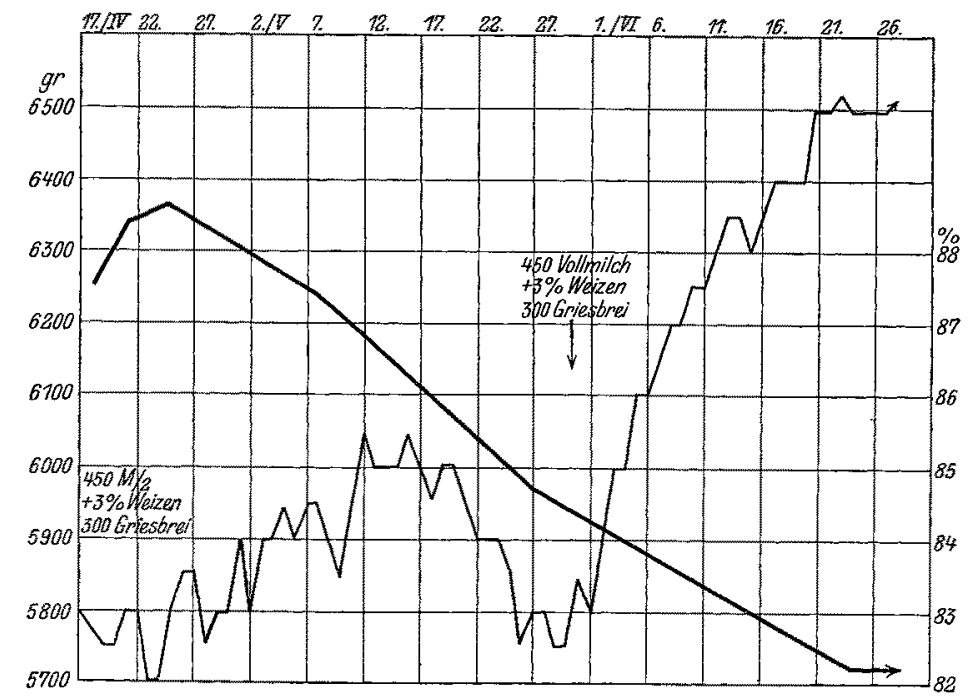

Fig. 10.

Anfälle von Wegbleiben waren fast nicht mehr zu bemerken. Von diesem Tage an wurde die Diät nur insofern geändert, daß das Volumen der Nahrung nicht vergrößert, sondern dieselbe nur konzentrierter gemacht wurde, indem statt Halbmilch wie bisher Vollmilch gegeben wurde. Von diesem Tage an setzte eine rapide Körpergewichtszunahme ein, das Kind wurde mit jedem Tage frischer, bekam eine sehr gute Gesichtsfarbe, lernte stehen und war im Gegensatz zu seiner früheren Unleidlichkeit bald der Stationsliebling. Die Besserungen im Blutbefunde gingen damit sehr rasch Hand in Hand. Nach 4 Wochen zählte ich: 4712000 Rote, $79 \%$ Hb, F. J. $=0,84,9200$ WeiBe, davon $79,6 \%$ Lymphocyten, $18,0 \%$ Polynueleäre, den Rest große Mononucleäre und Eosinophile. Kernhaltige Rote waren nur in ganz vereinzelten Exemplaren zu finden. Nach einem weiteren Monat, zur Zeit der Entlassung, war das Kind sehr frisch und munter, hatte ausgezeichnete Farben, bekan sehr rasch Zähne und ging schon am Gitter im Bett herum. Blutbefund: 4976000 Rote, $76 \%$ Hb, F. J. = 0,77, 6600 Weiße, davon 74,5\% Lympho- 
cyten, 20,5\% Polynucleäre, der Rest große Mononucleäre und Eosinophile. Keine pathologischen Formen der Weißen, keine Polychromasie, minimale Anisocytose, keine Erythroblasten. Gewichtszuwachs seit Eintritt $700 \mathrm{~g}$ in mehr als 2 Monaten, die Milz ist eben unter dem Rippenbogen noch zu tasten.

Wie verhielten sich nun in diesem Falle die Werte für den Blutwassergehalt? Am Tage des Eintrittes betrug derselbe $87,5 \%$, also wieder eine starke Erhöhung über die Norm. In den nächsten Tagen zeigte nun das Kind im Gegensatz zu den anderen Kindern keine Gewichtsabnahme, da es ja auch nicht möglich war, diesem jungen Kinde gemischte feste Kost zu verabreichen. Der Wassergehalt stieg daher auch in den ersten Tagen noch etwas an, bis auf 88,4 und 88,6\% (vgl. Fig. 10). Dann aber begann bei steigendem Körpergewicht, bei rascher

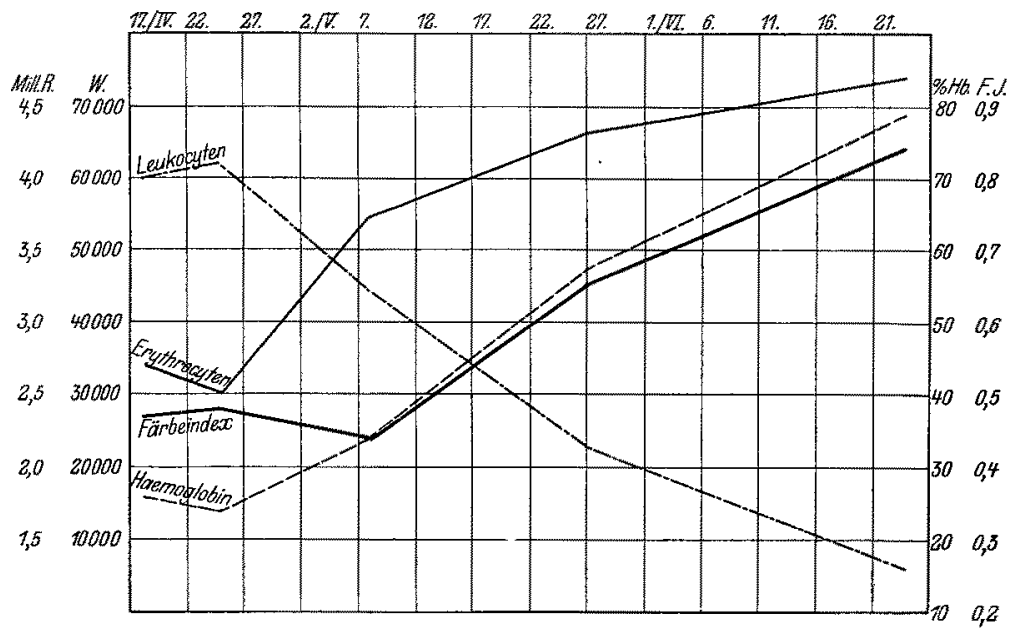

Fig. 11.

Verkleinerung der Milz und bei allmählicher Besserung des Blutbefundes ein rasches Sinken des Blutwassergehaltes, so daß derselbe zurzeit, wo die Körpergewichtskurve wieder umkehrte und ihren Tiefpunkt erreicht hatte, auf $84,7 \%$, also im ganzen um $3,9 \%$ gefallen war. Nun trat die Nahrungsänderung im Sinne einer Konzentrationserhöhung und damit gleichzeitig rapider Gewichtsanstieg ein. Diesmal aber blieben nicht wie in den anderen Fällen der Blutwassergehalt und auch die anderen pathologischen Erscheinungen unverändert, sondern der erstere sank im nächsten Monat um 2,5\%, die letzteren zeigten die im Auszug der Krankengeschichte detailliert wiedergegebenen Veränderungen im Sinne einer raschen Besserung. Um ein deutliches Bild davon zu geben, habe ioh in Fig. 11 in Kurvenform die histologischen Blutveränderungen 
darzustellen versucht. Das Ansteigen von Blutkörperchenzahl, $\mathrm{Hb}$ Gehalt und Färbeindex, besonders aber das Absinken der Leukocytenzahl von mehr als 62000 auf 6600 tritt deutlich in die Erscheinung.

Fasse ich nun die Resultate dieser Untersuchungen zusammen, so ergibt sich folgendes: Sämtliche untersuchten Kinder, die an miehr oder minder schweren Formen von Anaemia pseudoleucaemica litten, boten in der Anamnese deutliche Hinweise auf eine alimentäre Schädigung im Sinne einer überlangen und überreichlichen Ernährung mit großen Milchmengen. Alle Kinder boten neben der Blässe der Hautdecken, dem Milztumor und den bekannten histologischen Veränderungen des Blutbildes eine exzessive Hydrämie dar. Setzte man diese Kinder auf eine gemischte Kost mit tunlichster Einschränkung der Milch und Vermeidung großer Flüssigkeitsvolumina, so nahmen die Kinder sehr rasch an Körpergewicht $a b$ und verloren dabei einen Teil ihres Blutwassers; gleichzeitig trat eine rapideVerkleinerung der Milz, aber auch dies nur bis $\dot{z u}$ einem gewissen Grade, ein. Die meisten der beschriebenen Kinder zeigten während dieser rapiden $\mathbf{A b}$ nahme deutlich die Erscheinung des Durstfiebers, wodurch die Anschauungen von Heim und John eine Stütze erhalten. Ich muß ausdrücklich bemerken, daß ich dieses brüske Absetzen n ur zu $Z$ wecken des Versuches gemacht habe, daß es sich für die Praxis natürlich empfehlen wird, die mitunter unangenehmen Erscheinungen der plötzlichen Entwöhnung von den bisherigen großen Flüssigkeitsmengen zu vermeiden und langsam im Laufe mehrerer Tage die Nahrungsvolumina einzuschränken. Nach der anfänglichen Abnahme stieg das Körpergewicht ohne Änderung der Ernährung langsam und stetig, die Milz blieb klein, die pathologischen Veränderungen des Blutbildes blieben, wenn auch in vermindertem Grade, bestehen, ebenso ein noch ïmmer über die Norm erhöhter Wassergehalt des Blutes. Nur bei dem letztbeschriebenen Fall trat lediglich durch diätetische Maßnahmen eine vollständige Heilung ein. Ich lasse es dahingestellt, ob dieselbe vielleicht auch ohne diese erfolgt wäre, oder ob vielleicht die Heilung der Erkrankung der hämatopoetischen Apparate auf dem Umwege über die Ausschaltung der alimentären Noxe erfolgt ist. Bei der Mehrzahl der Fälle macht es den Eindruck, als ob neben dieser noch eine zweite Schädigung vorhanden wäre; welche den hämatopoetischen Apparat betrifft und welche durch die Nahrungsänderung unbeeinflußt bleibt. Welcher Art diese unbekannte Schädigung des blutbildenden Apparates ist, läßt sich nach den vorliegenden Untersuchungen kaum entscheiden. Obzwar sämtliche untersuchten Kinder 
an mehr oder minder schweren Graden von Rachitis litten, ist es doch kaum wahrscheinlich, daß diese Konstitutionsanomalie direkt Ursache einer Pseudoleukämie sein sollte. Andererseits konnte irgendwelche Wirkung einer Eisentherapie in mehreren Versuchen nicht konstatiert werden. Es bleibt also vorderhand diese Seite der Erkrankung, auch therapeutisch, unaufgeklärt. Wohl aber ist es sicher, daß in dem Krankheitsbild der Anaemia pseudolevcaemica alimentäre Ursachen mits pielen. Sie äußern sich in eben denselben Erscheinungen, wie wir sie im Tierexperiment bei wachsenden Hunden (Verminderung der Zahl der roten Blutkörperchen und des Hb-Gehaltes, Vermehrung des Wassergehaltes) oder bei den einfach mit Milch überernährten oder zu lange genährten Kindern gesehen haben und pfropfen sich den viel größeren Veränderungen der eigentlichen Pseudoleukämie gleichsam noch auf. Daraus ergibt sich mit Notwendigkeit die Forderung, diese alimentäre Komponente der Anaemia pseudoleucaemica in entsprechender therapeutischer Weise zu beeinflussen, wie es Czerny-Keller, Klotz usw. nach empirisch gefundenen Resultaten fordern, d.h. die Milchmenge auf ein möglichstes Minimum einzuschränken und eine gemischte Kost in geringen Volumina dafür einzuführen. Es gelingt ausschließlich mit dieser Diätvorschrift, sowohl die Hydrämie und damit a uch die Hautfarbe bis zu einem gewisșen Grade zu bessern und vor allem den Milztumor rasch und sicher zu verkleinern. Allerdings muß man sich dabei stets bewußt bleiben, daß in der Mehrzahl der. Fälle diese Besserung eben nur bis zu einem gewissen Grade zu erreichen ist, und daß die zweite bisher unbekannte Komponente der Erkrankung damit nicht beeinflußt werden kann. Es wäre gewiß erfreulich, wenn Fälle wie der letztbeschriebene mit vollständiger Heilung nicht als Ausnahmen zu betrachten wären.

\section{Der Mehlnährschaden.}

Nach bisher vorliegenden Untersuchungen an Tieren und Menschen werden bei diesem Krankheitsbild sehr grobe Veränderungen des Wasserbestandes im Organismus zu erwarten sein. Allerdings muß gleich vorausgeschickt werden, daß nach den bisherigen Angaben der Literatur diese Veränderungen nur für die hydropische und hypertonische Form allgemeinere Giltigkeit haben, während eine in demselben Rahmen liegende Erklärung der atrophischen Form bisher aussteht.

Aus dem Tierexperiment wissen wir, daß die einseitige Fütterung 
mit Kohlehydraten zu einer Wasseranreicherung des Organismus führt. Die schon oben zitierten Untersuchungen von Bischoff und Voit, die exakten Experimente Weigerts beweisen dies zur Genüge. Die Wassereinlagerung in die Gewebe kommt nach den grundlegenden Untersuchungen von $Z$ unt $z$ dadurch zustande, daß das Glykogen nicht wie Fett in wasserfreiem Zustand in der Zelle deponiert wird, sondern mit dem 2-3fachen seines Gewichtes an Wasser. Wenn z. B. der Glykogengehalt des Körpers durch Kohlehydratzulage in der Nahrung um $10 \mathrm{~g}$ steigt, so steigt das Gewicht des Körpers um $30-40 \mathrm{~g}$.

Haben wir nun zahlenmäßige Belege dafür, daß auch beim menschlichen Säugling durch ausschließliche oder fast ausschließliche Ernährung mit Kohlehydraten eine Wasseranreicherung des Körpers resultiert? Und wenn dies tatsächlich der Fall ist, in welchen Organen läßt sie sich nachweisen? Mit der Beantwortung dieser Frage würde ja gleichzeitig die ganze Pathogenese der Erkrankung klargestellt werden. Nun ist es natürlich sehr schwer, am lebenden menschlichen Säugling diese Frage exakt zu beantworten, und es wäre lediglich die Gesamtanalyse eines solchen Kindes, das aber vor dem Exitus keinerlei Gewichtssturz mitgemacht haben dürfte, imstande, uns darüber in eindeutiger Weise Auskunft zu geben. Eine solche Analyse liegt aber bisher nicht vor. Nun wissen wir aber, daß gewisse Organe und Gewebe nähere Beziehungen zum Wasserstoffwechsel haben und daß Veränderungen, welche sich in diesen, also vor allem im Bindegewebe und in der Muskulatur abspielen, maßgebend für die Wasserverteilung im Gesamtorganismus sind. Nach den Untersuchungen von Engels steht es fest, daß bei intravenöser Zufuhr physiologischer Kochsalzlösung bei Hunden alle Organe an Wasser zunehmen. Dieses in die Gewebe deponierte Wasser findet sich $\mathrm{zu}^{2} / 3$ in der Muskulatur und $\mathrm{zu} 1 / 6$ in der Haut. Die Muskeln nehmen dabei mehr Wasser auf, als ihrer prozentischen Menge im Körper entspricht. Wir müssen ihnen also vor allen anderen Gewebsarten sowohl absolut wie relativ die größte Bedeutung als Wasserdepots zuschreiben. Nach Befunden von Hauberisser und Schönfeld am Bindegewebe geschieht diese Wirkung nicht in absoluter Abhängigkeit von der Salzzufuhr, in Sonderheit nimmt „das $\mathrm{Na}$-Jon in keiner Weise eine exzeptionelle Stellung" ein. (Im Original gesperrt.) Daß diese Verbältnisse auch für den menschlichen Säugling Giltigkeit haben, scheint mir durch einen Befund Toblers gewährleistet, der seine Resultate durch Muskelanalysen von Kindesleichen erhielt. Der zweitgrößte Wasserwert sämtlicher Analysen, die Tobler über- 
haupt anstellte, betrifft ein an Mehlnährschaden verstorbenes Kind, trotzdem dasselbe unmittelbar vor dem Tode einen rapiden Gewichtssturz mitgemacht, also sicher noch viel Wasser verloren hatte.

Zur Untersuchung am Lebenden stand natürlich immer nur das Blut zur Verfügung, und je nach der Untersuchungsmethode, welche angewendet wird, stellen verschiedene Autoren verschiedene Theorien der Pathogenese des Mehlnährschadens auf. Während Heubner für die Entstehung des Krankheitsbildes einen Mangel an Eiweiß verantwortlich macht, glaubt Salge nach seinen Untersuchungen einen Salzmangel dafür anschuldigen zu müssen. Salge gewann diesen Findruck durch Bestimmung der Salze im Blut, und da ergaben sich nun große Unterschiede, je nach Alter und Konstitution des Kindes und nach dem Alter der Ernährungsstörung. Manche Kinder mit Mehlnährschaden zeigen gar keine Verminderung der Salze im Blutserum, während andere, besonders diejenigen Säuglinge mit weiter vorgeschrittener Form dieser Ernährungsstörung, eine deutliche prozentische Verminderung der Salze im Serum erkennen lassen. Salge erklärt diesen Befund dahin, daß die Wasserretention im Körper bezüglich ihrer Verteilung im-wesentlichen der Quellungsbreite der Organkolloide entspricht. Da diese am größten in der Muskulatur und Haut ist, finde sich hier die stärkste Wasserretention. Die Quellungsbreite des Blutes sei aber sehr gering, und deshalb finde sich hier keine Wasseraufnahme. Damit steht im Einklang eine Beobachtung von Keller, daß Kinder mit Mehlnährschaden, wenn sie mit salzhaltiger Kost genährt werden, stark Chlor retinieren, sich also offenbar im Cl-Hunger befinden, ,woraus selbstverständlich auf einen Salzhunger überhaupt geschlossen werden darf". Daß aber die Situation nicht so einfach liegt, daß also der Mehlnährschaden nicht einfach aus einem Salzhunger erklärt werden kann, beweisen schon die Untersuchungen Rietschels und die neuesten Befunde von Frank und Stolte, welche in der Leber von an Mehlnährschaden zugrunde gegangenen Kindern gezeigt haben, daß dieses Organ gegenüber der Leber normaler Vergleichskinder nicht nur wasserreicher, sondern auch salzreicher ist'). Czerny-Keller machen ein Zusammenwirken verschiedener Umstände für die Entstehung des Mehlnährschadens verantwortlich, 1. die Eiweißarmut der Nahrung, 2. ihre Fettarmut,

1) Anmerkung während der Korrektur: Aus einem von Klose gehaltenen Vortrag, dessen Inhalt mir derzeit nur auszugsweise bekannt ist, geht ebenfalls hervor, daß die Organe eines an Mehlnährschaden verstorbenen Kindes wasserreicher sind, als die eines normalen. 
3. die Fähigkeit der Kohlehydrate, Wasser zu binden und 4. den Mangel an Salzen, besonders an $\mathrm{Cl}$. Nach den Untersuchungen von Weigert führen Czerny - Keller die Herabsetzung der natürlichen Immunität auf die Wasseranreicherung des Organismus zurück und nicht auf die Salzarmut. L. F. Meyer weist in Kürze darauf hin, daß sowohl die hydropische als die hypertonische Form der in Rede stehenden Erkrankung durch Wasserretention zu erklären seien, daß aber ein zahlenmäßiger Beweis dieser Annahme noch ausstehe.

Läßt sich nun durch die Untersuchung des Blutes eine solche Annahme rechtfertigen? Lust sowohl als Reiß haben in ihren wiederholt zitierten Arbeiten darauf hingewiesen, daß schon die vorübergehende Zulage von Kohlehydrat zur Nahrung eine Hydrämie hervorruft. Ich kann nach meinen Untersuchungen dies vollauf bestätigen. Schon die Zulage des mildesten Kohlehydrates, des Schleims, bewirkt diese Anreicherung an Blutwasser.

F. S., 3 Monate alt, bisher nur mit Halbmilch und sehr geringen Zuckermengen ernährt. Wassergehalt des Blutes beim Eintritt $82,6 \%$. Wird auf Drittelmilch + Schleim gesetzt. Nach 48 Stunden beträgt der Wassergehalt des Blutes $83,4 \%$, also $0,8 \%$ mehr.

F. W., 7 Monate alt, bisher bei Brust. Wassergehalt des Blutes am Tage des. Eintrittes $82,9 \%$. Wird auf Drittelmilch + Schleim gesetzt, nach 24 Stunden beträgt der Blutwassergehalt $84,2 \%$, also $1,3 \%$ mehr.

Diese möglicherweise vorübergehenden Erniedrigungen der Blutkonzentration sollen nun keineswegs den Beweis dafür liefern, daß beim Mehlnährschaden eine Wasseranreicherung des Organismus statthat. Sollte aber diese Ansicht, die vor allem Rietschel prägnant ausgesprochen hat, zu Recht bestehen, sollten tatsächlich sowohl die hydropische Form des Mehlnährschadens in Wasseransammlungen im Bindegewebe, die hypertonische Form als Quellungszustände der Muskulatur ihre Erklärung finden, so müßte man mit der von mir angewandten Methodik, $d$. h. bei Kindern mit den eben genannten Formen von Mehlnährschaden, die keinen Gewichtssturz mitgemacht haben, die auch nicht fiebern, Erhöhungen des Blutwassergehaltes in sehr beträchtlichem Maße finden. Es müßte bei diesem Krankheitsbild, ebenso wie bei der Anaemia pseudoleucaemica, nicht einfach zu einer Verhinderung der physiologischen Austrocknung, d. h. zu einer relativ geringen Erhöhung des normalen Blutwasserwertes, sondern zu einer aktiven Steigerung desselben durch eine zweite Komponente, welche eben in der dauernden Darreichung von quellungsfähigem Kohlehydrat gegeben ist, und 
damit zu einer beträchtlichen Erhöhung der Blutwasserwerte kommen. Das ist nun auch tatsächlich der Fall. Die bei diesen Kindern gefundenen Werte bewegen sich sämtlich zwischen 85 und $86 \%$, übersteigen also sämtlich den Normalwert, aber auch diejenigen Werte, wie wir sie eben bei einer vorübergehenden Darreichung von Kohlehydrat gesehen haben.

Diese Feststellungen (Erhöhung des Blutwassergehaltes) im Verein mit den Untersuchungen Salges (Verminderung der Salze) werden uns zu der Anschauung führen, daß bei der hydropischen und hypertonischen Form des Mehlnährschadens die Hauptmasse des überschüssigen Wassers an Kolloide gebunden ist, daß dieser Umstand wahrscheinlich die hauptsächlichste und primäre pathogenetische Schädigung darstellt, und daß alle anderen Umstände wie Eiweiß-, Fett- und Salzmangel zweifellos mit im Spiele sind, aber doch erst in zweiter Linie in Betracht kommen.

Was folgt aus diesen Anschauungen für die Therapie? Bisher glaubte man den Mehlnährschaden vor allem durch die Deckung des Defizits an Eiweiß, Fett und Salzen heilen zu können. Dabei machte sich nun ein unliebsames Vorkommnis bemerkbar. Die Kinder, welche von einer kohlehydratreichen Kost auf eine kohlehydratfreie gesetzt wurden, erlebten rapide Gewichtsstürze. Besonders unangenehm wirkt in dieser Hinsicht die Frauenmilch, die unbeschadet ihrer sonstigen glänzenden Eigenschaften als Heilnahrung den Nachteil der Salzarmut hat. Es ist ganz fraglos, daß für schwere, besonders mit akuten Störungen und Infektionen komplizierte Formen von Mehlnährschaden ebenso wie für die atrophische Form desselben die Frauenmilch das ultimum refugium darstellt. Bei den unkomplizierten hydropischen und hypertonischen Formen aber, und nur von diesen ist hier die Rede, machen sich ähnliche Verhältnisse bemerkbar, wie sie schon von Keller und Freund bei der Reparation von akuten Ernährungsstörungen gegenüber dem Verhalten von kohlehydratreichen Gemischen hervorgehoben wurden. Tritt schon hier die Tatsache deutlich in die Erscheinung, daß die Kinder, welche sich bei Brustmilch reparieren, sehr lange im Gewicht stehen bleiben, daß es also geraume Zeit braucht, bis die Eigenschaften der salz- und kohlehydratarmen Frauenmilch zu einem Gewichtsanstieg führen, der dann allerdings sehr sicher zum Ziele leitet, so ist dies um so mehr bei diesen Formen von Mehlnährschaden der Fall. Hier ist nicht nur dieser Zeitraum des Gewichtsstillstandes, sondern vorher noch ein rapider Gewichtssturz durch Abgabe des überreichlichen Quellungswassers zu überwinden, bevor der solide Ansatz 
bei Frauenmilch beginnen kann. Das führte, wie ja bekannt, und wie ich mich früher selbst oft überzeugen konnte, beim Absetzen hydropischer und hypertonischer Kinder auf Frauenmilch zu dem Ereignis, daß dieselben den Eintritt der Heilung an der Brust nicht erlebten, sondern vorher am Kollaps zugrunde gingen.

Folgerichtig wäre also aus diesen Anschauungen die Forderung abzuleiten, Kinder mit unkomplizierter hydropischer und hypertonischer Form des Mehlnährschadens zur Vermeidung des Gewichts sturzes weiter auf kohlehydrathaitiger Kost zu belassen und ihnen das bisher bestehende Defizit an Eiweiß, Fett und Salzen auszugleichen. Uneingeschränkt ist diese Forderung unannehmbar, da man damit in der Zufuhr wasserbindender Nahrung, also in der ursächlichen Schädlichkeit fortfährt. Trotzdem kann man aber dieser Forderung nachkommen, wenn man nur dafür Sorge trägt, daß das zur Einlagerung der wichtigen Körperbestandteile, vor allem der Salze notwendige Wasser nicht ebenfalls von außen zugeführt, sondern vom Organismus selbst geliefert wird. Wenn man nämlich die zugeführte Nahrungsmenge in sehr kleinem Volumen gibt und dafür Sorge trägt, daß sie die bisher entbehrten Bestandteile von Eiweis, Fett und Salzen in genügender Menge enthält, so kann man den Organismus zwingen, das zur Ablagerung notwendige Wasser aus seinen durch die bisherige pathologische Ernährung angesammelten überschüssigen Beständen abzugeben. In die Praxis umgesetzt heißt das: Man wird Kinder mit unkomplizierter Form von hydropischem und hypertonischem Mehlnährschaden ruhig weiter Kohlehydrat in mildester Form (Schleim), eventuell unter einer Beigabe von einer Mahlzeit Buttermileh (zur Deckung des N- und Salzdefizits), und geringe Mengen Kuhmileh geben, die Gesamtmenge aber möglichst klein, unter dem der Norm entsprechenden Volumen wählen. Mit dieser Ernährungsweise vermeidet man den Gewichtssturz, der Organismus gibt das überschüssig angesammelte Wasser langsam ab, und erst, wenn eine normale Zusammensetzung des Körpers erzielt ist, kann auch die der Norm entsprechende Nahrung gegeben werden. Die weiter unten wiedergegebenen Krankengeschichten und Kurven zeigen, daß es in dieser Weise gelingt, ohne Anwendung von Frauenmilch (und solche steht ja nicht überall zur Verfügung), die besprochenen Formen des MehInährschadens zu heilen, ja daß die Gewichtszunahme schon nach wenigen Tagen, manchmal sofort einsetzt, während der Wassergehalt des Blutes dabei konstant abnimmt und dem Normalgehalt zustrebt, und während gleichzeitig die Hypertonie del 
Muskeln und die hydropische Beschaffenheit der Haut im gleichen Maße schwinden. Dafür, daß große Überschüsse an Wasser bei diesen Kindern vorhanden sein müssen und daß dieselben bei der geschilderten Ernährungsweise langsam abgegeben werden, scheint mir auch zu sprechen, daß bei keinem einzigen der Fälle trotz der Einführung kleiner Nahrungsmengen, irgendwelche Erscheinungen von Austrocknung an den Schleimhäuten, niemals auch nur die Andeutung eines „,Durstfiebers“ bemerkt wurde.

H. P., 7 Wochen alt, Frühgeburt im 8. Monat. War 3 Wochen bei der Brust, bekam dann alle 3 Stunden 6 EBlöffel Wasser +1 Kaffeelöffel Nestlemehl + 3 Stück Zucker. Ist seit einigen Tagen unruhig, zeigt aber keinerlei sonstige Erscheinungen

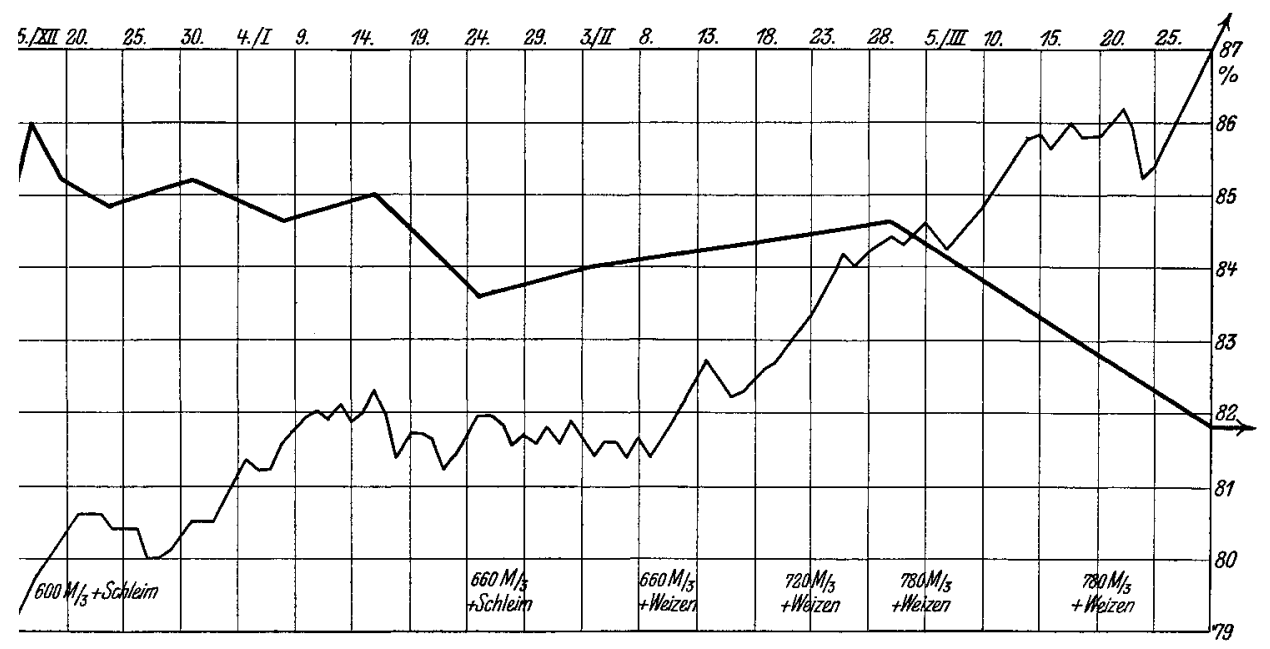

Fig. 12.

von Dyspepsie. - Bei der Aufnahme $54 \mathrm{~cm}$ lang, $3000 \mathrm{~g}$ schwer. Die Hautdecken sind blaß, die Haut fühlt sich ausgesprochen schwammig an. Normale Temperatur. Fast sämtliche Muskeln sind im Zustande starker Hypertonie; man kann das Kind an einem Arm aufheben, ohne daß derselbe gestreckt wird. Innerer Befund vollständig normal. Stuhl braun, schaumig, 3 mal täglich.

Das Kind wurde auf $600 \mathrm{~g}$ Drittelmilch + Schleim gesetzt und nahm gleich von Anfang an zu. Wie Fig. 12 zeigt, wurde diese geringe Nahrungsmenge durch 40 Tage beibehalten, während deren das Kind mit Schwankungen langsam zunahm. Nach ungefähr 3 Wochen konnte konstatiert werden, daß die Hypertonie deutlich geringer, wenn auch noch vorhanden war. Das Aussehen des Kindes war entschieden besser geworden, die Haut nicht mehr so pastös, wenn auch von einem normalen Turgor noch keine Rede sein konnte. Nach 6 Wochen wurde die Nahrungsmenge, da inzwischen Gewichtsstillstand eingetreten war, um $60 \mathrm{~g}$ gesteigert. Der Gewichtsstillstand hielt an, und nach weiteren 2 Wochen wurde statt des Schleims Weizenmehl gegeben. Von da an setzte guter Gewichtsanstieg ein. 
Fortlaufend wurden nun diese Mengen vorsichtig zunächst auf 720 , dann auf $780 \mathrm{~g}$ erhöht, und statt Drittelmilch Halbmilch gegeben. Die Menge von $780 \mathrm{~g}$ wurde aber niemals überschritten. Das Kind blieb während der ganzen Zeit frei von interkurrenten Störungen oder Infektionen und nahm im Laufe von ungefähr $31 / 2$ Monaten $900 \mathrm{~g} \mathrm{zu}$, und zwar gleich vom 1. Tage ab. Die Hypertonie war nach $1 \frac{1}{2}$ Monaten vollständig geschwunden, die Haut hatte dann guten Turgor, die Farbe des Kindes war ausgezeichnet. Auch seine psychische Entwicklung war vollständig normal.

Es handelte sich also um eine Kombination der hydropischen und hypertonischen Form des Mehlnährschadens, welche in der besprochenen Weise behandelt wurde. Der Blutwassergehalt am Tage der Aufnahme betrug $84,9 \%$, überschritt also die Norm um ein Beträchtliches. Nach Einführung der Schleimnahrung ergab sich die oben erwähnte vorübergehende Erhöhung des Blutwassergehaltes schon nach 48 Stunden bis auf $86,0 \%$. Nach weiteren 2 Tagen war dieselbe aber wieder geschwunden. Nun zeigte sich in wiederholten Bestimmungen, deren Resultate auf Fig. 12 veranschaulicht sind, daß der Wassergehalt des Blutes während der $3^{1} / 2$ Monate in Schwankungen kontinuierlich kleiner wurde. Während der ersten Wochen der Behandlung blieb er noch ziemlich hoch und es ist auffallend, daß auch die Hypertonie während dieser Zeit immer noch bemerkbar war. Als Ursachen dafür glaube ich die immerhin noch recht große Menge von $600 \mathrm{~g}$ pro Tag anschuldigen zu müssen. Es war dies einer der ersten Fälle, die ich in dieser Weise behandelte. Erst als das Kind älter und schwerer geworden war, und die Nahrungsmenge immer noch klein blieb, fand eine raschere Abgabe des Blutwassers statt und da ging auch die Hypertonie rasch zurück. Besonders während der letzten Zeit, wo das Kind schon viel raschere Zunahmen zeigte, erfolgte gleichzeitig eine raschere Abnahme des Blutwassers, welche in den $3^{1} / 2$ Monaten der Beobachtung vom Höchstwert bis zur Bestimmung bei der Entlassung mehr als $4 \%$ betrug.

Der folgende Fall konnte leider nur ambulatorisch beobachtet werden und soll daher in therapeutischer Hinsicht nicht weiter verarbeitet werden. Er zeigt nur, welchen Einfluß die Mehlernährung auf den Blutwassergehalt hat.

F. W., 8 Wochen alt, war 5 Wochen bei der Brust und bekam dann ausschließlich Reiswasser alle 3 Stunden. Seit 3 Tagen besteht eine akute Dyspepsie mit wiederholtem Erbrechen, zahlreichen, grünen schleimigen Stühlen und Abmagerung des Kindes. - $3600 \mathrm{~g}$ schwer, trotz der Abmagerung noch deutlich schwammige Haut, keine Hypertonie.

Trotz der bestehenden Dyspepsie, welche sichtlich zu einem raschen 
Verfall des Kindes geführt hatte und trotz der relativ nur kurze Zeit dauernden fehlerhaften. Mehlemährung ( 3 Wochen) betrug der Blutwassergehalt $84,0 \%$, war also sicher pathologisch erhöht.

P. B., 7 Monate alt, war einen Monat bei der Brust, bekam dann alle zwei Stunden einen Kaffeelöffel Nestlemehl in $1 / 81$ Wasser. Auch bei Nacht alle zwei Stunden gefüttert. Ein Versuch mit Zugabe von Milch ungefähr 1 Monat vor der Aufnahme wurde nach wenigen Tagen wegen Erbrechens wieder aufgegeben. Soll bei der Geburt $3 \mathrm{~kg}$ schwer gewesen und bei der Brust gut gediehen sein. Seit der künstlichen Ernährung fortdauernde Abnahme. Wird wegen des ungenügenden Gedeihens aufgenommen. - $58 \mathrm{~cm}$ lang, $3080 \mathrm{~g}$ schwer. Haut schmutziggrau, welk, sehr spärliches Fettpolster. Keine Zeichen von Rachitis oder Spasmophilie, deutliche Hypertonie an allen Extremitäten. Innerer Befund normal, keine Temperatursteigerung. Pirquet negativ. -.. Wird gleich nach der Aufnahme auf $500 \mathrm{~g}$ Drittelmilch mit Sehleim und $100 \mathrm{~g}$ Buttermilch gesetzt. Gleich vom 1. Tage an schwankungslose Zunahme. Nach 17 Tagen statt Drittelmilch Halbmilch. Zunahme ohne Unterbrechung. Nach 28 Tagen $3780 \mathrm{~g}$, also $700 \mathrm{~g} \mathrm{Zu}$ nahme in I Monat.

Hier handelt es sich um einen schweren Fall von Mehlnährschaden, der durch 6 monatliche ausschlieBliche Fütterung mit Nestlewasser hypertonisch, aber auch atrophisch geworden war. Der Wassergehalt im Blut betrug $82,8 \%$, zeigte also einen bedeutend niedrigeren Wert wie der der anderen Kinder, was wohl damit zusammenhängen mag, daß es, wie Czerny-Keller hervorheben, beim Utbergang der rein hydropischen oder hypertonischen Form in die atrophische zu einer Wasserverminderung des Organismus kommt. Wenn nun auch dieser Wert niedriger ist, als ihn die anderen Kinder mit hydropischer und hypertonischer Form von Mehlnährschaden ohne Atrophie zeigen, so ist er doch noch wesentlich höher als der von gleichaltrigen Normalkindern. Das dürfte sowohl den Umstand erklären, daß dieses Kind deutlich hypertonisch war, als auch die Wirksamkeit der Therapie. Das Kind vertrug die neue Nahrung sehr gut, nahrm gleich von Anfang an gut zu, und während dieser Zunahme sank auch der Wassergehalt des Blutes auf $81,4 \%$, was ungefähr der Norm für dieses Alter entspricht.

K. F., 31/2 Monate alt, war erst 6 Wochen bei der Brust, bekam dann nach einem Versuch mit einer Milchverdünnung, der aber mißlang, 3 stündlich 6 Eßlöffel Wasser + 1 Kaffeelöffel Nestlemehl +1 Würfel Zucker. Wird wegen ungenügenden Gedeihens aufgenommen. - $56 \mathrm{~cm}$ lang, $3300 \mathrm{~g}$ schwer, leicht abgemagert, Haut blaB und welk. Schwere Hypertonie der Extremitätenmuskulatur. Innerer Befund normal. - Das Kind erhielt $420 \mathrm{~g}$ Drittelmilch mit Schleim und $60 \mathrm{~g}$ Buttermilch und nahm bei sehr guten Stühlen gleich vom 1. Tage an zu. Nach 11 Tagen $3520 \mathrm{~g}$, was einer durchschnittlichen täglichen Zunahme von $20 \mathrm{~g}$ entspricht. Leider wurde das Kind nicht länger im Krankenhaus belassen. 
Bei dieser hypertonischen Form von Mehlnährschaden wurde ein Blutwassergehalt von $86,1 \%$ gefunden. Die gewählte Therapie führte prompt zum Ziel.

M. F., 2 Monate alt, Frühgeburt, war 12 Tage bei der Brust, dann durch 2 Wochen bei Drittelmilch mit Zucker, seit 3 Wochen 2 bis 3 stündlich Kufekewasser (ungefähr $100 \mathrm{ccm}$ ). Geburtsgewicht $2100 \mathrm{~g}$. Bei der Aufnahme $49 \mathrm{~cm}$ lang, $2250 \mathrm{~g}$ schwer, ausgesprochen hypertonisch. Haut rot, gut durchfeuchtet, fühlt sich prall an. Innerer. Befund vollständig normal. Wird auf $480 \mathrm{~g}$ Drittelmilch mit Schleim gesetzt und nimmt von Anfang an gut zu. Erst nach mehr als 4 Wochen Steigerung auf $600 \mathrm{~g}$, kurze Zeit nachber Erhöhung der Milchkonzentration. Im Verlaufe von 7 Wochen Zunahme um $780 \mathrm{~g}$. Die Hypertonie nahm langsam $a b$ und war ungefähr $31 / 2$ Wochen nach der Aufnahme vollständig gesehwunden.

Aus äußeren Gründen konnten bei diesem Kinde keine Blutwasserbestimmungen gemacht werden, doch gleicht sein Verhalten, besonders der Therapie gegenüber, vollständig dem der anderen Kinder.

\section{Die Bedentung des Wassers für die Pathogenese der exsudativen Diathese.}

Seitdem Czerny seine klassische Schilderung des Symptomenbildes der exsudativen Diathese gegeben und damit in der Pädiatrie die Lehre von den Konstitutionsanomalien überhaupt zu nevem Leben erweckt hat, war damit auch die Frage nach der Pathogenese dieser merkwürdigen Zustände aufgerollt. Wenn man sich eine Zeitlang gewehrt hat, in der oder jener Form die alte Humoraltheorie wieder ans Licht zu ziehen, und wenn es vielleicht auch heute noch einzelne Ärzte gibt, welche der Einführung der Begriffe „Konstitution“ und „Konstitutionsanomalie" eine Berechtigung absprechen, so geschah und geschieht es sicher nur deshalb, weil eine Fundierung des Begriffes auf exakter naturwissenschaftlicher Basis bislang noch aussteht. Bloch z. B. schreibt: „,. . und diese dunklen schwankenden Begriffe und ihre Beziehungen zu den Hautphänomenen sind durch Czern ys Mitteilungen kaum konkreter, physiologisch faßbarer geworden". Während wir in der Erkenntnis des Wesens der Ernährungstörungen, man könnte sagen, fast jeden Tag, sei es durch Nachahmung dieser Zustände im Tierexperiment, sei es im Stoffwechselversuch am Säugling, einen Schritt nach vorwärts tun, tappen wir bei einem Erklärungsversuch der Konstitutionsanomalien noch sehr im Dunkeln. In den folgenden Zeilen soll der Versuch gemacht werden, dem Wesen der exsudativen Diathese etwas näher zu kommen, wenn ich mir auch vollständig bewußt 
bin, das Problem keineswegs gelöst zu haben. Ich glaube aber zeigen zu können, daß gewisse Beziehungen zwischen den Erscheinungen der exsudativen Diathese und dem Wasserstoffwechsel des Körpers bestehen. Damit könnte man die bisherige unbestimmte Gleichung auf eine solche mit nur einer Unbekannten zurückführen, deren Lösung Aufgabe weiterer Forschung sein wird.

Von Czerny selbst wurden sowohl der Fett- als der Wasserstoffwechsel in nähere Beziehungen zur exsudativen Diathese gebracht, insofern als jede Art von Mästung, gleichgültig auf welche Art sie erreicht wird, die Manifestationen der in Rede stehenden Konstitutionsanomalie verschlimmert. An einer Stelle seiner diesbezüglichen Publikationen hat nun $\mathrm{Cz}$ ern y ganz deutlich ausgesprochen, daß es eigentlich doch nur der Wasserstoffwechsel ist, welcher unmittelbare und direkte Beziehungen zur exsudativen Diathese hat. „Versuchen wir uns aus den empirisch festgestellten Tatsachen eine Vorstellung darüber zu machen, worin die primären Ursachen der exsudativen Diathese zu suchen sind, so ergibt sich, daß es sich um einen kongenitalen Defekt im Chemismus des Körpers handelt, und dieser Defekt betrifft hauptsächlich jene Gewebe, welche die großen Schwankungen im Wassergehalt des Organismus ermöglichen. Je größer der Wassergehalt, um destomehr macht sich die exsudative Diathese bemerkbar. So erklärt es sich erst, daß wir mit einer entsprechend gewählten Nahrung, mit welcher wir den Wassergehalt des Körpers steigern oder herabsetzen, Besserungen und Verschlechterungen der Krankheitsanlage herbeiführen können." Wir werden weiter unten sehen, ob sich für diese empirisch gewonnenen Erfahrungen exakte Beweise erbringen lassen.

Es handelt sich vor allem darum, die ursprünglich von der Czernyschen Schule zur Erklärung des Wesens der exsudativen Diathese ebenfalls herbeigezogenen Beziehungen zum Fettstoffwechsel auszuschalten und damit das weitere Arbeitsgebiet einzuschränken. Dies scheint mir nach den bisher in dex Literatur vorliegenden Ergebnissen sehr leicht möglich. Steinitz und Weigert konnten im Stoffwechselversuch bei exsudativer Diathese eine nähere und direkte Beziehung zum Fettstoffwechsel keineswegs konstatieren. Moro konnte durch abundante Fettmást bei Kindern mit konstitutionellem Ekzem eine rasche und auffallende Besserung erzielen. Risel konnte 36 Kinder mit Obesitas beobachten, von denen 26 an Symptomen von exsudativer Diathese litten oder gelitten hatten. Meist handelte es sich um Kinder, die in den ersten beiden Lebensquartalen stark abgemagert waren und 
dabei Symptome von exsudativer Diathese geboten hatten, bei denen dann aber die Macies in das Gegenteil umschlug. Risel glaubt nun, trotzdem beim Fettwerden meist die Symptome der exsudativen Diathese schwanden, die beiden Erscheinungen in einen kausalen $\mathrm{Zu}-$ sammenhang bringen zu können. Wenn man aber Risels Krankengeschichten näher studiert, scheint dieser kausale Zusammenhang nicht so eindeutig zu bestehen. Abgesehen davon, daß nur $2 / 3$ der Kinder dieses Verhalten zeigten, hat Risel seine Kinder unter Vermeidung von Wasseransatz mit sehr knappen Milchmengen (niemals über $3 / 4$ Milch täglich) und unter Ausschluß von allen kohlehydratreichen Nahrungsmitteln (Buttermilch, Malzsuppe) ernährt. Gerade diese Beobachtung spricht dafür, daß die exsudative Diathese eher Zusammenhänge mit dem Wasserstoffwechsel als mit dem Fettstoffwechsel habe, da beim Fettwerden unter Vermeidung von Wasseransatz die Symptome von exsudativer Diathese verschwanden. Im übrigen aber existieren aus der Czernyschen Schule selbst Angaben, welche einen ausschließlichen oder nur direkten Zusammenhang von Fettstoffwechsel mit den Erscheinungen der exsudativen Diathese unwahrscheinlich machen. Stolte z. B. schreibt: „Um Mißverständnissen vorzubeugen, sei hier indessen ausdrücklioh betont, daß nicht fettreiche Nahrung an sich die latenten Erscheinungen der exsudativen Diathese provoziert, sondern nur ein Überschuß an solehen. So habe auch ich bei $5 \%$ Fett in der Kuhmilch eine ziemlich schwere Form der exsudativen Diathese abheilen sehen bei einem Kinde, das eben so knapp gehalten wurde, daß. es im Körpergewicht stehenblieb." Von Finkelstein wurde übrigens dieses Verhalten der exsudativen Kinder wiederholt betont.

Fragen wir uns nun, ob bisher direkte Beziehungen der exsudativen Erscheinungen zum Wasserstoffwechsel nachgewiesen wurden, so stoßen wir wieder auf die bekannten methodischen Schwierigkeiten. Empirisch wurden sie schon von Czerny festgestellt. „Äußerlich betrachtet ist natürlich in keiner Weise wahrnehmbar, wodurch ein Kind fett geworden ist. Es ist aber ein prinzipieller Unterschied, ob eine Mästung durch Fett oder Kohlehydrate erreicht wurde. Die letztere führt im Gegensatz zu der ersteren zu einem wasserreichen Organismus". Der direkte Nachweis des Einflusses eines wasserreichen oder wasserarmen Organismus oder einer Wasseransatz befördernden oder hemmenden Nahrung auf die Erscheinungen der exsudativen Diathese im Stoffwechselversuch steht bislang noch. aus. Bis jetzt war meist nur der Salzstoffwechsel in seinen Wechselbeziehungen zu den Manifestationen 
der exsudativen Diathese Gegenstand der Untersuchung. Bruck fand, daß sich Kinder mit Ekzem infolge exsudativer Diathese bezüglich ihres Mineralstoffwechsels bei ungefähr gleichen Versuchsbedingungen in Resorption und Retention der Salze nicht von normalen unterscheiden und glaubt, daß sich ,demnach bis jetzt keine engeren Beziehungen zwischen Salzstoffwechsel und Ekzem nachweisen" lassen. Daß dagegen solche Beziehungen existieren, erhellt aus den Untersuchungen von Meyer und von Freund. Der erstere konnte finden, daß Unterernährung beim ekzematösen Säugling eine beträchtlichere Salzausschwemmung hervorruft als beim normalen. Organische Nährstoffe (Casein und Fett) bewirken ebenfalls beim Ekzematösen eine etwas reichlichere Ausfuhr von Salzen. Meyer glaubt sich nach seinen Untersuchungen zu der Annahme berechtigt, daß der Ekzematöse über ein reichlicheres Salzdepot verfügt als der Normale. Freund machte Stoffwechselversuche an normalen und ekzematösen Kindern mit derselben Kost, die im allgemeinen ziemlich salzarm war, nur $\mathrm{Cl}$ in mäßigen Mengen enthielt. Da zeigte es sich nun, daß, während die normalen Kinder abnahmen, die drei Ekzemkinder durchwegs erheblich zunahmen, sogar Ödembildungen zeigten. Hand in Hand damit ging bei den Ekzemkindern eine stark positive Bilanz an Na. Aus diesem Verhalten läßt sich nach Freund eine Sonderstellung der Ekzemkinder gegenüber den Normalen bezüglich ihres Salzstoffwechsels ableiten. Diese beiden Arbeiten ergänzen sich insofern, als sie das Verhalten von Ekzemkindern den Salzen gegenüber in ihren beiden entgegengesetzten Möglichkeiten zeigen. Me yer bot Ekzemkindern eine salzarme Kost und zeigte, daß sie ihre Körpersalze sehr rasch abgaben, rascher als Normale, Freund führte Salze zu und bewies, daß die Ekzematösen dieselben rascher und in gröBerer Menge aufnahmen als Normale. Diese Befunde stehen in schönster Utbereinstimmung mit den Resultaten Menschikoffs, der an 6 Ekzemkindern zeigen konnte, daß dieselben eine erhöhte Labilität gegenüber dem $\mathrm{Cl}$ besitzen. Sie nahmen. $\mathrm{Cl}$ rascher auf und gaben es auch rascher wieder ab.

Diese Untersuchungen würden eine nähere Beziehung des gesamten Salzstoffwechsels zu den Erscheinungen, der exsudativen Diathese wahrscheinlich machen, Ältere und neuere Untersuchungen weisen noch darauf hin, daß speziell jenes Organ, an dem sich die Erscheinungen der exsudativen Diathese am frühesten und öftesten zeigen, die Haut, ganz besonders geeignet ist, Veränderungen ihres Salz- und Wassergehaltes zu zeigen. Grosz, der am Erwachsenen mit Ekzem, Prurigo, 
Psoriasis und Pemphigus den Cl-Stoffwechsel studierte, wies schon darauf hin, daß die Haut gleichsam als ein Depot für die temporäre Anhäufung von Kochsalz und Wasser funktioniert, und fand bei seinen Fällen, daß bisweilen schon klinisch eine erhöhte Succulenz der Haut in Erscheinung trat. Dagegen konnte Ba u $\mathrm{mm}$ eine solche Beziehung des Salzstoffwechsels zum Pemphigus nicht feststellen. Rocaz fand, daß beim konstitutionellen Säuglingsekzem besonders die Ernährung mit großen Flüssigkeitsmengen das Auftreten desselben begünstige.

Daß die Haut bei konstitutionellem Ekzem tatsächlich gegenüber den verschiedensten Reizen eine erhöhte Empfänglichkeit besitzt, beweisen die Untersuchungen von Schultz, Mautner und Rachmilewitsch. Die Abhängigkeit dieser Hautreaktion vom Chemismus des Gesamtorganismus hat in besonders schöner Weise Luithlen gezeigt, der an jungen Katzen und Kaninchen arbeitete. Sowohl Säuerung des Organismus als Zufuhr von oxalsaurem Natrium erhöhen die Reaktionsfähigkeit der Haut, während Ca-Zufuhr sie herabsetzt. Auch verschiedene Ernährung ändert diese Reaktionsfähigkeit. Mit Hafer ernährte Kaninchen zeigen eine Aufspeicherung von Salzen in ihrem Organismus, während es bei der Säurevergiftung zu einer Demineralisation kommt. Die mit Hafer ernährten Tiere zeigen eine größere Empfindlichkeit der Haut als die Kontrolltiere.

Erwähnen wir noch, daß nach Untersuchungen von Kern, der fand, daß exsudative Kinder auf Zulage von Natrium nucleinic. eine verlangsamte Ausscheidung der überschüssig eingeführten Harnsäure gegenüber der Norm zeigen, während früher von Nie mann nähere Beziehungen des Purinstoffwechsels zur exsudativen Diathese und von Uffenheimer auch Leim Arthritismus solche vermißt wurden, so ist damit die bisherige Literatur über nähere Beziehungen von Stoffwechselvorgängen zu den Erscheinungen der exsudativen Diathese erschöpft. Der Befund von H. und L. Hirschfeld über das Vorkommen von vasokonstringierenden Substanzen im Serum bei exsudativer Diathese konnte von Sa melson nicht bestätigt werden. Die bei manchen Fällen von exsudativer Diathese gefundene Eosinophilie wird von Aschenheim mit Recht nicht als gleichwertiges Symptom der exsudativen Diathese betrachtet. 1) Schließlich wurde auch noch der Versuch gemacht,

1) Anmerkung während der Korrektur. Neuestens findet Putzig mit verbesserter Methodik doch wieder eine Stütze für die zuerst von Langstein vertretene Anschauung, daß die Eosinophilie als gleichwertiges Symptom der exsudativen Diathese aufzufassen sei. 
das. Wesen der exsudativen Diathese oder eines Teiles ihrer Erscheinungen in einer, ,Vagotonie" zu suchen. Die Erfolge, die Krasnogorski in der Behandlung von nässenden Ekzemen mit Atropin erzielte, lassen sich aber zwanglos weniger durch eine Herabsetzung des Vagustonus als vielmehr einfach in einer lokalen Austrocknung der Haut erklären.

Wenn wir daher wieder zu dem von Czerny aufgestellten Satz zurückkehren, daß das Wesen der exsudativen Diathese im Chemismus des Wasserstoffwechsels zu suchen sei, so ergeben sich nur in den hier zitierten Versuchen, welche Beziehungen der Konstitutionsanomalie zum Salzstoffwechsel feststellen, Anhaltspunkte für die Berechtigung dieser Ansicht. Nachdem wir aber schon in den vorhergehenden $A b-$ schnitten gesehen haben, daB das Zusammengehen von Salz- und Wasserstoffwechsel nicht immer parallel erfolgt, sondern nur in einer gewissen bedingten Abhängigkeit voneinander, so wird erst der Beweis zu erbringen sein, ob sich Kinder mit exsudativer Diathese der Zulage und dem Entzug von Wasser gegenüber genau so verhalten, wie sie es nach den Versuchen von Freund und Meyer den Salzen gegenüber tun, d. h. ob sie Wasser rasch aufnehmen und rasch abgeben.

Bevor jedoch diese Frage entschieden werden kann, handelt es sich darum, festzustellen, ob überhaupt der Organismus des exsudativen Kindes absolut wasserreicher oder wasserärmer ist als der des normalen, resp. ob die Überernährung beim exsudativen Kind größeren Wasserreichtun bedingt, als beim normalen, was ja von vornherein nicht so unwahrscheinlich wäre. Um diese Tatsache sicherzustellen, habe ich zunächst in einfachen klinischen Beobachtungen aus dem Ambulatorium, dessen Publikum sich aus den Proletarierkreisen einer Vorstadt zusammensetzt, und bei dem die verschiedensten Manifestationen der exsudativen Diathese in ungemeiner Häufigkeit vorkommen, mir ein Bild zu machen gesucht, welcher Art die postulierte Utberemährung eigentlich ist. Es wurden während zweier Jahre sämtliche Kinder, die Erscheinungen von exsudativer Diathese irgendwelcher Art boten, untersucht, ihre Ernährungsanamnese erhoben und auf eigens hierzu gedruckten Formularen eingetragen. Auf diese Weise gelang es mir, einige hundert solcher Anamnesen zusammenzustellen, und ich habe im folgenden eine Auswahl von 30 Krankengeschichten von Kindern im Alter von 6 Monaten bis zu 12 Jahren zusammengestellt. Diese Zahl schien mir vollständig zu genügen, denn die betreffenden Angaben sind mit geringen Unterschieden fast bei allen Kindern gleich. 
L. N., J. N. 1569/12. 6 Monate alt. 14 Tage bei Brust, jetzt täglich $21 / 41$ Drittelmilch, einmal Suppe. Hatte immer Ekzem am ganzen Körper, schon 3 mal Schnupfen und Husten, Ohrenfluß, Schlaffes, blasses Kind, großer Bauch, ist fortwährend naß. Stuhl immer sehr hart.

A. M., J.-N. 2994/12. 7 Monate alt, 3 Monate bei Brust, jetzt täglich 11 Milch und 3/4 I Wasser. Hat ,alle Augenblick" Schnupfen, 1 mal schon Pneumonie. Typischer Milohnährschaden, enormer Meteorismus. Ekzem am Stamm, Strophulus an den Beinen. Sehr mager und schlaff. Ausgedehnte Bronchitis.

F. J., J.-N. 367/12. 13 Monate alt, 4 Monate Brust, dann Kuhmilch in unbekannter Verdünnung. Jetzt: I Kaffee, II Milch, III Suppe, Gemüse, IV Milch, V Tee. IBt noch nichts Festes. „Hat den Schnupfen noch nie verloren." Jetzt Angina, rinnende Nase, große Tonsillen, enorme Schwellung der Nackendrüsen. Uriniert ,alle Augenbliok". Stuhl 2 mal täglich.

J. B., J.-N. 15/12. 14 Monate alt, 7 Monate Brust, seit der Ablaktation folgende Diät: I Kaffee, II Milch, III Suppe, IV Milch, V Milch. Gesamtmenge pro Tag $11 / 4$. Sehr schlaffes, blasses Kind, Rachitis. Wiederholte Rhinitis, Bronchitis. 3 mal vorher schon im Ambulatorium wegen Pharyngitis und Angina.

F. G., J. N. 2711/12. 15 Monate alt, ist noch bei Brust, wird seit dem 8. Monat zugefüttert. Jetzt außer der Brust: I Kaffee, Semmel, II Wurst, III Suppe, Gemüse, IV = I, V Suppe, Gemüse. Wenn er schreit, bekommt er die Brust. Täglich außer der Brust $1 / 41$ Kuhmilch und 11 Wasser. Hat fortwährend Schnupfen und Husten. Jetzt ausgedehntes, impetiginös infiziertes Ekzem am Kopf und Stamm, rinnende Nase, Lichtscheu, Conjunctivitis, große Tonsillen. Pirquet negativ.

K. M., J.-N. 3889/12. 2 Jahre alt. 3 Monate Brust, dann Kuhmilch. Jetzt täglich 21 Kaffee (1), 1 mal Suppe und Gemüse, 1 mal Milchspeise. Fast jede Woche Katarrh, Schnupfen und Husten. Seit 1 Jahr Prurigo und Gneis. Lingua geographica. Tonsillarhypertrophie. Bronohitis, Otorrhoe, Pirquet negativ.

A. G., J.-N. 2753/12, 2 Jahre alt, 4 Monate bei Brust, seit Ende des 1. Jahres ,gemischte" Kost. Täglich $1 / 21$ Milch, $3 / 41$ Wasser. Jeden Tag Kartoffel. 1 mal Suppe und Gemüse, 1 Ei. 1 mal wöchentlich Fleisch. - Alle 2 Wochen Husten und Schnupfen, I mal Pneumonie. Derzeit adenoide Vegetationen und Bronchitis.

L. K., J.-N. 1383/12, 2 Jahre alt, 9 Monate Brust. Jetzt: I Kaffee, Semmel, II Butterbrot und Wurst, III Suppe und Gemüse, IV $=$ I, V Butterbrot und Tee. Gesamtmenge $1 / 21$ Milch und 11 Wasser pro Tag. Seit dem Alter von 3 Monaten „Vierziger". Jetzt horrender Milchschorf und Prurigo an Stamm und Extremitäten. Niemals' Schnupfen oder Husten.

K. F., J.-N. 5332/12, 2 Jahre alt. 9 Monate Brust. Jetzt täglich 21 Kaffee (!), sonst keine Nahrung. Sehr oft Husten und Schnupfen. Sehlaffes, auffallend blasses Kind. Tonsillarhypertrophie, schleimig eitrige Rhinopharyngitis, großer Banch, Nabelhernie. Die 3 anderen Geschwister haben dieselben Krankheitserscheinungen.

A. S., J.-N. 5444/12. 21/2 Jahre alt. 14 Monate bei Brust, seither ißt das Kind: I Kaffee, Semmel, II Sehmalzbrot, III Suppe, Gemüse, IV Kaffee, Semmel, $V$ Schmalzbrot. Tägliche Milchmenge minimal (für 7 Personen $3 / 41$ ) $3 / 41$ Wasser. Ist auffallend blaß, sehr schlaff; großer Bauch. Adenoide Vegetationen, Rhinitis. Alle 5 Kinder der Frau sind bla $B$ und ,in der Nase verstopft". 
R. W., J.N. 74/13. 2 Jahre alt. 5 Monate bei Brust. Jetzt 11/2 1 Milch, $1 / 41$ Tee, etwas Kaffee, 1 mal Suppe. - Sehr oft Schnupfen und Husten, enormer Gneis und Milchschorf, dick infiltriert und sekundär infiziert. Prurigo am Stamm. Großer Bauch. Rhinitis serosa. Adenoide Vegetationen, Tonsillarhypertrophie.

J. W., J.-N. 414/13. 2 Jahre alt. 4 Wochen bei Brust, seit Ende des 1. Jahres gemischte Kost. I Milch, Semmel, II Buttersemmel, III Suppe, Gemüse, IV = I, $\nabla$ Wurst. Täglich 11 Milch und 11 Wasser. - Sehr oft Schnupfen und Husten, I mal Pneumonie. Große Tonsillen, seröse Rhinitis. Ist sehr dick und schlaff. Gute Farben.

S. K., J.-N. 4044/12. 31/2 Jahre alt. 3 Monate bei Brust, seit dem Ende des 10. Monates Zufütterung. Jetzt täglich $1 / 21$ Milch, $3 / 41$ Wasser, 1 mal Suppe, I mal Mehlspeise, I mal Milchspeise. - Oft Schnupfen und Fieber, sehr schlaffes Kind, riesiger Bauch. Adenoide Vegetationen, multiple Hals. und Nackendrüsenschwellungen. Pirquet negativ.

R. H., J.-N. 2231/12. 3 Jahre alt. 5 Monate bei Brust, seit Ende des 1. Jahres gemischte Kost. Jetzt: I Brot, II Butterbrot, III Suppe, Fleisch, Gemüse, IV Brot oder Kaffee, V Suppe, Fleisch, Gemüse. Keine Milch. Täglich 11 Wasser. Hat fortwährend Husten und Schnupfen, schon 2 mal Pneumonie gehabt. Conjunctivitis, Rhinitis, Naseneingangsekzem.

J. B., J.-N. 224/12. 3 Jahre alt. 9 Monate Brust, dann Zufütterung. Ist auch jetzt noch teilweise bei Brust. I Kaffee, Semmel, II Brust, III Suppe, Gemüse, IV Brust, V Kaffee oder Brust. Täglich $1 / 41$ Kuhmilch und 11 Wasser. Hat oft Schnupfen und Husten, 1 mal Pneumonie, 1 mal Laryngitis.

L. D., J.-N. 1068/12. 3 Jahre alt. 14 Monate Brust, seither Zufütterung. Jetzt: I Kaffee, Semmel, II Butterbrot, III Suppe, IV Kaffee, Semmel, V Suppe, Gemüse. Täglich 1/4 1 Mileh, 3/4 I Wasser. Hat sehr oft Husten, 1 mal Lungenentzündung gehabt. Sehr schlaffes, blasses Kind, Rhinitis, Bronchitis. Adenoide Vegetationen. Tonsillarhypertrophie.

L. P., J.-N. 2538/12. 3 Jahre alt. 2 Jahre bei Brust (!), Jetzt täglich 11 Kaffee, $1 / 21$ Wasser, 1 mal Suppe, 1 mal Gemüse. Ausgedehnter Gneis und Milchschorf, Prurigo. Kein Husten oder Schnupfen.

K. F., J.-N. 4284/12. 4 Jahre alt. 9 Monate Brust, seit dem Ende des 1. Jahres gemischte Kost. I Kaffee, Semmel, II Schmalzbrot, III Suppe, IV = I, V Butterbrot. Täglich $1 / 4$ I Milch, 1 bis $1 \frac{1}{2}$ I Wasser. - Blasses Kind, großer Bauch. Adenoide Vegetationen, Tonsillarhypertrophie, Angina lacunaris. Sternaldämpfung. Pirquet positiv.

K. S., J.-N. 4342/12. 41/2 Jahre alt. 1 Jahr bei Brust, dann Zufütterung. Jetzt: I Kaffee, Semmel, II Schmalzbrot, III Suppe, Fleisch, Gemüse, IV = I, V Gemüse. Milch in kleinsten Mengen, täglich $1^{1 / 2} 1$ Wasser. „Hat durch die Nase keine Luft." Als Säugling Gneis und Milchschorf, jetzt adenoide Vegetationen und Tonsillarhypertrophie.

H. J., J.-N. 136/13. 41/2 Jahre alt. 4 Monate bei Brust. Seit dem Ende des 1. Jahres gemischte Kost. I Kaffee, $1 / 2$ Semmel, II Brot, III Gemüse und Mehlspeise, IV $=$ I, V Schmalzbrot. Weniger als $1 / 41$ Miloh täglich, $11 / 21$ Limonade. Leidet fortwährend an Schnupfen und Verschleimung. Tonsillarhypertrophie, adenoide Vegetationen, chronische Rhinitis; wurde schon wegen Polyposis narium operiert. 
H. E., J.-N. 386/13. 4 Jahre alt. 1 Monat Brust, dann ausschließlich Kuhmilch bis zum Ende des 2. Jahres (!). Jetzt gemischte Kost wie die andern. Täglich nur so viel Milch, als in den Kaffee kommt, 11/21 Wasser. Als Säugling Gneis, sehr oft Husten und Schnupfen, schlaff und blaß. Adenoide Vegetationen, Tonsillarhypertrophie, seröse Rhinitis.

L. St., J.-N. 1119/13. 4 Jahre alt, 1 Jahr bei Brust, dann gemischte Kost: I Kaffee, Semmel, II Ei, III 0, IV = I, V Butterbrot. Täglich $1 / 21$ Mileh und 11 Wasser. Hat fortwährend Husten und Schnupfen. Schlaffes, sehr blasses Kind, schwammiges Aussehen, großer Bauch. Vergrößerte Tonsillen, adenoide Vegetationen, seröse Rhinitis. Im Harn kein Eiweiß.

J. T., J.-N. 3064/12. 51/2 Jahre alt, 17 Monate bei Brust, dann gemischte Kost. Jetzt: I Kaffee, Semmel, II Butterbrot, III Suppe, Gemüse, 1 mal wöchentlich Fleisch, IV $=$ I, V Suppe. Täglich $1 / 41$ Milch, $3 / 41$ Wasser. 2 bis 3 mal wöchentlich Kartoffel. Hat sehr oft Schnupfen und Husten, 3 mal Langenentzündung, 1 mal Halsentzündung gehabt. Schlaffer, blasser Junge, großer Bauch. Tonsillarhypertrophie, adenoide Vegetationen, diffuse Bronchitis.

M. T., J.-N. 2591/12. 5 Jahre alt, nur ein paar Wochen bei Brust, dann Flasche. Seit Ende des 1. Jahres gemischte Kost. Jetzt: I Kaffee, Semmel, II Butterbrot, III Suppe, Semmel, IV = I, V Milchspeise., Sonst keine Milch, 11 Wasser täglich. - Oft Schnupfen und Husten, Pruxigo an den Streckseiten der Extremitäten, mäßig vergrößerte Tonsillen. Appetitlosigkeit. Pirquet positiv. Ein anderes Kind der Frau leidet an denselben Beschwerden und trinkt auch sehr viel Wasser.

L. K., J.-N. 3034/12. 7 Jahre alt. 10 Monate Brust. Seither gemischte Kost. Jetzt: I Kaffee, Brot, II Brot, III Suppe, Gemüse, IV $=$ I, V Suppe, Brot. Trinkt weniger als $1 / 41$ Milch, dagegen sehr viel. Wasser. „Er steht fortwährend beim Brunnen." Hat schon 3 mal Lungenentzündung gehabt, 1 mal Halsentzündung, 1 mal Otorrhoe. Schlaffes, blasses Kind, großer Bauch, offener Mund, schnarchende Atmung, rinnende Nase.

O. B., J.-N. 2259/12. 7 Jahre alt. 14 Monate bei Brust, dann täglich 21 Milch pro Tag (!). Erst seit Ende des 2. Jahres feste Nahrung. Jetzt: I Kaffee, Semmel, II Butterbrot, III Suppe, Gemüse, 2 mal wöchentlich Fleisch, IV = I, V.Suppe, Wurst. Täglich $1 / 21$ Milch, 11 Wasser. Hat bei jedem Temperaturwechsel Husten und Schnupfen. I mal Lungenentzündung, sehr oft Halsentzündung gehabt. Blasser, schlaffer Junge. Schnarchende, weithin hörbare Atmung, offener Mund. Rhinitis, Tonsillarbypertrophie.

F. H., J.-N. 2197/12, 8 Jahre alt. Niemals Brust. Bis zu 1/2 Jahren nur bei der Flasche. Jetzt: I Tee ohne Milch, Semmel, II Butterbrot, III Suppe, Gemüse, 1 mal wöchentlich Fleisch, IV $=1, \nabla$ Suppe, Gemüse. Keine Milch, täglich 11 Wasser. - Immer im Herbst und Winter Schnupfen und Husten. 3 mal Pneumonie gehabt. Wegen Polyposis operiert. 1 mal Otitis. Sehr schlaffer, blasser Junge, adenoide Vegetationen, Tonsillarhypertrophie, Rhinitis.

M. H., J.-N. 6032/12. 10 Jahre alt. 9 Monate bei Brust, seither gemischte Kost. Jetzt: I Kaffee, Semmel, II Butterbrot, III Suppe, Gemüse, IV = I, V Suppe, Gemüse. Täglich 11 Milch, 11 Wasser oder mehr. Zu Ende des 1. Jahres Gneis, hat sehr oft Schnupfen gehabt. Tonsillarhypertrophie, adenoide Vegetationen.

M. P., J.-N. 98/13. 10 Jahre alt. 9 Monate Brust, seit dem Ende des 1. Jahres gemischte Kost. Jetzt: I Kaffee, Semmel, II Schmalzbrot, III Suppe, Brot, IV 
$=\mathrm{I}, \mathrm{V}$ Schmalzbrot. Weniger als $1 / 41$ Milch täglich, 11 Wasser. Hat sehr oft Schnupfen, fortwährend „Anstoßen“. Hat 1 mal Lungenentzündung gehabt. Blasses, unterernährtes Kind. Großer Bauch. Adenoide Vegetationen, chronische Rhinitis.

O. P., J.-N. 2885/12. 12 Jahre alt. 6 Monate bei Brust, seit Ende des 1. Jahres gemischte Kost. Jetzt: I Kaffee, Schmalzbrot, II Brot, III Suppe, Brot, IV Kaffee, Brot, V Kaffee, Brot. Täglich 21 Kaffee (!) und mindestens 11 Wasser (!). Hat als Säugling durch einen ganzen Winter „Vierziger" gehabt. Hat alle 2 Wochen Schnupfen. Ist auffallend blaß, schlaff, sehr fettarme Haut. Adenoide Vegetationen, alimentäre Glykusorie. Der Bruder ist mit derselben Affektion aufgenommen, trinkt ebensoviel Kaffee und sehr viel Wasser.

Was nun die Ernährung dieser Proletarierkinder anlangt, so kann von einer ,absoluten" Ubberernährung keine Rede sein. Moro und Kolb haben bei einer ähnlichen Untersuchung diesen Umstand ebenfalls festgestellt. Wir finden bei vielen Kindern manchmal überlange ausschlieBliche Ernährung an der Brust (bis zu 2 Jahren!), wir finden aber fast bei sämtlichen Kindern, daß sie lange Zeit ausschließlich mit flüssiger Nahrung, bisweilen bis zum Alter von 2 bis 3 Jahren, ernährt wurden, und daß sie ,gemischte" Kost sehr spät erhielten. Wie sieht nun diese aus? Die Kinder erhalten vorwiegend eine Kohlehydratdiät (Brot, Kartoffel, Kohlehydrateinlage in die Suppe), mit bisweilen geradezu grotesken Flüssigkeitsmengen. Zum Frühstück bekommen die Kinder meist dünnen Kaffee oder Tee, vormittags Brot, mittags Suppe und Gemüse, nachmittags wieder Kaffee und Brot, abends entweder neuerdings Kaffee oder wieder Suppe und Gemüse. Die meisten der Kinder erhalten nur ein- bis zweimal wöchentlich Wleisch, hie und da ein Stück Wurst, und geringe Mengen Fett in Form von Butter oder Schmalz. Welcher Beschaffenheit der Kaffee ist, den die Kinder zwei bis dreimal am Tage genießen, mag daraus hervorgehen, daß die jedesmal gestellte Frage nach der gesamten pro Tag verbrauchten Milchmenge bei älteren Kindern, die außer dieser keine sonstige Milchmahlzeit erhielten, fast. immer dahin beantwortet wurde, daß weniger als $1 / 41$ verbraucht werde. Die Flüssigkeitsmengen, welche diese Kinder einführen, nehmen manchmal ganz unwahrscheinliche Dimensionen an. Ganz abgesehen davon, daß sie ja zu jeder Mahlzeit vorwiegend flüssige Kost bekommen, trinken die Kinder ganz unglaubliche Quantitäten des sonst in seinen Qualitäten gewiß nicht hoch genug einzuschätzenden Wiener Hochquellenwassers, manchmal nach strikten Angaben der Mutter bis zu 2 bis 31 am Tag. Im Verein mit den reichlich zugeführten Kohlehydraten kann diese Tatsache gewiß nicht gleichgültig sein. Offenbar werden 
die Kinder dazu durch den Umstand veranlaßt, daß sie fast immer an adenoiden Vegetationen und chronischen Rhinitiden leiden, daher durch die behinderte Nasenatmung gezwungen sind, fast beständig den Mund offen zu halten und diese lokale Austrocknung der Mundschleimhaut durch beständiges Wassertrinken auszugleichen. Daher ist auch die sehr of gemachte Angabe bemerkenswert, daß diese Kinder auch bei Nacht erwachen und nach Wasser verlangen.

Diese Kinder leiden nun an sämtlichen Manifestationen der exsudativen Diathese, von der Lingua geographica und dem Milchschorf angefangen bis zu den Erkrankungen des lymphatischen Rachenringes und den rezidivierenden Katarrhen der oberen Luftwege, die dann später meist durch wiederholte Infektionen sehr kompliziert werden. In dieser Beziehung kann ich mich nach meinen Beobachtungen vollkommen denen von Moro und Kolb einerseits, Benfey und Bahrdt andererseits anschließen. Die Erkrankungen werden sehr häufig bei Geschwistern gesehen. Adenoide Vegetationen, Tonsillarhypertrophie und Erkrankungen der Luftwege finden sich ebenso bei Kindern, die früher Erkrankungen der Haut gehabt haben als bei solchen, die in der Säuglingszeit davon verschont geblieben waren.

Zeigen nun solche Kinder eine starke Vermehrung des Wassergehaltes im Blut, wie wir sie z. B. bei der Anämie oder beim Mehlnährschaden gesehen haben, wo Werte zwischen 86 und $88 \%$ gefunden wurden? Einige willkürlich herausgegriffene Zahlen mögen diese Fragen beantworten. Bei dem obengenannten 3 Jahre alten Kind L. D., das an chronischer Rhinitis, Bronchitis, adenoiden Vegetationen und Tonsillarhypertrophie litt und das an die Abteilung aufgenommen wurde, betrug der Wassergehalt des Blutes in wiederholten Bestimmungen, während das Kind frei von fieberhaften Prozessen war und auch nicht an akuter Ernährungsstörung litt, immer um 81,5\%. Bei K. M., der an denselben Affektionen litt, 2 Jahre alt war, betrug er $81,8 \%$, bei einem 3 jährigen Kind, R. L., das in den vorliegenden Krankengeschichten nicht zitiert ist und das wegen eines enormen sekundär infizierten Milchschorfes und wegen Strophulus aufgenommen wurde und vorher die übliche ,gemischte" Kost mit einer täglichen Trinkmenge von 2 bis 31 Wasser erhalten hatte, betrug der Wassergehalt des Blutes $82,4-81,8 \%$. Aus den später für andere Zwecke reservierten Krankengeschichten entnehme ich folgende Zahlen. Bei einem 2 monatlichen Säugling, der mit großen Trinkmengen ernährt, wegen Milchsehorfes und Milchnährschaden aufgenommen wurde, betrug der Wassergehalt des Blutes 
$83,3-83,7 \%$, bei einem anderen ebenfalls 2 monatlichen Säugling mit ähnlicher Anamnese 82,6-82,8\%. Bei einem 3 monatlichen Säugling, der an ausgedehntem Milchschorf, Gneis und Intertrigo litt, und der frei von akuten Ernährungsstörungen und fieberhaften Prozessen war, betrug der Wassergehalt des Blutes bei der Aufnahme $83,4 \%$, bei einem anderen 3 monatlichen Kind mit derselben Affektion 82,6-83,4\%.

Diese Zahlen, welche als Beispiel für viele derartige genügen mögen, zeigen mit aller Deutlichkeit, daß in bezug a uf den absoluten Gehalt des Blutes an Wasser bei exsudativen Kindern kein Unterschied gegenüber anderen Kindern besteht. Die Überernährung entweder durch ausschließliche lange Ernährung an der Brust oder durch zu lange oder überreichliche Fütterung mit Kuhmilch, ebenso die einseitige Ernährung mit Brot und Kartoffeln und groben Wassermengen bei älteren Individuen führen bei exsudativen Kindern ebenso wie bei normalen einfach zu einer Verhinderung der physiologischen Austrocknung, was sich bei der Untersuchung des Wassergehaltes im Blut entweder in einem Verharren auf dem möglichen Maximum des Normalen oder in einer geringen Erhöhung dieses Wertes kundgibt. Ein Wert von $84 \%$ wurde bei diesen Kindern niemals erreicht.

Eine Bestätigung dieser Zahlen finde ich in den Angaben von L ust, der aber aus seinen Befunden keinen eindeutigen Einfluß der Ernährung auf den Wassergehalt des Blutes ableiten kann. Von den 7 Säuglingen mit exsudativer Diathese, welche dieser Autor untersuchte, haben gerade diejenigen, welche mit großen Trinkmengen - eraährt wurden (über $1 \frac{1}{2} 1 \mathrm{Milch}$ ), die höchsten Blutwasserwerte $(82,8-83,2 \%)$. Von den älteren Kindern, die Lust untersuchte, haben Kinder, welche 11 Milch und mehr pro Tag getrunken haben, einen Wert von $82,2 \%$, während Kinder mit gemischter Kost einen Blutwassergehalt zeigen, welcher darunter liegt, woraus Lust den Schluß zieht, daß es schwer verständlich wäre, ,wenn das Wesen der exsudativen Diathese sich in einer Anomalie des Wasserbestandes erschöpte". Wie wir gesehen haben, kann davon keine Rede sein. Die Erhöhung des Wassergehaltes im Blut ist einfach eine Folge der Ernährung und hat mit der exsudativen Diathese an sich nichts zu tun. Dies geht sohon aus den Tierexperimenten, welche ich im ersten Teil der Arbeit besprochen habe, hervor. Es gelingt leicht, bei einem wachsenden Hund die physiologische Austrocknung seines Organismus dureh entsprechende Ernährung aufzu- 
halten oder auch den Wassergehalt seines Körpers durch diese Ernährung sogar zu erhöhen. Es gelingt aber nicht, dieses Versuchstier künstlich exsudativ z u machen. Daher ist es auch verständlich, daß Eckert bei seinen eingangs wiederholt zitierten Versuchen schließlich zu einem negativen Resultat kommen mußte.

Nun haben wir in den Versuchen von Freund, Meyer und Menschikoff gesehen, daß exsudative Säuglinge eine gewisse Labilität im Salzstoffwechsel aufweisen, d. h. daß sie - im speziellen Fall - Cl leicht aufnehmen, aber auch leicht wieder abgeben. Es wird nun nachzuweisen sein, ob diese Labilität auch für den Wasserhaushalt besteht und ob dieselbe eventuell unabhängig vom $\mathrm{Cl}$-Stoffwechsel sich geltend machen kann.

Auch hier machen sich methodische Schwierigkeiten insofern geltend, als wix es bei den gewöhnlichen Formen des Ekzems ja schon nicht mehr mit den primären Äußerungen der exsudativen Diathese, sondern mit komplizierten. Prozessen zu tun haben. Nach Czerny kennzeichnet die exsudative Diathese solche Kinder, ,,deren Haut Neigung zur Exsudation besitzt". Wenn wir also diese Frage aufrollen, so ist es nicht angängig, sekundäre Prozesse, die erst auf dem Boden der „Exsudation“ entstehen, zur Beurteilung heranzuziehen und ihrem Bestehenbleiben oder Verschwinden eine direkte Beziehung zum Manifestwerden oder Latentbleiben der Konstitutionsanomalie zuzuschreiben. Das Ekzem in seinen mannigfachen Formen und Varianten ist dieser ersten Exsudation als sekundärer Vorgang aufgepfropft. Wir werden, wenn wir diese komplizierte Frage studieren wollen, wirklich die einfachsten und primären Manifestationen der exsudativen Diathese in den Rahmen unserer Betrachtungen ziehen müssen - schon aus heuristischen Gründen.

Eine wirklich primäre Manifestation der exsudativen Diathese, die wir, was für das Studium der Frage ja besonders wichtig ist, in ihren ersten Anfängen bei klinisch beobachteten Fällen entstehen sehen, ist der Milchschorf. Er bietet, wie Klotz treffend bemerkt, gleichsam einen Indikator für das Manifestwerden der Konstitutionsanomalie, beziehungsweise für die Zweckmäßigkeit unseres Ernährungsregimes. Es wird nun die Frage sein, ob ein einfacher und direkter Zusammenhang zwischen dem ersten Auftreten des Milchschorfs und dem Wasserhaushalt des Körpers existiert.

Auch hier sollen zunächst klinische Beobachtungen angeführt werden. Es ist bekannt, daß die exsudativen Erscheinungen der Haut versehwinden, wenn große Gewichtsstürze eintreten, und daß diese Hauterschei- 
nungen wieder auftreten, wenn die Gewichtskurve in Reparation übergeht. Nun könnte man natürlich daraus einen Zusammenhang der exsudativen Erscheinungen mit allen Begleiterscheinungen des Gewichtssturzes erschließen. Finkelstein hat vor kurzem einen Fall beschrieben, wo ein 2 Monate altes Kind nach einer schweren Dyspepsie 4 Wochen nach Beginn der guten Zunahme plötzlich ein Ekzem des Kopfes und Gesichtes bekommt, das erst 10 Wochen später abzuheilen beginnt. Schon vor ungefähr $1 \frac{1}{2}$ Jahren, also vor dieser Finkelsteinschen Beobachtung konnte ich einen Fall in eindeutiger Weise während seines ganzen Verlaufes verfolgen, bei dem die Situation insofern einfacher lag, als es sich nicht um ein ausgedehntes Ekzem, sondern eben nur um einen Milchschorf handelte, dessen Verschwinden und Wiederauftreten mit bestimmten Punkten der Gewichtskurve zusammenfiel und im Verein mit früheren Beobachtungen eine einfache Deutung erlaubte.

F. D., 3 Monate alt (Fig. 13). Am 28. IX. 1912 wegen Hernie aufgenommen. $5300 \mathrm{~g}$ schwer, gut aussehendes Kind, von mäßigem Turgor. Anßer der Hernie vollständig normaler Befund. Bei $840 \mathrm{~g}$ Halbmiloh mit Schleim noch geringe Abnahme. Am 1. X. Steigerung auf $900 \mathrm{~g}$ Halbmilch mit Weizen, worauf sofort gute Zunahme einsetzt. Am 4. X. tritt ein deutlicher Milchschorf auf. Das Gewicht ist bis zum 5. X. von $5200 \mathrm{~g}$ auf $5330 \mathrm{~g}$ gestiegen, bleibt dann 2 Tage stehen. Am 8. beginnt Gewichtsabfall. Vermehrte Stühle. Am 9. X wurde ein Teetag eingeschoben. Weiterer Gewichtsverlust. Am 12. X. war der Milchschorf bei einem Gewicht von $5200 \mathrm{~g}$ verschwunden. Das Kind bekam dann $780 \mathrm{~g}$ Liebigsuppe, wobei das Gewicht noch bis zum 14. X. bis auf

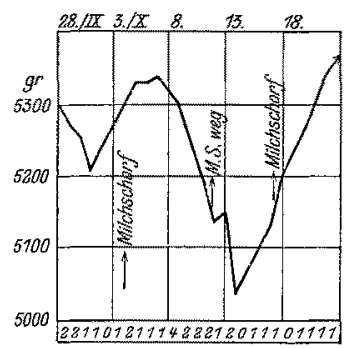

Fig. 13. $5030 \mathrm{~g}$ fiel. Am 15. begann guter Gewichtsanstieg, am 17. X. erschien der Milchschorf wieder.

Das Kind zeigte also zur Zeit seiner Einlieferung keinerlei exsudative Erscheinungen. Nach der Aufnahme begann Gewichtsanstieg, 3 Tage später erschien der Milchschorf. Dann akquirierte das Kind in der Anstalt eine leichte Dyspepsie, 3 Tage nach Beginn des Gewichtsabfalles war der Milchschorf verschwunden. Er erschien neuerdings 2 Tage nach Umbiegen der Gewichtskurve. Hier haben wir also einfachste Beziehungen vor uns, nicht ein kompliziertes Ekzem, das unabhängig von jeder konstitutionellen Minderwertigkeit auf jeden Fall Tage bis Wochen zu seiner Abheilung benötigt, sondern die primäre Manifestation der exsudativen Diathese. Andererseits haben wir eine ganz leichte akute Ernährungs- 
störung vor uns, bei der nur an einem Tag einmal 4 Stühle auftraten, mit einem sehr mäßigen Gewichtsverlust, also möglicherweise nur ein „Konzentrationsverlust" Toblers. Der Milchschorf zeigt ein absolutes Parallelgehen mit dem Auf- und Absteigen der Gewichtskurve. Erinnern wir uns daran, daß nach den früher erwähnten Untersuchungen anderer Autoren und nach meinen eigenen Bestimmungen jede akute Ernährungsstörung, auch die leichteste, mit einem Wasserverlnist einhergeht, und da $B$ in der Reparation zunächst das in Verlust geratene Wasser restituiert wird (ich erinnere z. B. hier an Fig. 5 dieser Arbeit), so werden wir ungezwungen einen Zusammenhang zwischen dem Auftreten und Versehwinden des Milchschorfes und dem Auf- und Absteigen des Wassergehaltes vermuten können.

Ein ähnlicher Fall ist folgender:

F. M., 2 Monate alt, Frühgeburt, bisher in der Anstalt bei Brust, dann bei Allaitement mixte von Brust und Buttermilch gut gediehen. Am 25. IV. 1913 $4200 \mathrm{~g}$ schwer, akquiriert das Kind eine Dyspepsie. Täglich 4 bis 5 Stühle, 1 bis 2 mal Erbrechen. Gewichtsabfall bis auf $3740 \mathrm{~g}$ in 8 Tagen. Am 29. IV. Teetag, dann Eiweißmilch in steigenden Mengen. Dabei sofortige Besserung der Stühle, aber noch leichter Gewichtsabfall bis zum 2. V. An diesem Tage biegt die Kurve um, am nächsten Tage tritt der Milchschorf auf.

Dieser Fall nähert sich mehr der Finkelsteinschen Beobachtung. Er betraf ein Kind, das bisher vollständig frei von exsudativen Symptomen gewesen war und das nach einer schweren Dyspepsie, im Verlaufe deren es $460 \mathrm{~g}$ an Gewicht verlor, bereits einen Tag nach dem Umbiegen der Gewichtskurve einen Milchschorf bekam, der sich später wieder verlor. Auch da können wir einen Zusammenhang mit dem Wasserhaushalt vermuten, insofern als der Milchschorf zu einer Zeit auftrat, wo sicher der Organismus nur bestrebt war, den erheblichen Verlust an Wasser hereinzubringen und gewiß noch nicht imstande gewesen sein dürfte, das übrige Defizit an organischem und anorganischem Material zu decken.

Läßt sich dieser vermutete Zusammenhang auch zahlenmäßig nachweisen? Man ist bei solchen Versuchen natürlich mehr oder weniger auf den Zufall angewiesen, da man ja bei einem Kinde, das keine manifesten Erscheinungen von exsudativer Diathese bietet, nicht wissen kann, ob und wann es einen Milchschorf bekommen wird. Doch bin ich in der Lage, mehrere solche Fälle mitteilen zu können, wo aus anderen Gründen bei den Kindern Blutwasserbestimmungen gemacht wurden, so daß auch knapp vor und nach dem Auftreten des Milchschorfes solche zur Verfügung standen. 
L. L., 2 Monate alt. Wegen àkuter Dyspepsie bei chronischer Ernährungsstörung aufgenommen. $52 \mathrm{~cm}$ lang; $2700 \mathrm{~g}$ schwer, atrophisches Kind. Bei kleinen Mengen Drittelmilch mit Schleim sofort einsetzende Reparation. Nach 2 Wochen $2920 \mathrm{~g}$ schwer. Erste Bestimmung des Blutwassergehaltes ergibt $79,6 \%$, also noch einen sehr niedrigen Wert. Weiter kurzer Gewichtsanstieg bis $3000 \mathrm{~g}$ und nun wochenlanger Stillstand trotz qualitativer und quantitativer Steigerung der Nahrung. Dabei aber gute Stühle. 3 Wochen nach der ersten Bestimmung ergab eine weitere Untersuchung den Wert von $80,9 \%$, der also auch noch recht niedrig ist. Nach 4 Tagen setzt unvermittelt ein Gewichtsanstieg ein, der aber nur 2 Tage dauert. Am 2. Tage dieses Anstieges tritt Milchschorf auf. Eine Wasserbestimmung an diesem Tage ergab einen Wert von $82,2 \%$, also eine brüske Zunahme um $1,3 \%$.

Bei einem 2 monatlichèn Atrophiker, in dessen sehr langsamer Reparation wochenlanger Gewichtsstillstand eintritt, wird ein für das Alter niedriger Blutwasserwert gefunden, 2 Tage nach dem Einsetzen eines kurzen Gewichtsanstieges tritt Milchschorf auf, während gleichzeitig der Wassergehalt des Blutes um $1,3 \%$ in die Höhe geht.

A. R., 5 Monate alt, wegen Tuberkulose aufgenommen. $4500 \mathrm{~g}$ schwer. Das Kind ist schon längere Zeit auf der Abteilung, nimmt langsam an Gewicht zu, produziert aber mitunter sehr lange Gewichtsstillstände. Wiederholte Bestimmungen vorher, die zu anderen $Z$ wecken unternommen worden waren, ergaben Werte von 81,3 bis $82,2 \%$, die ungefähr der Norm entsprechen. Am 27. XII. 1912 trat bei diesem Kinde, das schon seit 4 Tagen im Gewichte stillstand und das auch, wie gleich vorausgeschickt sei, durch weitere 8 Tage eine vollständig horizontale Gewichtskurve hatte, ein Milchschorf auf. An diesem Tage Temperatursteigerung bis $37,5^{\circ}$. Zufälligerweise war 2 Tage vorher der Blutwassergehalt bestimmt worden und hatte einen Wert von $82,9 \%$, also in einer Höhe, die bis jetzt noch nicht beobachtet worden war, ergeben. Die Wiederholung am Tage des Auftretens des Milchschorfes ergab $83,0 \%$, wenige Tage nachher $83,1 \%$. Während der folgenden Zeit immer subfebrile Temperaturen und Beginn einer schwer verlaufenden Tuberkulose.

Bei diesem 5 monatlichen Kind trat während einer Zeit, wo das Gewicht vollständig stillstand, wo aber der Wassergehalt des Blutes die bisher durch viele Wochen bestimmten Werte um ein Wesentliches überschritt (als Ursache dafür kann nur der Nachschub der Tuberkulose bei dem Kinde, das während dieser Zeit immer Fiebersteigerungen aufwies, verantwortlich gemacht werden), gleichzeitig mit dieser Steigerung des Blutwassergehaltes ein Milchschorf auf. Auffallend ist hier, daB dieses Einsetzen des Milchschorfes vollständig unabhängig von der Gewichtskurve war, dagegen ganz parallel mit dem Eintreten der Hydrämie, die offenbar durch das Fieber bedingt war, ging.

A. W., 2 Monate alt (Fig. 14), hatte eine leichte Dyspepsie mitgemacht und wurde deswegen aufgenommen. $3900 \mathrm{~g}$ schwer, ohne irgendwelche Zeichen von exsudativer Diathese. Doch gab die Mutter an, daß das Kind schon früher an 
Rhagaden gelitten habe. Das Kind wurde des Versuches halber erst auf geringe Mengen Drittelmilch gesetzt, nahm bei dieser Nahrung nicht zu, sondern sogar eher etwas ab. Die Nahrung war ja auch kalorisch vollständig unzureichend. Nach 5 Tagen wurde der Nahrung Sehleim zugesetzt, was dem Kalorienbedürfnis dieses Kindes sicher auch noch lange nicht entsprach. Es nahm anfänglich zu, dann wieder ab. Die Gewichtslkurve macht im ganzen den Eindruck der Horizontale mit Schwankungen.

Dieses Kind wurde also absichtlich des Versuches halber so knapp. gehalten, daß es nicht zunehmen konnte. Der anfängliche Blutwasser-

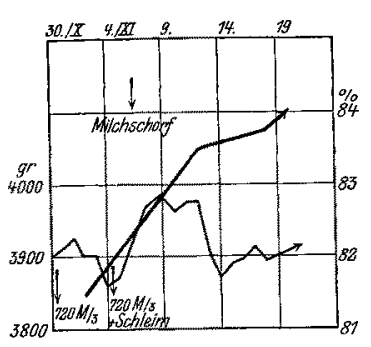

Fig. 14. gehalt betrug $81,5 \%$. Am 4 . XI. 1912 wurde der Nahrung Schleim zu gelegt. Diese Nahrung konnte bei dem Kinde keinen dauernden Gewichtsansatz erzielen, wohl aber war sie imstande, wie ich früher zeigen konnte, eine prompte Hydrämie hervorzurufen. Tatsächlich sehen wir aus Fig. 14 eine rapide $\mathrm{Zu}$ nahme des Blutwassergehaltes. 36 Stunden nach Einführung des Schleims betrug der Blutwassergehalt 83,3 , also $1,8 \%$ mehr als früher und zu derselben Zeit trat ein Milchschorf auf. Der Blutwassergehalt stieg in den nächsten Tagen noch weiter auf 83,7 und $84,0 \%$ und der Milchschorf blieb ebenfalls bestehen.

Wählt man also -in dieser Weise einfachste Beziehungen zwischen den Krankheitserscheinungen der exsudativen Diathese und dem Wassergehalt des Blutes, so ergeben sich ganz ungekünstelt eindeutige Zusammenhänge. Nicht die absolute Höhe des Wassergehaltes im Blute ist es, welche Beziehungen zu den einfachsten Manifestationen der exsudativen Diathese hat, sondern das plötzliche Ansteigen desselben. Dies konnte an Fällen gezeigt werden, welche diese plötzliche Vermehrung ihres Blutwassers während der Reparation von einer Ernährungsstörung oder durch Auftreten von Fieber oder durch Zulage von Kohlehydrat zur Nahrung erfuhren.

So interessant nun diese Feststellungen sind, so ist damit, um zu den Untersuchungen von Freund, Meyer und Menschikoff zurückzukehren, die eine Labilität der exsudativen Kinder in der Aufnahme und Abgabe von $\mathrm{Cl}$ gefunden haben, noch nicht eine Labilität der Wasseraufnahme (unabbängig von den Salzen) konstatiert, wenn sie auch wahrscheinlich ist. Eine raschere Aufnahme von Wasser bei exsudativen als bei normalen Kindern festzustellen, hat methodische Schwierigkeiten und ist nicht beweisend. Man könnte eben die betreffenden Kin- 
der nur dürsten lassen und dann bei Wasserzulage konstatieren, ob exsudative Kinder dasselbe raseher aufnehmen als normale. Es ist aber vorauszusehen, daß jedes Kind, auch das normale, wenn sein tägliches Bedürfnis an Wasser eingeschränkt wird, bei Wasserzulage dasselbe dann gierig aufnehmen würde. Wohl aber haben wir im umgekehrten Vorgang, in der mehr oder minder raschen Wasserabgabe bei Kindern, deren Wassergehalt die Norm überschreitet, ein Mittel in der Hand, eine solche Labilität zu konstatieren.

Wir haben einerseits gesehen, daß bei Kindern, gleichgültig ob sie exsudative Erscheinungen bieten oder nicht, duroh eine ausschlieBliche oder zu lange Ernährung mit Milch und bei älteren Kindern durch einseitige Fütterung mit Milch oder Kohlehydraten bei reichlicher Wasseraufnahme eine Verhinderung der physiologischen Austrocknung eintritt, so daß sie bei Aussehluß der bekannten Fehlerquellen eine Erhöhung ihres Blutwassergehaltes aufweisen; wir haben andererseits in einem früheren Abschnitt dargelegt, daß solche Kinder, sofern sie nicht exs udativ sind, wenn sie auf ein geringeres Nahrungsvolumen und eine ihrem Alter entsprechende Kost gesetzt werden, langsam das bisher aufgestapelte, überschüssige Wasser abgaben. Ihre Gewichtskurve bleibt während dieser Zeit entweder horizontal (z. B. Fig. 9) oder fällt langsam ab (linke Hälfte der Fig. 15). Wir konnten weiter konstatieren, daß während dieser Zeit der Wassergehalt des Blutes kontinuierlich bis zu normalen Werten abnahm, um dann, während das Kind ohne Nahrungsänderung wieder zuzunehmen begann, in gleicher Höhe oder leicht abfallend zu bleiben. Wir konnten ferner an mehreren Beispielen nicht exsudativer Kinder. zeigen, daß dieser ,innere Umbau“ ungefähr 2 bis 3 Wochen in Anspruch nahm. Man konnte sich also aus diesen Darlegungen die Vorstellung bilden, daß bei in der beschriebenen Weise überernährten, aber nicht exsudativen Kindern, wenn sie richtig ernährt werden, die überschüssig angesammelte Wassermenge langsam, eben in 2 bis 3 Wochen abgegeben würde, und daß dann erst, nachdem die richtige Zusammensetzung des Organismus erreicht ist, der normale Aufbau des Körpers sich in der langsam steigenden Gewichtskurve ausdrückt. Dieser Versuch - und ich glaube wohl nicht noch einmal erwähnen zu müssen, daß dieses brüske Absetzen auf die normale Diät nur experimenti causa geschah, daß man in der Praxis solche Kinder ganz allmählich von der bisherigen pathologischen Ernährung entwöhnen und sie schrittweise auf die richtige Diät führen wird - gibt uns ein Mittel in die Hand, exsudative Kinder auf ihr Verhalten zu prüfen. Wir 
haben in ihnen dasselbe Ausgangsmaterial vor uns, wie bei den „,normalen" Kindern mit aus den beschriebenen alimentären Ursachen pathologisch erhöhtem Blutwassergehalt. Setzen wir diese exsudativen Kinder brüsk auf die ihnen zukommende Diät, so haben wir auch dieselbe Versuchsbedingung wie bei den ,normalen“ Kindern. Der Ausfall des Versuches erlaubt daher direkte und eindeutige Schlüsse auf den Einfluß des Bestehens der Konstitutionsanomalie.

Gehen wir auch hier wieder zunächst von rein klinischen Beobachtungen aus.

K. M. (das Kind wurde schon unter den ambulatorisch behandelten Füllen erwähnt), 2 Jahre alt, bekam 3 Monate Brust, dann Kuhmilch in unbekannter Menge. IBt jetzt täglich 1 mal Suppe, 1 mal Gemüse, 1 mal Milchspeise, selten Fleisch. Täglich 21 Kaffee (!), kein Wasser. Das Kind hat "fast jede Woche" Katarrh, Husten und Schnupfen. Seit 1 Jahr Prurigo und Gneis. Lingua geographica, Tonsillarhypertrophie, Bronchitis, Otorrhöe. Pirquet negativ. Gewicht bei der Aufnahme $10100 \mathrm{~g}$. Das Kind erhält sofort nach der Aufnahme folgende Diät: I $200 \mathrm{~g}$ Milch +2 Semmeln, II = I, III $200 \mathrm{~g}$ Griessuppe, 2 gehäufte ESlöffel Hackfleisch und dieselbe Quantität passiertes Gemüse, IV gehackter Schinken und Buttersemmel. - Das Kind wurde täglich gewogen und hatte bereits nach 48 Stunden den Tiefpunkt seiner Gewichtskurve erreicht. Es hatte in dieser Zeit $350 \mathrm{~g}$ abgenommen. Von da ab begann bei genau derselben Diät, die von Anfang an gleich gern genommen wurde, langsamer Gewiehtsanstieg. In 31 Tagen nahm das Kind $1050 \mathrm{~g} z \mathrm{z}$.

Dieses 2 jährige Kind war also mit enormen Mengen von Kaffee, sonst aber recht dürftig ernährt worden, so daß wohl von einer absoluten Überernährung keine Rede sein kann. Das Gewicht von $10 \mathrm{~kg}$ am Ende des zweiten Jahres spricht doch wohl auch eher für Unterernährung. Nun wurde das Kind auf eine gemischte Kost gesetzt, die seinem Alter und Ernährungszustand angepaßt war; keinesfalls bedeutete sie eine Unterernährung, denn das Kind nahm in einem Monat dabei mehr als $1 \mathrm{~kg} \mathrm{zu}$, aber erst dann, nachdem es in den ersten 48 Stunden $350 \mathrm{~g}$ abgenommen hatte. Wir sehen also hier dasselbe Phänomen wie bei den in der beschriebenen Weise fehlerhaft ernährten "normalen“ Kindern. Nach dem Absetzen auf gemischte und rationelle Kost erfolgt zunächst eine Gewichtsabnahme. Bei diesem exsudativen Kinde vollzieht sich dieselbe aber nicht wie bei den Normalkindern in 2 bis 3 Wochen, sondern in $48 \mathrm{Stunden.} \mathrm{Schon} \mathrm{dieser} \mathrm{kurze} \mathrm{Zeitraum,}$ in welchem dieser verhältnismäßig große Gewichtsverlust erfolgte, erlaubt die Vermutung, daß es sich nur um abgegebenes Wasser handeln könne.

F. T., 3 Jahre alt, war $1 \mathrm{Jahr}$ bei der Brust, hat von da ab mitgegessen. Jetzige Ernährung: I Milch, Semmel, II Würsteln, III Suppe, IV Kaffee, Semmel, V Kaffee. 
Trinkt sehr viel Wasser außerdem. Wird wegen mächtigen Gesichtsekzems und Ohrenfluß aufgenommen. Starker Gneis. Tonsillarhypertrophie, seröse Rhinitis. Pirquet pasitiv. Gewicht bei der Aufnahme $9900 \mathrm{~g}$. Am Tage der Aufnahme bekommt das Kind sofort folgende Diät: I $200 \mathrm{~g}$ Milch, 1 Semmel, II 3 Biskuits, III $200 \mathrm{~g}$ Griessuppe, 3 Eßlöffel Hackfleisch und ebensoviel passiertes Gemüse, $\mathrm{IV}=\mathrm{I}, \mathrm{V}$ Sohinken und Butterbrot. Außerdem $200 \mathrm{~g}$ Wasser auf den ganzen Tag verteilt. Das Kind nahm die Nahrung sofort und willig. Gewichtsabnahme von $300 \mathrm{~g}$ in den ersten 72 Stunden, von da ab gute Zunahme, $1500 \mathrm{~g}$ in 35 Tagen.

Der Fall ist ganz analog dem früheren. Ein 3 jäbriges Kind, das bisher im wesentlichen nur von Milch, Suppe und Kaffee gelebt hat, befindet sich bei der Aufnahme in einem recht desolaten Zustand (9900 $\mathrm{g}$ mit 3 Jahren!) mit zahlreichen Erscheinungen von exsudativer Diathese. Das Kind wird sofort auf gemischte Kost mit relativ gar nicht so kleinen Trinkmengen gesetzt, nimmt die neue Nahrung sofort gut und verliert in den ersten 72 Stunden des Spitalsaufenthaltes $300 \mathrm{~g}$ an Gewicht. Erst dann beginnt bei derselben Nahrung die Zunahme.

K. F., 2 Jahre alt, war 9 Monate bei der Brust und trinkt seither nichts anderes als Kaffee. Er hat noch niemals etwas Festes zu sich genommen. Vor mehreren Wochen überstand das Kind eine Pleuropneumonie, deren Reste jetzt noch nachweisbar sind. Hat schon oft Husten und Schnupfen gehabt. Tonsillarhypertrophie, adenoide Vegetationen. Aufnahme wegen Stechen in der Brust. Das Kind ist bei der Aufnahme $10400 \mathrm{~g}$ schwer und wird sofort auf gemischte Kost gesetzt. I Kaffee, Semmel, II 3 Biskuits, III Griessuppe, Hackfleisch, Gemüse, IV $=I, V$ Griesbrei, Butterbrot. Von dieser Nahrung nahm Pat. nur Kaffee, Semmel, Suppe und Milchspeise zu sich. Gemüse und Fleisch refüsierte er in den ersten Tagen hartnäckig. Gewichtsabnahme in den ersten 48 Stunden $400 \mathrm{~g}$. Dann Gewichtsstillstand durch weitere 48 Stunden, von da ab gute Zunahme, $1150 \mathrm{~g}$ in 32 Tagen. 5 bis 6 Tage nach der Aufnahme entschloß sich das Kind, auch die übrige Nahrung anzunehmen.

Dieses 2jährige Kind hatte nach der Ablaktation im 9. Monat durch 11/4 Jahr ausschlieBlich von Kaffee gelebt. Bei der Aufnahme wurde zwar von der gereichten gemischten Kost nicht sofort alles genommen, aber doch so viel, daß die neue Nahrung gegenüber der bisher genossenen gewiß keine Unterernährung bedeutete. Trotzdem erfolgte eine rapide Gewichtsabnahme um $400 \mathrm{~g}$ in 48 Stunden und dann erst Zunahme.

R. W., 2 Jahre alt, war 5 Monate bei der Brust und wurde seitdem ausschlieblich mit flüssiger Kost ernährt. Täglicher Verbrauch: $11 / 21$ Milch, $1 / 41$ Tee, etwas Kaffee und Suppe. Hatte mit 8 Monaten zum ersten Male Gneis, bald darauf Gesichtsekzem, das sich mehr und mehr verbreitete. Seit 6 Wochen ausgedehntes Ekzem des ganzen Körpers. Das Kind hatte schon oft Schnupfen und Husten und hat auch jetzt wieder eine Bronchitis. Es uriniert sehr oft, der Stuhl ist sehr hart und weiß. Die Haut des Gesichtes und des behaarten Kopfes ist dick infiltriert, mit gelblichen Krusten bedeckt und durch Rhagaden zerrissen. Ebenso 
am Hals und Stamm weitverbreitetes Ekzem. Intern vollständig normaler Befund. Keine Temperatursteigerung, Pirquet negativ. Gewicht bei der Aufnahme $13800 \mathrm{~g}$. - Das Kind wird sofort auf gemischte Kost gesetzt. I $150 \mathrm{~g} \mathrm{Milch}$, 1 Semmel, II 1 geschabter Apfel, III $200 \mathrm{~g}$ Griessuppe, je 2 EAlöffel Hackfleisch und passiertes Gemüse, IV $=I, V$ Butterbrot und Würstel. Die Kost wird merkwürdigerweise von dem Kinde sofort gern genommen und restlos verzehrt. In den ersten 72 Stunden nimmt das Kind $1000 \mathrm{~g}$ (!) ab. Dana erfolgt durch 4 Tage Gewichtsstillstand und von da ab nimmt das Gewicht langsam zu, $1000 \mathrm{~g}$ in 60 Tagen.

Der Fall bestätigt vollständig die anderen Beobachtungen und zeigt in besonders auffälliger Weise, wie ein Kind, das bis zu seinem zweiten Jahre noch niemals etwas Festes genossen hat, wenn es auf gemischte Kost gesetzt wird, in den ersten 3 Tagen um ein ganzes Kilogramm abnimmt, zum Ansatz $1 \mathrm{~kg}$ solider Körpersubstanz dann aber volle 2 Monate braucht. Es kann hier auch ohne direkte Bestimmung wohl keinem Zweifel unterliegen, daß ein Gewichtsverlust von $1000 \mathrm{~g}$ in 72 Stunden zum größten Teil nur aus abgegebenem Wasser bestehen kann.

Solcher Beispiele können beinahe täglich in einem Krankenhaus, dessen Publikum sich aus derart ernährten Kindern zusammensetzt, beobachtet werden. Ich will nachträglich hervorheben, daß man bei derartigen Fällen meist beobachten kann, daß besonders die Hautaffektionen der exsudativen Diathese bei einem Ernährungsregime, wie wir es anwandten, und unter geeigneter Lokalbehandlung sich ziemlich rasch bessern und vor allem sehr selten rezidivieren. Ich habe aber in den Krankengeschichten absichtlich diese Veränderungen der exsudativen Erscheinungen nicht notiert, da es nach den obigen Auseinandersetzungen nicht angebracht erscheint, direkte und einfache Beziehungen zwischen diesen komplizierten, zum großen Teil sekundären Erscheinungen der exsudativen Diathese und dem Wassergehalt des Organismus zu konstruieren. Man kann selbst von der zweckmäßigsten Ernährung nicht verlangen, daß sie an sich ein impetiginös infiziertes Ekzem oder eine durch wiederholte Anginen zerklüftete und narbig veränderte Tonsille zum Verschwinden bringt.

Es ist nun unschwer, dieses Verhalten der exsudativen Kinder auch zahlenmäßig nachzuweisen. Um ein besseres Vergleichsobjekt gegenüber nicht exsudativen Kindern zu haben, wähle ich zwei Beispiele an Säuglingen, da ja auch das Verhalten überemährter, nicht exsudativer Kinder gegenüber dem Absetzen auf eine knappe Diät an Säuglingen geschildert wurde.

F. S., 3 Monate alt, war niemals bei der Brust und bekommt alle 2 Stunden Halbmilch. Die Gesamttagesmenge beträgt 11 Milch +5 Stück Zucker. Vor 3 
bis 4 Wochen bekam das Kind Gneis, vor 2 Wochen Ausschlag im Gesicht, seit 1. Woche ist derselbe auch auf den Körper übergegangen. Der Stuhl war immer gelb, 1 - bis 2 mal täglich. - Bei der Aufnahme $5200 \mathrm{~g}$ schwer, $63 \mathrm{~cm}$ lang, kräftig, gut genährt. Ausgedehnter Gneis und Milchschorf, papulöses Ekzem am ganzen Körper. Reichliche Lymphdrüsenschwellungen. Interner Befund normal. Das Kind wird des Versuches halber auf $600 \mathrm{~g}$ Drittelmilch mit Schleim gesetzt. Nach vorübergehendem Gewichtsansteig sinkt das Körpergewicht innerhalb von 4 Tagen um $320 \mathrm{~g}$, bleibt dann mit einigen Schwankungen horizontal. Inzwischen ist der Schleim durch Weizenmehl ersetzt und das Nahrungsvolumen etwas gesteigert worden. Langsame Zunahme.

Was wir oben an älteren Kindern gesehen haben, zeigt sich hier bei einem 3 monatlichen Säugling mit ausgedehnten exsudativen Erschei-

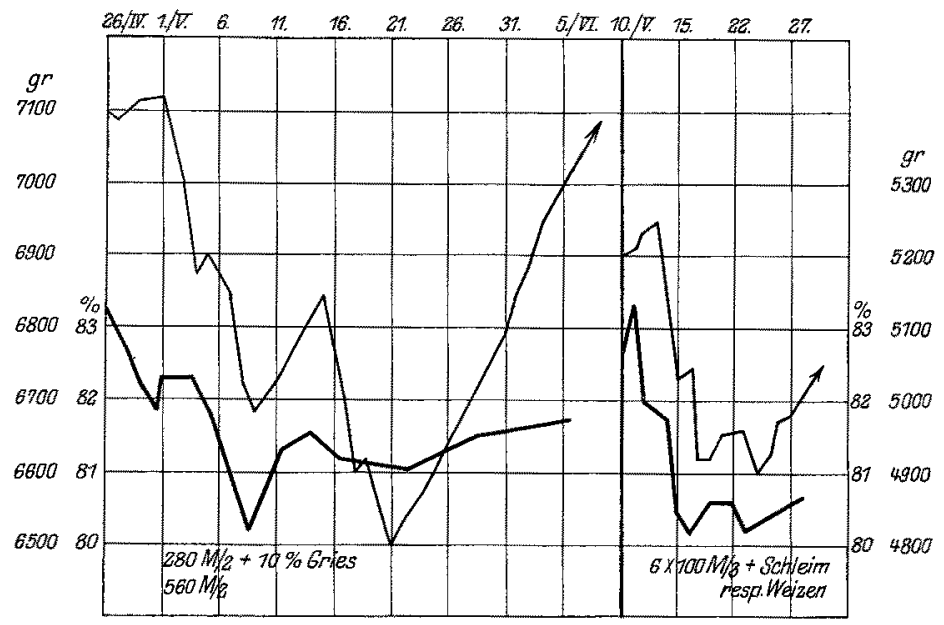

Fig. 15.

nungen. Beim Absetzen auf knappe Nahrungsmengen verliert er binnen 4 Tagen mehr als $300 \mathrm{~g}$ an Gewicht, bleibt dann eine Zeitlang stehen und nimmt dann langsam zu. Hier wurde nun auch der Wassergehalt des Blutes geprüft und ergab während der Gewichtsabnahme ein vollständiges Parallelgehen der Gewichtskurve mit der Wassergehaltskurve (rechte Hälfte der Fig. 15). Der anfängliche Wassergehalt des Blutes betrug $82,6 \%$. Nach Schleimzulage trat die bekannte vorübergehende Hydrämie auf, 83,4\%. Und nun beginnt ganz parallel der Gewichtskurve ein rapides Sinken des Blutwassergehaltes. Nach 24 Stunden $82,0 \%$, nach weiteren 48 Stunden $81,7 \%$, nach weiteren 24 Stunden $80,6 \%$. Nun bleibt auch die Kurve des Blutwassergehaltes niedrig und zeigt unter der Nahrungszulage eine geringe Zunahme.

Um einen besseren Vergleich zwischen diesem exsudativen und 
einem „normalen“ überernährten Kind zu ermöglichen, habe ich in Fig. 15 die beiden entsprechenden Kurven nebeneinander gestellt. Die linke Hälfte betrifft das früher (Seite 448 ) beschriebene Kind A.-L. Dasselbe war 8 Monate alt, mit immensen Kuhmilchmengen überernährt, wurde auf knappe Kost, die es anfangs nicht nehmen wollte, gesetzt, und gab dabei $600 \mathrm{gr}$ seines Körpergewichtes ab. Sein Blutwassergehalt betrug rund $83 \%$ und wurde um ungefähr $3 \%$ niedriger. Die Zeit des „,inneren Umbanes" betrug 21 Tage. Auch bei diesem eben beschriebenen exsudativen Kind finden wir im Anfang des Versuches nicht nur das Absetzen auf eine kleinere Nahrungsmenge an sich, sondern sicher auch die Wirkung einer Unterernährung, ebenso wie bei dem ersten Vergleichskinde, das die neue breiige Nahrung nicht nehmen wollte. Auch dieses überernährte exsudative Kind hat einen Blutwassergehalt von rund $83 \%$, es verliert ebenfalls davon $3 \%$ - aber in 4 Tagen. Die rechte Hälfte der Fig. 15 zeigt fast genau dasselbe Bild wie ihre linke Seite, aber nur auf einen ganz kurzen Zeitraum zusammengeschoben. Dem Absetzen auf kleine Nahrungsmengen, respektive einer Unterernährung gegenüber verhalten sich normale Kinder so, daß sie das während der Ưberernährung angesammelte überschüssige Wasser langsam, im Laufe von 2 bis 3 Wochen abgeben, während exsudative Kinder zu diese $m$,inneren Umbau“ bloß Stunden bis Tage benötigen.

J. W., 6 Monate alt, 6 Wochen bei Brust (2stündlich), dann Halbmilch durch 3 Wochen, dann wegen ,Darmkatarrhs" täglich 800 bis $900 \mathrm{~g} \mathrm{2/3}$ Milch mit Nestle. Seit 4 Monaten Gneis, später Gesichtsekzem, das jeder Behandlung trotzt. - Bei der Aufnąhme $62 \mathrm{~cm}$ lang, $5570 \mathrm{~g}$ schwer. Ausgebreiteter schwer infizierter Gneis, der die gesamte behaarte Kopfhaut bedeckt. Die linke Wange von impetiginösem Ekzem eingenommen. Die Haut stark gereizt, leicht blutend. Interner Befund normal, kein Fieber. Wird sofort auf folgende Diät gesetzt: $520 \mathrm{~g}$ Halbmiloh mit Weizenmehl, $260 \mathrm{~g}$ dicker Griesbrei. Stühle immer in Ordnung. Kein Erbrechen. In den ersten 2 Tagen Abnahme um $200 \mathrm{~g}$, dann Gewichtsstillstand durch 10 Tage, hierauf ohne Nahrungsänderung langsame Zunahme.

Der Fall stellt also bei einem 6 monatlichen Säugling ungefähr das dar, was die klinischen Beobachtungen an älteren Kindern gezeigt.haben. Das Kind bekommt bei (nicht einmal sehr großen) Mengen von $2 / 3$ Milch mit Mehl schwere exsudative Symptome und wird dann auf eine kalorisch eben knapp ausreichende, flüssigkeitsarme Diät gesetzt. Daraufhin erfolgt sofort eine Gewichtsabnahme um $200 \mathrm{~g}$ in den ersten 48 Stunden, dann Gewichtsstillstand. Hierauf nimmt das Kind bei derselben Nahrung zu. Der anfängliche Wassergehalt des Rlutes betrug $83,4 \%$, entspricht also genau dem bekannten Wert für in der besehriebenen 
Weise fehlerhaft ernährte Kinder. Nach 48 Stunden ist der Wert auf 82,2 , also um $1,2 \%$ gesunken und bleibt nun während der ganzen Zeit der Beobachtung (12 Bestimmungen in 2 Monaten) in dieser Höhe. Die Abgabe des überschüssigen Wassers beim Absetzen auf eine knappe Diät, die aber diesmal keine Unterernährung bedeutete, war in $48 \mathrm{Stunden}$ vollzogen.

Ebenso wie wir früher gesehen haben, daß nicht die absolute Höhe des Blutwassergehaltes es ist, welche das exsudative Kind charakterisiert, sondern das plötzliche Hinaufschnellen desselben, welches in innigen Beziehungen zum Auftreten des Milchschorfs steht, ebenso sehen wir, daß es die rasche, in wenigen Stunden bis Tagen bewerkstelligte Abgabe des durch die fehlerhafte Ernährung überschüssig angesammelten Wassers ist, welche exsudative Kinder gegenüber nicht exsudativen auszeichnet, welche zu dieser Abgabe Wochen brauchen. Diese Feststellungen scheinen mir zu den am Salzstoffwechsel von Fre und, Meyer und Menschikoff gemachten Beobachtungen in bestem Einklang zu stehen.

Diese Befunde im Verein mit den früheren führen also zu einer vollständigen Bestätigung der von $\mathrm{Czerny}$ seinerzeit gemachten Annahme, da $\beta$ es sich bei der exsudativen Diathese um einen kongenitalen Defekt im Chemismus jener Gewebe handelt, welche zum Wasserstoffwechsel in den engsten Beziehungen stehen. Es ist aber ausdrücklich zu betonen, daß für die exsudative Diathese der Defekt im Chemismus der Gewebe zu suchen ist, nicht in der Innervation. Denn man kann sich ganz gut vorstellen, daß die überrasche Ausfuhr von Wasser und Salzen, beziehungsweise der rapide Ansatz derselben auch unter dem Einfluß eines übererregbaren Nervensystems zustande kommt. Welcher erfahrene Säuglingsarzt erinnert sich nicht jener ,nervösen“ oder "sènsiblen“" Kinder, die aus nichtiger Ursache beängstigende Gewichtsstürze erleben, verfallen aussehen und einem Kollaps nahe sind, und sich dann sofort wieder erholen, deren Reparationskurve selbst bei Nahrungsmitteln, welche kohlehydrat- und salzarm sind, z. B. Frauenmilch, nicht wie bei einer schweren Ernährungsstörung erst langsam einlenkt, dann vielleicht einige Zeit horizontal verläuft, um dann langsam anzusteigen, sondern sofort unter einem spitzen Winkel wieder raschen Gewichtsanstieg anzeigt. Auch diese Fälle zeigen eine Labilität ihres Wassergehaltes, doch unter dem Einfluß der pathologisch gesteigerten Nervenerregbarkeit. Bei der exsudativen Diathese ist die Labilität im Chemismus der 
Gewebe dem Wasser gegenüber oder mit anderen Worten in einer pathologisch veränderten Art der Wasserbindung an die Zellbestandteile zu suchen.

\section{Anhang.}

A. Die Beziehungen der exsudativen Diathese zur Anämie der Säuglinge.

In aller Kürze sei hier noch eines Umstandes gedacht, der hervorgehoben zu werden verdient. Die Krankengeschichten derjenigen älteren, eben beschriebenen Kinder, die lange Zeit fehlerhaft ernährt waren, die dann des Versuches halber auf gemischte Kost mit geringen Nahrungsvolumina gesetzt wurden und dabei rapid an Gewicht verloren, um dann langsam zuzunehmen, erinnern an die meisten Krankengeschichten der unter dem Titel „Anämie der Säuglinge“ beschriebenen Fälle. Auch dort finden wir bei denjenigen Kindern, wo dieser Versuch gemacht werden konnte, also bei den ersten 5 dort beschriebenen Fällen ziemlich rasche Gewichtsabnahme in kurzer Zeit, damit Hand in Hand gehend eine rasche Abgabe eines Teiles des vermehrten Blutwassers und ein ebenso rasches Zurückgehen des Milztumors bis zu einem gewissen Grad. Während nun allerdings bei den Fällen von exsudativer Diathese der - Blutwassergehalt bis zur Norm absinkt, bleibt er bei den Fällen von Anaemia pseudoleucaemica auch nach der ersten Abnahme auf einem pathologisch erhöhten Niveau stehen. Doch bietet bei dem sicher aus mehreren Komponenten zusammengesetzten Krankheitsbild der Anaemia pseudoleucaemica dieses Verhalten eine große Ähnlichkeit mit dem Verhalten exsudativer Kinder, wenn sie brüsk auf gemischte knappe Diät gesetzt werden. Tatsächlich bieten nun 4 von den 5 in Frage kommenden Kindern deutliche Symptome von exsudativer Diathese dar. -

Dazu kommt noch die bisher unaufgeklärte Frage des Milztumors und das auffallend rasche Verschwinden desselben bei den wiederholt angestellten Versuchen. Ich erinnere hier daran, daß Czerny-Keller den Milztumor bei der Anaemia pseudoleucaemica teils für infektiösen Ursprungs, teils für ein Symptom der exsudativen Diathese halten. „Wir selbst zählen den Milztumor nicht infektiösen Ursprunges bei Säuglingen zu den Symptomen der exsudativen Diathese, weil sich derselbe durch eine zweckentsprechende Ernährung zur Rückbildung bringen läßt." Immerhin bleibt aber bemerkenswert, daß nur in den leichteren Fällen (z. B. bei den von mir beschriebenen Zwillingen) der Milztumor vollständig verschwindet, während in den schwereren Fällen die 
vergrößerte Milz gleich nach dem Absetzen auf gemischte Kost gleichzeitig mit dem Sinken des Blutwassergehaltes rapid kleiner wird, da $B$ aber gewöhnlich ein kleiner harter Rest des Milztumors ebenso wie ein Teil des pathologisoh vermehrten Blutwassers bestehen bleibt. Dieser Zusammenhang gibt doch wohl zu denken. Da aber das Bild der Anaemia pseudoleukaemica bisher noch keine vollständige Aufklärung gefunden hat, da sicher zwei, vielleicht sogar mehrere Faktoren an der Entstehung der Krankheit beteiligt sind, da die Art der Schädigung des haematopoetischen Apparates bisher noch nicht aufgeklärt ist und da schließlich auch sämtliche Kinder mit Anämie an Rachitis litten, deren Rolle bisher nicht abzuschätzen ist, so enthalte ich mich hier einer entschiedenen Meinungsäußerung darüber, ob das rasche Zurückgehen des vermehrten Blutwassers und des Milztumors bis zu einem gewissen Grade auf Kosten einer exsudativen Diathese zu setzen ist, die an der Entstehung des Krankheitsbildes mitbeteiligt ist.

\section{B. Der Status lymphaticus.}

Auch bezüglich dieses Krankheitsbildes, das ja heute noch vollständig jeder Aufklärung entbehrt, seien in Kürze einige Beobachtungen registriert, ohne mit denselben - das Thema bedürfte sicher eines eingehenderen Studiums - einer bestimmten Meinung Ausdruck geben zu wollen. Als charakteristisch für den Status lymphaticus wird neben einer gewissen Anfälligkeit verschiedenen Noxen gegenüber das Auftreten plötzlicher Todesfälle, besonders der sogenannte „Narkosetod" angesehen.

Ich muß hier auf die eingangs zitierten Tierexperimente verweisen. In dem dort beschriebenen „,zweiten Versuch" wurden 3 Hunde desselben Wurfes verwendet, von denen einer mit gemischter Kost und beliebigen Mengen Milch, ein zweiter ebenfalls mit gemischter Kost und etwas Wasser, der dritte ausschlieBlich mit Kuhmilch ernährt wurde. Der Versuch dauerte im ganzen $2 \frac{1}{2}$ Monate. Nach Ablauf dieser Zeit wollte ich diesen Tieren so wie im ersten Versuch Teile der Rückenhaut und der darunter liegenden Muskulatur entfernen, um in diesen Geweben Wasserbestimmungen zu machen. Zum Zweck des Eingriffes wurden die Tiere mit reinem Äther narkotisiert. Die beiden gemischt ernährten Tiere wurden zuerst operiert und vertrugen den Eingriff ganz gut. Die Narkose war eine vollständig normale. Nach ungefähr 5 Minuten trat ein Exzitationsstadium ein, dem bald darauf tiefer Schlaf folgte. Die Tiere erwachten auch bald nach dem Eingriff. Der dureh $2 \frac{1}{2}$ Monate a usschließlich mit großen Kuhmilchmengen genährte Hund starb nach den ersten Tropfen Äther, welche auf den Korb gegossen wurden. 
Bei den nun folgenden Versuchen hatte ich keine Gelegenheit zu konstatieren, ob dieses Zusammentreffen nur ein zufälliges gewesen war oder nicht. Erst beim letzten Versueh bot sich wieder Gelegenheit dazu. Diesmal handelte es sich wieder um 3 Hunde, von denen einer als Kontrolle mit gemischter Kost, der 2. ausschließlich mit Kuhmilch, der 3. mit gemischter Kost und großen Mengen Wassers ernährt wurde. In diesem Falle dauerte der Versuch nur $1 \frac{1}{2}$ Monate. Ich versuchte nun die Tiere abermals mit Äther zu narkotisieren. Keines der Tiere ging bei der Narkose ein, wohl aber ergaben sich bemerkenswerte Unterschiede in der Menge des verbrauchten Äthers und in der Zeit, welche vom Beginn des Auftropfens bis zum Eintritt tiefen Schlafes verging.

Art der Ernährung

Kontrolle mit gemischter Ernährung . . . Gemischte Ernährung und Wasser . . . Ausschließliche Kuhmilohernährung . . .

$\begin{array}{cc}\text { Menge des ver- } & \text { Daner bis zum Ein- } \\ \text { brauchten Äthers } & \text { tritt der Narkose } \\ 22 \mathrm{ccm} & 7 \mathrm{Min} . \\ 30 \mathrm{ccm} & 8 \mathrm{Min} . \\ 8 \mathrm{ccm} & 41 / \mathrm{g} \mathrm{Min} .\end{array}$

Der Unterschied ist doch auffallend. Das nur mit Kuhmilch durch $1 \frac{1}{2}$ Monate ernährte Tier braucht nur $1 / 3$ bis $1 / 4$ der Äthermenge und etwas mehr als die Hälfte der Zeit bis zum Eintritt der Narkose gegenüber den beiden anderen Tieren.

Die Beobachtungen sind nicht genügend groß an Zahl, als daß daraus weitgehende Schlüsse gezogen werden könnten. Aus diesen beiden Versuchen läßt sich aber eine Bestätigung der Ansicht von Czer ny - Keller, daß der Status lymphaticus ,,kein eigenes Krankheitsbild, sondern nur eine Form der exsudativen Diathese" ist, nicht ableiten. Denn das ausschließlich mit Kuhmilch ernährte Tier zeigt gegenüber der Kontrolle nur eine Verhinderung seiner physiologischen Austrocknung, beziehungsweise eine leichte Vermehrung seines Blutwassergehaltes, aber nicht die für die exsudative Diathese von uns als charakteristisch angenommene Labilität der Wasserbindung.

\section{Literaturverzeichnis.}

Aschenheim, E., Verh. d. deutschen Ges. f. Kinderheilk. 1912.

Ba um m, G., Archiv f. Dermatol. u. Syphilis100, S. 105. 1910.

Benfey und Bahrdt, Zeitschr. f. Kinderheilk. $\boldsymbol{\gamma}$, S. 5/6.

Berend und Tezner, Monatsschr. f. Kinderheilk. 10, 2.

Bezold, Zeitschr. f. wissenschaftl. Zoologie 8, S. 487. 1857.

Biedert, Jahrb. f. Kinderheilk. 1\%, S. 251.

Birk, Monatsschr. f. Kinderheilk. 1910, S. 279, 505, 595.

Bittorf, Der Wasser- und Kochsalzstoffwechsel und seine Bedeutung für Pathologie und Therapie. Halle 1911.

Bisch off und Voit, Die Gesetze der Ernährung des Fleischfressers. Leipzig u. Heidelberg 1860 . 
Bischoff, Zeitschr. f. rationelle Med. 20, S. 75. 1863.

Blauberg, Zeitschr. f. Biol. 40.

Bloch, Ergebnisse der inn. Med. u. Kinderheilk. 2.

Borowikow, Biochem. Zeitsohr. 48.

Bruck, Monatsschr. f. Kinderheilk. 8, S. 8.

Busch, Zeitschr. f. experim. Path. u. Ther. 14, S. 2.

Camerer sen., Zeitschr. f. Biol. 14, 16, 18, 33.

- Jahrb. f. Kinderheilk. 30, 56.

- Der Stoffwechsel des Kindes. Tübingen 1896.

— jun., Zeitschr. f. Biol. 39; 40; 43.

- Stoffwechsel und Ernährung im ersten Lebensjahr. Handb. v. PfaundlerSchloßmann. 1.

Chaniewski, Zeitschr. f. Biol. 20.

Chiarolanza, Zeitsohr. f. klin. Med. 94.

Cohnheim und Lichtheim, Virchows Archiv 69. 1877.

Czerny, Jahrb. f. Kinderheilk. 70; 61, 51.

- Med. Klin. Nr. 23, 1913.

- Monatsschr. f. Kinderheilk. 1, S. 1; 2, S. 2; 4, S. 1; 6. S. 1; \%, S. 1 .

- Archiv f. experim. Pathol. u. Pharmakol. 34.

- Zeitschr. f. ärztl. Fortbildung 9, S. 2.

- Assoc. intern. de Pédiatrie. Congrès de 1912.

- Keller, Handbuch.

Dastre und Loye, Arch. de Physiolog. norm. et pathol. 2. 1888.

Dennstedt und Rumpf, Zeitschr. f. klin. Med. 58.

Dona u, Die Arbeitsmethoden der Mikrochemie. Handb. d. mikrosp. Technik ,Mikrokosmos ${ }^{\natural}$. Stuttgart.

Durig, Archiv f. d. ges. Physiol. 85.

Eekert, Ursachen und Wesen angeborener Diathesen. Berlin 1913.

Edgeworth, Lancet 1911.

Engels, Archiv f. experim. Pathol. u. Pharmakol. 51.

Fehling, Archiv f. Gynäkol. 11. 1877.

Finkelstein, Zeitsch. f. Kinderheilk. 8, S. 1.

- Med. Klin. Nr. 37, 1907.

- Therap. Monatshefte Nr. 34, 1912.

Finkelstein, Lehrb. d. Säuglingskr.

Fischer, Das Oedem. Dresden 1910.

Flesch, Ergebn. d. inn. Med. u. Kinderheilk. 3.

Forster, Zeitschr. f. Biol. 12.

Frank und Stolte, Jahrb. f. Kinderheilk. 78, S. 2.

- und Wolff, Jahrb. f. Kinderheilk. \%8. Ergänzungsheft.

Freund, Jahrb. f. Kinderheilk. 59.

- Verhandl. d. deutschen Ges. f. Kinderheilk. 1910.

Frey, Arehiv f. d. ges. Physiol. 139.

Friedenthal, Ergebn. d. inn. Med. u. Kinderheilk. 9.

Grawitz, Klin. Pathologie des Blutes.

- Deutsches Archiv f. klin. Med. 91.

Gregor, Monatsschr. f. Psych. u. Neurol. 10, S. 2. 
Grosz, Wiener klin. Wochenschr. Nr. 9, 1899.

Gundobin, Die Besonderheiten des Kindesalters. Berlin 1912.

Hagner, Zeitschr. f. Kinderheilk. 8, H. 1.

Ha mburger, H. I., Osmotischer Druck und Tonenlehre.

Ham merschlag, Zeitschr. f. klin. Med. 20.

Ha uberisser und Schönfeld, Archiv f. experim. Pathol. u. Pharmakol. $r 1$.

Heim und John, Zeitschr. f. Kinderheilk. 1, 4; 3, 2.

Henneberg, Kern und Wattenberg, Journ. f. Landwirtsch. 26. 1878.

He ubner, O., und W., Jahrb. f. Kinderheilk. $g 2$.

Hermann, Handb. d. Physiol. 1881.

Hirschfeld, H., und L., Münch. med. Wochenschr. Nr. 31, 1911.

Hock und Schlesinger, Beiträge zur Kinderheilk. (Herausgeg. von Kassowitz).

Hoffmann, Zeitschr. f. Biol. 8.

Höber, Physikal. Chemie der Zelle und Gewebe. III. Aufl.

v. Hösslin, Verhandl. d. Ges. deutscher Naturf. u. Ärzte 1883.

Hof meister, Archiv f. experim. Pathol. u. Pharmakol. 28.

Iscovesco, Sem. médic. 25.

Jacksch, Zeitschr. f. klin. Med. 23.

Jakubowitsch, Archiv f. Kinderheilk. 14.

Japha, Erkrankungen des Blutes und der blutbereitenden Organe. PfaundlerSchlossmanns Handb. II.

Jungklaus, Med. Klin. Nr. 9, 1912.

Karnitzki, Archiv f. Kinderheilk. 36.

Kastner, Zeitschr. f. Kinderheilk. 3, 5/6.

Keller, Jahrb. f. Kinderheilk. $\mathbf{5 1}$.

Kern, Jahrb. f. Kinderheilk. 78.

Klotz, Die Bedeutung der Konstitution für die Säuglingsernährung. Würzburg 1911.

Koeppe, Jahrb. f. Kinderheilk. 73.

Krasnogorski, Monatsschr. f. Kinderheilk. 12, Nr. 3.

Krug, Noordens Beiträge zur Lehre vom Stoffwechsel des gesunden und kranken Menschen. Heft 2.

Langstein und Niemann, Deutsche med. Wochenschr. Nr. 2, 1910.

- Rott und Edelstein, Zeitschr. f. Kinderheilk. $\boldsymbol{\gamma}, \mathbf{3} / 4$.

Lawes und Gilbert, Philos. transact. Part. 2. 1859. Zit. nach Hermann.

Lederer, Monatsschr. f. Kinderheilk. 12.

Lesage, Lehrb. der Krankheiten des Säuglings. Übersetzt von Fischl. Leipzig 1912. Loyd, Journ. of Physiol. 1887.

Luithlen, Wiener klin. Wochenschr. Nr. 20, 1911; Nr. 18, 1912.

- Archir f. experim. Pathol. u. Pharmakol. 68.

Lust, Jahrb. f. Kinderheilk.

Magnus, Archiv f. experim. Pathol. u. Pharmakol. 44; 45.

Marchand, Zentralbl. f. norm. u. pathol. Anat. 22, S. 14.

Margolis, Zur Frage vom Einfluß der vermehrten Wasserzufuhr auf den Stoffwechsel des Säuglings. Inaug.-Diss. Straßburg 1911.

Mautner, Zeitschr. f. Kinderheilk. 8, 6.

Menschikoff, Monatsschr. f. Kinderheilk. 10.

Me yer, L. F., Jahrb. f. Kinderheilk. 71 ; 65, $\gamma_{0}$ 
Meyer, L. F., Zeitschr. f. Kinderheilk. 5, 1.

- Ergebn. d. inn. Med. u. Kinderheilk. 1.

- Biochem. Zeitschr. 12.

Michel, C. r. de la soc. de biol. 1899.

Moeli, Berliner klin. Wochenschr. 1894.

Monti, Archiv f. Kinderheilk. 18.

Moore, Archiv f. d. ges. Physiol. 14\%.

Moro, Monatsschr. f. Kinderheilk. 11.

- und Kolb, Monatssehr. f. Kinderheilk. 9.

Morawitz, Volkmanns Sammlung klin. Vorträge Nr. 462, 1907.

Müller, E., Jahrb. f. Kinderheilk. 1910. Ergänzungsheft.

Neumann, Archiv f. Hyg. 36.

Niemann, Jahrb. f. Kinderheilk. $\boldsymbol{r 4 ;}$ r.

- Zeitschr. f. Kinderheilk. 6, 5/6.

Ohlmüller, Zeitschr. f. Biol. 18.

Oppenheim, Archiv f. d. ges. Physiol. 23.

Op penheimer, Zeitschr. f. Kinderheilk. 3, 2.

Orgler, Biochem. Zeitschr. $\$ 8$.

Overton, Nagels Handb. d. Physiol. 2, S. 744. 1907.

Padtberg, Archiv f. experim. Pathol. u. Pharmakol. 63.

Panum, Virchows Archiv 29.

Pauli, Archiv f. d. ges. Physiol. 136.

Pauli, Kolloidchemie der Muskelkontraktion. Dresden und Leipzig 1912.

Pfa undler, Zeitschr. f. Kinderheilk. 3, 5/6.

Pfeffer, Pflanzenphysiologie 1, S. 116. Leipzig 1897.

Pies, Monatssohr. f. Kinderheilk. 1910.

Pincussohn, Zeitschr. f. allgem. u. experim. Path. u. Ther. 10.

Plehn, Deutsches Archiv f. klin. Med. 91; 92.

Plesoh, Zeitschr. f. experim. Pathol. u. Ther. 6.

Ponfick, Virchows Archiv 62.

Pregl, Die quantitative Mikroelementaranalyse organischer Substanzen. Handb.

d. biochem. Arbeitsmethoden von Abderhalden. 1912.

Přibram, Kolloidchem. Beihefte 2, $1 / 2$.

Rachmilewitseh, Jahrb. f. Kinderheilk. $\boldsymbol{\gamma}$.

Ranke und Darenberger, Archiv f. Anat. u. Physiol. 1862.

Reiss, Jahrb. f. Kinderheilk. 70.

v: Reuss, Zeitsehr. f. Kinderheilk. 4, 5; 6.

Rietschel, Deutsche med. Wochenschr. Nr. 19, 1908.

Risel, Zeitschr. f. Kinderheilk. 2, 2/3/4.

Rocaz, Arch. de méd. des enf. 15, S.81. Zitiert nach Leiner, Monatsschr. f. Kinderheilk. 10.

Rosenstern, Zeitschr. f. Kinderheilk. 2, 6.

Rott, Zeitschr. f. Kinderheilk. 1, 1.

Rubner, Lehrb. d. Hygiene 1900.

- und Heubner, Zeitschr. f. Biol. 36 and 38.

R usz, Monatsschr. f. Kinderheilk. 10.

Salge, Jahrb. f. Kinderheilk. z6. 
502 R. Lederer: Die Bedeutung des Wassers für Konstitution and Ernährung.

Salge, Münch. med. Wochenschr. Nr. 36, 1911.

-.. Zeitsehr. .. Kinderheilk. 1, 1.

Sandelowski, Deutsches Archiv f. klin. Med. 96; 100.

Schade, Zeitschr. f. experim. Path. u. Ther. 14.

Schiff, Jahrb. f. Kinderbeilk. 54; 64.

Schlesinger, Archiv f. Kinderheillk. 3\%.

Schloss, Jahrb. f. Kinderheilk. $\boldsymbol{\gamma}$.

- Deutsche med. Wochenschr. Nr. 22, 1910.

- Die Pathologie des Wachstums im Säuglingsalter. Berlin 1911.

- Zeitschr. f. Kinderheilk. 3, 5/6.

Schlossmann und Sommerfeld, Ernährung des Kindes jenseits des ersten

Lebensjahres. Pfaundler-Schlossmanns Handb. I.

Schmaltz, Deutsches Archiv f. klin. Med. 4\%.

Sch midt, Med. Klin. 1911.

Schridde, Münch. med. Wochenschr. Nr. 8, 1910.

Schultz, Archiv f. Dermatol. u. Syphilis 113.

Schulz, Zeitschr. f. Kinderheilk. 3, 3.

Sehwenkenbecher und Inagaki, Archiv f. experim. Path. u. Pharm. 55

Singer, Deutsche med. Wochenschr. Nr. 51, 1912.

Soxhlet, Zeitschr. d. landwirtschaftl. Vereines in Bayern 1881.

Sommerfeld, Archiv f. Kinderheilk. $\mathbf{3 0 .}$

S piegler, Zeitschr. f. Biol. 41.

Steinitz, Jährb. f. Kinderheilk. $\mathbf{5 9}$.

— und Weigert, Monatsschr. f. Kinderheilk. 1905; 1910.

- Jahrb. f. Kinderheilk. 60.

- - Hofmeisters Beiträge, 1905.

Stolte, Münch. med. Wochenschr. Nr. 51, 1912.

- Biochem. Zeitschr. 35.

Strauss, Deutsche med. Wochenschr. 1912, Nr. 45.

Tixier, Assoc. intern. de Péd., Congrès 1912.

Tobler, Jahrb. f. Kinderheilk, $\boldsymbol{7 3 .}$

- Archiv f. experim. Pathol. u. Pharmakol. 62.

- Verhandl. d. deutschen Ges, f. Kindexheilk. 1911.

Traube, Der Haftdruck, Beitrag zur Theorie der Lösungen.

- Verhandl. der deutsehen physikalisehen Ges, 10, S. 22.

Uffenheimer, Monatssehr. f. Kinderheilk. 1912.

Vierordt, Physiologie des Kindesalters. Gerhardts Handb. I.

Vogt, Therapeutische Monatshefte 1912. August.

Voit, Hermanns Handb. d. Physiol. s. 6, 1881.

Wahlgren, Archiv f. experim. Pathol. u. Pharmakol. 61.

Weigert, Jahrb. f. Kinderheilk. 61.

Weill et Gardêre, La pathol. infantile 9.

Weiske and Wildt, Zeitschr. f. Biol. 10.

Ziegler, Versamml. deutscher Naturforsch. und Ärzte 1912.

Zuntz, Bergwanderung und Höhenklima. Berlin 1906.

Wien X, Kundratstr. 3. 